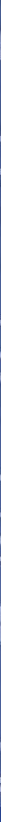

Routledge Interdisciplinary Perspectives on Literature

\title{
CONTEMPORARY NARRATIVES OF AGEING, ILLNESS, CARE
}

Edited by

Katsura Sako and Sarah Falcus

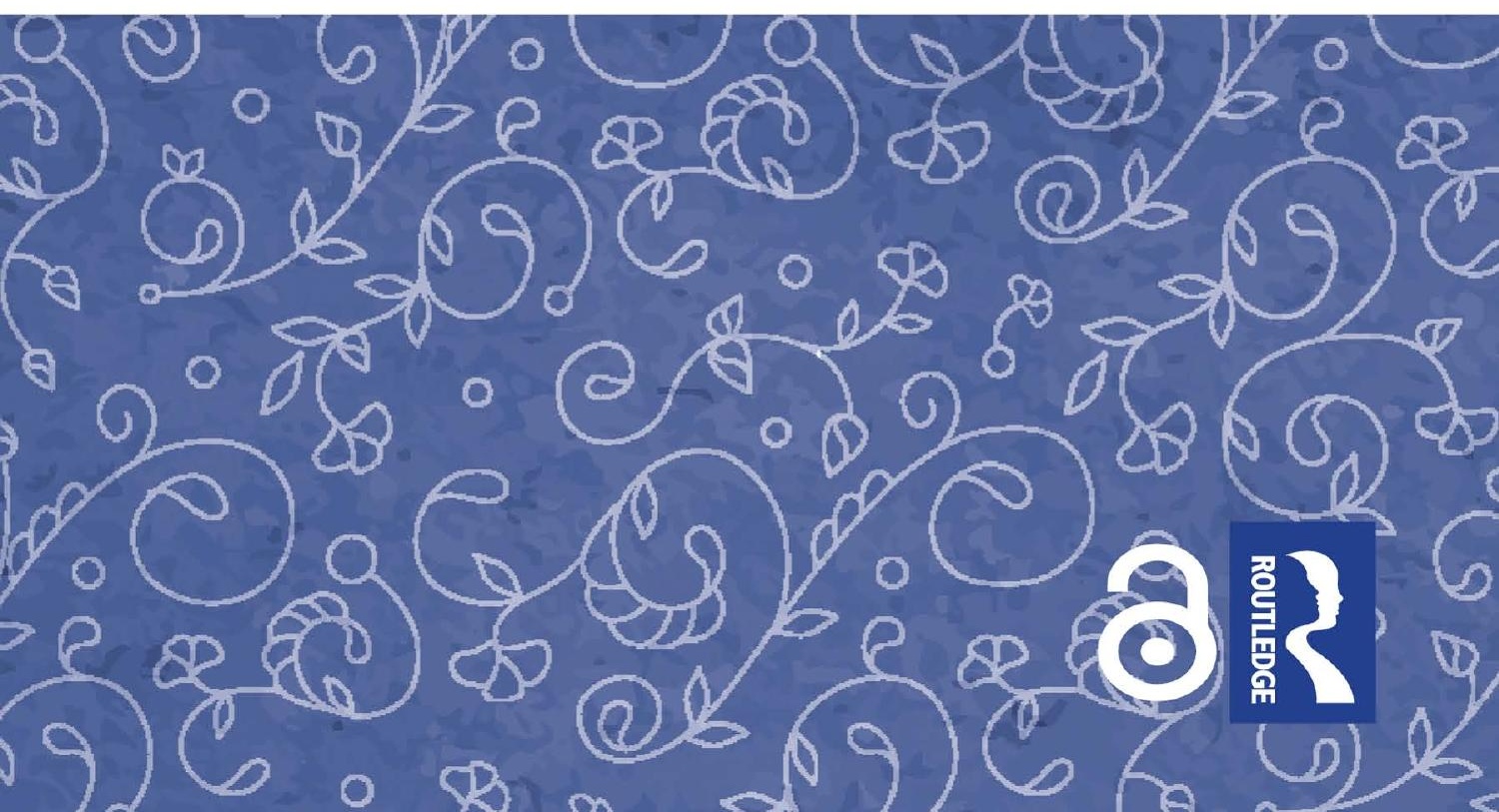




\section{Contemporary Narratives of Ageing, Illness, Care}

This collection of essays explores cultural narratives of care in the contexts of ageing and illness. It includes both text-based and practicebased contributions by leading and emerging scholars in humanistic studies of ageing. The authors consider care not only in film (feature and documentary) and literature (novel, short story, children's picturebook) but also in the fields of theatre performance, photography and music.

The collection has a broad geographical scope, with case studies and primary texts from Europe and North America but also from Hong Kong, Japan, Australia, Argentina and Mexico. The volume asks what care, autonomy and dependence may mean and how these may be inflected by social and cultural specificities. Ultimately, it invites us to reflect on our relations to others as we face the global and local challenges of care in ageing societies.

Katsura Sako is Professor of English at Keio University, Japan. She has research interests in literary and cultural studies of the life course, ageing and gender. She has published in journals such as Contemporary Women's Writing, Feminist Review and Women: A Cultural Review. She is the co-author, with Sarah Falcus, of Contemporary Narratives of Dementia: Ethics, Ageing, Politics (Routledge, 2019). She has held multiple research grants, including Fund for the Promotion of Joint International Research (Fostering Joint International Research) from the Japan Society for the Promotion of Science, which funded the conference Ageing, Illness, Care in Literary and Cultural Narratives that was held at the University of Huddersfield in 2019 and provided the basis for this volume.

Sarah Falcus is a Reader in Contemporary Literature at the University of Huddersfield. She has research interests in literary and cultural gerontology, science and speculative fiction, and children's literature. She is the co-author, with Katsura Sako, of Contemporary Narratives of Dementia: Ethics, Ageing, Politics (Routledge, 2019). She is the co-editor, with Alison Waller, of a special issue of International Research in Children's Literature (2021) that brings together children's literature studies and ageing studies. 


\section{Routledge Interdisciplinary Perspectives on Literature}

138 Orientalism and Reverse Orientalism in Literature and Film Beyond East and West

Edited by Sharmani Patricia Gabriel and Bernard Wilson

139 Narratives of Scale in the Anthropocene

Imagining Human Responsibility in an Age of Scalar Complexity Edited by Gabriele Dürbeck and Philip Hüpkes

140 Figures of the Migrant

The Roles of Literature and the Arts in Representing Migration

Edited by Siobhan Brownlie and Rédouane Abouddahab

141 Commodifying Violence in Literature and on Screen

The Colombian Condition

Alejandro Herrero-Olaizola

142 The Theological Dickens

Edited by Brenda Ayres and Sarah E. Maier

143 Connecting Literature and Science

Jay A. Labinger

144 Migrating Minds

Theories and Practices of Cultural Cosmopolitanism

Edited by Didier Coste, Christina Kkona and Nicoletta Pireddu

145 Contemporary Narratives of Ageing, Illness, Care

Edited by Katsura Sako and Sarah Falcus

146 Cultures of Currencies

Literature and the Symbolic Foundation of Money

Edited by Joan Ramon Resina

For more information about this series, please visit: www.routledge.com/ Routledge-Interdisciplinary-Perspectives-on-Literature/book-series/RIPL 


\section{Contemporary Narratives of Ageing, Illness, Care}

Edited by Katsura Sako and Sarah Falcus 
First published 2022

by Routledge

605 Third Avenue, New York, NY 10158

and by Routledge

2 Park Square, Milton Park, Abingdon, Oxon, OX14 4RN

Routledge is an imprint of the Taylor \& Francis Group, an informa business

(C) 2022 selection and editorial matter, Katsura Sako and Sarah Falcus; individual chapters, the contributors

The right of Katsura Sako and Sarah Falcus to be identified as the authors of the editorial material, and of the authors for their individual chapters, has been asserted in accordance with sections 77 and 78 of the Copyright, Designs and Patents Act 1988.

The Open Access version of this book, available at www. taylorfrancis.com, has been made available under a Creative Commons Attribution-Non Commercial-No Derivatives 4.0 license.

Trademark notice: Product or corporate names may be trademarks or registered trademarks, and are used only for identification and explanation without intent to infringe.

Library of Congress Cataloging-in-Publication Data

A catalog record for this book has been requested

ISBN: 978-0-367-52839-3 (hbk)

ISBN: 978-1-032-20014-9 (pbk)

ISBN: 978-1-003-05861-8 (ebk)

DOI: $10.4324 / 9781003058618$

Typeset in Sabon

by Apex CoVantage, LLC 


\section{Contents}

1 Ageing and Care in the Visual Field: The Photography of Martine Franck

SHIRLEY JORDAN

2 Improvisation and Vulnerability: Circuits of Care in Performances of Age and Ageing

BRIDIE MOORE

3 The Bucket List and More: Exploring Care Practices in an Australian Residential Aged Care Home Through a "Narra-theatrical" Lens

JANET GIBSON

4 "Come Healing of the Spirit, Come Healing of the Mind": The Evolution of Care in Sylvain Biegeleisen's The Last Postcard and Twilight of a Life AMIR COHEN-SHALEV

5 Dementia in Familial Documentary Film: The Ethics of Representation and the Ethics of Care RAQUEL MEDINA

6 Re-orientating Hesitantly: Approaching the Entangled Temporalities of Cinema, Dementia, and Hong Kong From a Decolonial Viewpoint 
vi Contents

7 Ghost on the Canvas: Glen Campbell's Musical Narratives of Ageing, Alzheimer's Disease, and Care SIMON BUCK

8 A Glut of Slippers: The Chronotope of Older Age in the Contemporary North American Short Story ELIZABETH BARRY

9 Old Friends: Reimagining Care Relations Through Helen Garner's The Spare Room SALLY CHIVERS

10 Care, Generations and Reciprocity in Children's Picturebooks in Japan

KATSURA SAKO AND SARAH FALCUS

List of Contributors

Index 


\section{Acknowledgements}

The publication of this volume, both in print and in the form of Open Access, is funded by the Japan Society for the Promotion of Science (KAKENHI: Project No.17KK0030). 
$\because$ Taylor \& Francis

Taylor \& Francis Group

http://taylorandfrancis.com 


\title{
Introduction
}

\author{
Katsura Sako and Sarah Falcus
}

COVID-19 brought into sharp relief the intersection of ageing, illness and care. This global pandemic exposed what we already knew: that we live in a world of global competition, not cooperation, as rich countries of the Global North competed with each other to vaccinate their populations whilst offering a derisory number of vaccines to countries with more restricted access to the drugs that save both individual lives and the wider social and economic systems within which we live. Global division, dispute and lack of cooperation then mirrored often divisive national discourses and policies that are strongly inflected by age itself.

Most obviously, COVID-19 made explicit the ageism found in policies and practices around care and illness. Edward F. Ansello outlined the ways in which ageism directed the practical, emotional and economic responses to the pandemic in the US, arguing that "older adults [were] last in priority." Commenting early in 2021 on the high number of COVID19 deaths in American long-term care homes, Margaret Morganroth Gullette called this "American eldercide," drawing attention to lack of regulation and underfunding. In the UK, the Care Quality Commission (CQC) reported in November 2020 that, during the early months of the pandemic, Do Not Resuscitate (DNR) orders may have been put in place without the consent of care home residents (including older people and those with learning disabilities) or the knowledge of their families. And for those with a DNR order, medical care was sometimes withheld, with delays in calling doctors or people being coerced into advance COVID plans that stipulated that they would stay at home without treatment if they contracted the disease (CQC). Even in Japan, which recorded much smaller numbers of cases of infection and death than the US and the UK, the Japan Geriatrics Society felt the need to reassert its opposition to triage on the basis of age alone and recommend Advanced Care Planning to ensure that older people received the care and treatment that they considered best for them (The Japan Geriatrics Society).

Responses to COVID-19 draw attention to both how we care and how we talk about and understand care, especially care for older people. The use of language by media, government and public health professionals 


\section{Katsura Sako and Sarah Falcus}

was identified as a particular issue in relation to age and the pandemic (British Society of Gerontology). A whole vocabulary of care and vulnerability mushroomed during this crisis. In countries such as the US, UK, Ireland and Sweden, the language of "cocooning" and "shielding" created a narrative of benevolent protection around the confinement of older people and those considered vulnerable as a result of pre-existing conditions. Nevertheless, as Michaela Schrage-Freuh and Tony Tracy point out, well-meaning political and social statements about protecting "the elderly" simply reinforced the sense of a homogenous and vulnerable group whose removal from active everyday life would not be significant (see also British Society of Gerontology). Older adults were positioned as endangered others, who needed the help and support of younger people, without any recognition of the reciprocal nature of that support and the important roles older adults play in society (Chivers, "How We Rely").

The "protection" of older people also highlighted the difficult balancing act between protecting life and sustaining economic activity. Societies approached this challenge in different ways. The Swedish method, which imposed limited restrictions, was praised by some citizens in the country and those elsewhere who lamented the loss of freedom they felt in response to their own nations' more restrictive policies. Nonetheless, the Swedish approach proved to have a damaging effect on older people, with a much larger number of deaths recorded amongst older people in Sweden than in the other Nordic countries (Claeson and Hanson). As countries such as the UK lifted restrictions, age and generation were once more in the political crosshairs as the vulnerability of young, unvaccinated people to long COVID was debated. Age, therefore, proved to be a deeply economic and political matter and, as those working in age studies have long recognised, must be considered in its intersections with race and ethnicity, and with class and wealth. COVID-19 - and the endless stream of statistics used to narrativise the crisis - laid bare the ways in which health and care are determined not only by age, but by race, ethnicity and relative privilege, with a higher mortality rate associated with certain groups and geographical areas.

All this took place alongside the existing alarmist discourse around ageing and care in many countries of the Global North, countries with increasingly, often rapidly, ageing populations. With demographic changes come macro political and economic concerns about the support of a growing retired population by a dwindling number of workers, and the impact of an increasing number of older people upon public services. These concerns feed into the "crisis of care" narrative that is prominent in many countries with ageing populations and neoliberal economies. Against the backdrop of these dominant political and economic discourses are the situated experiences of older people, experiences that are various and complex. 
In thinking about care, we accept both the intangibility and instability of its definitions. Nevertheless, we follow many in feminist ethics who see two broad aspects to care: the giving and taking of practical support for daily living - clearly crucial in in the lives of many older people; and an understanding of care as "caring about," something that involves obligation and responsibility, as an individual and as a society:

In its broadest meanings, care is complex and multidimensional: it refers both to the dispositional qualities we need to care for ourselves and others, such as being attentive to human needs and taking responsibility to meet such needs, as well as to the concrete work of caring. To care well requires that both of these elements be present: a disposition to care and care work.

(Tronto 130)

Care, then, has a moral meaning that concerns "intersubjective dimensions such as affect, emotion or compassion" (Andersen et al. 569). Care raises fundamental questions about what it means to be human and to co-exist with others. It forces us to confront the vulnerability and dependency that is antithetical to our reliance upon the notion of autonomous subjecthood (Feder and Kittay; Kittay; Tronto). At the same time, care is entangled within specific social and cultural contexts, and care needs and care labour are subject to and shaped by (global) power relations. Feminist ethics of care have consistently recognised the roles of gender, race, ethnicity and class in caring practices and locations (Hankivsky). In our contemporary world, what Kittay calls "dependency concerns" disproportionately affect women, poorer people and those experiencing racial inequalities (4). And, given the global economics of care, migrants are often those who undertake dependency care in many wealthy nations of the Global North (Kittay 4-5).

For Joan Tronto, care offers us "a perspective from which to think about human life" (130). Care becomes a kind of lens through which broad and macro-scale decisions and judgements become linked to specific lives and experiences (Tronto 130-1). This collection aims to employ that perspective - using concrete and contextual examples to consider broader issues around care, ageing and what it means to live with others. The volume is underpinned by the assumption that the humanities matter to gerontological research and to the experience of ageing; more specifically, it assumes that the stories we tell about our ageing selves are both informed by and help to shape the ways in which we grow older, in health and in illness (Chivers, Silvering; Gullette, Aged; Marshall; Woodward, Aging and Figuring Age). Cultural narratives of ageing, illness and care - whether in the form of film, popular music or theatre - complicate the dominant discourses outlined earlier. Complicit or questioning, these narratives are an important part of gerontological knowledge. In this 


\section{Katsura Sako and Sarah Falcus}

volume, we consider what it means to represent, think about and enact caring practices across a variety of national and cultural contexts, and across different genres and media.

The chapters address not only the representation of care, but how engagements with narrative and cultural practices can be a form of care, one that displaces political and economic discourses of crisis and burden with ideas of attention, patience and relationality. In this way, this volume is part of a wider conversation about the potential of cultural practices to change the ways in which we relate to the world and, specifically, encourage more empathetic, relational and fundamentally ethical practices of care for others (see for example Bitenc; Gibson; Hamington and Rosenow; Maginess). Shirley Jordan opens this area of inquiry with her exploration of the ethical potential of photography, focusing on Martine Franck, a photographer who has so far drawn little attention in the field of ageing studies. Jordan's assertion that Franck's documentary photography establishes an ethics of care is echoed in Chapter Two in Bridie Moore's description of the "circuit of care" created in theatrical practice. Examining both Peggy Shaw's Ruff and Moore's own use of improvisatory techniques with her father as he lived with Alzheimer's disease, Moore argues that the caring relationships established and made possible through performance interrogate the binary of carer and caredfor in productive ways. Like Moore, Janet Gibson considers the value of theatrical practice in care for and with older people, analysing the ways in which "narra-theatrical" practices create space for different dynamics of care in an Australian residential care home.

Three further chapters in this volume concentrate upon the experience and representation of dementia, this time in film. This is in recognition of both the significance of dementia for many in later life, but also the cultural visibility of the condition. As gerontologists Paul Higgs and Chris Gilleard argue, the close link between dementia and ageing has led to the "Alzheimerisation of ageing," which is "re-setting the coordinates of what ageing and old age mean in contemporary societies" (176; see also Burke; Gullette, Ending; Katz). Cognitive health is indelibly associated with ageing at the levels of cultural discourse and individual experience. The three film chapters all explore how personal and national memories are entwined and how individuals affected by dementia and those who care for them navigate their relations to each other and to the past - to familial, national and postcolonial history. Amir Cohen-Shalev's discussion of two documentary films made by Sylvain Biegeleisen about his mother and their relationship uses the comparison between the films - made seven years apart - to consider how they offer a way of reconceptualising the movement into what might be termed "old old age." Similarly focusing upon embodied care in familial documentary film, Raquel Medina examines both care as represented on film and documentary practice as a form of care, through analysis of the Mexican 
documentary film Tiempo suspendido (2015) by Natalia Bruschtein and El Señor Liberto y los pequeños placeres (2018) by the Spanish filmmaker Ana Serret. In the final chapter devoted to film and care, MaoHui Deng analyses Hong Kong film Summer Snow (1995) to emphasise the importance of hesitancy and temporal re-orientation in our care for and attention to someone living with dementia. Ultimately, these chapters demonstrate that narrative practices and the ways in which viewers relate to them can be understood as forms of care.

The perhaps utopian possibilities of these approaches are, however, juxtaposed with chapters that explore the ways in which care for older people comes under pressure, especially in the economic and social climates of the Global North. Although anti-ageism seems to be gaining force in public discourse, it is often underlain by anti-ageing sentiments. The discourse of "successful ageing" is a case in point (Katz and Calasanti). The persistence of anti-ageing sentiments creates ambiguity around ageing in popular cultures that are dominated by youth and consumerism, as scholars such as Josephine Dolan have shown. In this volume, Simon Buck explores this ambiguity through the career of Glen Campbell, who navigated the post-1960s youth-oriented music world in the US as he grew from a youthful, blonde, masculine icon to a "legend" living with Alzheimer's. Although Campbell's fame and access to resources enabled what Moore describes in her chapter as a "circuit of care," Buck illustrates how Campbell must still negotiate the cultural meanings of loss - loss of youth, masculinity and self - in sustaining his legacy.

The discourse of successful ageing prevails not only in the popular cultural space but more broadly in many neoliberal societies, demanding that populations be fit, able and productive. We are confronted by the question of how we care in a world that is dominated by economic and political agendas that prioritise competition and production, a world that allocates few resources to care for those vulnerable and dependent. It is not only social care systems that are under strain. Changes in life courses and choices in many societies have unsettled traditions of kinship-based care. Nonetheless, care responsibility is constantly shifted towards the private realm, making informal caregiving "part of standard care" (Andersen et al. 569). We, as individuals, may care or may wish to care, but our "right to care" (West), both as caregiver and as care recipient, is precarious, and we need new systems and networks to channel our caring resources. Three literary chapters in this volume focus on a specific system/institution of care, where care meets the political and cultural economy.

Elizabeth Barry explores care and ageing in the contemporary short story from North America, drawing on the concept of the chronotope to examine time and space: the sense of an ending and the "closed system" of the institutional care home. Exposing, interrogating and challenging assumptions about ageing, old age and the space of care, Barry argues 
that the short story is a particularly appropriate form for the representation of the vicissitudes and the pleasures of the later stages of life. Whilst familial and intergenerational relationships are central to the texts in Barry's chapter - and to our wider discourses of care and ageing - Sally Chivers looks beyond these to critique what might seem a perfect alternative to our heterosexual imaginary: friendship. As Sasha Roseneil argues: "While the idea of 'family' retains an almost unparalleled ability to move people, both emotionally and politically, much that matters to people in terms of intimacy and care increasingly takes place beyond 'family' in and among networks of friends" (332). Recognising the value of moving beyond the familial model when it comes to caring for as well as caring about, Chivers remains sceptical of the political and economic forces behind the popularity of what she calls "curated friendships," sometimes seen as a solution to the perceived problems of isolation and loneliness in older people. Chivers turns to fiction - Australian novelist Helen Garner's The Spare Room (2008) - to explore the practice and politics of friendship-based care.

Our final chapter returns to the familial, with a reminder of the persistence of the gendered ideal of kinship-based care. We analyse contemporary Japanese children's picturebooks and their depiction of a complex form of intergenerational, reciprocal care, a relational care that can limit as well as expand autonomy. Annemarie Mol suggests that "good care" in the West tends to be based on the individualistic "logic of care" or "the single ideal of choice and the rationalism that it is tied up with" (6). Generational care in Japanese picturebooks complicates the understandings of autonomy, relationality and responsibility that underlie that "logic of care," posing the question of what "good care" may mean for both individuals and societies. Depicting, without questioning, gender-based home care, these books are also vessels of "the ideology of familism" that seeks to confine women in a caring role (Holstein 235), "mask[ing] the costs of necessary caretaking of dependents" (Fineman 215).

The pandemic forced us to address care at all levels: individual, familial, communal, social and national. Care itself changed in the pandemic's "conditions of radical uncertainty"; in the light of national restrictions, we were "pushed to improvise and to decide what kind of care we want to create and be part of" (Baraitser and Salisbury 9). More broadly, the pandemic foregrounded the interrelatedness of societies and individuals, even as it forced us physically apart. The pandemic, then, made explicit Tronto's claim about social interdependence: "In an age in which societies are so integrated, it is difficult to start to think about the public good and not understand that our interests are connected to the flourishing of all others, not just those closest to us" (143; see also Fine and Tronto). The interconnectedness that she emphasises is evident in this volume: in the links it implicitly makes between a range of national and cultural contexts and in its close attention to the narratives that bind us - as 
practitioners, performers, audiences and readers. Collectively, this volume asks what care means, how it may be enacted, what systems we may need or want to support those who care and those who receive care. We do not wish to sound idealistic, however. We are aware that we are asking these questions at a time when there is a mounting social demand for tangible and swift action, and when we have witnessed and experienced, in the form of coronavirus vaccines, the practical power of scientific research to make an impact on a global scale. And yet, the disparities in care we witnessed during the pandemic confirm that, powerful as it may be, economic and political logic alone cannot produce the kinds of caring for and about that we might desire. We must continue to be mindful and hopeful - of cultural narratives and practices and their potential to bring about change, change that may be subtle and slow. If "serious work on cultural transformation must accompany political work to alter policies" (Holstein 241), it is our hope that this volume plays a part in this.

\section{Works Cited}

Andersen, Rikke Sand et al. "Caring as Sharing. Negotiating the Moral Boundaries of Receiving Care.” Critical Public Health, vol. 30, no. 5, 2019, pp. 567-76.

Ansello, Edward F. "Agesim in the Age of COVID-19." Age in Action. Virginia Center on Aging, scholarscompass.vcu.edu/vcoa_editorial/54.

Baraitser, Lisa, and Laura Salisbury. “'Containment, Delay, Mitigation': Waiting and Care in the Time of a Pandemic.” [version 2; peer review: 2 approved]. Wellcome Open Research, vol. 5, no. 129, 2020, https://doi.org/10.12688/ wellcomeopenres.15970.2.

Bitenc, Rebecca. Reconsidering Dementia Narratives: Empathy, Identity and Care. Routledge, 2019.

British Society of Gerontology. "BSG Statement on COVID-19: 20 March 2020." www.britishgerontology.org/publications/bsg-statements-on-covid-19/ statement-one.

Burke, Lucy. "The Locus of our Dis-ease: Narratives of Family Life in the Age of Alzheimer's." Popularizing Dementia: Public Expressions and Representations of Forgetfulness. Edited by Aagje Swinnen and Mark Schweda. TranscriptVerlag, 2015, pp. 23-42.

Chivers, Sally. The Silvering Screen: Old Age and Disability in Cinema. U of Toronto P, 2011.

- "How We Rely on Older Adults, Especially during the Coronavirus Pandemic." The Conversation, 30 Jul. 2020, theconversation.com/how-we-relyon-older-adults-especially-during-the-coronavirus-pandemic-143346.

Claeson, Mariam, and Stefan Hanson. "COVID-19 and the Swedish Enigma." The Lancet, vol. 397, no. 10271, 2021, pp. 259-61, https://doi.org/10.1016/ S0140-6736(20)32750-1.

Dolan, Josephine. Contemporary Cinema and "Old Age": Gender and the Silvering of Stardom. Palgrave Macmillan, 2018.

Feder, Ellen K., and Eva Feder Kittay. "Introduction.” The Subject of Care: Feminist Perspectives on Dependency. Edited by Eva Feder Kittay and Ellen K. Feder. Rowman \& Littlefield, 2002, pp. 1-12. 


\section{Katsura Sako and Sarah Falcus}

Fine, Michael, and Joan Tronto. "Care Goes Viral: Care Theory and Research Confront the Global COVID-19 Pandemic." International Journal of Care and Caring, vol. 4, no. 3, 2020, pp. 301-9, https://doi.org/10.1332/2397882 20X15924188322978.

Fineman, Martha L. A. "Masking Dependency: The Political Roles of Family Rhetoric." The Subject of Care: Feminist Perspectives on Dependency. Edited by Eva Feder Kittay and Ellen K. Feder. Rowman \& Littlefield, 2003, pp. 215-44.

Gibson, Janet. Dementia, Narrative and Performance: Staging Reality, Reimagining Identities. Palgrave Macmillan, 2020.

Gullette, Margaret Morganroth. Aged by Culture. U of Chicago P, 2004.

- Ending Ageism, Or How Not to Shoot Old People. Rutgers UP, 2017.

—. "'An American Eldercide': Some 39\% of COVID Deaths Are in Nursing Homes. We Must Do Better.” Cognoscenti, 19 Jan. 2021, www.wbur.org/ cognoscenti/2021/01/19/biden-covid-pandemic-national-mourning-ceremonymargaret-morganroth-gullette.

Hamington, Maurice, and Cecilia Rosenow. Care Ethics and Poetry. Palgrave Macmillan, 2019.

Hankivsky, Olena. "Rethinking Care Ethics: On the Promise and Potential of an Intersectional Analysis." The American Political Science Review, vol. 108, no. 2, 2014, pp. 252-64.

Holstein, Martha. "Home Care, Women, and Aging." Mother Time: Women, Aging, and Ethics. Edited by Margaret Urban Walker. Rowman \& Littlefield, 2000, pp. 227-44.

Japan Geriatrics Society [Nihon ronen igakkai]. "Shingata korona Uirusu kansensho ryukoki nioite koreisha ga saizen no iryo oyobi kea wo ukerutame no nihon ronen igakkai karano Teigen - ACP jissen no taimingu wo kangaeru." 2020,jpn-geriat-soc.or.jp/coronavirus/pdf/covid_teigen.pdf.

Katz, Stephen, and Toni Calasanti. "Critical Perspectives on Successful Aging: Does It 'Appeal More Than It Illuminates'?” The Gerontologist, vol. 55, no. 1, 2015, pp. 26-33, https://doi.org/10.1093/geront/gnu027.

Kittay, Eva Feder. Love's Labor: Essays on Women, Equality and Dependency. 2nd ed. E-book ed. Taylor and Francis, 2019.

Maginess, Tess, editor. Dementia and Literature: Interdisciplinary Perspectives. Routledge, 2017.

Marshall, Leni. Age Becomes Us: Bodies and Gender in Time. State U of New York P, 2015.

Mol, Annemarie. The Logic of Care: Health and the Problem of Patient Choice. Routledge, 2008.

Roseneil, Sasha. "Foregrounding Friendship: Feminist Pasts, Feminist Futures." Handbook of Gender and Women's Studies, 2012, pp. 322-41.

Schrage-Frueh, Michaela, and Tony Tracy. "Happy In? Ageing and Ageism in the Age of Coronavirus and Cocooning.” Moore Institute, 23 Apr. 2020, mooreinstitute.ie/2020/04/23/happy-in-ageing-and-ageism-in-the-age-of-coronavirusand-cocooning/.

Tronto, Joan. "Care as the Work of Citizens: A Modest Proposal." Women and Citizenship. Edited by Marilyn Friedman. Oxford UP, 2005, pp. 130-45. 
West, Robin. "The Right to Care." The Subject of Care: Feminist Perspectives on Dependency. Edited by Eva Feder Kittay and Ellen K. Feder. Rowman \& Littlefield, 2003, pp. 88-114.

Woodward, Kathleen. Aging and Its Discontents. Indiana UP, 1991.

—, editor. Figuring Age: Women, Bodies, Generations. Indiana UP, 1999. 


\title{
1 Ageing and Care in the Visual Field
}

\section{The Photography of Martine Franck}

\author{
Shirley Jordan
}

What can photography tell us about ageing and our attitudes to it? What are the conditions necessary for breaking ageist paradigms in the visual field? And how can photography depict - and promote - an ethics of care? This chapter focuses on such questions by bringing to prominence the extraordinary body of work on ageing produced by Belgian-born humanist photographer Martine Franck (1938-2012). One of the few women photographers of her generation to gain an international reputation, Franck produced an extensive body of photographs dedicated to documenting the lives of older, often marginalised people, in both domestic and institutional environments, in France and elsewhere in the world. These images have received no serious critical attention, yet arguably they occupy a significant place in the history of gerontology. They also provide a rich opportunity to re-consider the phenomenology of the photograph and the photograph's potential as a hospitable communicative field and promoter of care within the broader terrain of visual gerontology.

This chapter focuses closely on Franck's first photo book on ageing, Le Temps de vieillir: Journal d'un voyage [The Time to Grow Old: A Travel Diary] (1980), which turns ideas of journeying and discovery to original purposes. ${ }^{1}$ The chapter analyses Franck's practice in light of arguments made by age studies pioneer Margaret Morganroth Gullette, whose wryly titled Ending Ageism or How Not to Shoot Old People asks how photography might help to promote an "anti-ageist gaze" (27). It suggests an implicit dialogue set up by Franck with French existentialist philosopher Simone de Beauvoir's seminal La Vieillesse [The Coming of Age] (1970), notably regarding a shared critique of the lack of adequate social care in France and condemnatory portrayals of state-run nursing homes in the mid- to late-twentieth century. It also examines Franck's practice through a lens of contemporary care theory. Franck sets out the impetus for her project as a fundamental engagement with one of the most pressing dilemmas of our lived experience: "I wanted to find out why old age is 'disturbing' and how people are differently affected by the fact of ageing” (Le Temps 9). Here I assess her achievements in bringing

DOI: $10.4324 / 9781003058618-2$ 
us to look differently at older people and examine how she seeks to establish, through her practice of documentary and portrait photography, an ethics of care.

\section{Martine Franck: Photography as Care}

Ageing and old age were a core concern in Franck's work from the 1970s onwards. It will be helpful to begin our exploration with some general points about this unusual photographic preoccupation. Over thirty years and in hundreds of powerful images, Franck used her camera to probe the social conditions of ageing and the phenomenology of the daily lives of older people from many walks of life. She made photographs of them in their domestic environments, in institutions, in social gatherings and alone, providing challenging and memorable images which tackle unrelentingly the many-facetted nature of marginalisation. Not least of these facets was - and arguably remains - the special visual problem that society has made of older people, who struggle for legitimacy in the visual repertoire. Franck's distinctive work interrogates that problematic in ways that remain imperative today and seeks to draw the spectator in to share her position of resistance and concern.

Franck's work on ageing marked out the singularity of her vision within the male-dominated Magnum photographic agency of which she was a member, raising the issue of what care theorist Sandra Laugier refers to as the "gendered hierarchy of the objects of intellectual research" (217). More specifically, I contend, Franck saw photography as an opportunity to foreground an ethics of care and this position allows us to make an argument for the place of the camera within the evolution of feminist care theory. If the ethics of care as currently theorised "emphasises the importance of context, interdependence, relationships, and responsibilities to concrete others" (Koggel and Orme 1) then care was, as we will see in my close analyses of Le Temps de vieillir later in this chapter, clearly the driver of her practice. ${ }^{2}$ In sharp contrast to her photographer husband Henri Cartier-Bresson, who favoured the anonymity of street photography and enjoyed snatching images on the hoof, Franck's concentrated and sensitive focus on selected individuals and groups relied instead on an ethos of exchange, consistent with Carol Gilligan's contention that for women, "the logic underlying an ethic of care is a psychological logic of relationships" (In a Different 73). ${ }^{3}$ While, like all photographers, Franck might take advantage of serendipity, her default position was to seek to understand people and phenomena in depth and over time. Photography, a technology so readily associated with objectification, plunder and possession, was conceptualised by her in a quite different way. She referred to the camera as an obstacle, "a barrier that one is constantly breaking down, so as to get closer to the subject" (Baring 1). Pursuing this idea of the barrier in dialogue with John Berger, she notes: "To cross to the 


\section{Shirley Jordan}

other side, you can only get there by momentarily forgetting yourself, by being receptive to others; hence, as a photographer, I am in two different worlds at once" (One Day 13). These ideas of crossing, enhanced receptivity and straddling worlds provide an important insight into how Franck's camera was implicated in care.

Franck's photographs of older people offer the most arresting instances of how her documentary drive, her fascination for photography as meeting place and her sustained ethical practice come together as care. These images characteristically hover between social documentary shots, portraits and what Mark Edward Harris in a study of the travel photo essay calls "environmental portraits": that is, "photographs of a person in a location or scene that relates to who they are or what they do" (18). The issues underpinning recent scholarship in cultural and feminist gerontology - that ageing is an ontological blind spot; that the old are kept on the periphery of our field of vision; that ageing is in excess of what we are willing to imagine (both in general and for ourselves); that it is subject to a special kind of denial determined by what Kathleen Woodward in "Performing Age" calls "the youthful structure of the look" (162); and that older people, and perhaps especially older women, have no easy place in visual culture and are readily erased ${ }^{4}$ - were informing Franck's work long before they came to prominence in contemporary cultural gerontology. She was, then, ahead of her time, exploring the lives of older people against a backdrop of near-invisibility in a society dominated by the youth culture that exploded in the 1960s and certainly not buoyed up in her project by the kind of surge in interest in ageing that has marked our entry into the twenty-first century. Her interest in the lives of older people led to a lengthy relationship, beginning shortly after publication of Le Temps de vieillir, with the charitable association Les petits frères des Pauvres [The Little Brothers of the Poor] whose work with older people she supported and documented. ${ }^{5}$ The association reserved a privileged place for photographers in their midst, as a means not only of spreading the news about their activities but, more radically, in service of the ambition to bring about a shift in society's relationship to older people. In the tradition of social documentary, then, the camera was clearly seen by Franck as a tool for social change with radical potential. More than this, however, it became in her hands the instrument whereby the spectator is intimately challenged to interrogate the entire premise of their relationship to old age. What is especially remarkable is not so much Franck's rationale for capturing the lives of older people but the quality of her attentiveness.

Inherent in each of Franck's images is a tender, patient back story. Each tells us something about her practice of establishing relationships, waiting, listening, and fostering respect and reciprocity; indeed, one might argue that her photographs are not "taken" but rather "made." They ask to be considered within an extended time frame, not just as a moment 
frozen in time, but as what Geoff Dyer has referred to as photography's "ongoing moment." Franck's images are at once a residue, and a promoter, of the relationality that is her true goal. This shift in appreciation is critical for it takes us to the heart of the troubled ethics of photography, especially where vulnerable human subjects are concerned. Franck's images record and provoke encounters and create contemplative spaces intended to encourage the viewer to think beyond the confines of their own age-bound horizon. Above all, each is attuned to the most prominent argument in the recently emerged raft of care theory: that care ethics require heightened receptivity to vulnerability. According to Laugier, the "first tenet" of an ethics of care is that "the human is vulnerable" (219), and it is on this terrain that the encounter between photographer, spectator and subject is forged by Franck. Care, defined as a "response appropriate to the other, according to circumstance" and necessitating "an experimental attitude, a sensibility to the situation and the ability to improvise" (226; original emphasis) seems an excellent fit with Franck's practice as she photographs older people. Further, as her work develops beyond Le Temps de vieillir, Franck increasingly seeks to capture the activity and agency of care and to interrogate what Lisa Baraitser has called the "historical material conditions and institutional arrangements that enable the process of caring for, and caring about each other and the world" (14).

\section{Le Temps de vieillir: Journal d'un voyage}

Le Temps de vieillir is the first of Franck's photo books to address the subject of ageing. It constitutes a landmark in the photographer's career in as much as it announces the centrality of gerontology to her project, sows the seeds for further collaborative and solo productions related to older age and begins to interrogate the socially constructed nature of looking at other age groups. While the photographs collected in the book were put on show outside its pages, ${ }^{6}$ the book's impact is undoubtedly different from that of the gallery exhibition. Its specificity lies in its intensive interrogation of the reader's learned patterns of looking at older people and its concentrated effort to open further avenues in an essential area of social and cultural enquiry which had begun to gain new prominence in France.

Le Temps de vieillir is an idiosyncratic and complex volume whose ideologically motivated structure gradually becomes apparent as we leaf through its pages. It is best considered as a photo essay, that is, a set of photographs intended to be viewed and to produce its effect as a whole and to create a series of emotions in the viewer. It is intent on social critique, on bringing sharply to public awareness the inequalities of ageing at a moment when ageing and old age were being addressed with new intensity in France. It is also intent on exploring 
what the conditions might be for ageing well. One of its peculiarities is that it was commissioned for a series of photography books. Entitled "Journal d'un voyage" [Travel Diary], the premise of this series was to afford selected photographers free rein to make and to document a journey that they had longed to undertake. When the series editor, Daniel Filipacchi, invited Franck to contribute, he had in mind the photographer's powerful landscape images such as those in her recent book on the Lubéron region of France (Les Lubérons). Instead, Franck seized the opportunity for a metaphorical journey, via sixty-four photographs taken between 1967 and $1980^{7}$ in which she would attempt to explore the gulf that, as she saw it, separated older people from the flow of the everyday world. In accepting to incorporate Franck's project in his series, Filipacchi was prepared to take on the production of a book whose subject matter condemned it to commercial failure, for while Franck's portraits were of interest to fellow photographers, there was then no market for this kind of project. Franck herself noted the uncomprehending or even hostile reactions that her subject matter provoked: "I very rapidly noticed, in fact, that people prefer to pass over the subject of old age in an embarrassed half-silence or dodge it with quips such as: 'Why photograph old men rather than babies?'” (Le Temps 9). Filipacchi's courageous decision resulted in the publication of a work which may now be read as a powerful landmark in the history of visual gerontology.

Let us return for a moment to the trope of the travel diary. While Franck's photographs in Le Temps de vieillir do involve travel in as much as they range widely across cultures, including China, India, Japan, the UK and the USA, the trope of the journey is most consistently applied metaphorically to the idea of old age constituting an undiscovered country. Franck, who was just over forty when the volume was produced, was keen to explore an idea which continues to thread through ageing studies, that of the "unreachability" of people in later life and the untranslatable nature of their experience: what kinds of meeting can be forged across this gulf? At the same time, however, Franck's project interferes with preconceptions of unreachability, since a photographic travel diary is by definition structured by the excitement of serial encounters, by an a priori fascination for otherness on the part of the voyager and by a sustained contemplation about difference and similarity as photographer and subject are momentarily conjoined - often in mutual scrutiny and ideally in hospitality - via the lens. Ideally, rather than having their preconceptions confirmed, the traveller instead discovers what they did not know to be there. Using the idea of the traveller's gaze and its framing of cultural others to think about intergenerational encounters proves, then, to be a cannily suggestive move, one with the potential to jolt reflection about preconceived notions of age-based difference in spectators both older and younger. 
The terms of encounter that are woven into the photo essay's cover image launch Franck's interrogation of looking - in both directions across the generational divide. Her establishing shot seeks gently yet persistently to have us interrogate how we look, where we look, what we see and what we do not. It shows an anonymous, older woman visitor to an exhibition of Belgian art in Paris's Grand Palais in 1972. She is bending to peer over her spectacles at the title of a Surrealist painting by Martine Delvaux. Above her in the painting, three identical naked young women walk implacably, one behind the other, towards the surface of the canvas, their bodies illuminated by moonlight, in stark contrast to her own body which is hunched and hidden by its thick coat. The woman thus "leans in," as Franck puts it, "towards youth" (Le Temps 82). Franck sets us off here with a rich and wry allegory not only about the passage of the years, about anticipation and memory and about the regulation of women's bodies in Western art, but also about not seeing and about missed intergenerational encounters: though youth and age lean towards each other in this image, there is no exchange of gazes, no entering of each other's world. Though the young woman at the front of the painting seems to look out beyond its surface to examine what she will become, the older woman who stoops outside the frame is otherwise absorbed. There is no meeting here, just isolated acts of scrutiny.

Before Franck lets us loose on her other photographs, she invites us to contemplate a dense array of preparatory material, a jumble of images, quotations, clichés and myths related to a spectrum of positions on older people and later life. First comes a double-page scrapbook crammed with roughly cropped details from iconic paintings and photographic portraits and constituting a miniature visual essay in its own right (Le Temps 4-5). Each fragment is captioned in Franck's scribbled hand, giving us the title, date and artist or photographer. On the left-hand page cluster reminders of art historical conventions which, as Michelle Meagher notes in "Art, Ageing and the Body," "so often link the old body with, on the one hand degeneration and death, and on the other hand wisdom and self-reflection" (85). We are shown a detail from Piero della Francesca's poignant Death of Adam (c. 1466); Rembrandt's pitiless self-appraisal in his unfinished Self-Portrait with Beret (c. 1659); Frans Hals's austere, yet charitable, Woman Regents (c. 1664); and Goya's terrifyingly patriarchal caricatures of crones, Las Viejas (c. 1808), scrutinising themselves in a looking glass for residues of sexual attractiveness. On the right-hand page, as if to draw attention to the differential power of the medium, are photographs. Franck selects Félix Nadar's mesmerising portrait of his grey-haired mother; Edward Sheriff Curtis's powerful study of a wrinkled Chinook woman; a portrait of astronomer John Herschel, by Julia Margaret Cameron; ${ }^{8}$ Leonard Freed's picture of an older German couple visiting the grave of their son; and Cartier-Bresson's photograph of two semi-naked Balinese women - one young and one in later life - standing 
in the bustle of a street market. Franck's collage primes us: how have Western art and photography mediated the experiences of old age? What have they told us about it? How have they situated spectators across age groups in relation to later-life experience?

There follows Franck's short diary (Le Temps 9-16). Here, her page is split. On the left-hand side is an account of and rationale for her project; on the right, a rich compilation of literary quotations related to ageing from classical authors such as Victor Hugo, Marcel Proust and William Shakespeare. The most frequently quoted work in this section is Simone de Beauvoir's La Vieillesse, a ground-breaking study which deals with the issue of ageing at a time of prevalent marginalisation and devaluation of older people in Western industrialised societies. Here, Franck readily reveals her indebtedness. Selected quotations highlight the social and economic inequalities that mark later life; the variable construction of old age across cultures; the meaning (or lack of meaning) attributed to late life; and the dwindling of respect for experience in a technocratic society which sees age as a falling-off and a failing, and which prioritises instead the values associated with youth.

\section{A Dialogue With Simone de Beauvoir}

One of the ways in which we may productively frame Franck's ongoing project on ageing, both in and beyond Le Temps de vieillir, is by reading it alongside $L a$ Vieillesse. This is an important critical gesture. I contend that Le Temps de vieillir, published ten years after Beauvoir's remarkable and angry study, sets up an intricate dialogue with the author of La Vieillesse that goes well beyond the un-glossed quotations I have just alluded to and that implicitly responds to the philosopher's injunction to her reader to break the conspiracy of silence that sweeps the problems of ageing to the margins and facilitates the unproblematised dehumanisation of older people. Franck and Beauvoir were not close contemporaries - there are thirty years between them - but they were working at the same time, and their projects overlapped. ${ }^{9}$ La Vieillesse was published when Beauvoir was sixty-two and contending, sometimes bitterly, with her own ageing as a woman; Franck, thirty-two at that moment, was already busy taking photographs of older people and showing deep ethical interest in their lives as well as indignation about social neglect. The energy, determination, scope and focus of their respective projects on ageing bear comparison. Like Beauvoir, Franck is bent on making visible via a thoroughgoing investigation what goes unseen. Unlike Beauvoir, who notoriously recoils with horror and loathing in the face of ageing, not least her own (she speaks in La Force des choses of ageing as a scandal, a violation and a monster crouching on her chest as she sleeps), ${ }^{10}$ Franck is driven not by an overriding sense of alienation but by an instinctive, empathic curiosity. 
Franck's preface raises some of the key issues regarding unequal ageing that structure $\mathrm{La}$ Vieillesse, such as social class and poverty, how gender influences experiences of ageing, capitalism's routine discarding of workers who have outlived their usefulness and the provision of care, both in the home and in institutions. She was familiar with an important report of 1962, the Rapport de la Commission d'étude des problèmes de la vieillesse [Report of the Commission for Study of the Problems of Old Age] which argued that caring for older people in their own homes, allowing them to stay there as long as possible and keeping them integrated in the community should be public policy priorities. Her photographs - as we will see - contribute explicitly to making that argument. Franck and Beauvoir were both fascinated too about how different cultures treat older people. Though Franck's main focus is on France, her definition of old age as "a biological and social fact which depends on how the individual is treated by the collectivity" (Le Temps 15) leads her to draw together photographic evidence from a range of far-flung places and to make comparative observations. Thus:

[t]he status of 'old people' is a crude reflection of the society in which they live. The artificial segmentation of Western societies into age brackets opens the door to generational segregation. Let everyone manage as best they can; personal and family responsibility is fraying away. It seems to me that this is connected to life in cities. In the countryside and in Eastern countries older people retain genuine roles and are not brutally cast aside. Their contribution is considered, not only their cost to society. Old age seems to me less harrowing there because, generally speaking, it is not accompanied by a brutal cessation of activity.

(ibid. 12)

Towards the end of her diary Franck notes the efforts that have been made in France in recent years and praises, for instance, the Centres de l'âge d'or [Golden Age Centres] which organise meals, coach trips, slide shows and so forth, but adds: "These activities cannot fill the gulf of segregation between ages, or replace the social function that any older person could have" (ibid. 15). She argues for a viable, active place for older people, highlights the abruptness of retirement that strips individuals of their sense of identity and leaves them project-less, admires the Swedish model and its flexible, comprehensive state support (also spoken about at length by Beauvoir) (ibid. 13) and calls upon younger people to mobilise and press for a change of attitude.

While Franck's staple observations in her diary are similar to those of Beauvoir, her medium and mode of knowledge production are, of course, different. Where the tight arguments and superabundance of factual material in Beauvoir's 600-page La Vieillesse require intellectual involvement, 
Franck's photo essay is a series of raw encounters that constitute prompts to do our own thinking, to confront the crisis of looking in which older people are enmeshed and, critically, to feel. It is as though Franck seized on Beauvoir's reiterated complaint about the numerous ways in which society colludes in ensuring the invisibility of old age - a willed invisibility so naturalised that it is itself invisible - and sought to tackle it precisely through a visual project, one that challenges us to meet ageing head on not through reading about it, but through encounters which are more direct because they are visual. Even though, as Gullette observes, "ageism is not solely a visual pathology," what she calls the "social optic" nonetheless performs "several kinds of dirty work in hypervisual, bodyfocused societies" (23) and does so intensively, especially in photography. When it comes to ageing, then, and to the all-too-ready objectification of older people, the photograph, one of society's primary instruments of self-knowledge, which both constructs and records meaning, is especially good to think with.

\section{The Photograph in Visual Gerontology}

Art historian W. J. T. Mitchell's ever-useful prompt to ask ourselves "What do pictures want?" takes on a sharply new relevance with regard to the photograph in visual gerontology and ideas of responsible looking. Here arise a number of questions that are specifically pertinent to Le Temps de vieillir: what can photography do in tackling perceptions of ageing? What does an anti-ageist photograph look like? How might the multiple gazes circulating in and generated by the photograph, which between them negotiate its meaning, break the cyclical reproduction of, and collusion in, ageist ideologies? Let us turn briefly to examine Gullette's ideas about photographic counter-practices. The images that she praises for not "shooting old people" offer distractions from the idea of oldness, elude the prevailing declinist imagery and push ageing into the "second tier" (42) of our consciousness so that it is overwritten by something else. They invite us to linger, surprising and even delighting us as they challenge preconceptions about later life and bring us to gloss oldness differently. While the selection of photographs that she curates for us dates from the mid-twentieth century, she observes that the early twenty-first century in particular "may be a propitious time in portraiture of the old" (27) and her choices lean towards experimental art photography. She is enthused by the monumental photographic portraits, so surprising and arresting in their scale and context, that contemporary French urban artist JR pastes onto a host of unlikely urban surfaces in his famous Wrinkles of the City projects (2008-2015), prompting passersby in global cities to ponder age, the ageing process and how they affect the identity of both people and place. She explores at length Jeff Wall's The Giant (1992) in which a statuesque nude older woman, digitally 
enlarged so that she dominates the vast space of a public library, seems bizarrely invisible to those around her. It is true that the visual conceits and suppleness of digital image-making and novel forms of display can do remarkable things in getting us to think afresh about ageing, jolting us and re-framing questions with tremendous impact: the imaginaries of ageing projected by Gillian Waring and Cindy Sherman, with their prosthetics and knowing digital self-transformations, come to mind..$^{11}$ But I wonder whether Gullette is in danger of replicating what Davis refers to as "the gerontological assumption that the most effective way to combat societal ageism is to flood the cultural sphere with unreservedly 'positive' images of older people" (61).

Franck's documentary emphasis and analogue technology make her corpus very differently nuanced, and she has her own way of threading through visual gerontology's minefield. One of Gullette's concerns that is relevant to Franck, however, is precisely that photographic collections devoted to the theme of old age are inherently reductive; that they homogenise, carelessly lumping together older people like so many tools with which to think through part of the human condition, rather than presenting them as interesting subjects in their own right. "[B]eing asked to page through a series," claims Gullette, "weakens each solo image" (28-9). It is important to examine how Le Temps de vieillir stacks up against such a charge. First, the sheer breadth and diversity of Franck's photographs in terms of the cultures, situations and walks of life represented point against homogenisation. Her anti-declinist stance and keenness to depict what it means to age well give rise to engaging, uplifting and distinctive photographs, ranging from veteran runners in the annual Figaro cross-country run in the Bois de Boulogne (1979) to older women enjoying a game of bowls in Worthing (1980). A dermatologist whose practice in Paris is still going strong even though she is over 80 (1980), a man preparing his mastiff for a dog show in Carlisle (1978) and several portraits of grandparents with grandchildren speak to us in different ways of the satisfactions available in older age. Franck's desire to collect and display positive images of ageing is an important dimension of her practice as care. Yet she is intent too on social critique and, as we will see in the following section of this chapter, on making visible the unpalatable truths about dependency and isolation in a society that does not prioritise care for those in later life. Such ills above all needed to be documented by the camera, not re-imagined by it in uplifting form. This means that images of decline necessarily form a powerful part of Le Temps de vieillir, contributing to its diversity and integrity.

One of the structural choices in Franck's collection is, however, potentially troubling. I am immediately struck by her decision to reserve the information about each photograph for an appendix. This choice, puzzling at first, means that her subjects as we encounter them are anonymised, decontextualised and hence all the more easily offered up 
less as individuals than as depictions of a common state: old age. Yet I am tempted to turn such an interpretation on its head: we might easily construe the gesture instead as a critique of the ageist gaze, an invitation to look for difference and therefore an integral part of the book's forceful argument for change. The power of Le Temps de vieillir as a thematic collection derives, in my view, from the questions that such undecidability prompts and the ways in which these questions position us. This undecidability includes Franck's skilful shuttling and slippage between image types: documentary images (which we typically think of as holding the spectator at a distance) and portraits (which are, as we know, intended to draw us in). As we leaf through the pages and are buffeted by multiple calls on our imagination, intellect and affect, it is the intimate appeal of the portrait that hovers around each image and persistently engages us. As Graham Clarke notes, the photographic portrait "simultaneously represents the photographic image at its most obvious and yet at its most complex and problematic"; it brings us to ask "precisely what, and who, is being photographed" $(102,101)$; and, most usefully for our purposes here, its boundaries are uncertain. "Perhaps," muses Clarke, "we are entitled to ask at what point an image may be called a portrait" (114; original emphasis). This conundrum will underpin my analyses of specific images from Le Temps de vieillir in the following section.

\section{Photography and Contexts of Care}

Franck's expanded view of and intensive interest in care led her to document the lives of older individuals whose well-being is conspicuously bound up with care facilities, services, institutions and structures. The preface to Le Temps, as well as certain of the photographs within the book, raises the issue of providing adequate support for those who wish to remain in their homes rather than be taken into care, a question which Franck describes as "one of the problems of our civilisation" (Le Temps 14). Throughout her corpus, Franck's photographs of people are typically attentive to the importance of home. Seeing subjects in their daily, domestic environment, surrounded with the artefacts that make ontological sense of who they are, suggests the layered richness of their lives: "I have often photographed people in their homes because I feel that they reveal themselves more in their everyday space, surrounded by their objects" (Le Temps 11). Building on this fascination and on the affective pull of home, her photographs of older people have us shuttle imaginatively between the late-life dilemma of home as healthcare setting and healthcare setting as home. Here I offer short explorations of images which evoke for me particularly powerful responses to this problem and at the same time to Clarke's question about the portrait raised earlier. All of them depict people in institutions or situations of care. All open layers of thinking and feeling about late life, giving a distinctively 
gerontological gloss to Susan Sontag's suggestion that any photograph offers "inexhaustible invitations to deduction, speculation and fantasy" (23). All send me powerfully back to myself, and the more I linger with them, the more it seems to me that rather than constructing a challenge to the ageist look, many of them simply exceed any idea of it.

The caption for a photograph of 93-year-old Mme. Vidal informs us that she lives alone on the sixth floor of a Parisian apartment block without a lift and is no longer capable of going out but is visited several times a week by Accueil et Service [Home Support Services]. These visits, we are told, have "spared her the hospice" (Le Temps 84), although she clearly lives in confinement, and the jumble of decaying domestic objects among which she sits are eloquent on the struggle that is her day-to-day life. A welter of sensory suggestions works powerfully upon me as I meet the sitter's gaze and begin to think into and beyond the frame to entertain the intractable difficulties of her existence. Other photographs which have as subtext the problem of sustaining home invite us to imagine and to care about what this might mean in an institutional setting. Here we feel the tension between an everydayness that the individual has created and one that is created for them. A pair of photographs made in 1975 in the Hospice d'Ivry in the southeastern suburbs of Paris shows how residents have decorated their respective corners of a shared room. In one, Franck empathetically, non-judgementally captures one man's fantasy world, consisting of an array of "girlie" photographs plastered upon the wall above his bed and demarcating his space. In another, an old woman is cocooned by layers of crocheted cushions and other elaborate, handmade artefacts. These are powerful studies suggestive of making home and of seeking to retain self-narrative and memory within institutional contexts. The subjects look awkward within them: the man is de-centred and almost leaving the frame, while the tiny woman appears lost and engulfed in her soft furnishings, her gaze distant. In emotional terms, these still images of home-making are unsettling and put me on the spot in ways that are hard to process and that are medium-dependent: the instantaneous production of such shifting and intense affects is simply unavailable to prose.

As I have suggested, Le Temps de vieillir contains a cluster of images which show Franck's emerging interest in the conditions that prevailed in institutions of "care" (the scare quotes here are deliberate) in 1970s France. Acquiring these images was arduous. Franck notes that she had to wait for four years to be permitted access to the vast and foreboding Maison de Nanterre, one of the largest institutions, and that once there she was permanently accompanied by an intrusive official. Situated in the western suburbs of Paris, the Maison de Nanterre had some 4,800 beds. The scandalously inhumane conditions and brutalising treatment of residents were extensively critiqued by Beauvoir as a core instance of society's neglect in a documentary film made after publication of La Vieillesse, 


\section{Shirley Jordan}

and there is a sense that in her own visit Franck is on the philosopher's trail. ${ }^{12}$ The dominant note in Franck's photographs is social isolation. She observes that in this vast hospice, men and women are segregated not only in the dormitories and canteens but also in the gardens and yards, "where only 'legal' couples are allowed to speak to each other"; it is, she comments, "striking to note the lack of communication between people, who pass by each other without connecting" (Le Temps 86). The implications for mental health are deeply troubling. In one particularly telling photograph, Franck's powerful concern for care patently manifests itself as critique by the way in which she purposefully short-circuits the multiple acts of contact inherent in photography (see Figure 1.1). There is simply no access to the three subjects in this image, just as there is no contact between them. They, and I, remain steeped in a solitude which is difficult to interpret and which pains me. The strong triangular composition, the divergent gazes and the inattentiveness of the women to each other (also to the photographer and hence to us) suggest an aphasic environment. Any opportunity for encounter is denied us by the central figure's turning her back on us, while the other women are differently absorbed, one of them already slipping her way out of the frame. Here the photograph as meeting place - as portraiture - slides into reportage; there is no conduit into the situation or the subjects' inner worlds. They are depicted as (having been made) unreachable.

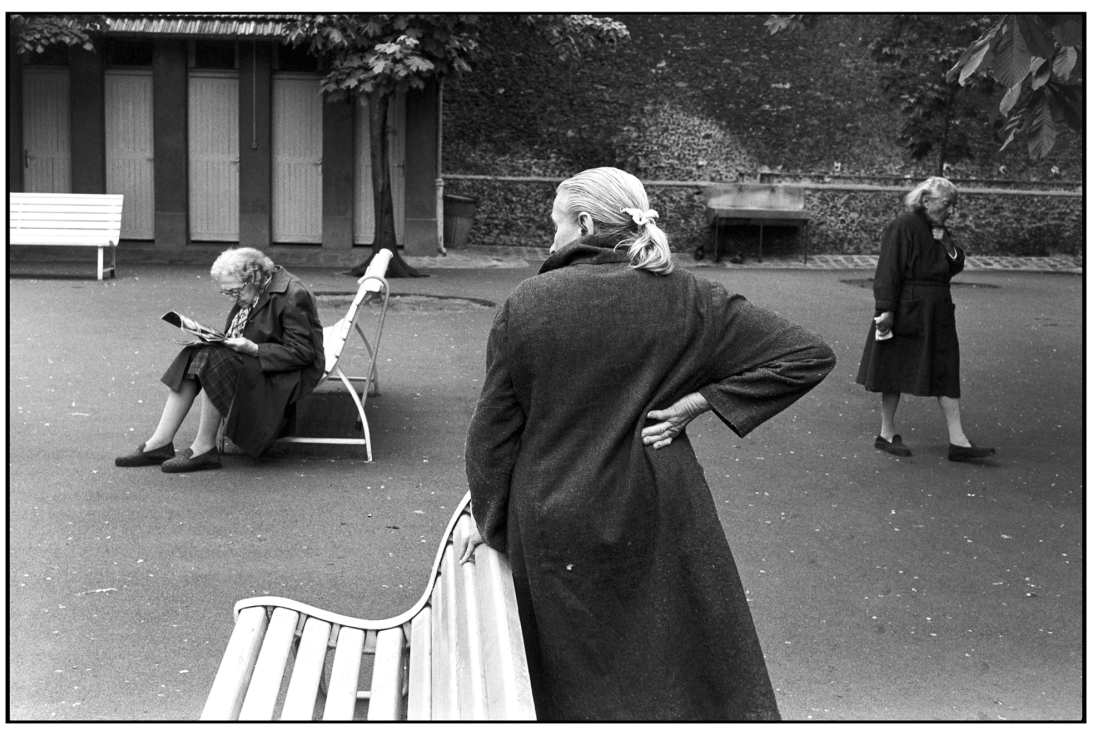

Figure 1.1 Hauts de Seine. "Maison de Nanterre," 1978 (C) Martine Franck/ Magnum Photos. 
Let us turn now to a quite different order of photograph, a powerful declaration of selfhood captured during a protracted encounter in the refectory of the hospice of Ivry-sur-Seine in 1975 (see Figure 1.2). This is clearly not just a portrait, but a portrait with attitude. It has a singular energy and dynamism about it, generated by its subject who controls the image and whose playful, slightly disruptive agency is appealing. She is photogenic. The camera likes her, and her portrait does not connote loneliness or isolation but rather speaks of a rich imaginative life. I am not sure that the photograph pushes age into the "second tier" of my consciousness (Gullette 42); I do not stop seeing the woman's age, but it is far

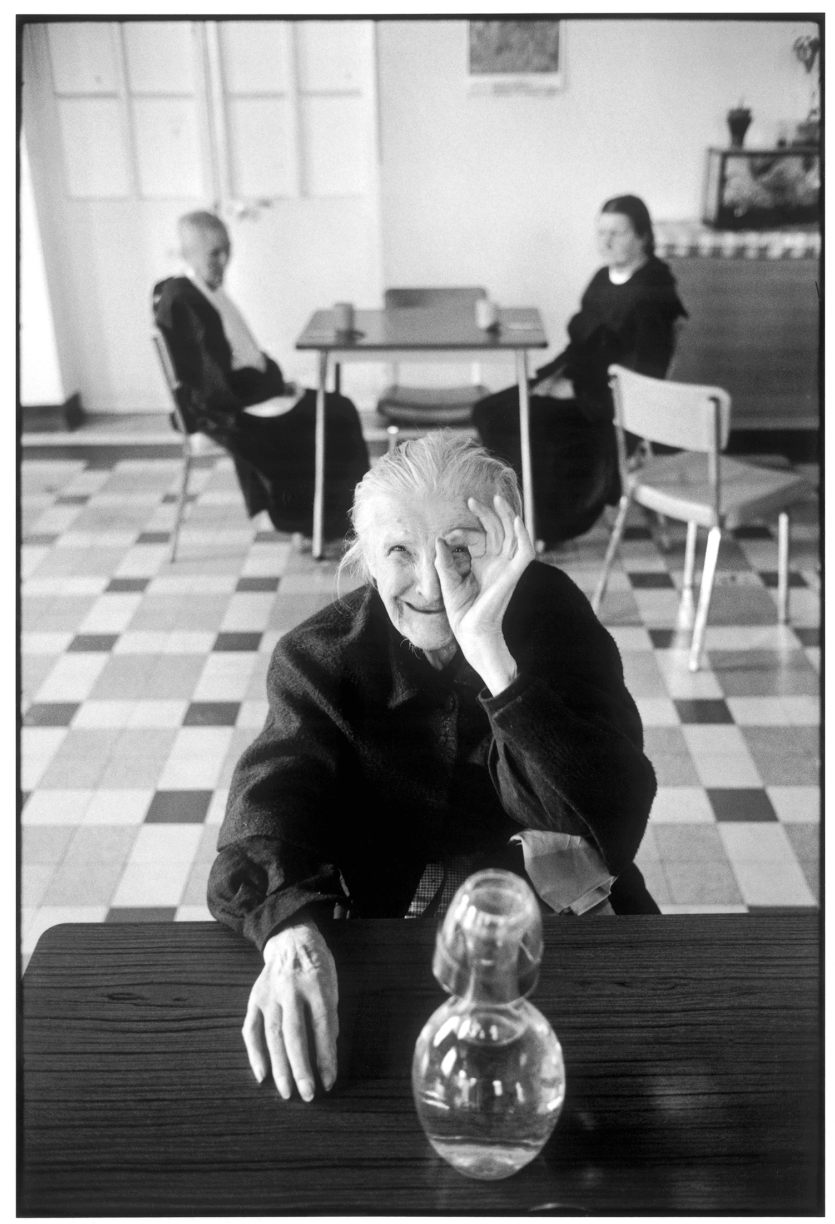

Figure 1.2 Val de Marne. Ivry-sur-Seine. Hospice, 1975 (C) Martine Franck/Magnum Photos. 


\section{Shirley Jordan}

from being all I see. The quality of the intergenerational exchange going on at the moment when the image was taken is energising, unpredictable and exciting; we sense a shared moment of pleasure. The image's composition is rigorous and rich in implications. Its three horizontal bands suggest that the encounter takes place within a Foucauldian power dynamic: the old woman is scrutinised from back and front, sandwiched between the gaze of what appear to be guardians or gatekeepers - shadowy figures whose quiet, regulatory presence is nonetheless confirmed by the way in which they hover in the top band - and that of Franck, alluded to by the indicators of bare hospitality - a table and a carafe of water - in the bottom band. But a more powerful compositional directive is given by the photograph's inverted triangle, all its energy coalescing at the point of encounter. Thus, I am drawn over and over to the woman's strong hand resting on the table and reaching towards Franck, almost breaking the frame.

This portrait is eloquent about the terms of Franck's humanistic practice. Portraiture, she tells us, requires sustained contact, proper listening and "begins with a conversation" (Women/Femmes 90). It is not about asking the subject to pose, but rather to choose how they reveal themselves. Franck prefers to make pictures when communication is, or has been, intense; when her meeting with the other is about something more than the photograph; and when that something more is determined as far as possible by the sitter. Here, the old woman turns the tables on Franck, creating her own lens and looking back in a spontaneous, ludic gesture which implicitly nudges us to ask how we might be seen in return by the older people we are looking at thanks to Franck's lens, as well as reminding us that there is more than one position from which to view the world. If all portraits (barring the selfie) are the result of an encounter, most elide that fact and provide what appears, thanks to one of photography's most invidious sleights of hand, to be uninterrupted access to the subject. This photograph, on the contrary, is about co-presence and a mutual gaze; it depicts an encounter and the terms of that encounter. As for the politics of the exchange, the woman's gesture, while it cannot turn the tables, levels the stakes somewhat. She declares an interest in Franck and in what Franck is doing. In the imaginary lens crafted by her curled thumb and index finger lies, in fact, the stakes of the entire project of Le Temps de vieillir which is to interrogate the structure of the look and learned ways of seeing: who is looking, from what position on the spectrum of age are they looking and how have they learned to see? The image is thus not about decline but about the possibility of vital intergenerational relationships. It alludes to the hope that the result of looking - specifically of looking through a device with a lens - will be to produce a special kind of reciprocal focus, a meeting place. Referring to collections of images of older people, Gullette notes: "I turn such pages languidly, looking for distinctiveness" (29); she would find it in abundance here. 
The final photograph I shall analyse was made in 1980 and is glossed by Franck as follows: "Two sisters who live together in the 13th area of Paris; the Misses Gravin, 82 and 83 years old. The young girl works for "Accueil et Service" and provides care twice a day" (Le Temps 87) (see Figure 1.3). This is a particularly challenging photograph in which the care givers are represented along with the recipient and the burdens that fall upon them implied. It spares us nothing as it presents us with latelife infirmity and vulnerability and valorises the habitually invisible acts of care that are a daily part of life for many older people. Here Franck's exploration and cultivation of care explicitly incorporate "giv[ing] voice and attention to humans who are undervalued precisely because they perform unnoticed, invisible tasks and take care of basic needs" (Laugier 218). We might set this image in dialogue with the first of this collection's close-to-death images, Death of Adam in the opening collage, where Adam begs his son Seth for the oil of mercy, although Franck's is a much more difficult image of dependency, no doubt in part because, although it is painterly, it is not a painting but a photograph. It is one of the most intimate of the book's images and raises the question of what can and what should be photographed, yet without itself seeming intrusive. "Not everything can be photographed," says Franck; "There are moments where suffering, human decline seize you and stop you [while] other situations, even if they are sociologically interesting, may have nothing to say

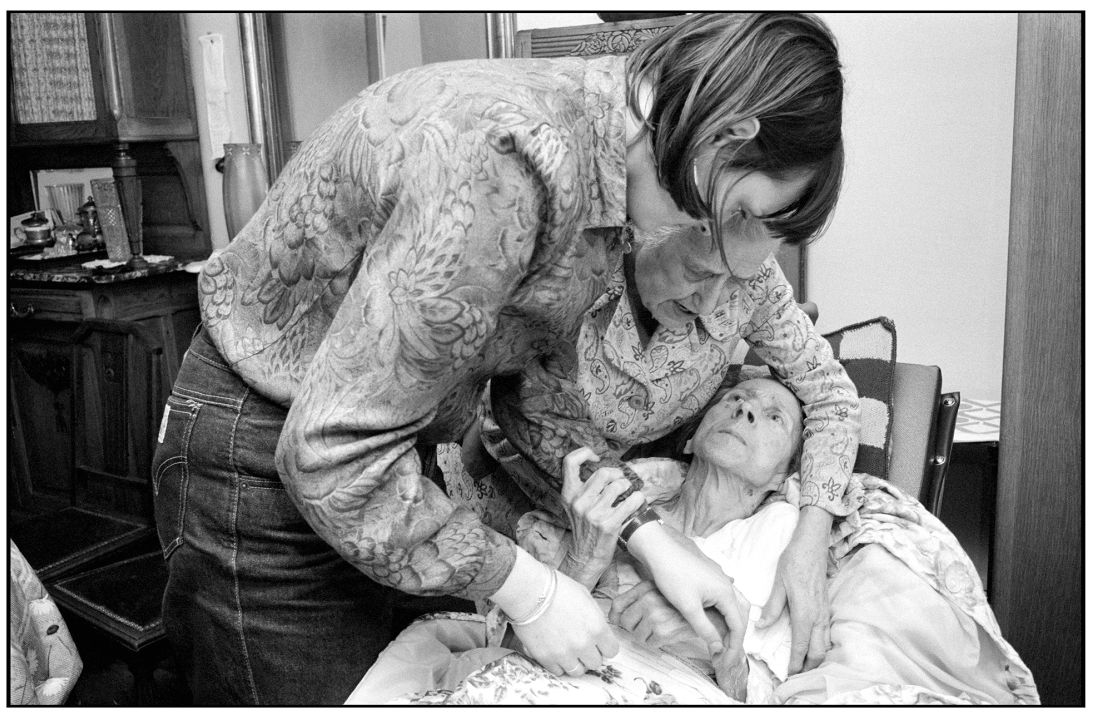

Figure 1.3 Paris. 12ème arrondissement. Association "Accueil et Service," visite à domicile, 1980 @ Martine Franck/Magnum Photos. 
on a visual level" (Le Temps 11). Both the subject matter and the composition of this photograph powerfully raise the question of how we are to look at Franck's images of care, what we might look for within them and what she intends they will prompt.

For me, this photograph occupies a productively troublesome borderland. Am I asked to attend to an idea (that is, an idea of care, documented through a specific act of caring) and a state (illness in late life) or, following the language of portrait photography, to focus on the inner self of the central subject? Referring once more to Clarke's question: is this in any sense a portrait? The question is critical, because if I think not, then I am conceding to view the central figure reductively as representative only of need. I am reminded - although the category of photograph is very different - of the difficult debates generated by the portraits that Richard Avedon made of his father in the last stages of a terminal illness, debates around intrusiveness, ethics and aesthetics. Here the moving, intense choreography of interlocking bodies and gazes, confirming that the self is always in the hands of others, gives value to the activity in train; yet there is also insistence on the experience and the inner world of the central figure. I am caught on the cusp between my immediate reaction to the photograph as document and an urgent call to feel my way more deeply into the picture's experiential dimension; to ask the right kinds of questions of it and of myself. What Franck offers us here is a singularly heightened photograph of care, which also dignifies care. "As a concept," remarks Alessandro Pratesi, "care encompasses both instrumental tasks and affective relations, ranging from activity to ethics, that is, from 'taking charge' of others' physical well-being to 'feeling concern' for others' physical and psychological well-being" (96; original emphasis); all of these dimensions of care are captured here by Franck. Not only does her photograph valorise the gestures and what Lisa Baraitser has called the "stuck" time of care (time marked by "unprofitable" acts of "waiting, staying, delaying, enduring, returning" [14], so out of kilter with the urgent acceleration that has become life's normative pace), it also transposes everyday gestures into an image of powerful symbolic value. It is consistent with the suggestion of ethical theorist Annette Baier that we bring to the fore of our ethical considerations qualities such as gentleness (219) and, returning to Laugier, that we take on board the routine physicality of care: "care [as] a practice, not 'only' a moral feeling or disposition" (226). It has extraordinary gravity and a pronounced dramatic dimension. It emphasises what binds us as we care: the touch and the gaze. As I lean in to scrutinise the cluster of bodies and faces, I know that there is a potential for voyeurism, but Franck is ever tactful, unthreatening and discreet. The image's strong composition binds together form and content in a powerful example of how Franck's sociological, humanitarian purpose was served by the drive to formal experimentation and stringent aesthetic criteria which she rarely sacrificed. This photograph of an explicit act 
of care constitutes in itself an act of care as it takes us to an extreme of empathy: transfixed at the bonds in evidence in this urgent knot of bodies, my identification shuttling between the web of relationships that they imply, I know as I transfer my gaze to the central figure that I am looking, potentially, at myself.

Although she did not articulate it in these terms, it seems to me that the multiple encounters to which Franck invites us in Le Temps de vieillir, encounters which repeatedly test what empathy theorist Kathryn Robson has referred to as "the grammar of location and distance that structures and shapes relations of empathy and compassion" (693), are intended to lock us in to a view of social relations as organised around dependency and vulnerability and thus to have us measure the importance of care for human life. Such recognition entails, as feminist theorists of care have noted, understanding that dependence and precariousness are not accidents that happen only to others. Although Beauvoir divided $\mathrm{La}$ Vieillesse into two parts - first, older people seen from outside their world as objects of knowledge; second the view of self, time and world from within - Franck's every image keeps us profitably snagged between these two perspectives, effectively reminding us that, as Judith Butler so neatly observes, "dependency fundamentally defines us" (33). Thus, it is on the common terrain of vulnerability, captured by the lens, that Franck's photographs of older people address the imperative so powerfully articulated in Beauvoir's La Vieillesse: "We must stop cheating: the whole meaning of our life is in question ... let us recognize ourselves in this old man or that old woman" (5).

\section{Legacies}

Franck's Le Temps de vieillir launched her reputation as a major photographer, led to her intensive work with Les petits frères des Pauvres and constituted the first stage in her production of one of the most extensive photographic records of the lives of older people to exist anywhere in the world. How can we explain, then, that the current chapter is the only critical assessment to date of what surely constitutes a major landmark in cultural gerontology ${ }^{13}$ Here we might return to connect Franck with Beauvoir once more, for in spite of favourable views upon its publication, La Vieillesse was also until recently largely ignored, "neglected by feminists, humanists, gerontologists, historians and philosophers alike" (Katz n.p.). Thus, a quietly consensual side-lining of two courageous and extraordinary endeavours to change perceptions of older people demonstrates the enduring validity of the very critique that propelled both philosopher and photographer into action in the first place. It is only in recent years that serious engagements with Beauvoir's La Vieillesse have emerged and that it has been brought to prominence again, largely by feminist scholars of ageing. ${ }^{14}$ It is time to revisit Franck's work in 


\section{Shirley Jordan}

the same way and, putting an end to three decades of critical neglect, to situate it firmly within the evolving histories of cultural and visual gerontology. This chapter has made a start. In particular, I have argued that Franck's relentless attempt to re-educate society's gaze and to reinstate older people and our relationships with them in the visual field anticipates the emphasis on care with which we are today becoming so familiar, and seeks to make of care ethics a "politics of the ordinary" (Laugier). It is the powerful connection between Franck's work as praxis and contemporary theories, practices and imaginaries of care which, in my view, deserves wider scholarly enquiry.

\section{Notes}

1. Martine Franck, Le Temps de vieillir. Journal d'un Voyage - 4 (Paris: Filipacchi-Denoël, 1980). Franck's books are not translated. Translations in this chapter are my own.

2. It is worth noting that Franck's work intersects with gender studies and disability studies as well as ageing studies. She promoted a range of causes, from women's rights to the deprivations of children with disabilities, and was deeply committed to working within marginal communities. Her powerful respect for others thus establishes her practice as one that is generally driven by ethical issues and the challenges of care, although I contend that care manifests itself in distinctive ways where her photographs are of older people.

3. I do not seek to develop in this chapter a specifically feminist argument, but my appreciation of Franck's moral sensibility is certainly in tune with the connection that many care theorists draw between women's intimate understanding of marginalisation and the development of care ethics. See, for instance, Gilligan, "Moral Orientation"; Kittay and Feder; Koehn; Tronto and Fisher.

4. "For women, old age weighs heavy and the risks of solitude are greater" (Franck, Le Temps 11).

5. Some of this work is collected in Martine Franck, De temps en temps.

6. Publication of the book was followed by an exhibition entitled Le Temps de vieillir, shown at the Musée Nicéphore Niépce in Châlon-sur-Saône (1981), and the Malmö Museum in Sweden (1982).

7. Though some of the photographs pre-existed the commission, most were taken close to the year of publication and in direct response to the challenge. It was this commission that launched Franck's career as a photographer of ageing subjects and documenter of the provision of care, both formal and informal.

8. Cameron made numerous photographs of older people and was a strong influence on Franck.

9. I have to date been unable to discover whether Franck conversed directly with Beauvoir about her work on ageing, although the two women attended many of the same women's rights events in 1970s France, with Franck documenting some of these, so the opportunity was certainly there.

10. "just before I come back to reality, a giant beast settles on my breast: 'It's true! It's my nightmare of being more than fifty that's come true!' " (Beauvoir, Force of Circumstance 656).

11. I am thinking of Waring's Rock ' $n$ ' Roll 70 Wallpaper (2019) and Sherman's portraits of herself as ageing screen stars from the Golden Age of cinema (2016). 
12. This harrowingly frank documentary, PROMENADE AU PAYS DE LA VIEILLESSE / A WALK IN THE COUNTRY OF OLD AGE (1974) was made by Marianne Ahrne in the hospices at Ivry and Nanterre. For an account of the film, see Oliver Davis, Age Rage and Going Gently: Stories of the Senescent Subject in Twentieth-Century French Writing (164-9 and 197-204). Ahrne notes that Beauvoir had not been granted access to Nanterre and had not been to Ivry while researching The Coming of Age (201).

13. There exists one other piece, "Martine Franck au pays de la vieillesse," a largely descriptive tribute penned by Michel Christolhomme, then Director of Les petits frères des Pauvres, shortly after Franck's death.

14. See in particular Silvia Stoller (ed.), Simone de Beauvoir's Philosophy of Age: Gender, Ethics and Time. de Gruyter, 2014.

\section{Works Cited}

Baier, Annette. Postures of the Mind: Essays on Mind and Morals. U of Minnesota P, 1985.

Baraitser, Lisa. Enduring Time. Bloomsbury, 2017.

Baring, Louise. Martine Franck. Phaidon, 2007.

Beauvoir, Simone de. Force of Circumstance. Penguin, 1968.

- La Vieillesse (Gallimard, 1970); The Coming of Age. Translated by Patrick O'Brian. Putnam, 1972.

Butler, Judith. "On Cruelty.” London Review of Books, vol. 36, no. 14, 2014, pp. 31-3.

Christolhomme, Michel. "Martine Franck au pays de la vieillesse." Gérontologie, vol. 164, Nov. 2012, pp. 26-43.

Clarke, Graham. The Portrait in Photography. Reaktion Books, 1992.

Davis, Oliver. Age Rage and Going Gently: Stories of the Senescent Subject in Twentieth-Century French Writing. Rodopi, 2006.

Dyer, Geoff. The Ongoing Moment. Canongate Books, 2012.

Franck, Martine. Les Lubérons. Éditions du Chêne, 1978.

- Le Temps de vieillir: Journal d'un Voyage - 4. Filipacchi-Denoël, 1980.

- De temps en temps. Trois-Cailloux Éditions, 1988.

- One Day to the Next. Thames and Hudson, 1998.

- Women/Femmes. Steidl, 2010.

Gilligan, Carol. In a Different Voice. Harvard UP, 1982.

- "Moral Orientation and Moral Development." Justice and Care: Essential Readings in Feminist Ethics. Edited by Virginia Held. Westview Press, 1995, pp. 31-46.

Gullette, Margaret Morganroth. Ending Ageism or How Not to Shoot Old People. Rutgers UP, 2017.

Harris, Mark Edward. The Travel Photo Essay: Describing a Journey through Images. Routledge, 2018.

Katz, Stephen. "Simone de Beauvoir's The Coming of Age: The Humanities and Gerontology's Diagram of Science.” Age Culture Humanities, vol. 3, 2016, ageculturehumanities.org/WP/simone-de-beauvoirs-the-coming-of-age-thehumanities-and-gerontologys-diagram-of-science/.

Kittay, Eva Feder, and Ellen K. Feder, editors. The Subject of Care: Feminist Perspectives on Dependency. Rowan and Littlefield, 2002. 


\section{Shirley Jordan}

Koehn, Daryl. Rethinking Feminist Ethics: Care, Trust and Empathy. Routledge, 1998.

Koggel, Christine M., and Joan Orme, editors. Care Ethics: New Theories and Applications. Routledge, 2015.

Laugier, Sandra. "The Ethics of Care as a Politics of the Ordinary." New Literary History, vol. 46, no. 2, 2015, pp. 217-40.

Meagher, Michelle. "Art, Ageing and the Body." Routledge Handbook of Cultural Gerontology. Edited by Julia Twigg and Wendy Martin. Routledge, 2015, pp. 85-92.

Mitchell, W. J. T. What do Pictures Want? The Lives and Loves of Images. U of Chicago P, 2006.

Pratesi, Alessandro. "The Productivity of Care: Contextualising Care in Situated Interaction and Shedding Light on its Latent Purposes." Care Ethics: New Theories and Applications. Edited by Christine M. Koggel and Joan Orme. Routledge, 2015, pp. 94-108.

Robson, Kathryn. "The Limits of Empathy and Compassion in Delphine de Vigan's No et moi and Les Heures souterraines." Modern Language Review, vol. 110, no. 3, 2015, pp. 677-93.

Sontag, Susan. On Photography. Penguin, 1977.

Stoller, Silvia, editor. Simone de Beauvoir's Philosophy of Age: Gender, Ethics and Time. de Gruyter, 2014.

Tronto, Joan, and Berenice Fisher. "Towards a Feminist Theory of Caring." Circles of Care: Work and Identity in Women's Lives. Edited by Emily Abel and Margaret Nelson. SUNY Press, 1990.

Woodward, Kathleen. "Performing Age, Performing Gender." NWSA Journal, vol. 18 , no. 1,2006 , pp. 162-89. 


\title{
2 Improvisation and Vulnerability \\ Circuits of Care in Performances of Age and Ageing
}

\author{
Bridie Moore
}

\section{Introduction}

This chapter explores the notion of a circuit of care occurring in performance practices related to age and ageing, paying attention to how it operates regarding cognitive disability, particularly in Ruff (2012), performed by Peggy Shaw. This show was directed by and co-devised with Shaw's long-time collaborator Lois Weaver; the pair is known as Split Britches. Here I explore how stroke survivor Shaw performs the complexity of ageing and fragile subjectivity and how her performance and other activities inspired by her performative response to her stroke sets up a circuit of care between audience, performer and dramaturg. I explore how Ruff explicitly acknowledges physical and cognitive fragility through the content and technical details of the performance and through Weaver's interventions from the auditorium. I note how Shaw's performance expertise, in spite of her cognitive difficulties, confounds expectations of post-stroke dependency and how her duty of care as a performer extends to informing and educating audiences about the symptoms and effects of stroke, thus completing the circuit of care in $R u f f$. The chapter also examines other examples of theatre practice with old people, which, taken together, illustrate how circuits of care can be established by participatory and improvisatory performance practices. Such performative situations challenge the normative notion of the carer as giver and the cared for as receiver, equalising the status of both. In order to explore this, I use James Thompson's "aesthetics of care" (430) and Eva Feder Kittay's notion of "taking up" (Webteam) in care relations and pay attention to the notion of vulnerability, a recent development in political and legal philosophy that challenges the focus on the situation of dependency in care ethics.

\section{A Circuit of Care}

Having identified circuits of care in particular performance practices, I searched the literature but found few relevant entries. However, I was

DOI: $10.4324 / 9781003058618-3$ 


\section{Bridie Moore}

intrigued by an article by feminist geographers Sara Dorow and Shingirai Mandizadza, writing about US oil camp workers on Alberta's oil sands, working away from their families for short periods, that highlighted a "circuit of care," "that occurs within and through a regime of mobile work" (1244). The authors quote Loretta Baldassar and Laura Merla, describing a circuit of care as "the reciprocal, multidirectional and asymmetrical exchange of care" (Dorow and Mandizadza 1244). Both Baldassar and Merla's and Dorow and Mandizadza's research studies a geographical, temporal and gendered circuit existing between workers and their families which, as Dorrow and Mandizadza say, "reproduce[s] a labor force that is available, flexible, and conditioned for work" (1253). Though the geographical distance that seems to define the notion of "circuit" in these two publications is not present in the working relations that we find in Ruff, and the circuit developed in the show supports an efficacious mutuality between audience, performer and dramaturg rather than one that readies a workforce for the demands of commercial oil production - I would like to borrow this same image of work and care in a circular relation for my analysis of what occurs in the performance of Ruff and in other performance situations.

\section{Ruff}

According to director Lois Weaver, the performance piece Ruff "visually and verbally translates Shaw's internal experience of illness and aging into an external assemblage of her multifaceted, creatively capable, aging brain." Split Britches' website notes that:

There are dark spots and blanks in Peggy's memory now. Yet in paying tribute to the family, friends and performers who have inspired and kept her company over the years, she reflects on what is lost and equally celebrates the space left behind for new insight. Handing objects to audience members, calling out to Lois for help in the audience, and maintaining the constant presence of collaborators in projections and text, the performance lays bare the devices of care present in Peggy's life, foregrounding the ways in which a solo performance is never really solo.

(Ruff)

Shaw and Weaver began performing in the 1970s, founding both Split Britches (with Deb Margolin) and W.O.W. Cafe theatre collective in New York in 1980. Over the next 40 years, it became the norm for Weaver to play the "Femme" in the partnership while Shaw presented herself in what she calls "Gentleman Drag," taking on the significations of masculinity: the sharp suit and tie, short hairstyle and the swaggering cuff-andtie-straightening body style of a guy from a 1950 s movie. ${ }^{1}$ This norm was 
fully established by the time Shaw took on a solo career after Split Britches temporarily separated in the mid-1990s. Born in 1944, Shaw is now a veteran performer, and as such her disruptive gender-play also intersects with and complicates the figure of the "old woman" in performance, one that is rarely seen centre stage in British mainstream drama. ${ }^{2}$ Ruff daringly exposes the complexities of ageing subjectivity, on the threshold of what Peter Laslett calls "the fourth age of true dependency and decrepitude" $(\mathrm{x})$, that is, age so advanced that it represents a state lying "beyond the social and ... the scope for agentic transgression" (Gilleard and Higgs 138). Shaw is aided in her particular "agentic transgression" by the "social" support of the audience, of her collaborator Lois Weaver and of a "host of Lounge singers, movie stars, rock and roll bands and eccentric family members living inside her" (Vimeo). Shaw "channels" a cast of charismatic characters - for example, embodying Elvis's sexual potency in her rock star persona who sings "The Hokey Pokey" in a strutting, fist-in-the-air, microphone-tilting style - these remembered (and now enacted) figures populate the places in Shaw's brain left dark by the stroke. ${ }^{3}$ In her BBC Radio Four interview, she explained:

After my stroke . . . I was able to define that I wasn't an original person, that I had a combination of a lot of people inside of me that I wanted to talk about and thank for all their help. Like Leonard Cohen, and Marlon Brando and Elizabeth Taylor, Malcolm X, Otis Redding all the people I relied on for my songs and my monologues.

(Smith 26:50)

These figures, which she embodies on stage, provide her supporting cast. Her allies - including an all-female backing band who appear, one by one, projected onto a greenscreen behind her - support her in a performance that is openly "compromised" by the effects of her stroke. ${ }^{4}$ The greenscreen functions both as a metaphor for the losses Shaw has suffered and enables a performance of care enacted by this support system, these virtual friends, projected on the screen. So the notion of care, aid and support for the performer is an explicit feature of this performance; however, I will argue in the next section that the show - with the veteran performer at its centre - establishes a circuit in which the audience serves Shaw, Weaver serves Shaw, Split Britches the company (Weaver and Shaw) cares for the audience and Shaw specifically serves the audience.

When Shaw first enters, she takes out a bottle of water, explaining how, after her stroke, she has a tendency to cough at unpredictable times, and she asks an audience member to hold her bottle and other items. This at once signals the vulnerability of the whole performance and is the step that engages the audience in a circuit of care involving the performer, audience and dramaturg. Shaw's skilful opening appeal to the audience for aid, and other features of the show, also exemplify 


\section{Bridie Moore}

Thompson's "aesthetics of care," which he says features "sharing, support, co-working and relational solidarity within a framework of artistry or creative endeavor" (438); this perfectly describes the supportive circuit created within the show. In Ruff, Shaw depends openly on autocue, something which clearly acknowledges her cognitive disability (her inability to memorise); indeed, she sets up these devices as part of the opening of the show. Her occasional interruptions of the piece to ask her director Weaver - who sits in the audience - about the next sequence or move, make explicit the fragility which the stroke has produced, incorporating this fragility into the performance aesthetic, one which enlists the notion of care. However, this is not unidirectional: Shaw's duty of care as a performer is to engage, inform and entertain the audience, which she does with skill, and while the audience receives this offer, they are being readied by Shaw's performance expertise to acknowledge her cognitive needs and offer caring and supportive actions. Reviewer Kim Solga remembers:

Then - guilelessly, but with (as ever) killer timing - she handed me her orange.

"Will you hold my orange, please?" She spoke the line with utter sincerity, looking straight into my eyes; now I was in her . . . space, part of this new, uncertainly bodied performing world.

Commenting also on Weaver's role in modeling how to navigate this "new, uncertainly bodied ... world" Solga observes:

Weaver . . . is a crucial presence ... and on the night I attended she operated as a kind of audience fulcrum, a model for the spectator-caregiver role into which I felt I had been cast. . . . she was both spectator and actor-manager: when Shaw could not remember where she was meant to be on the stage at any given moment, she called out ... "Lois, am I supposed to be here now?" Weaver replied without missing a beat, "Yes. You're fine."

In this way, a circuit of care is established between audience, performer and dramaturg, with the performer and the dramaturg modelling the way the audience can provide care in this open and explicit performance situation.

Beyond the show, the performative solution to the losses Shaw's stroke has brought about has been translated into a productive outcome for other stroke survivors. As well as an informative post-show talk (discussed later), Shaw and Weaver are currently involved in research investigating 
the therapeutic effects of greenscreen avatars and motion capture in stroke survivor treatment, which has emerged from a Split Britches residency at the University of Tasmania, Australia, in which the technology is used as a "technique for seeing radical alternate possibilities ... framing Peggy's newfound disabilities as possibilities for innovation" ("Greenscreening”). Participatory performance methods coupled with greenscreen and motion capture technology enable stroke survivors to fantasise and enact a series of possible futures, thus framing "disability as a source for technological and performative innovation, an ethos which has ... shifted paradigms around neurodiversity" (ibid.). ${ }^{5}$ In addition to the work beyond the theatre, on stage, through her energetic singing, Shaw educates the audience about the F.A.S.T. protocol, which helps diagnose and dictates action for or on behalf of those experiencing a stroke. ${ }^{6}$ Consequently, in the wider and continuing influence of her work and in her role as entertainer and educator within the show, Shaw establishes herself as not only the cared for but also the carer. In this way the aesthetics of care that Thompson discusses is enhanced and deepened as a circuit of care is also created.

\section{Aesthetics of Care}

Thompson first witnessed the qualities he catalogues as part of an "aesthetics of care" as a third party in a real-life relationship between physiotherapist and patient. Gunshot victim and colleague Antoine Muvunyi, whom Thompson was hosting in his own home, received postoperative medical care in the UK, and Thompson was struck by the aesthetic value in this relationship. According to Thompson, the beauty of such care relationships flows from the relational qualities demonstrated. These he names as "clarity of purpose, mutual respect, intimacy and a [breath-taking] quality of touch" (431). After first pinpointing this aesthetic in the treatment of Muvunyi, Thompson then draws our attention to how theatre projects may also create such relational and caring aesthetics, predicated on the same qualities, ones that "present relational opportunities and are an important moment of regard" (438). Though touch is not generally an important element of the show Ruff, "clarity of purpose, mutual respect, [and] intimacy" are clearly present. Weaver and Shaw's 40-year collaboration assures their intimacy and mutual respect, and the performance also promotes this between performer and audience, as witnessed by Solga earlier. Clarity of purpose is evident in the subject matter of the show (the serious stroke that Shaw had in 2011 and the impetus to explore that). Solga also witnesses mutual respect and intimacy when Shaw - handing her the orange - looks her straight in the eye and when Weaver does not miss a beat before reassuring Shaw with, "Yes. You're fine." The beauty of this exchange is substantially reinforced when one considers the circuit of care that Shaw establishes through her relation 
to the audience as well as to those beyond the performance, as discussed previously. Thompson argues that "an aesthetics of care can be demonstrated in the astonishing sense of connection between different people involved in making art together" (439), and here this includes the togetherness of the performer, audience and dramaturg in a virtuous circuit. Thompson also contends that "the professional cannot be sustained ethically without a commitment to the potential for it to blur dynamically with the personal" (432). Here Split Britches is staging not only the experience of the stroke but also the bonds that tie the two collaborators in a long-term personal relationship, one that is actually furthered artistically by the onset of Shaw's disability. Moreover, this includes the audience - many of whom have had a long-term viewing relationship with the troupe, but in any case, are themselves the subject of care.

On the subject of that long-term viewing relationship, I first saw Peggy Shaw perform in her co-production with Clod Ensemble, MUST - The Inside Story (2011), at the King's College Anatomy Theatre in London. I was struck by the charismatic sexiness of her performance. At the time I was unaware that Shaw had just recovered from a serious stroke. Her performance was immaculate, seamless and energetic. She didn't need any interventions from her fellow performers - the Clod Ensemble of musicians - and she didn't appeal to the audience or other individuals for any sort of help in completing the show. I can only (after years of puzzling about this) assume that, because she had been touring the show since 2009, it was fully embedded in her consciousness, to the degree that the stroke had not had the power to dislodge this engrained memory. I was surprised then to see that the performance of $R u f f$, which I attended a few years later, showed Shaw to be something less than confident with this new material. For me, then, the beauty of the latter performance lay in the very fact of its existence and the way it reinforced my fervent hope that fragility and disability in old age were no reason for disappearance from the stage. I was cared for implicitly by a performative example of productive and creative old age. In addition to this important exemplar, at the end of the performance that I saw in Manchester in May 2014, Dr Khalil Kawafi, consultant stroke physician and clinical lead at The Pennine Acute Hospitals NHS Trust, took part in a post-show discussion about stroke, giving advice on how to recognise it and what to do when symptoms appear. ${ }^{7}$ For Thompson, the aesthetics of care "does not exist within one particular person or object of the work, but appears in-between those involved" (438). This post-show event opened a pedagogical and caring space "in-between" those who "attended," allowing interaction and dialogue while teaching about the medical and social aspects of stroke that might not have been understood before. Shaw's continued presence onstage, her openness about her own experience both in performance and post show, coupled with Weaver's innovative directorial expertise, exemplify the care that theatre can enact towards its 
audience/participants, care which mitigates the vulnerability caused by lack of awareness about stroke and its symptoms.

In the circuit of care opened between audience-performer-dramaturg, disabled participant Shaw is as much a partner as any other member. As autobiographical performer and member of the company she, vulnerable and openly "performing" her condition, contributes to the audience's wider knowledge and understanding - an act of care in itself, at least in pedagogical terms. Acknowledging the contribution and agency of the nominally "cared for" (and therefore acknowledging their subjectivity) completes the circuit of care in this performance: as proposed earlier, Weaver serves Shaw, the audience serves Shaw, Split Britches the company (Weaver and Shaw) cares for the audience through post-show pedagogy and Shaw serves the audience through her ability to engage and entertain and through informative songs and revealing autobiographical testimony. One question remains: how is Weaver served in this circuit? Weaver gives care, but it's not a one-way relation: she has enjoyed a sense of professional fulfilment. Kim Solga (who held Shaw's orange) comments that:

for Weaver it was an especially satisfying project. Shaw's new uncertainties meant that the two needed to work in new ways, affording Weaver fresh dramaturgical control, the freedom to help problemsolve new challenges and the chance to write a good deal more than she normally does.

So, Weaver has derived considerable professional and creative pleasure from this work. She is cared for in this circuit by a sense of completion, her new writing and dramaturgical innovation, not to mention involvement in the new research project detailed earlier. She is certainly served by my acknowledgement here that this is an exemplary framework for effective performative care. Moreover, I imagine her sense of relation to her co-worker and former lover Peggy Shaw is reinforced and deepened by this opportunity to collaborate on a show exploring such a deeply personal topic.

\section{Vulnerability}

The notion of vulnerability is key to understanding the operation of what I propose as a circuit of care. Daniel Engster, in his 2019 article "Care Ethics: Dependency and Vulnerability," discusses how the concept of vulnerability "redirects thinking about care away from a narrow focus on dyadic dependency relationships" (110). He describes how feminist, political and legal philosopher Martha Fineman introduces the concept of vulnerability as "a constant and universal feature of human 
existence - something that applies to everyone always" (Engster 101). Drawing on Fineman's recent work, and that of Tiina Vaittinen and of Susan Dodds, Engster argues that adopting the notion of vulnerability in place of dependence, allows a rethinking of care ethics:

Vulnerability encompasses real and potential, short- and long-term threats to our well-being that arise simply from being in the world and living in relation to others. We are vulnerable to discrimination, humiliation, disrespect, loss of persons we love, loss of objects or things that are important to us, bodily and mental deterioration, mental illness, and many other undesirable states.

In this formulation vulnerability is a way of expanding the political application of care ethics to recognise that all human beings are in a constant state of vulnerability, subject to a "susceptibility to harm" (ibid. 106). Care, in Engster's view, therefore, is defined as "everything we do to reduce human beings' susceptibility or exposure to harm, needs, loss, coercion, domination, and other unwanted conditions or events" (106). Looking at Ruff, Split Britches and Shaw's performance at once exposes Shaw's own vulnerability but also acknowledges and reduces the vulnerability of all those present; this reduction of susceptibility to harm, potentially, extends even to the audience's loved ones. Through her performance, Shaw - the nominally "dependent" subject - is exhibiting all the actions of "care" as Engster defines it. Her openly fragile performance is designed directly to protect against the vulnerability of audiences (and their loved ones) from the devastating effects of late diagnosis of stroke. It also protects against the stigma associated with the resulting impairment and fragility, thus twice mitigating the audience's vulnerability to stroke. As Engster argues,

When we care about people's vulnerability, we show concern for them not only during periods of dependency but also for their susceptibility to the various harms, frustrations, disappointments, and losses that may afflict them over the course of their lives, including those we generate (sometimes inadvertently) through our communal institutions and norms.

So, in presenting this innovative performance, in establishing a circuit of care predicated on the notion of the vulnerability of all present (and those beyond the auditorium), Split Britches have collectively established a sense of agency for all concerned, and particularly for Shaw with her newfound disabilities, who could otherwise have been perceived as merely dependent in this professional and performative relationship. ${ }^{8}$ 


\section{Improvisation}

The techniques of theatre making, particularly of improvisation and devising, have a lot to offer to practices of care. Benjamin Gillespie, in his review of Ruff, comments that Shaw has "not only . . . lost her ability to fully recall her own past experiences, but she is also unable to memorize lines, forcing her style to be inherently rough, improvised, and broken" (576). The word "ruff," whilst suggesting "rough," is also equivalent to the UK English word "riff," implying a sense of spontaneity and improvisation. No doubt Shaw and Weaver embrace this ambiguity. This practice of improvisation, though it may appear "rough" from the audience's perspective, is a technique in which Shaw, a veteran performer, is expertly experienced. Improvisation is fundamental to creativity and has rules that are set down in various theatre and performance training texts, some of the earliest being Viola Spolin's 1963 Improvisation for the Theatre, John Hodgson and Ernest Richards' 1966 Improvisation and Keith Johnstone's 1979 Impro: Improvisation and the Theatre. These rules include, among other things: openness to the input of others; vulnerability to the moment; generosity with your own creative ideas; a sense of presence in the space; a concentration on the "now;" a go-with-the-flow attitude; a concerted playfulness; a willingness to accept offers (saying "yes") and to offer something in return (saying "yes, and ...”). Such responsive, non-judgemental techniques are powerful tools of communication when caring for those with complex, cognitive impairments, as Anne Davis Basting and her work on both The Penelope Project at the Luther Manor care home in Wisconsin and the TimeSlips Method of improvisational, non-linear story-creating with people living with dementia have proved ("From Islands" and TimeSlips; Basting et al., The Penelope Project). Nicola Hatton in her essay "Participatory Theatre and Dementia" draws attention to how "people with dementia often improvise as part of their everyday lives, and the basic practice of 'saying yes' in dramatic improvisations is a strategy that can support their participation in theatre projects without fear of failure" (77). The stress upon the commonly advocated "yes, and ..." principle in improvisation dictates that players should accept the "offer" as made and take this further with an "offer" of one's own. Chana Joffe-Walt's 2014 This American Life podcast "Magic Words" discusses how Karen Stobbe takes the improvisation mantra "step into their world" and accepts whatever way her mother (who is living with Alzheimer's) interacts by responding, "yes, and ...", trusting this key technique in theatre improvisation to help her relate closely to her mother. To give a spoken example of the "yes, and ..." principle here (though this can also exist in non-verbal improvisation), one might say that Player Number Two, replying to Player One's "offer" "we were once in the park" - might say "Yes, and the park was overrun 
with skateboarding office workers.” To this offer, Player One might then reply, "Yes, and this wasn't good when they fell off and tore their nice office clothes." Then they might begin a co-constructed story of how their bosses reacted, what they did to rectify the situation or how they all decided to leave their jobs and go off to train for the next skateboarding World Championships. As you can see by this flight of fancy, creativity is engendered through the "yes, and ..." principle, which guards against any sense of failure, validates the contribution of both players in the performance through the affirmation "yes," leading on towards the creative collaboration with the adjunct "and ...". The emphasis, in improvisatory practice, on actively accepting chimes closely with my notion of a circuit of care, and though it is not generally named as such, a sense of care for one's co-performer is vital to the success of any improvisation.

The "Improv for Care" program undertaken by Ruth Almen and Jessica Caldwell with caregivers of people living with dementia, at the Cleveland Clinic Lou Ruvo Center for Brain Health, Las Vegas, has shown "promise as an intervention for caregivers to improve stress, mood, and coping skills" (852). Julie Dunn, Michael Balfour and Wendy Moyle have also documented the efficacy of Relational Clowns (also called Clown Doctors, Elder Clowns, or Hospital Clowns) in dementia care through their Playful Engagement research project (see also Balfour et al.). These performers work spontaneously with individuals in care settings and use improvisation, storytelling and music to engender what Dunn et al. call "quality moments of life" (50). Through spontaneity and play, the performers engage in meaningful moments, even with people at the very end stages of dementia (ibid. 49). They offer a sense of connection with previous professional activities (ibid. 49-50) and raise the status of participants through offering the opportunity for play and agency (ibid. 48). More pertinently, it can be seen in the following example from the study that the improvisation brings a "quality moment of life" to the clown performer as well: Tiny and Dumpling - clowns participating in the study at Wesley Mission, Brisbane, Queensland, Australia - engage with resident Joan about which jewellery Dumpling should choose to wear to an upcoming dance. Dumpling also enlists Joan as an ally in her dispute with Tiny (her "twin brother") about spending money on such expensive things. Finally, Dumpling asks Joan for advice about how to dance. Joan engages enthusiastically, counselling Tiny to "Play it calm" (ibid.), conspiring with Dumpling and laughing heartily throughout. In a similar way to that which benefitted Weaver in terms of professional fulfilment, this interaction is particularly validating for Clark Crystal (Tiny) and Anna Yen (Dumpling); Dunn et al. observe that " $[t]$ his visit, punctuated with extended laughter from Joan, was rich in reciprocal engagement, for Clark and Anna seemed to be absorbed in the action and enjoying their time co-creating these moments with Joan" (48). The research project 
as a whole not only feeds Crystal and Yen's enjoyment but represents a considerable professional achievement that had important aims, namely,

to identify the benefits of applied theatre practices on social isolation, depressed mood and quality of life of residents of residential aged care homes who are living with dementia; determine the benefits of applied theatre practices on the community of carers, including those directly and indirectly involved with the project; and to analyse the applied theatre practices to identify those that achieve the most significant responses from people living with dementia in residential aged care facilities.

(Dunn et al. 38-9)

The performance research work and improvisatory practice undertaken here set in motion a circuit of care that serves all. As Joan's and the other residents' agentic participation feeds the professional life of the researchers (Dunn, Balfour and Moyle), it also enables a mitigation of the vulnerability of all participants and even readers by demonstrating new ways of relating between all people living and working with dementia, in the widest sense of that phrase. This circuit of care also extends to subjects and their loved ones who may be living with dementia in the future.

\section{Improvising With My Father}

This reciprocal and circular practice in improvisation, in which each accepts and supports the other, is reminiscent of the Split Britches performance practice in Ruff, detailed previously. However, this understanding also relates closely to a personal story that exemplifies not only a circuit but also the aesthetics of care. ${ }^{9}$ My father George Arthur Rodgers (1931-2018), once a consummate semi-professional pianist, when his Alzheimer's was well-advanced and he had almost lost the powers of speech, used to tap most delicately and sensitively on the edges of the tables and trace the outline of patterns in the tablecloths in his care home in Sheffield. When I had despaired of any sort of conversation with him, I used to accompany him in this sort of activity, which I likened to the way he used to caress the keys of his Bechstein piano as I watched over his shoulder years before. What developed was an improvisation, tenuous and breakable, but nevertheless a form of communication that emerged through responding to his physical impulses. We would begin to play creatively together with our hands, tapping out rhythms, stroking fingers, tickling lightly, me copying him often and he mostly initiating the play. I used my understanding of improvisation, gained through many years of working in and teaching theatre, and miraculously what often happened was that - as well as smiles of pleasure - a moment of 
lucidity interrupted the play; my father would say something coherent, or notice me or another person in some specific way; he came back to what I can only describe as some sort of recognition of me, himself and his surroundings. This, I believe, was brought about through the persistent, improvisatory attitude and activity that we engaged in and the ways that he accepted our interactions; he took up my improvisational offer. Eva Feder Kittay puts forward the importance of "taking up" in care relationships. She develops what Joan Tronto called "the fourth phase of care" (134-7). Drawing on Nel Noddings' and Tronto's ideas, she argues that the "taking up of another's actions" constitutes and completes the action of care (Webteam). This affords a dignity (and I argue agency) to the person taking up the care. Kittay distinguishes this "taking up" as the deciding factor in what constitutes care:

If care must be received as care by the one cared for, then many things that we sometimes identify with care, such as caring intentions or affect will be insufficient to be care. If care needs to be completed in the other, then actions that are overweaning [sic] or paternalistic will not be taken up as something desirable - as something that is really caring - by the cared for.

(ibid.)

In Kittay's terms, my father "took up" my improvised actions and I "took up" his, completing the circuit. There was no overweening intention or affect and, despite George being my father, paternalism was not present in these interactions. At times I would repeat or "riff" off his words, sounds or movements, and an oral and physical dialogue would emerge that, in turn, seemed to give him access to more verbal and facial expression. This gave me the sense that my father hadn't "gone" in the way that is familiar in popular descriptions of people living with Alzheimer's, but that he had just lost (or mislaid) access to his facility for expression and the ability to connect with others. I found myself grateful to have developed the skills of relation that theatre making has taught me and which enabled my father, however fleetingly, to express and reinforce his relation to others. For what was most valuable to me in those last months was how this improvisatory practice helped him connect with those who loved and cared for him most, myself included. My profound sense of a circuit of care existing in this relation with my father is brought into even sharper focus when one thinks that he was the one who cared for me in my infancy and childhood and beyond. Even four years before his death, when he was newly diagnosed, he held me and sang to me during a moment of my own acute distress, using his own musical performance to care for me. Nel Noddings (Caring: A Feminine and Caring: A Relational) draws attention to how we conceive of caring as rooted in our 
past experience of care, reflecting that "I have a picture of those moments in which I was cared for and in which I cared, and I may reach towards this memory and guide my conduct by it if I wish to do so" (Caring: A Relational 80). Drawing on her observations and my own feeling of filial loyalty, I can conclude that with my father, through our improvisatory actions, a circuit of care not only existed in the moment of caring but also intergenerationally across our lifetimes as well.

So, care and connectivity, relation and mutuality, linked to theatre practice are evident in this narration of the last months of my father's life; the memory of how it enriched our experience of the time and of each other and how we were creating our relation in the physical and temporal space between us, was crucial to my sense of well-being and resilience when he died in March 2018. Improvisation set up a circuit of care in which we both benefitted; both of us taking up the actions of the other, achieving Thompson's "intimacy and quality of touch that I [he] found breath-taking" (431). These are treasured memories of our familial interaction at the end of my father's life; the improvisations themselves and now my memories of them are beautiful to me and therefore sustaining. Like Weaver and the Playful Engagement researchers detailed earlier, I was gratified that my professional skills had been put to new and innovative use. This story of my father is - as I have shown - just one in a growing list of performance interventions that exemplify the mutuality and inter-connectedness that performance and theatre making are predicated on, and one that shows how performance can set in motion and exemplify a circuit of care.

\section{Conclusion}

Evidently, in these and other examples, care is circuitous. It benefits both the nominal carer and the nominally cared for when taken up by the latter, revealing all to be interdependent in this circuit. My use of improvisational performance techniques to generate this circuit of care with my father replicates emerging techniques used with people living with neurological conditions such as dementia. Relational Clowns that bring "quality moments of life" to people living with dementia and the TimeSlips and Penelope projects developed by Ann Basting in care homes in Wisconsin are among the examples of this that I have drawn attention to here. As the example of Ruff demonstrates, theatre techniques afford individuals living with cognitive impairments and their carers access to meaningful and mutually sustaining relations. More work is needed to research the ways in which theatre techniques and performance are efficacious in establishing and/or maintaining such circuits of care. I would hope such research would demonstrate further how - difficulties and complications not withstanding - improvisation practices can bring benefits to all 


\section{Bridie Moore}

parties in the process (including those not present) and how they might acknowledge subjectivity and intergenerational connectedness, both in the moment and across time.

\section{Notes}

1. Shaw described her attire as "Gentleman Drag" at the post-show discussion of the performance of Must, which I attended on 15 November 2011.

2. In my survey of the 2011/2012 Autumn/Winter season of British mainstream drama I counted 25 productions, 22 of which were new works, which explicitly highlighted issues of age and/or ageing in their publicity or content. There was therefore a perceived increase in roles for elders and middle-aged actors. However, my critique concluded that more roles for older people do not necessarily guarantee a subversion of the accepted script of ageing but may inadvertently amplify the normative construction of old age. See Moore, ageculturehumanities.org/.

3. For a heavily edited video of $R u f f$, comprising mostly of Shaw's stand-up routine within the show, see hemisphericinstitute.org/.

4. As we find from the Split Britches website: "This is an ongoing project in partnership with Pat Healey and Rosella Galindo Esparzo at the Department of Electronic Engineering and Computer Science, Queen Mary University of London" ("Ruff").

5. To see a short video on these exploratory workshops, go to https://vimeo. com/438148408.

6. F.A.S.T. stands for Facial drooping, Arm weakness, Speech difficulties and Time to call emergency services, see www.stroke.org/en/about-stroke/ stroke-symptoms

7. To see the post-show discussion, go to YouTube Split Britches: RUFF - Science Stroke Art 2014. www.youtube.com/watch?v=H0RvcpNrQc0.

8. By enlisting Engster's notion of vulnerability, I intend in no way to downplay the lived experience of people living with disabilities, only to argue that by acknowledging vulnerability to the disabling effects of stroke I can show that the performance might mitigate or even avoid these effects entirely.

9. I tell this story as a story about care, and also because a playwright I knew who recently died told me to write about it as it impressed him as significant. What it showed me was that the techniques I have learned as a theatre maker and teacher are valuable in relational and caring terms. These include how to read a room, the atmosphere of the group, facial expressions and mood of individuals present, how to create something out of nothing, how to enlist and rely on others and how to be reliable yourself (trust).

\section{Works Cited}

Almen, Ruth, and Jessica Z. Kirkland Caldwell. "Improv for Care: Teaching Caregivers Improvisation Improves Mood and Sense of Burden." Innovation in Aging, GSA 2019 Annual Scientific Meeting, vol. 3, Supplement 1, 2019, p. 852, https://doi.org/10.1093/geroni/igz038.3133.

Basting, Anne Davis. "From Islands to Networks: Using Improvisation to Build Relationships Among Individuals and Systems." Applied Theatre: Creative Ageing. Edited by Sheila McCormick. Bloomsbury Methuen Drama, 2017, pp. 163-86. 
Timeslips, www.timeslips.org/. Accessed 23 Dec. 2020.

Basting, Anne Davis et al. The Penelope Project: An Arts Based Odyssey to Change Elder Care. U of Iowa P, 2016.

Baldassar, Loretta, and Laura Merla. "Introduction: Transnational Family Caregiving through the Lens of Circulation." Transnational Families, Migration and the Circulation of Care. Understanding Mobility and Absence in Family Life. Edited by Loretta Baldassar and Laura Merla. Routledge, 2013, pp. 3-25, https://doi.org/80/0966369X.2018.1425287.

Balfour, Michael et al. "Complicité, Le Jeu and the Clown: Playful Engagement and Dementia." Applied Theatre: Creative Ageing. Edited by Sheila McCormick. Bloomsbury, 2017, pp. 105-24.

Dodds, Susan. "Dependence, Care, and Vulnerability." Vulnerability: New Essays in Ethics and Feminist Philosophy. Edited by Catriona Mackenzie et al. Oxford UP, 2014, pp. 181-203.

Dorow, Sara, and Shingirai Mandizadza. "Gendered Circuits of Care in the Mobility Regime of Alberta's Oil Sands." Gender, Place \& Culture, vol.25, no. 8, 2018, pp.1241-56, https://doi.org/10.1080/0966369X.2018. 1425287.

Dunn, Julie et al. “Quality of Life or 'Quality Moments of Life': Considering the Impact of Relational Clowning for People Living with Dementia.” Research in Drama Education: The Journal of Applied Theatre and Performance, vol. 24, no. 1, 2019, pp. 38-52, https://doi.org/10.1080/13569783.2018.1544889.

Engster, Daniel. "Care Ethics, Dependency, and Vulnerability." Ethics and Social Welfare, vol. 13, no. 2, 2019, pp. 100-14, https://doi.org/10.1080/17496535. 2018.1533029.

Fineman, Martha. The Autonomy Myth: A Theory of Dependency. The New Press, 2004.

- "The Vulnerable Subject: Anchoring Equality in the Human Condition." Yale Journal of Law and Feminism, vol. 20, no. 1, 2008, https://digitalcom mons.law.yale.edu/yjlf/vol20/iss1/2.

- "The Vulnerable Subject and the Responsive State." Emory Law Journal vol. 60, no. 2, 2010, pp. 251-75.

- "Equality, Autonomy, and the Vulnerable Subject in Law and Politics." Vulnerability: Reflections on a New Ethical Foundation for Law and Politics. Edited by Martha Fineman and Anna Grear. Ashgate Publishing, 2013, pp. 13-27.

- "Equality and Difference - The Restrained State." Alabama Law Review, vol. 66, no. 23, 2015, pp. 609-26.

Gilleard, Chris, and Paul Higgs. "Ageing Abjection and Embodiment in the Fourth Age." Journal of Aging Studies, vol. 25, no. 2, 2011, pp. 135-42, https://doi.org/10.1016/j.jaging.2010.08.018.

Gillespie, Benjamin. "Ruff by Peggy Shaw and Lois Weaver (review)." Theatre Journal, vol. 65, no. 4, 2013, pp. 576-77, https://doi.org/10.1353/tj.2013.0101.

"Greenscreening." www.split-britches.com/greenscreening. Accessed 23 Dec. 2020.

Hatton, Nicola. "Participatory Theatre and Dementia." Performing Health and Wellbeing. Edited by Veronica Baxter and Katherine E. Low. Bloomsbury, 2017.

Hodgson, John, and Ernest Richards. Improvisation. Methuen, 1966. 


\section{Bridie Moore}

Joffe-Walt, Chana. "Magic Words: Rainy Days and Mondays." This American Life, (podcast) www.thisamericanlife.org/532/magic-words/act-two. Accessed 23 Dec. 2020.

Johnstone, Keith. Impro: Improvisation and the Theatre. Methuen, 1979.

Laslett, Peter. A Fresh Map of Life. Weidenfeld \& Nicholson, 1989.

Moore, Bridie. "Depth, Significance and Absence: Age Effects in New British Theatre." Age, Culture Humanities, no. 1, 2014, pp. 163-95, ageculturehumanities.org/WP/depth-significance-and-absence-age-effects-in-new-british-theatre.

Noddings, Nel. Caring: A Feminine Approach to Ethics and Moral Education. U of California P, 1984.

. Caring: A Relational Approach to Ethics and Moral Education. 2nd ed. U of California P, 2013.

"Ruff." Split Britches. www.split-britches.com/ruff. Accessed 23 Dec. 2020.

Smith, Arthur. "Interview with Peggy Shaw." BBCRadio 4 Loose Ends, 2016 (22:5032:35), learningonscreen.ac.uk/ondemand/index.php/prog/0C4116EC?bcast= 121432924. Accessed 23 Dec. 2020.

Solga, Kim. "What Feminists Do When Things Get Ruff." Performance Research: A Journal of the Performing Arts, vol. 19, no, 2, 2014, pp. 135-37, https://doi. org/10.1080/13528165.2014.928529.

Spolin, Viola. Improvisation for the Theatre. Northwestern UP, 1963.

Thompson, James. "Towards an Aesthetics of Care, Research in Drama Education." The Journal of Applied Theatre and Performance, vol. 20, no. 4, 2015, pp. 430-41, https://doi.org/10.1080/13569783.2015.1068109.

Tronto, Joan. Moral Boundaries: A Political Argument for an Ethic of Care. Routledge, 1993.

Vaittinen, Tiina. "The Power of the Vulnerable Body: A New Political Understanding of Care." International Feminist Journal of Politics, vol. 17, no. 1, 2015, pp. 100-18, https://doi.org/10.1080/14616742.2013.876301.

Vimeo. "Peggy Shaw: Ruff Interview." vimeo.com/56764000. Accessed 23 Dec. 2020.

Weaver, Lois. "Professor Lois Weaver, BA (Radford University, Virginia USA)." www.qmul.ac.uk/sed/staff/weaverl.html. Accessed 19 May 2021.

Webteam. "Eva Fedar Kittay Interview, June 2013." Ethics of Care, ethicsofcare. org/eva-fedar-kittay/. Accessed 23 Dec. 2020. 


\section{The Bucket List and More}

Exploring Care Practices in

an Australian Residential

Aged Care Home Through a

"Narra-theatrical" Lens

\section{Janet Gibson}

Marcia Bannister and Jessie Anderson lived in the Australian residential care home, Starrett Lodge, operated by Uniting Care ${ }^{1}$ and located on the central coast of New South Wales, Australia, until their deaths in 2019. Though both Marcia and Jessie lived with dementia, Marcia held the "role" of Bucket List Sales Manager and Jessie that of Bucket List Assistant Sales Manager. In addition, Marcia and Jessie were the List's co-instigators, and actively involved in setting up the Calendar Girls Project (2017), which was a fundraiser for the List. The Bucket List involves residents drawing names out of a hat at intervals over time (usually every month) to determine which of them, on that occasion, gets to have a wish fulfilled before they die: dreams accomplished have ranged from a trip to an expensive restaurant in a chauffeur-driven car to skydiving jumps. As many residents cannot afford to participate in the Bucket List without financial help, most likely because of their lower socio-economic status, ${ }^{2}$ List activities are subsidised in various ways. One past example was the composition and publication of residents' life stories, followed by the sale of these books to family and friends (Sanchez Interview no. 4); other examples include the residents baking and selling biscuits and the sale of calendars featuring the residents photographed in various locations and poses.

Deeming the Bucket List (BL) and the Calendar Projects (CPs) to be "care practices" for older people, including those living with dementia, I offer them as my principal objects of study in this chapter to explore what is generated when these practices are viewed through the intersecting lenses of "theatrical narrativisation" and "performance consciousness." "Theatrical narrativisation" is a term I have coined to describe individual and communal story worlds acknowledged by the "spectators" viewing and interacting with the "performers" of these worlds. "Narra-theatrical," another neologism of mine, is an analogous descriptor to "theatrical narrativisation." "Performance consciousness" is defined by Richard Schechner as that which "activates alternatives: 'this' 


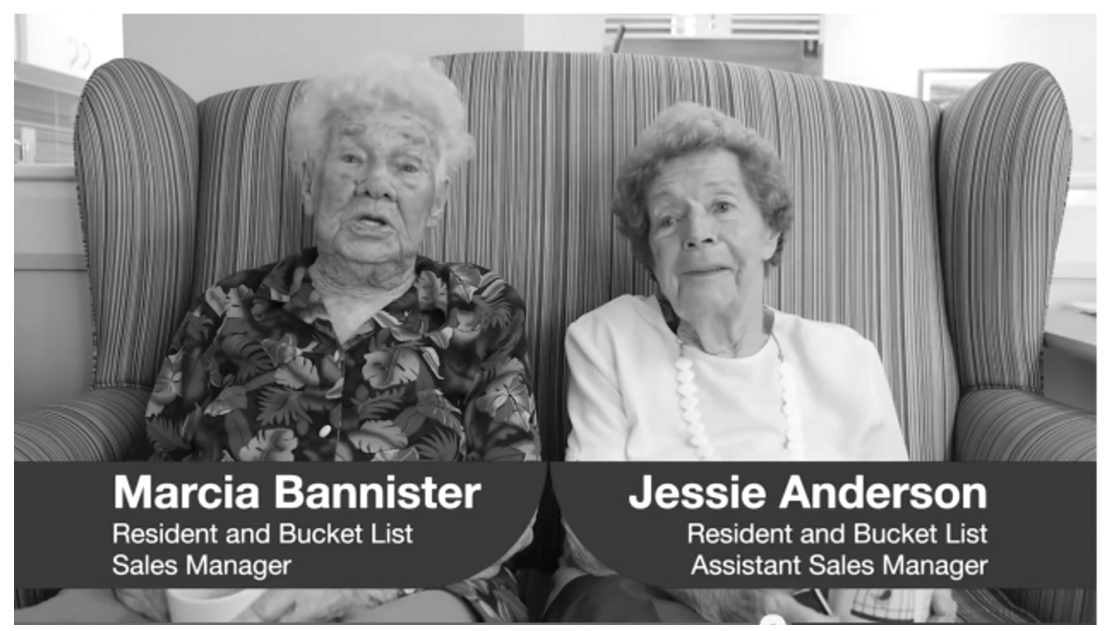

Figure 3.1 Video still from Finding the Why: Enabling Active Participation in Life in an Aged Care Facility. Used with permission of Corinne Maunder.

and 'that' are both operative simultaneously. . . [it] is subjunctive, full of alternatives and potentiality" (Between 6). Here, Schechner is not alluding to any one person's consciousness but isolating what happens when "performers - and sometimes spectators too - are changed by the activity of performing" (ibid. 4; my italics). Schechner argues that in performance, ordinary people and objects can be transformed as they are simultaneously "'not themselves' and 'not not themselves," allowing "multiple selves [to] coexist in an unresolved dialectical tension" which may either be permanent, such as in initiation rituals, or temporary, as in art theatre (ibid. 6). In this chapter, I intend to deploy all these concepts to bring into sharp focus the interrelationship of care, subjectivity, narrative and performance. ${ }^{3}$

Performance is sometimes defined narrowly, solely in terms of its aesthetic manifestations. While acknowledging that theatre, dance, music and performance art are clearly performances, Schechner contends that performance must be understood more broadly as a continuum of actions extending from "ritual, play, games, sports, popular entertainments, the performing arts . . . and everyday life performances to the enactment of social, professional, gender, race, and class roles, and on to healing (from shamanism to surgery), the media, and the internet" (Performance 7). For Schechner, another way of understanding the performance continuum is to see that theatre, dance, music, film and other artistic displays are the "is" of performance, deemed so from historical-social contexts, 
convention, usage and tradition (ibid. 12). However, Schechner contends that anything can be studied "as" performance, meaning that performance questions can be asked of whatever is being studied, including questions about location, appearance and behaviour, staging, clothes worn, any objects in use, as well as the roles people play and how these change over time (ibid.12, 22).

In this chapter, mobilising Schechner's idea that performances of everyday life, including performances of care, might be studied "as" performance, I present an analysis of the BL and the CPs on the basis of questions derived from the methodological repertoire presented earlier, bolstered by theatre theorist and semiotician Patrice Pavis' "performance analysis." I have undertaken this inquiry, not by visiting the care home and viewing the practices myself as "live" performances but through recourse to what Pavis terms "supplementary documents" (40). In the case of the BL and the CPs, these documents comprise a short film about the BL (Corrine Maunder's Finding the Why), ${ }^{4}$ a TV show about both the BL and the CPs (SBS television's Dancing with Dementia) ${ }^{5}$ and other media sources such as newspaper articles. I first "met" Marcia and Jessie in Finding the Why. Unfortunately, I never met them in person. My research is also based on four structured interviews with the activities officer at Starrett Lodge, Vicki Sanchez, all conducted via email and telephone. Sanchez worked at Starrett Lodge for 13 years. She started working there as a care attendant, gaining skills as she worked. A year into this work, she stepped into the role of activities officer, going to TAFE (Technical and Further Education) to complete a Certificate Four in Lifestyle. Sanchez was a key figure in helping the residents set up the $\mathrm{BL}$ and the CPs.

In sum, in this chapter, I harness performance tools to reframe two particular care practices (the BL and the CPs) as "narra-theatrical." In so doing, it is my hope that this reframing will encourage other ways of "seeing" in residential care homes for older people - arguably more ethical ways - in which the capacities and creativities of those who live in care homes may be perceived and celebrated, with implications for improving quality of life. My stance here is avowedly utopian (Dolan), with hope that the lenses of theatre and performance can afford promising ways of positioning older people, including those with dementia or memory loss, even in unofficial "theatre" spaces. Proposing these practices as "narra-theatrical" is a hypothetical move on my part; that is, at present, these practices are not interpreted as "narra-theatrical" by the participants and the institution. Before outlining my rationale for deploying the phrase "narra-theatrical" and pursuing the previous arguments through examining the $\mathrm{BL}$ and the CPs, I will explore the relationship I hope to elucidate between performance, spectatorship and care, which supports and drives many of my arguments in this chapter. 


\section{Janet Gibson}

\section{Performance, Spectatorship and Care}

Performance requires spectators. If we accept the idea that "we are all, in a manner of speaking, performers" (States 108), then it follows that we are all also spectators to the performances of others in our lives. In my view, this dyadic partnership has an ethical dimension which is actuated through intersubjective embodied communicative encounters. These encounters may also be deemed creative when the performers in them (residents at Starrett Lodge in this case) are encouraged, or allowed, to adopt "roles" that move beyond the sometimes restrictive "roles" allocated to them by the spectators in their lives (family, carers and other residents) because of their age or illness. If these encounters continue over time and are based on mutual respect, then I argue that an ethics of care is likely set in motion. ${ }^{6}$

Anthropologist Steven P. Black makes a similar point about the "fundamental bidirectionality" of care as a basis for ethics when he writes:

Social activities of care both constitute and are made relevant by morally/ethically framed relationships with others and oneself. Although it is not always recognized as such, embodied communication is central in care activities and in the constitution of moral/ ethical care. Care is instantiated in interpersonal encounters through the social organization of diverse semiotic resources such as gesture, facial expression, body orientation, prosody, phonology, morphosyntax, the materiality of media artifacts, and the built environment.

Theatre and performance rely on embodied semiotic resources, as does care. The latter is a complex term to define: "a shifting and unstable concept" which is variously applied to different individual feeling states, the practices of medicine, health and family caregiving, as well as biopolitics and discourses (Buch qtd. in Black 80). But as Black contends, most "understandings of care have in common an emphasis on relationality and activity" (ibid.; my italics). Sufficient to note here is the premise on which this chapter proceeds: that a "care practice" is an embodied, responsive activity/engagement between at least two people in a care facility, an activity that is respectful of each person's selfhood even if that person is at a more dependent and vulnerable stage of life compared to others in the encounter (e.g., the residents compared to the care workers). At its nucleus, a "care practice" is one that understands that to be human is forged in relationship with others.

The practices at the heart of this chapter "perform a mode of care" evident in their "caring structures," that is, evident in the care taken in their development and enactment (Stuart Fisher 2-3). This type of care defies those insistent " 'care-less" " processes increasingly evident in the 
running of care homes as profit machines in global neoliberal economies (ibid.). With these homes, the focus is on economies of profit and loss measured through regimes of formulaic efficiency, whereas the practices examined in this chapter can be viewed as embodied and artful, invoking the affective qualities of "attentiveness, sensitivity and responding to needs" (Held 39) and gesturing to an "aesthetics of care," defined as "a set of values realised in a relational process that emphasise engagements between individuals or groups over time" (Thompson 430, 437). ${ }^{7}$

Although there are several other lenses through which the BL and the CPs could be construed, an obvious one being social citizenship, ${ }^{8}$ as a theatre and performance studies scholar, it is the ethical and creative power of the "gaze" of theatre and performance on care and its practices in care facilities for older people that I want to actuate in this chapter. Underutilised in relation to dementia, care and age studies scholarship in general, the theatrical "gaze" and its companion "performance consciousness" provide unique challenges to the "diagnostic gaze" (Kuppers 137) predominant in many care homes and in views of the older people living in them.

I will elaborate. The "diagnostic gaze" is activated when older people living with dementia (PLWD) are seen primarily as embodiments of an impaired brain and their behaviours as symptoms of awful diseases for which there are no cures. It is also activated when older people in general are seen only in terms of what they have lost because of likely changes in some of the physical (and cognitive) capacities they might have had when younger. This is the "master narrative of decline," in Margaret Morganroth Gullette's words (130), a narrative as much responsible for the effects of ageing on older people as biology itself, constraining their identity formations in a net of debility. As Gullette argues, socio-culturally located ideas about ageing often constrict the choices older people and those with dementia can make in their lives. But, as noted earlier, "performance consciousness" creates spaces of possibility and transformation; it activates alternatives. As an active agent of performance consciousness, theatre too might open spaces of possibility. Even though theatre as an art form might conform to, rather than challenge, decline narratives, its toolkit contains role-playing, a vital counter to decline narratives, which when put into use might allow people of any age to be who they were at previous times of their lives or to become someone they may never have been. In this chapter, the theatrical "gaze" and "performance consciousness" are presented as alternatives to deficit views that do not take into account the still extant creative possibilities of older people living in care homes, including those living with dementia, and what they might have to give to their peers and carers in intersubjective encounters.

As a parenthesis, I acknowledge that some people in care facilities, such as those with late-stage dementias, might not be capable of doing very much at all: they could be in a coma, for instance, or unable to 


\section{Janet Gibson}

communicate using words. However, I maintain that the possibility exists for seeing them as able to engage with their care partners, ${ }^{10}$ if only affectively, not cognitively, in small moments, for example, through bodily responses, such as crying or smiling at care partner prompts. My idea is aligned with Eva Feder Kittay's notion of the "completion of care" where, because the body can take up care, it deserves to be treated with dignity (see van de Kamp). However, these views require a shift on the part of the care partner in the intersubjective encounter and this change is connected to how subjectivity is conceived and the ethical implications of this shift. There is not scope in this chapter to address these ideas in detail, but they are embedded in the notion of ethical spectatorship and how we might "see" people differently through the lens of theatrical narrativisation.

\section{Why "Narra-Theatrical” Practices?}

I frame the practices explored in this chapter as "narra-theatrical" for two main reasons. One is to expand the meaning of narrative in dementia and care practices and studies; the other is to acknowledge the performative or playacting element of these practices. ${ }^{11}$ Turning first to narrative, I must underscore at the outset its polyvalence. For my purposes here, I take it to be a sense-making device (Herman 2013, Hutto 2007a, 2007b qtd. in Bitenc 5) braided to the personal, human-scale, everyday experiences of people and their life worlds. I also see it as strongly knitted to the grander, though limited, cultural repertoire of stories on which we all draw to tell our personal stories (Frank). In the case of dementia, I label this restricted arsenal of narratives the "right kind" of dementia story (Gibson 2), circulating accounts of loss, despair, failure, tragedy and burden and not telling of the extant or nascent abilities of people living with dementia. It focuses on their pasts, or on futures made grim for us all by the probability of a "silver tsunami" coming to destroy lives and push societies towards catastrophe.

The "silver tsunami" is a metaphor that has been used frequently across media platforms, particularly those reporting on the economy such as The Economist and Forbes magazines (see, for example, Das) to augur a massive growth in ageing populations, which these media outlets predict will pose a huge burden on younger people. Most gerontologists would agree that there is indeed a contemporary global trend of ageing without any parallel in the history of humanity (Mangan 19). In 2045, the number of old people is expected to exceed the number of the young with accompanying economic and health care impacts on many societies (United Nations qtd. in Mangan 19-20). But it is worthwhile considering that the associations accompanying this trend - words such as "crisis," "catastrophe" and "tsunami" - could do as much damage in the ethical sphere as the predicted trend could do in the economic. When old people 
populate media narratives as the main drivers of these changes, draining personal or familial emotional, physical and financial resources, then it follows that these dependent humans will likely be framed as "burdens" to the economy, to society, to us all. This is partly because, as literary theorist Lucy Burke argues, the language of economics has infiltrated common thinking about relationships and love; in particular, "the logic of the market and its values now infiltrates the experience and perception of what it means to live with dementia" (26) and, I would add, what it means to live in a world with older people. As Burke argues, reducing love and relationships to "a form of exchange" leaves no room for understanding or embracing relationships with those who fall out of "the logic of this 'contract'" (28): those who are perceived as unable to give back something in return for a care investment.

Apart from these "burden" narratives, reminiscence features as one of the most popular psycho-social interventions in care homes today, via "life-history discussions, life writing, life reviews, narrative and reminiscence of various kinds" (Mangan 124-5). For those living with dementia, it often plays out as a narrow band of life-story practices (e.g., My Memories scrap books and Life Story work) restricted to particular structures and styles, while other types are ignored. For older people as a rule, reminiscence has become accepted as a primary means for the older person to look back on his/her life and reflect on past experiences, including unresolved difficulties and conflicts, and in this way to find some peace. Gerontologist Robert Butler proposed reminiscence to be a "naturally occurring, universal mental process" (66). Although there are some good reasons for the use of reminiscence one being that many people living with dementia remember more from their pasts (long-term memories) than their recent present (working memories) - I argue that expanding the narrative palette would help to reimagine the personhood of older people with or without dementia, at a broader socio-cultural level. Only conceiving of older people in terms of who they were rather than who they are now or who they could $b e$, may be constricting, not only of their possibilities, but those of the narrative form itself. I contend that performed narratives that deviate from a reliance on the word need to be promoted, including new stories or ways of performing them that more fully understand and build on the capacities and creativities of older people and those living with dementia.

In turn, I think that these reconfigurations of narrative could challenge the current negative myths, the "right kind" of dementia stories and decline narratives that circulate about older people. Through first reinterpreting certain practices played out in residential care homes as "narra-theatrical" and then valuing them as such, older people could be seen as productive (or even positively disruptive) members of their immediate residential communities. 


\section{Janet Gibson}

In referring to older people as "productive," I am not sanctioning an ableist neoliberal valorisation of productivity. Instead, I am drawing on disability theorists David Mitchell and Sharon Snyder's idea of "the capacities of incapacity" (180). Mitchell and Snyder, writing in reference to people living with "communication - and cognition - based disabilities," argue that these people have been subject to "imprisoning cultural concepts of inferiority" $(28,183)$. Along with Mitchell and Snyder, I argue for people living with dementia and older people to be seen as "potentially active [and] agential" (183) and, in Elizabeth Grosz's terms, for their lives to have "the condition of, or capacity for action in life" (Grosz qtd. in Mitchell and Snyder 183). Seeing older people as productive on their own terms means acknowledging their capacity for action, their potentiality. Productivity as used here in reference to the residents of Starrett Lodge is opposite to what Mitchell and Snyder term the "flattening gestures" (29) that limited neoliberal ideas place on older people's ingenuity: ideas which facilitate the restrictive "roles" often allocated to them by care home staff who are notoriously "risk averse," as Colin McDonell, one-time manager of Starrett Lodge, tags them in the film Finding the Why (12:10). McDonell is a registered nurse who worked for Uniting Care as a manager for 15 years and is now a Dementia Consultant at Calvary Care and an Honorary Fellow at the Faculty of Science Medicine and Health at the University of Wollongong, Australia. He contends that care staff commonly encourage residents to stay away from any activities perceived as unsafe and that residents in many of these care facilities also usually wait for care home staff to do things for them because that is the way many institutions work. In the case of the BL and the CPs, the residents have disrupted common care home procedures by instigating activities that they want to do without always gaining the permission of the authorities in the home and often by insisting on their right to a dignity of risk in some situations (see the SBS Insight TV show Dancing with Dementia 28:04-42).

The second, and predominant reason I collocate the words "narrative" and "theatrical" in reference to the specific practices examined in this chapter is to acknowledge their performative or playacting elements. A standard dictionary definition of "theatrical" usually defines it first, as "of or relating to theatre," commonly seen as either a place or a form of high art, and second, as " 'exaggerated or affected'," especially as related to human behaviour (Quick and Rushton 1). While acknowledging this negative construal of the word "theatrical," I want to examine what is often overlooked when thinking about what theatre is, to make clear in what way and for what reasons I favour the term "theatrical" in this chapter.

Theatre derives from the Greek "theatron," denoting "a place for looking," which carries with it dual meanings of location and at the same time "a particular form of sense perception" (Balme 1), the latter 
meaning tending to be overshadowed by that of its located-ness. This latter connotation emphasises the imaginative collusion of the spectator and the performers, and takes the meaning of theatre away from its association with buildings and high art. The associated term theatricality underscores that things, actions, people and places are not in themselves theatrical but are rendered as such by a combination of aesthetic conventions and discursive practices that determine around which phenomena we place the frame of theatrical apprehension (Balme 89-91). In tandem with this point, I want to stress that it is of critical importance to remember that in viewing the bodies, actions and behaviours of other people, that is, in spectating, what we see is not "real" in any objective sense. We are always looking at bodies that are discursively constructed and regulated through language, socio-cultural practices and institutions: that is, our perceptual experience is governed by these systems, to a large extent, a vital point to remember in reference to the "reality" of ageing and dementia.

A final important point I want to make here is in regard to the political potential of theatre, which is embedded in its capacity for pretence, that is, in showing things that do not exist (Kelleher 10) and in proposing alternative realities, while still being in contact with the "grain of the absent reality" (ibid. 24). In other words, through the theatrical lens, things can be brought into existence that might not otherwise have been thought of, allowing spectators to deliberate on what could be different to the present situation (ibid. 26). My argument is that if we see the participants in the $\mathrm{BL}$ and the CPs through the lens of theatre and performance, with the care home and other environments acting as the "stage" for their performances, then the possibility exists to begin to move away from ingrained and limiting discourses about older people and those living with dementia in care homes towards imagining other, more magnanimous ways of seeing them.

\section{Bucket List Origins}

Before 2010, when the BL started, residents at Starrett Lodge did all the usual activities likely to be found in a care facility for older people, such as bingo, craft and games. The genesis of the BL can be tracked to residents watching the film The Bucket List starring Jack Nicolson and Morgan Freeman. After viewing the film, some of the Starrett Lodge residents told Vicki Sanchez, the activities officer, that they were "looking for an adventure" (Interview no. 1). When Sanchez suggested that the residents write their own "bucket lists," they all laughed at the title with good humour (ibid.). The colloquialism contained a tongue-in-cheek nod to the death they were keenly aware was coming as well as a commitment to achieving a few of their dreams and doing "something outrageous" before they died (ibid.). (The performative potential of this latter phrase 


\section{Janet Gibson}

is clear, presaging the ways in which the BL activities undertaken were often highly dramatic, such as skydiving.) Thus, the birth of the practice was firmly embedded in an intertextual relationship with both a film and a colloquialism, to which the film also owes its title. That is, right from its inception the practice references narrative and performance, connecting the practice to a performed story world in the film where two older, terminally ill men travel the world together to do things on their wish lists before they die; also, right from the beginning, the practice connects the real (the wishes of the residents) and the imaginary (the film).

When the BL started, there were 60 residents and the corresponding number of rooms at Starrett Lodge (Sanchez Interview no. 3). Although only 15 rooms were allocated specifically for people living with dementia, most of the residents had some memory loss (ibid.). Together, the residents and Sanchez decided that the order of action would be determined by drawing residents' names out of a hat. The issue though was finding money for the activities. Sanchez told me that "no one [in Uniting Care or indeed the residents themselves] was going to pay for it" (Interview no. 1). So, to support the BL, the residents, spurred on by Marcia and Jessie, decided that they would bake biscuits and sell them to the other residents and staff. According to Sanchez, Marcia would go door to door with the bags of biscuits, beautifully tied into bundles of six, with ribbons attached by Jessie. Marcia would do this "rain, hail or shine" (Interview no. 1), going from one room to another in the facility. Sanchez and the residents aimed to do a BL activity monthly, and Sanchez notes that during her time working at Starrett Lodge, she helped arrange BL events for approximately 45 people, with some residents doing a BL activity more than once (Interview no. 3). A typical BL item costs about 300 dollars, which takes roughly three months to raise. Some examples of List activities include drinks and lunch at a restaurant, helicopter rides, massages and day trips to various scenic locations. The BL won a 2014 better practice award from the Australian Aged Care Quality Agency.

\section{A “Narra-Theatrical” Lens}

Several points of interest arise when the "care practices" at the heart of this chapter are viewed through a "narra-theatrical" prism, rather than as responsibilities for tasks that might not normally be expected of older people in a care home. Firstly, there is the undoubted theatricality of many of the fundraising pursuits underpinning the Bucket List (which are all brought to life in Dancing with Dementia). In the case of the baking and selling of biscuits to raise money for the BL, the senses of scene, property and ritual in this fundraiser become palpable, with the narrative in operation evident as one of capacity and agency as opposed to one of decline and loss. In Dancing with Dementia, one important scene which underpins this narrative is the hum of a big "industrial" 
kitchen thronging with residents working together and care attendants helping. Though the residents were not unfamiliar with the kitchen, they had never "claimed" it in this way before the advent of the BL (Sanchez Interview no. 4). The ceremonial elements of this scene comprise the habitual cooking in the kitchen with the staff and the residents working and chatting together, wearing their hairnets and, sometimes, their blue latex gloves. The theatrical properties of the kitchen scene include the cellophane biscuit bags and the ribbons of various colours to tie them up. Other theatrical scenes not recorded in Dancing with Dementia but told to me by Sanchez (Interview no. 4) include the regular jaunts taken by Marcia around the multiple residential buildings at the facility at certain times of the day regardless of the weather, with a basket full of gaily beribboned biscuit bags, knocking on the residents' doors and breaking their isolation. The final story that emerges from these fundraising activities is one of camaraderie, connection and commitment. It tells of intersubjective, embodied and communicative encounters between residents and between residents and staff, arguably activating an ethics of care. Intersubjective, because the residents are forging relationships with each other and the staff; embodied, because they are using their bodies to bake and wrap biscuits; and communicative, because they are talking to each other and the staff as they go about their activities.

Secondly, Marcia and Jessie were the "managers" of the BL. As I noted at the beginning of the chapter, "performance consciousness" (Schechner, Between 6) activates alternatives: "this" and "that" are both operative simultaneously. If we take this lens to look at Marcia and Jessie, then we can see that they were both managers of the List and acting as managers in an obvious conflation of the real and the imaginary. I say this because they directed the project when they were alive, and they were the main initiators of the fundraising activities for the List and in this way were, in a sense, leaders of other residents at the home. However, they were not managers in any commonly understood sense of the term, except, as more and more residents wanted to be on the BL, Marcia and Jessie worked with other residents in the home and delegated some activities to them. For example, Jessie organised the "process line for the production of the biscuits" (Sanchez Interview no. 2). But unlike managers commonly do, they did not receive a wage; they also did not have to write reports to more senior staff and so on. But involving themselves in the project meant that they did get to act out these "roles" to the extent possible when they were 80-year-old (plus) residents of a care home.

The theatrical part of the phrase "narra-theatrical" links the day-today activities Marcia and Jessie were involved in with a hyper-real conception of their "roles." The fiction, that they are managers of the BL, meets with the absent reality, that they are in fact not managers but residents, to underscore what is possible rather than what is not possible. Having others (spectators) engage with their "roles" means that both 
the performers (in this case Marcia and Jessie), and the spectators (in this case the workers in the facility and the other residents) are complicit with the fiction, which allows dual personas to emerge, held in a dialectical tension. As performers in the BL fundraising scenes, Marcia and Jessie were "changed by the activity of performing"; that is, in Schechner's dispensation, they were simultaneously "'not themselves' and 'not not themselves" "(Between 4, 6; my italics). Seeing themselves as BL managers allowed Marcia and Jessie to grow in confidence such that their agency in the home increased; they started to think about other ways in which they could express themselves and whether or not they needed permission to do so, as is evidenced in the CPs, to be discussed shortly.

Jessie and Marcia's first BL activity involved hiring a limousine to go for drinks by the water together, as they had become inseparable friends at the facility. On this occasion, Jessie, in Dancing with Dementia (25:24), exposes what can be interpreted as another "narra-theatrical" element of the BL, when she refers to being treated like "a lady" by the waiter at the establishment where she and Marcia went for drinks. Looking at the activity through the lens of theatrical narrativisation, rather than just as an outing, what is revealed is that Jessie was able to move away from her "role" of resident of a care facility in a lower socio-economic area who, being on a limited income, would not be able to treat herself to such an outing. In her own terms, she had become "a lady." Jessie had actively changed the narrative she was living in, if only temporarily, through dressing up for the occasion, with makeup and a corsage. Jessie stepped into the "role" of someone who could afford to be driven to the restaurant in a limousine, a car often associated with wealth and celebrity. On top of that, the waiter responded to her in "role," treating her like a lady in what can be seen as a "walk-on" part in the theatrical narrative. But when viewed through the lens of ethical spectatorship, he can also be seen as responder to the call from Jessie to be treated like the lady she had dressed up to be.

\section{Other BL Activities and Care}

Skydiving is another popular BL activity. The first resident to skydive was an 85-year-old who did not have dementia. Although he had jumped from a plane when he was younger, his family, at first, would not give permission for him to do so, as they were worried about the risks involved. The facility manager at the time, Colin McDonnell, and other care workers at Starrett Lodge, like Vicki Sanchez, could see how much this skydive meant to the resident and supported him to do it - finally negotiating, after a tussle with the family, the necessary permission for him to do the dive. His response to the flight was "I feel ageless" (Sanchez Interview no. 1). More recently, a skydive was taken by another Starrett Lodge resident, Elmer Anderson, a man with Lewy Body Dementia 


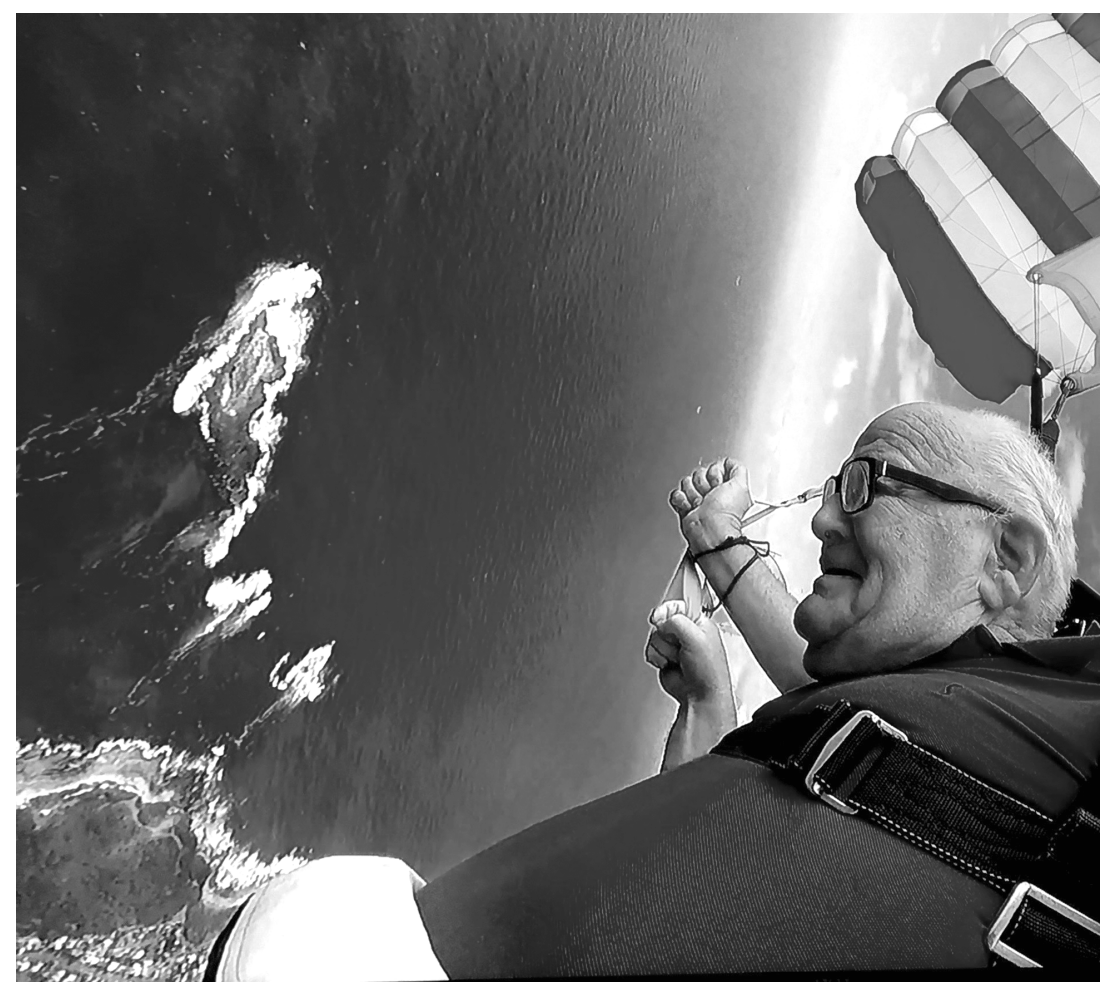

Figure 3.2 Elmer Anderson's Bucket List. Photo by Skydive Photos. Used with permission of Brooke Grundy.

who had never done this before (see Figure 3.2). He was not worried about the risk involved, as he "was going to die anyway" he told Sanchez (Interview no. 1).

The struggle to allow the 85 -year-old to skydive is an example of feminist care ethicist Nel Noddings' "engrossment" in action. For Noddings, care should be undertaken above and beyond professional duty; in this way it becomes relational, particular, not bound by generalities and rules (17). For Noddings, variation is to be expected. Engrossment lives in the variable and never fully understood person who is other than oneself, in the "particular" other, in a specific set of circumstances (17). Kittay's "completion of care" is also activated when care partners take the particularity of each situation and person into account "to see who they are, who that person is, what their life looks like, the way they are speaking" and so on (van de Kamp n.p.; italics in original). In contrast, when the focus in a care home shifts from seeing older people, including those living with dementia, not as particular people but as "problems," 
then rules - rather than a characteristic variation in response to the needs of the cared-for - will predominate.

But Kittay's ideas need to be tempered by acknowledging the impossibility of ever seeing things or people as they really are (Crary qtd. in Bleeker 27). Things, and people, are always presented from within a certain "vision," prisms dominated by culturally restrictive discourses that become naturalised over time. In the case of older people living in care facilities, once they are living in care homes, or even before, these dominant discourses tend to be about loss, deficiency, decline and incapacity; the "diagnostic gaze" (Kuppers 137) is also likely still in operation. It is in this regard that the "narra-theatrical" gaze and "performance consciousness" could be useful activators of other ways of seeing which open up possibilities for those living in care homes. I will now turn to the companion project for the $\mathrm{BL}$, the CPs, to galvanise the "gaze" of theatre and performance in this fundraising venture.

\section{The Calendar Projects}

Two calendars have so far been produced to support the BL activities one in 2017 and the other in 2019. In this endeavour, the residents were following the example of numerous other Australian calendars produced by organisations to make money, where usually young men or women, who are often celebrities to some degree, are photographed nude or partially clad. ${ }^{12}$ The first project was instigated by the women at Starrett Lodge, steered by Marcia and Jessie, who did not seek permission from management before they went ahead with this project. (Not seeking permission before acting is, in this instance particularly, a creative and agentic initiative, which arguably can be linked to the effects of the roleplaying undertaken by Marcia and Jessie, in particular, in the BL.)

In Calendar Girls 2017, the female residents of Starrett Lodge were photographed to look as if they were nude (in fact, it was only their shoulders which were bared). ${ }^{13}$ The more recent 2019 calendar features the men in the Lodge with their shirts off, performing "roles" for the calendar. Figure 3.3 shows a man posing as a firefighter. Other men posed with vehicles (including a motorcycle and a Cadillac). A male resident impersonating a biker was photographed on a motor bike, wearing leather pants and a leather jacket. He told Sanchez that posing for the photo was "one of the best times of his life" (Interview no. 1). One resident posed in a boxing ring, another as a baker in an apron, and Elmer Anderson posed as Mr July in a garden, with the rubric "Manscaping" above his image. In some of these instances, the men were expressing a continuity of identity in that these were interests from their lives as younger men; in other instances, they were using their imaginations to create new "roles" for themselves. With both, they were evidently acting out stories of importance for them, which either helped them to repair 


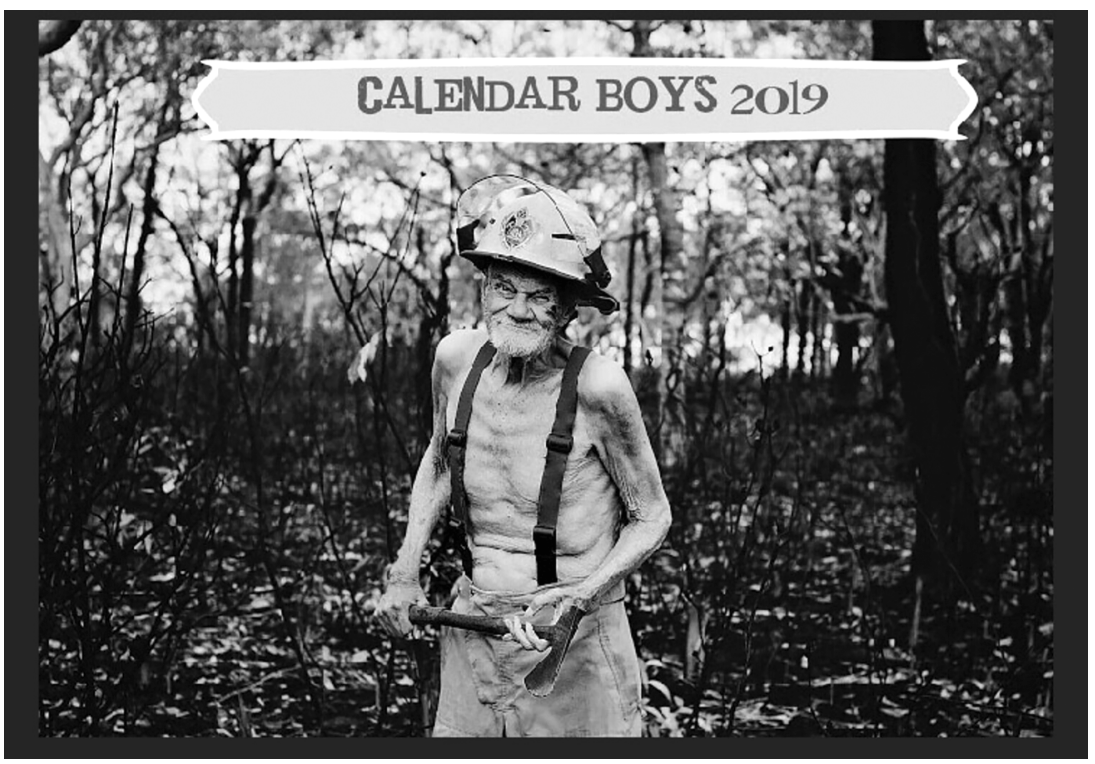

Figure 3.3 Calendar Boy. Photo by Trudi Sanchez. Used with permission of Trudi Sanchez.

identities fractured by moving into the home or to connect with personas they had never had.

It is my contention that the performance-based narrativisations of the CPs gave a form to those identities damaged by the move to a care home and advancing age and dementia; they also provided a way for the men in particular to contribute to raising money for the BL, given that the men did not usually participate in the baking activities. In playing the role of a biker or a firefighter and so on, the men were able to put on costumes and use props to re-experience what it felt like - in the case of the biker, for example - to be young, fit, physically powerful and (possibly) sexually alluring again. (The biker's costume consisted of black leather pants and his prop was a big black motorbike.) In other instances, the residents experienced the feeling of being in costume and propped up for the first time, doing something they always wanted to do but didn't when they were younger, perhaps because in the past they were more concerned about people's opinions. Residents "will have a go at anything," Sanchez told me, as they have lost the stultifying concerns about "what people might think" which they might have had when they were 20 to 40 years younger (Interview no. 1). Through their "narra-theatrical" performances in the CPs, the residents were able to act in roles that, even if for a limited time, reinstated the sense of agency usually not accorded to older people living in residential care homes. 
Seeing the CPs through the lens of theatrical narrativisation unlocks a way of perceiving older people living in care homes as more than just embodiments of problematic deficit discourses. Role plays and role shifts activate "performance consciousness" (Schechner, Between 6) and facilitate the revisioning of the subjectivity of these older people, allowing new types of relationships to be forged with others, principally their care partners and communities. This can be seen in Dancing with Dementia, when the manager Colin McDonell expresses a mix of surprise and pride that the residents did not first check with him about undertaking the CPs. The creation of new types of relationships with their communities is also evidenced in the fact that the residents' activities have been written up in several local newspapers, and they have appeared on various national television shows as celebrities of the moment. After the first Calendar Project, the residents were invited onto Sunrise Channel 7: appearing on TV then became a Bucket List activity. They have become visible, and their voices are being heard on local and national television stations and in other media.

\section{The Bucket List Today}

Presently (as of January 2021) there are rooms for 80 residents at Starrett Lodge, in contrast to the 60 rooms when the BL started in 2010. The BL today involves many more residents who all cook, bake and do whatever they can to raise money to achieve their own and others' BL goals. According to Sanchez (Interview no. 2), there are no residents who do not want to be involved in the BL or its fundraising activities because they all want to have their wishes fulfilled. Of note is that the baking activities that support the success of the List were a large part of many of the residents' lives before moving into the Lodge, especially for the female residents. These everyday practices of identity (Lloyd 205) are frequently taken over by institutional care workers when residents move into care homes: activities are done for them instead of by them or, indeed, with them. On entering Starrett Lodge, many of the residents would have lost their "roles" as cook, cleaner and so on; for this reason, the BL not only provides many residents with a chance to act in ways that had never been part of their lives (evident in the managerial roles assigned to Marcia and Jessie) but also affords some continuity and identity repair in terms of who they were before they entered the home and their ongoing interests from the past. The residents become "participants" rather than "recipients," with the staff "on tap rather than on top," in the words of Colin McDonell (Finding the Why 8:34, 8:04). From sharing the joy of someone else achieving a goal that they have never been able to achieve, particularly at this stage of their life, to taking on a mentoring "role" when more capable individuals are buddied 
up with those who are more cognitively impaired, the BL is all about building relationships of care.

All the activities take place in a network of relationships with others, as well as with the objects being produced, whether it is biscuits, books or calendars. The care home staff and residents all work together in the kitchen to get the biscuits cooked, which gives the residents an opportunity to be part of a community. All the workers at the home, and the activities officer, are also instrumental in establishing this context of care; that is, they pay attention to and value the skills the residents offer to the BL, recognising and celebrating their input to the collaboration. As Held notes: "[ $t]$ he values of caring are especially exemplified in caring relations, rather than in persons as individuals" (242). Once the money has been raised, often through the activities done by the women in the kitchen, the staff then help to bring the residents' wishes to fruition (Sanchez Interview no. 1). Names are still drawn out of a hat to see whose turn is next.

\section{Rider}

In seeing these practices through the utopian lenses of theatre and performance, the residents at Starrett Lodge have a chance to be seen as full of potential rather than deficient as is the risk with the "diagnostic gaze" (Kuppers 137; Gullette). Although the initiative lies with the spectator in the case of dementia, in particular, in performance there is always a relational element connected to the intersubjective process of encounters over time: herein lies hope for changes to formulaic and regulated ways of interpreting dementia and the people who live with it, and older people more generally. Theatrical narrativisation can help do this.

Unfortunately, practical and organisational changes at Starrett Lodge that were due to the first lockdown resulting from the COVID-19 epidemic in early 2020 affected the operation of the BL. One of the changes was Vicki Sanchez's retirement from paid work at Starrett Lodge. Her role of activities officer was filled by a person who, early in 2020, was unable to return from overseas, so no one was in the role, and the BL was discontinued for a while. Another change was the introduction of a "Household" model to the home, in which the residents spend a typical day at home with all the "spontaneous" activities they want to do facilitated by the care workers. According to Sanchez (Interview no. 2), this model and the BL were sidelined during this time. The attenuation of the $\mathrm{BL}$ points to how important the role of an activities officer is in rallying action regarding the List. It also appears to indicate the importance of the role of specific people in assembling support for the BL, such as Marcia and Jessie. Luckily, the new activities officer is now back in Australia, and the BL is once again operational. 


\section{Conclusion}

As the primary foci of this chapter, the $\mathrm{BL}$ and the CPs underscore the relationship between ageing, illness, care, narrative and performance. Framing these care practices as "narra-theatrical," though they are not interpreted in this way by the participants and the institution, is a theoretical proposition which I have brought to these practices because of my previously expressed desire to explore what can be revealed through the utopian lenses of theatre and performance, and the performance of "roles." In these innovative "care practices," theatrical narrativisation and capacity building through agency emerge as central. Here, care meets possibility (the latter activated through the lenses of theatre and performance), and older people living in care facilities are not marginalised by the "diagnostic gaze" (Kuppers 137) as deficit nor are they sidelined by the "decline narrative" (Gullette 13), because they are not being judged as cognitively wanting, incapable of changing or unable to contribute to their communities in meaningful ways. Through the "narra-theatrical" lens, older people living in care facilities can be seen as productive contributors rather than just recipients of care, "takers" or burdens. Through this lens these residents might step out of their expected "roles" into new ones and in the process constricting narratives which connect them only to their past identities, or, paradoxically, which see them as powerless to live into those past identities if they so choose, might be changed. The role plays and narrative improvisations of the $\mathrm{BL}$ and $\mathrm{CPs}$ open up possibilities for many of the residents at Starrett Lodge to live in new and dynamic ways and to be appreciated by the spectators of these performances of possibility.

\section{Notes}

1. Uniting Care Australia is a nationwide corporation responsible for the Uniting Church's community services arrangements. Aged care in Australia is either run as not-for-profit, for-profit (private) or by the government. Uniting Care is one of the largest not-for-profit organisations in Australia, with more than 550 services across New South Wales and the Australian Capital Territory (Uniting). Though the corporation is connected to a religious body, Uniting Care is committed to "celebrat[ing] diversity of ability, age, ethnicity, faith, sexual orientation, intersex variation or gender identity and welcome[ing] everyone exactly as they are" (www.uniting.org/uniting-careers/ diversity-and-inclusion).

2. The Central Coast Local Government Area has a considerably lower income makeup than Greater Sydney and NSW. In 2019, it was found that median household incomes were "around $70 \%$ of Greater $S y d n e y$, and a much higher proportion of local households were on very low and low incomes" (Community Partnerships).

3. "Theatre" and "performance" are intimately connected terms, with "performance" usually the über-label under which "theatre" sits (Balme). 
4. The film focuses on the personhood and relational approaches encouraged by management and staff at Starrett Lodge (including Colin McDonell, exmanager of Starrett Lodge, and Vicki Sanchez) which help residents to find meaning in their lives. It shows that Starrett Lodge has a unique approach to enabling active participation in life for care residents through methods like paying attention to the environment, for example, bringing more light into the facility; activities such as encouraging residents to write and publish their life stories; intergenerational and interspecies programs, by which babies and animals are brought into the facility; and the innovative Bucket List and other projects.

5. SBS stands for the Special Broadcasting Unit, which has a radio, television and online presence across Australia. It was founded in 1977-1978 to provide ethnic broadcasting to the rapidly changing population demographics resulting from increased migration. "Dancing with Dementia" was an episode of the weekly interview show Insight, which was conducted by Jennie Brockie for nearly two decades up until recently and now has Kumi Taguchi as the anchor. Insight is Australia's leading forum for debate and first-person stories. The "Dancing with Dementia" episode included a panel of people and their families, as well as audience members, living with dementia and people working in the field. The Bucket List and the Calendar Projects are given time along with an interview with Colin McDonell, who was the Starrett Lodge manager at the time. Around 26 minutes into the show, the residents are filmed in the kitchen wrapping biscuits in cellophane and adding blue ribbons to them.

6. Multiple versions of (feminist) care ethics (Held 169) have emerged over the past 30 years. In general, care ethicists argue that universal moralities, built on the image of the autonomous, rational, independent, "agentic" individual, overlook the reality of human interdependence and that, for so many stages of human life, we are dependent on others to survive and flourish. The ethics of care "addresses rather than neglects moral issues arising in relations among the unequal and dependent" (Held 13), which is the case in relationships between so called "cognitively intact" people and PLWD.

7. Thompson's hope that this aesthetics "could be orientated as much to institutional care practices as it might be to community-based theatre" (440) was one of the inspirations for this chapter.

8. Social citizenship as defined by Bartlett and O'Connor (Broadening the Dementia Debate) is a view of citizenship which sees civic agency in people as contributing to the socio-cultural mechanics of the contexts in which they live.

9. In criticizing the "diagnostic gaze," I am fully cognisant that diagnoses often have helpful and therapeutic purposes and outcomes. PLWD, many older people and their care partners require access to expert medical care and support services whose provision rests, to a certain extent, on diagnostic definitions and categories. Without definitive medical assessment and certification, persons who require support, as well as their care partners, would not have their needs met by institutionalised services.

10. I prefer the term "care partner" to that of carer or even caregiver, to acknowledge the relational nature of interactions between the people involved in care practices - whether these interactions occur between the older people or PLWD themselves, or the care workers or family members or friends of the care home residents. But for the sake of descriptive precision, it is sometimes important for me to use phrases such as carer or care attendant. 
11. I use the terms "narrative" and "story" interchangeably, despite the fact that certain literary studies scholars define these terms discretely, with "story" as the events that happen and "narrative" as the showing or telling of those events involving sequence (movement from beginning to finish), space (detours from the sequence) and time (Cobley 5-17). For philosopher Paul Ricoeur (Time and Narrative), "narrative" is time; it is about expectation and memory and not just paying attention to events on a timeline. However, I am guided here by Arthur Frank's contention that the words "narrative" and "story" overlap so frequently that sustaining divisions between them in consistent usage is impossible. Frank also refuses a formal definition of stories, contending that stories, in their very ontology, constantly evade classification.

12. In the UK, this has not always been the case. See, for example, the original WI calendar girls.

13. This project was once again inspired by a film, as was The Bucket List. This time, it was the 2003 film Calendar Girls.

\section{Works Cited}

Balme, Christopher. The Cambridge Introduction to Theatre Studies. Cambridge UP, 2008.

Bartlett, Ruth, and Deborah O'Connor. Broadening the Dementia Debate: Towards Social Citizenship. Policy Press, 2010.

Bitenc, Rebecca. Reconsidering Dementia Narratives: Empathy, Identity and Care. Routledge, 2020.

Black, Steven P. "The Ethics and Aesthetics of Care." Annual Review of Anthropology, vol. 47, no. 1, 2018, pp. 79-95.

Bleeker, Maikke. Visuality in the Theatre: The Locus of Looking. Palgrave Macmillan, 2011.

Buch, Elena D. "Anthropology of Aging and Care." Annual Review of Anthropology, vol. 44, no. 1, 2015, pp. 277-93.

Burke, Lucy. "The Locus of Our Dis-Ease." Popularizing Dementia: Public Expressions and Representations of Forgetfulness. Edited by Aagje Swinnen and Mark Schweda, Aging Studies, vol. VI. Transcript, 2015, pp. 23-41.

Butler, Robert N. "The Life Review: An Interpretation of Reminiscence in the Aged." Psychiatry, vol. 26, no. 1, 1963, pp. 65-70.

Cobley, Paul. Narrative. Routledge, 2001.

Community Partnerships. Submission to Federal Government - Raise the Rate for Newstart and Youth Allowance. Central Coast Council Wyong Office, 2019.

Das, Anita. "A Silver Tsunami Invades the Health of Nations.” Forbes. 11 Aug. 2015, www.forbes.com/sites/reenitadas/2015/08/11/a-silver-tsunami-invadesthe-health-of-nations/?sh=4356603efd67.

Dolan, Jill. Utopia in Performance: Finding Hope at the Theater. U of Michigan P, 2005.

Frank, Arthur W. Letting Stories Breathe: A Socio-Narratology. U of Chicago P, 2010.

Gibson, Janet. Dementia, Narrative and Performance: Staging Reality, Reimagining Identities. Palgrave Macmillan, 2020.

Gullette, Margaret Morganroth. Aged by Culture. U of Chicago P, 2004. 
Held, Virginia. The Ethics of Care: Personal, Political, and Global. Oxford UP, 2006.

Kelleher, Joe. Theatre and Politics. Palgrave Macmillan, 2009.

Kittay, Eva Feder. "The Completion of Care - With Implications for a Duty to Receive Care Graciously." Care Professions and Globalization. Edited by Ana Marta González and Craig Iffland. Springer, 2014, pp. 33-42.

Kuppers, Petra. "Towards the Unknown Body - Silence, Stillness, Space in Mental Health Settings.” Theatre Topics, vol. 10, no. 2, 2000, pp. 129-43.

Leibing, Annette. "Entangled matters - Alzheimer's, Interiority, and the 'Unflattening' of the World." Culture, Medicine and Psychiatry, vol. 32, no. 2, 2008, pp. 177-93.

Lloyd, Jayne. "Taking Care of the Laundry in Care Homes." Performing Care: New Perspectives on Socially Engaged Performance. Edited by Amanda Stuart Fisher and James Thompson. Manchester UP, 2020, pp. 204-14.

Mangan, Michael. Staging Ageing: Theatre, Performance and the Narrative of Decline. Intellect, 2013.

Mitchell, David T., and Sharon L. Snyder. The Biopolitics of Disability: Neoliberalism, Ablenationalism, and Peripheral Embodiment. U of Michigan P, 2015.

Noddings, Nel. Caring: A Relational Approach to Ethics and Moral Education. U of California P, 2013.

Pavis, Patrice. Analyzing Performance: Theater, Dance, and Film. Translated by David Williams. U of Michigan P, 2003.

Quick, Andrew, and Richard Rushton. "On Theatricality." Performance Research, vol. 24, no. 4, 2019, pp. 1-4, https://doi.org/10.1080/13528165.20 19.1655350.

Ricoeur, Paul. Time and Narrative. Translated by Kathleen Blamey and David Pellauer, vol. 3. U of Chicago P, 1988.

Sanchez, Vicki. Personal Interview no. 1. Friday 17 Aug. 2018.

—. Personal interview no. 2. Friday 29 May 2020.

- Personal interview no. 3. Tuesday 9 Nov. 2020.

- Personal interview no. 4. Monday 29 Mar. 2021.

Schechner, Richard. Between Theatre and Anthropology. U of Pennsylvania $\mathrm{P}, 1985$.

- Performance Studies: An Introduction. 4th ed. Routledge, 2020.

States, Bert O. "Performance as Metaphor." Performance: Critical Concepts in Literary and Cultural Studies. Edited by Philip Auslander, vol. 1. Routledge, 2003, pp. 108-37.

Stuart Fisher, Amanda. "Introduction: Caring Performance, Performing Care." Performing Care: New Perspectives on Socially Engaged Performance. Edited by Amanda Stuart Fisher and James Thompson. Manchester UP, 2020, pp. 1-17.

Thompson, James. "Towards an Aesthetics of Care." Research in Drama Education: The Journal of Applied Theatre and Performance, vol. 20, no. 4, 2015, pp. 430-41.

Uniting. About Us. www.uniting.org/about-us\#: :text=We're\%20proud\%20 to $\% 20$ be, disability $\% 2 \mathrm{C} \% 20$ chaplaincy $\% 20$ and $\% 20$ community $\% 20$ services. Accessed 12 Oct. 2020. 


\section{Janet Gibson}

van de Kamp, Jeannet. "The Completion of Care as Taking Up of Another's Actions as Care.” Interview with Eva Feder Kittay, 28 Jan. 2018, https:/ethic sofcare.org/completion-care-taking-anothers-actions-care/.

\section{Filmography}

The Bucket List. Directed by Rob Reiner. Warner Brothers, 2007.

Dancing with Dementia. Season 2015, episode 11, SBS Insight, 28 Apr. 2015, 7 Jun. 2020, www.sbs.com.au/ondemand/video/428900419962.

Finding the Why; Enabling Active Participation in Life in an Aged Care Facility. Directed by Corinne Maunder. Co-produced by Corrine Maunder and Cathy Greenblatt. Fire Films Australia, 2014, www.youtube.com/ watch? $\mathrm{v}=\mathrm{hZN} 1 \mathrm{CyEiFNM}$.

It Takes a Community - A Relationship Focused Approach to Celebrating and Supporting Old Age. Directed by Corinne Maunder. Co-produced by Corrine Maunder and Cathy Greenblatt. Fire Films Australia, 12 Nov. 2017, www. youtube.com/watch?v=IUJWFWXz-wY. 


\title{
4 "Come Healing of the Spirit, Come Healing of the Mind"
}

\author{
The Evolution of Care in \\ Sylvain Biegeleisen's The Last \\ Postcard and Twilight of a Life
}

Amir Cohen-Shalev

Confronting dementia often leaves family members not only helpless but also speechless, having insufficient vocabulary - verbal as well as affectivewith which to come to terms with the condition. Taking care of and caring for a parent living with dementia is often unbearably difficult. This frustratingly mutual helplessness (of the person living with dementia as well as the relative-cum-caretaker) is surely a challenge. Yet, recognising these difficulties can also be an asset in dementia care because it foregrounds the necessity to find non-conventional means of communication. As a medium transcending the quintessentially verbal while reaching into visual, oral, and kinaesthetic modalities, film can illustrate, elicit, and encourage such new forms of care.

In what follows, I turn to a diptych of documentary films that depict family relationships and care in ageing, films that provide a rare and unique opportunity for viewers to follow the developmental trajectory of care relationships. The bio-political representation of the very old is too often comprised of "bed and body work," leaving no room for dialogical exchange. The very old hence become a body with no embodiment, namely, a body literally devoid of metaphor and robbed of symbolic values. As a window into the dynamic caring relationship between adults, I analyse here two autobiographical documentary films. These films, The Last Postcard (2009) and Twilight of a Life (2015), were made seven years apart, by the same filmmaker, Sylvain Biegeleisen. Both focus on his relationship with his mother at two different points in her (and accordingly his) life. The Last Postcard documents their bond when the mother, Dianne, is 87 and fully in command of her mental and, to a considerable extent, her physical capacities. Seven years later, her son/the film director comes back to be with her, when the now-94-year-old Dianne is completely bed-ridden and not always lucid.

Sylvain Biegeleisen was born in Antwerp, Belgium, in 1948. The two documentaries about his mother, Dianne, were filmed in Belgium, in French, and are co-produced in Belgium and Israel. Dianne and her first 
husband (Meir) fled from Nazi-occupied Belgium, were caught in France, and were sent to a concentration camp from which Meir did not return. Dianne survived, was reunited with her two sons, returned to Antwerp, remarried (to Jacque) and there had a third son, Sylvain, who left his home in Antwerp at the age of 18 and immigrated to Israel, where he has lived since then. This turbulent family history, which is never fully revealed within the documentaries, serves as a background for the issues discussed and exposed in the first film.

Watching the films in the chronological order of their making is a rare opportunity to examine and contemplate intra-psychic transformations in caring behaviour, and parent-child role reversal in the context of ageing. This chapter will describe how the first film raises issues of consent and obligation, but seen chronologically, the later film, Twilight of a Life, moves from the hierarchical, fraught relationship in The Last Postcard to a relationship that acknowledges vulnerability and is more respectful and, interestingly, reciprocal, and slower. In analysing care attitudes and practices in chronological sequence across the films, I hope to reinforce a concept of elder care that is not only holistic and compassionate but at the same time relational (Cohen-Shalev, "The Ties"; Hendricks) as well as creative (Bellas et al.) and evolving in accordance with late-life twists and turns.

Furthermore, the view of old age in these two films, seen together, captures an ambiguity inherent in older age of simultaneously possessing a sense of self and otherness about oneself (Cohen-Shalev, "Both"). The social space of the frail older person is characterised by many ambiguities: role reversal (of parents and children) as well as rolelessness; the incongruence between social image and self-image; and the replacement of linear time by cyclical time (Gubrium and Holstein; Hazan, Old Age, The Limbo People). Instead of the expected resolution in the social space, dilemmas become suspended; oppositions are dismantled and presented in their bare essentials (Hazan, "Beyond Discourse"). Where there used to be a firm, linear, and hierarchical logic, there is now a loose, cyclical reflection that may also be relevant to care.

\section{Role Reversal and Care in Literature on Ageing}

In gerontological as well as popular discourse, one often finds references to the notion of role reversal, where parents and children switch roles of care giver and care receiver. Early parenthood means taking care of young children. Late parenthood means, for more families than ever before in history, that adult offspring take care of ageing parents, while the latter may become physically, practically, and cognitively dependent on their offspring. Popular culture in general, and the mainstream film industry in particular, have over the past couple of decades given some attention to the necessities and difficulties embedded in elder care. 
The growing Hollywood list features, for example, Nothing in Common (1986), in which Tom Hanks plays a glib Chicago ad exec whose parents split up, forcing him to take sole responsibility for his diabetes-stricken dad (Jackie Gleason); The Savages (2007), with Philip Seymour Hoffman as a theatre professor who, with his sister (Laura Linney), must figure out what to do with their confused 85-year-old father; or Still Alice (2014) and What They Had (2018), about caring for a spouse/parent with Alzheimer's Disease (played by Julianne Moore and Blythe Danner, respectively). Indeed, movies about older people, and the challenges their children face once they become a parent's primary caregiver, populated every corner of the Sundance 2020 festival (Mann).

Within the public discourse, taking care of the older person has led to the perception of this age as a "second childhood," dependent on others (Covey). A parallel theoretical conception is found in Bryan Turner, who discusses childhood and old age as homologous in terms of social liminality and disengagement, or what he calls lack of reciprocity. The derogatory view of older people as childish and dependent, and the "elderspeak" (equivalent to baby talk) sometimes used to address them, are an indication of what Jenny Hockey and Allison James call the discourse of infantilisation:

The cultural pervasiveness of metaphors of childhood within the discourses surrounding aging and dependency ... has become "naturalized." It is seen as somehow inevitable, as the way things are. Through this culturally constructed model of dependency, many of those in old age and others who are infantilized - the chronically sick or disabled, for example - may be made to take a conceptual position alongside children on the margins of society.

Such a discourse of infantilisation, or childishness, is a powerful mechanism of social control. The discourse becomes so taken for granted that, although prescribed from the outside, it can turn into a lived-in reality, the so-called "mask of ageing" (Featherstone and Hepworth, "Images," "Mask").

Another indication of the social control of ageing is that research on late-life care relationships is mostly geared toward the practical aspects of caregiving (Ask et al.; Evans and Lee; Godwin et al.). However, for a simultaneous, two-way caring interaction to take place effectively, a certain degree of psychic maturation is necessary for both parties involved in the caring relationship. By this I mean that reciprocity underlies the move from the practical component of "taking care of" to the humanistic concept of "caring for," especially where caring for the old is concerned. It is a perception of the care relationship as a mutual, two-way interaction that transcends the dominant, functionally hierarchical perception of 
care. However, such a shift is not simple. It requires seeing old things in a new light; a paradigm change propelled by a new point of view and new premises. Rudolf Arnheim argues that artistic development in late life consists in moving away from a hierarchical mode into holistic integration. Arnheim's distinction originated in the need to account for stylistic changes in the art of ageing painters of the past; yet, if we take art as the pinnacle of human potential (Jacques), the developmental move offered by Arnheim could have relevance to care relationships. Simply put, caregiving and care-receiving are interchangeable in actual situations, and the reversal of roles is more externally induced than internally evolving.

My approach to care follows Eva Feder Kittay ("Ethics," "Getting," Learning), who in a series of works developed an ethics of care emphasising relationality that is based on the personhood and dignity of people - including those with cognitive impairments. Such an ethics of care takes caring relationships as a morally fundamental form of relationship and value. The moral agent is a caring self, who can look past their own immediate needs and desires to take on the cares of the other as her own. Such care foregrounds the affective connection between people as prior to a calculative reason that binds self-interested persons. In this view, people without disabilities are only "temporarily abled." Dependency relationships between "unequals" are often inevitable, and therefore assistance should not be seen as a limitation but as a resource. Care, in this vein, should be gender-blind; as Amelia DeFalco also contends, both men and women are equally dependent on care for their survival and therefore are equally obligated to provide care for others.

Increases in longevity over the past few decades have had an impact on reciprocal caring relationships in which both the cared-for and the caretaker are old. What used to be a midlife person taking care of an older person is becoming an old person taking care of a very old one. The psychological barriers formerly separating adulthood from old age, thus providing security (albeit illusory) for the carer, have collapsed with growing life expectancy. The carer, now older, is often in the age brackets once allotted to the elderly. Care in the family has become the old caring for the still older. The result is a combination of reduced physical stamina and, to no lesser degree, the intra-psychic pressures stemming from felt proximity to death and dying on the part of the family member providing the care (Qureshi and Walker).

\section{Part I. "Hide and Seek" Duality in The Last Postcard}

The Last Postcard commences with Sylvain's efforts to gain his mother's consent to the filming. Approaching 60, he is driven by a palpable sense of urgency to record his mother's story. It should be more so for 87-yearold Dianne, but, for various reasons, the pressure is less immediate for her. She has to be coaxed. Sylvain's motivation for the project is clear-cut, 
while his mother is ambivalent about the filming. He wants to expose his family's history; she is more given to hiding and suppressing. The necessity for Sylvain to detonate family secrets and find some closure has been burning in him for decades. Though not all is said, and large chunks are missing from the filmed narrative (e.g., the whole of Sylvain's adult life in Israel), there are occasional hints of family secrets, instigating a desire in the viewer for completion and contextualisation.

The title of the film refers to a postcard written by Dianne's first husband, Meir Chupko, while he was in a concentration camp - the last she heard from him before he was killed. Back in Antwerp, Dianne remarried and had a third son, Sylvain. The postcard was hidden by Dianne from her family, together with her first wedding ring. Years later, the postcard mysteriously disappeared. Dianne suspected her husband, whose jealousy of his dead predecessor made him try to erase his memory. Many years after the death of Jacque, and a few weeks before the making of the film, she discovers that her firstborn son "stole" the postcard as a souvenir of a father he was too young to know. Thus, the postcard as an object, and its real and imagined existences, uncovers a complex family story.

We also learn that Sylvain left his home in Antwerp at the age of 18 and immigrated to Israel, where he has lived since. In an interview after the release of Twilight of a Life, he mentions his mother's anti-Zionist sentiment (Biegeleisen). While not overtly acknowledged in The Last Postcard, it is very likely that leaving home and his mother against the background of the Holocaust and committing himself to Zionism in adolescence must have been a major force in the director's life and personality and a cause for significant tension between the two. It seems that what persuaded Dianne to consent to the making of the documentary was the embedded promise to get her son back:

SYLVAIN: Why did you agree to make the film?

DIANNE (HANDS CLENCHED, SITTING STIFFLY VOICE HARDENED): Why did I agree? To gain my son. I had felt there was a something separating us, a gap. . . . I didn't understand where it came from [pause] but I felt it. . . . [increasingly restless] I don't know how to bridge this gap between us. . . . I don't know. I don't understand, I don't know (close-up on her hands nervously lighting a cigarette).

There is an implied question here: "gaining" a son (we will come back to the use of this mercantile jargon later in the chapter) seems such an obviously strong argument that we are left to wonder why there should be any hesitation or conflict. Yet there definitely is. The gain is explicit, yet there is an implicit loss too. Though for Sylvain there was something to be gained by the project (a sense of closure in a turbulent lifelong relationship), for Dianne it also spelled ambivalence. It meant risking a position of control. By consenting to participate in Sylvain's project, she 


\section{Amir Cohen-Shalev}

might find herself in an inferior position. Put differently, she would have to relinquish her well-kept position of taking care of a child, something she is certain of having fulfilled to the utmost, and instead must confront her son's perspective on their turbulent relationship. As the instigator and as the director, Sylvain also takes the lead. He is directing, while Dianne consents to be directed, for the first time.

\section{Death Did Us Part: The Past Revisited}

In The Last Postcard, Sylvain takes his mother on a tour of the fragments and ruins of their past in order to reconstruct a story of their dyad that will give them meaningful closure and a sense of resolution. The focus is on the movement from a more confrontational/hierarchical relationship to one of mutuality. Therefore, Sylvain intentionally avoids going into the gruesome details of the war and the Holocaust, careful not to offset the focus.

The film makes clear that as a school child, Sylvain remembers feeling left out, rejected by a dominant mother and unable to connect to his father. This is the motivating force behind his persistent efforts to involve Dianne in his cinematic project. Yet, when he eventually succeeds, he meets a different narrative, one that openly clashes with his. In Dianne's narrative, her love for him was unconditional and total. Being a mother and raising and taking care of her family had been at the centre of her life. Her life story clearly validates her argument, leaving her son little room for debate. She sums up her life project in the statement: "I have succeeded in keeping the family together." With this hard truth, mother Dianne acknowledges Sylvain's core narrative of parental deprivation but at the same time transcends it. When Sylvain tries to defend his claim for recognition of his lifelong hurt by arguing that "a small child is expected to respond like I did," she reminds him that an adult with a childhood wound, justified as it may be, is expected to take responsibility for his life. It is significant that, at this point in the film, the director-son appears for the first time in front of the camera. The two protagonists are filmed seated side by side in the open space of a beach resort. The medium twoshot is the first one to show both people in a film where Sylvain is usually behind the camera, heard but not seen. Moving in front of the camera is a visual parallel of mutuality.

From this point on, the camerawork signals a move from a prototherapeutic conscious endeavour by the filmmaker to a reciprocal caring platform. The collaboration in front of the camera transforms their parent-child dyad into an equal dialogue of care and respect. The two protagonists have moved from confrontation to collaboration, with the old child's (Sylvain's) anxiety re-centring on the welfare and survival of the other as a whole person.

Reading Sylvain's struggle with unresolved childhood difficulties through the lens of Erik Erikson's model of life span ego-development 
(Life), we can place Sylvain in transition between the stage of middle adulthood, singularly concerned with the dilemma of Generativity and Stagnation, and the eighth and final stage, in which the Ego is occupied with Integrity versus Despair. My understanding, using Erikson's terms, is that making The Last Postcard facilitated this transition. Sylvain comes to realise that the hurt he had insistently clung to throughout his life has become a manifestation of Ego-Stagnation. The pull toward Integrity, nurtured by his mother's sharp straightforwardness (in itself a manifestation of Integrity) offers an opportunity to re-work, perhaps for the first time, unresolved ego dilemmas and climb the ladder of ego development (Erikson et al.). ${ }^{2}$

As Integrity replays earlier dilemmas and binds these dilemmas together within a life-review process (Butler; Erikson, The Life), it reshapes and reframes issues of trust, autonomy, guilt, identity, and care. Taking centre stage, Integrity means - as Dianne makes clear - renouncing childish narcissistic hurts and doubts, painful as they may have been or still are, and replacing backward circular movement with compassionate consideration of the present.

\section{From a Past Tense to a Present Calm}

A change of tone, from interpersonal tension to calm wistfulness, characterises the closing moments of The Last Postcard. The camera now mirrors, as its movements become restricted, the slowing down of activity in advanced old age. It is a new reality for the old Dianne, and these last scenes capture her learning the steps. Climbing a home ladder to get to the upper shelves of a kitchen cupboard shakes her confidence; the news of a newborn great-grandchild has her in tears (tears of happiness, but still a change in affective vocabulary). The ending of The Last Postcard becomes a quiet lamentation for old age, descriptive and not analytical, its orientation turned from the vagaries of the past toward the conditions of the present. Sylvain returns to his position behind the camera, becoming more a sympathetic observer than an interested participant. The Last Postcard becomes in these later scenes a contemplation of the condition of old age. What the camera reveals is that behind the hardheaded determination of a Holocaust survivor who had kept her family together against all odds lurks an 87-year-old human being, who, for the first time in a life crowned by physical stamina and strength of character, experiences a different vision of her life and is forced to negotiate a difficult relationship with her son. Sylvain's camera continues to record, but now, perforce, it records the uncertainty and anxiety of physical decline. Sylvain does not disappear, but he seems to demand no attention, and his being behind the camera yields itself for the sole purpose of attending to his mother. In this new capacity as a caring attendant, he accompanies her when she is hospitalised, through moments of frailty, neediness and 
anxiety. At her bedside in the hospital, we get a glimpse of what is in store for the next film. Although neither protagonist could have predicted the future, the nature of care and caring behaviour that are expressed in the last moments in The Last Postcard is a nod towards their meeting seven years later that is characterised by reciprocity, mutuality, and creative imagination in care relationships, as depicted in Twilight of a Life.

\section{Part II. "Sunset, Sunrise": Life-Giving and the Reciprocal Model of Caring in Twilight of a Life}

The Last Postcard is about the repair work of mother-son relationships, reconciling their loaded personal history of memory and loss. In Twilight of a Life, repair work is substituted by a different kind of work that I wish to term, after Monterescu and Hazan, a "business of the present."

Watching the two documentaries one after the other is a disorienting experience. Twilight of a Life introduces the viewer to dementia-driven changes of identity and the self and the enigmatic emergence of a person whose parental identity is only partially present, or not at all. A few months before the filming of Twilight of a Life started, Dianne became bed-ridden, occasionally confused, and requiring full nursing care. She was returned to her home from the hospital, and most of the 70-odd minutes of Twilight of a Life take place in the room she is confined to, her only living space made into a location of filming. This confined space is the location of a momentous transformation, already glimpsed in the final scenes of The Last Postcard, in the nature of care, moving towards a reciprocal exchange of affection and support.

The opening shot is a frontal close-up of Dianne's face, with the camera positioned vertically above it. For viewers who have not seen The Last Postcard, being put "face to face" with the protagonist's ravaged, yet curiously alive, portrait of extreme old age can be a disturbing experience. Viewers who saw her in The Last Postcard will probably be doubly shocked because they may not recognise the woman in the face in front of them. The strong-minded, immovable matriarch who defended the stability of her family has been changed almost beyond recognition.

Twilight of a Life opens, in the same way as The Last Postcard, with Sylvain trying to establish a "working contract" with his mother; however, this is a different task altogether seven years later. The ethics of consent are more challenging when lucidity is in doubt, and Twilight of a Life documents a condition of consciousness in very old age that expresses on-off fluctuations of lucidity in dementia. When Sylvain presents the project to her as "a film about you and me," it is not any longer "you the mother and me the son" but two human beings in the process of rediscovering each other, with knowledge of their past nexus put aside, or 
practically "forgotten," in line with Anne Basting's imperative in the title of her book about dementia, Forget Memory. Sylvain and his mother's caring interactions are marked by confusion and lucidity, disorientation and re-orientation, to breed a caring universe singularly their own. This environment of care is contingent upon a willingness (in both) to convert confusion and bewilderment into the certainty and immediacy of the senses. These in turn depend on suspension of binaries and hierarchical categories.

Starting in utter stillness and with no discernible backdrop, the seemingly protracted silence of the opening shot is broken by Sylvain in voice-over: "This is a film about you and me," he says, not asking for permission but rather announcing it. In this exclamation the issue of consent becomes superfluous. In place of formal consent, the opening quickly arrives at a proposition of equal partnership. Instead of Sylvain bargaining for her consent, Dianne plays along with her son as a partner, making an offer he cannot refuse. Moreover, she offers herself as a script writer.

They discuss the question of utility versus futility in a fascinating dialogue:

DIANNE: In nine out of ten, you gain [pause, then emphatically]. Nothing! [right hand pointing toward the camera, drawing a circle denoting "zero"]

SYLVAIN: The point is not necessarily to make profit, but to create emotions.

DIANNE [EVIDENTLY MAKING AN EFFORT TO ORGANISE HER THOUGHTS]: That is all? What is this "emotion?" We gain from it? What are you trying to say? On one hand you say we gain nothing, on the other hand "emotion." If there is emotion, it means people will come to watch the film. You are talking nonsense. ... You can't imagine the clientele we are going to have. So on with the work!

Dianne actually "means business." It is not the first time she uses mercantile vocabulary: as previously noted, at the beginning of The Last Postcard she confesses to having been persuaded to take part in the film because of the prospect of gaining her son back. In Twilight of a Life, she is outright excited by the prospect of gaining an audience. The gain-loss paradigm has become a central organising principle in a life that has seen both sides in the extreme and has learnt to skilfully manipulate it for sheer survival. The choice of vocabulary stays the same, yet the content has changed, from survival (in the first film) to benevolent altruism, from material gain to arousing emotions, in her words, "touching" others. It is touching other lives that profoundly connects mother and son, taking their partnership onto another level. Contrary to their previous effort, where a film was intentionally made for a specific relational system, here 
it is a wide group of others who will be touched. Dianne makes a move in social consciousness, from self-oriented to other-oriented.

Dianne's change in the second film involves more than the expected decline of health or mental deterioration. At the end of The Last Postcard, Sylvain left her wistfully awed by the growing need to come to terms with ageing and loss of autonomy. Seven years later, we meet a Dianne who is totally dependent and yet curiously joyful and uncannily optimistic. As the film unfolds, she manifests an affectionate, emotionally expressive and socially outgoing side, at odds with the affectively, expressively reticent self of the previous documentary. At one point, looking directly and intensively at her son, she says, "I love you." Sylvain is heard sobbing in the soundtrack. After The Last Postcard, this moment of mutual care is moving because of the sadness embedded in the situation, through the direct, childlike authenticity of the affect, together with the realisation that Sylvain may be hearing it for the first time.

The close-up of the very old Dianne, uttering the words "I love you" while looking directly at her son, conveys the emotion as if it had been given birth with the words rather than having existed before. In the film, the emotion finds its place in the very moments when the mother does not fully recognise the man in front of her as her son. Even when her memory is failing, and her home as it used to be is no longer there, even when she is constantly dependent on others, Dianne opens her eyes and says to Sylvain: "I love you." Or she is seen caressing his face with her hand, without saying anything.

\section{Collapsing Categorical Barriers: The Underlying Logic and Internal Validity of De-differentiation}

The power of emotional and affective connection also characterises the more abstract discussion that the mother and her son have concerning the purpose of the film and how it is meant to influence its audience. The opening dialogue exemplifies the old woman's leap of consciousness as a dialectical process. First, Dianne produces a thesis: gain as a material thing and therefore unlikely to be obtained out of a film about "you and me." Sylvain, in response, makes a distinction between material gain and emotions (antithesis). Criticising her son for this very distinction, Dianne provides a synthesis whereby emotions are profitable in and of themselves. Touching the lives of people is not dichotomous or antithetical to making a profit but a real possibility of gain in and of itself. This flip, from mercantile materiality to things of the soul, going back and forth (a moment later she inquires as to the possibility of selling the film) demonstrates mental agility that is far away from the limiting and negative picture of old age drawn by gerontology or popular culture. The dual meaning of value, that of profit and that of merit, plays out at the service of a partnership with a significant other, the man behind the 
camera who seems to be willing to participate in spreading a message of pressing importance.

Once the commercial prospects of the film-to-be as well as its purpose (touching the emotions of the audience) are established, there remains the question of content, namely, what it is to be about. 94-year-old Dianne, disabled and bed-ridden, emphatically announces her plans:

SYLVAIN: When you talk about life and death, it touches everyone.

DIANNE: I'm building something that rests on the future. Not the past... the future.

S: Are you talking about death?

D: I'm talking about life ... about life, not about death.... Don't people see enough death on TV? Do they need a supplement? We need to talk about life!

In these lines, future and life, like profit and emotion, the concrete and the abstracted, merge together. With limited future and little time left ("I don't have much time left," admits Dianne in one of her many painfully clear moments) the present, combined of multiple fleeting moments, becomes a unity rather than something to de-construct analytically. This emergent temporal unity depends on the abolition of the past and with it of the impending future. The Last Postcard is about life too, yet it has the familiar chronotope of a "road movie," organising time vertically and linearly. This sense of time is no longer operative in this second documentary, replaced by a centrifugal, circular atemporality. Where cinematography de-constructed time for psychological re-construction in the first film, it now captures moments of a dyadic interaction.

\section{Contraction of Time, Care, and the "Business of the Present”}

Whether forgetting, suppressing, or consciously ignoring the past, restructuring time to exclusively address matters of the present transforms the demands of affective care. Having established a resonant rapport with the person his mother has come to be, most of Twilight of a Life is devoted to Sylvain experimenting with an altered caring repertoire. Such care is attuned to Dianne's momentary, sense-centred experience. Most memorably significant for the issue of care are their mutual excursions in the realms of sound, touch, movement, and taste. The complete return to sensual feelings is manifested by the mother's expressed joy in touch, taste, sound, and movement, restricted as it is. "Caressing is a language ... it is everything!" says Dianne in eloquent French, at the same time converting language into almost abstract, pure sensuality as - in a close-up - her hand caresses/talks with her son's hand. 


\section{0}

Moving from touch to sound, the role of music in therapy, especially for people with dementia, is well documented in nursing literature and research (Bellas et al.). In Twilight of a Life, the effect of music is presented in terms of interpersonal contact and pleasure rather than in the usual cognitive terms. Sylvain sings songs by Jacques Brel, accompanying himself on the guitar, not so much, it seems, to improve memory or promote continuity of self in Dianne but for the sheer pleasure of the intimacy these sounds foster. In one scene he sings to his mother a song he wrote especially for her, a song characterised by tonal simplicity and repetition, in which her joy in mouthing the refrain is evident. It is music qua intimate communication, more than a therapeutic tool.

Dianne provides a unique illustration of the actual twilight, blending light (lucidity) and darkness (disorientation) in a way that evokes the many types and stages of dementia in old age. Lying in her bedroom, in her house, she asks Sylvain: "There is here a bedroom, where I am sleeping ... I don't know where they put me ... where am I exactly?” Sylvain, with a plate of food in his hand, reassures her that this is indeed her home. Dianne says: "Bon appetit. ... Since you say you are in my home, I am saying 'Bon appetit." This is one of many examples illustrating how Dianne reflects on her own lack of orientation. She identifies the working elements (recalling the conventional etiquette of interpersonal behaviour) and employs them while acknowledging her fractional awareness. With her son as a partner, such played-out patterns of interaction also become signals of introspection, for example, when she says: "You always want to stay at home, to have a hand that warms you. But where is my home?" These moments of dialogue hinge on and are realised through interaction. As Dianne sums it up: "You are the one that gives me strength. When we are two, we have so much strength.”

\section{Conclusion}

The two films discussed here provide several important insights into the dynamics of care in old age, more specifically regarding the move from a personal to meta-personal mode of relationship. My reading highlights old age and dementia as an expression of "other-wise" personhood: a state of lost hierarchies, social as well as interpersonal hierarchies, and the egalitarian sense-centredness that potentially emerges instead. When the very old are represented through the bio-political lens of "bed and body work," this leaves little or no room for dialogical exchange. This is where The Last Postcard and Twilight of a Life offer something new to this paradigm, even if they are not the only films to do so. Moving beyond the accepted role of a child-cum-caretaker, Sylvain assumes another, more pertinent role: that of participant observer. This may be key for communicating with a parent with dementia. 
Instead of the apparent rationality of consent, autonomy, agency, and rights (The Last Postcard), Twilight of a Life shifts into a contract of relationality and caring. What distinguishes Twilight of a Life as a creative portrait of the very old living with dementia is its humanistic normalisation of old age. Relational care, in the sense exemplified in Twilight of a Life, is contingent upon normalising old age. When Sylvain asks Dianne how old people should be treated by others, she replies with astonishing simplicity, in a single word: "Normal." Such normality expresses itself in simple things of the present (Hazan, "Holding"): joint activities (singing, touching, affective responsiveness) and humour; open, wide laughter; and self-irony ("I'm not old enough to know"). Interaction, no longer informed by past or future conflicts hinged on lost or anachronistic roles, becomes a trans-generational experience of bare humanness, made up with the work of here and now in its concrete and sensuous antics, touch, smell, taste, movement, and sound.

\section{Notes}

1. This paper incorporates some material that originally appeared in Amir CohenShalev, "From the Unbearable Weight of the Past to the Bare Lightness of the Moment," Gerontology and Geriatrics, 2016, vol. 43, no. 3, pp. 83-96.

2. This kind of self-treatment is reminiscent of that undergone by Dr. Borg, the elderly protagonist in Ingmar Bergman's Wild Strawberries (1957). Erikson found this inspirational (see Cohen-Shalev, "Both" and Visions).

\section{Works Cited}

Arnheim, Rudolf. "On the Late Style." New Essays on the Psychology of Art. Edited by Rudolf Arnheim. U of California P, pp. 285-96.

Ask, Helga et al. "Mental Health and Wellbeing in Spouses of Persons with Dementia: The Nord-Tróndelag Health Study." BMC Public Health, vol. 14, 2014, p. 413.

Basting, Anne D. Forget Memory. John Hopkins UP, 2009.

Bellass, Sue et al. "Broadening the Debate on Creativity and Dementia: A Critical Approach.” Dementia, vol. 18, no. 7-8, 2018, pp. 2799-820.

Biegeleisen, Sylvain. "Interview with Koby Meidan." Israeli Educational television, 20 Jan. 2016 [Hebrew].

Butler, Robert. "The Life Review: An Interpretation of Reminiscence in the Aged.” Psychiatry, vol. 26, no. 1, 1963, pp. 65-70.

Cohen-Shalev, Amir. "Both Worlds at Once" - Art in Old Age. American UP, 2002.

- Visions of Aging: Images of the Elderly in Film. Sussex Academic Press, 2008.

-. "The Ties That Bind: Late Life Creativity - A View from on the Silver Screen.” New Frontiers in Creativity. Edited by Shulamith Kreitler. Nova Science Publications, 2019.

Covey, Herbert C. "A Return to Infancy: Old Age and the Second Childhood in History." International Journal of Aging \& Human Development, vol. 36, no. 2, 1992, pp. 81-90. 


\section{Amir Cohen-Shalev}

DeFalco, Amelia. Imagining Care: Responsibility, Dependency, and Canadian Literature. U of Toronto P, 2016.

Erikson, Erik H. The Life Cycle Completed: A Review. Norton, 1982.

Erikson, Erik H. et al. Vital Involvement in Old Age. Norton, 1986.

Evans, David, and Emmanuel Lee. "Impact of Dementia on Marriage: A Qualitative Systematic Review.” Dementia, vol. 13, no. 3, 2014, pp. 330-49.

Featherstone, Mike, and Mike Hepworth. "Images of Aging." Aging in Society: An Introduction to Social Gerontology. Edited by John Bond and Peter G. Coleman. Sage, 1990.

- "The Mask of Aging and the Post-modern Life Course." The Body: Social Process and Cultural Theory. Edited by Mike Featherstone et al. Sage, 1991, pp. 370-89.

Godwin, Kyler M. et al. "The Longitudinal and Dyadic Effects of Mutuality on Perceived Stress for Stroke Survivors and their Spousal Caregivers." Aging and Mental Health, vol. 17, no. 4, 2013, pp. 423-31.

Gubrium, Jaber, and James Holstein, editors. Ageing and Everyday Life. Blackwell, 1990.

Hazan, Haim. The Limbo People: A Study of the Constitution of the Time Universe among the Aged. Routledge and Kegan Paul, 1980.

—. "Holding Time Still with Cups of Tea." Constructive Drinking: Perspectives on Drink from Anthropology. Edited by Mary Douglas. Cambridge UP, 1987, pp. 205-19.

—. Old Age: Constructions and Deconstructions. Cambridge UP, 1994.

. "Beyond Discourse: Recognizing Bare Life Among the Very Old." Foucault and Aging. Edited by Jason L. Powell and Azrini Wahidin. Nova Science Publishers, 2006, pp. 157-70.

- "From Ageless Self to Selfless Age: Toward a Theoretical Turn in Gerontological Understanding." Understanding Well-being in the Oldest Old. Edited by Leonard W. Poon and Jiska Cohen-Mansfield. Cambridge UP, 2011, pp. 11-26.

Hendricks, Jon. "Creativity Over the Life Course - A Call for a Relational Perspective." Journal of Aging and Human Development, vol. 48 no. 2, 1999, pp. 85-111.

Hockey, Jenny, and Allison James. Growing Up and Growing Old: Ageing and Dependency in the Life Course. Sage, 1993.

Jacques, Elliott. "Death and the Midlife Crisis." International Journal of Psychoanalysis, vol. 14, 1965, pp. 502-14.

Kittay, Eva Feder. "The Ethics of Care, Dependence, and Disability." Ratio Juris, vol. 24, 2011, pp. 49-58, https://doi.org/10.1111/j.1467-9337.2010.00473.x.

- "Getting from Here to There: Claiming Justice for People with Severe Cognitive Disabilities." Medicine and Social Justice: Essays on the Distribution of Health Care. Edited by Rosamund Rhodes et al., 2nd ed. Oxford UP, 2012, pp. 313-24.

- Learning from My Daughter: The Value and Care of Disabled Minds. Oxford UP, 2019.

Mann, Court. “At Sundance. An Unlikely Spotlight: Your Aging Parents.” Desert News, 6 Feb. 2020, www.deseret.com/entertainment/2020/2/6/21125266/ sundance-2020-elderly-caregiving-falling-the-father-dick-johnson-is-deadsome-kind-of-heaven. 
Monterescu, Daniel, and Haim Hazan. Twilight Nationalism: Politics of Existence at Life's End. Stanford UP, 2017.

Qureshi, Hazel, and Alan Walker. The Caring Relationship: Elderly People and their Families. Palgrave Macmillan, 1989.

Turner, Bryan S. “Aging, Dying and Death." Medical Power and Social Knowledge. Edited by Bryan S. Turner. Sage, 1987, pp. 11-31.

\section{Filmography}

Biegeleisen, Sylvain. The Last Postcard. Zen Productions, 2009. . Twilight of a Life. Zen Productions, 2015.

Chomko, Elizabeth. What They Had. United Pictures, 2018.

Glatzer, Richard, and Wash Westmoreland. Still Alice. Lutzus-Brown, 2014.

Jenkins, Tamara. The Savages. Fox Searchlight Pictures, 2007.

Marshall, Garry. Nothing in Common. Delphi Films, 1986. 


\title{
5 Dementia in Familial Documentary Film
}

\author{
The Ethics of Representation \\ and the Ethics of Care ${ }^{1}$
}

\section{Raquel Medina}

In the past two decades, an increasing number of documentary films have explored the effect of dementia on the person living with it and/or the effect it exerts on those caring for them. Some of these films are directed and narrated by the children or grandchildren of the person living with dementia and focus on difficult ethical issues that result from combining familial care with the documentary practice. If storytelling about and with people living with dementia is a powerful way to highlight issues such as vulnerability and care, this vulnerability can be further increased when filmmakers exert their narrative power with the purpose of both/ either reconstructing a past that is no longer remembered by the people living with dementia and/or narrating their present. People living with dementia are already vulnerable in social settings due to their dementia, but documentary practice can greatly add to their vulnerability.

This chapter examines two documentary films: the Mexican Tiempo suspendido [Time Suspended] (2015) by Natalia Bruschtein and the Spanish El Señor Liberto y los pequeños placeres [Mr Liberto and the Small Pleasures] (2018) by Ana Serret. In Bruschtein's film, the filmmaker interviews her grandmother Laura Bonaparte, who lives with dementia and is well known as one of the co-founders of the movement "Madres de la Plaza de Mayo" in Argentina. In Serret's film, the filmmaker records the daily life of her father Liberto Serret, a retired civil engineer and inventor who has Alzheimer's disease and lives with his daughter, son-inlaw, and grandchildren.

Documentaries about and with people living with dementia such as these two films are powerful tools that raise important issues such as the ethics of representation, vulnerability and care. Hence, how these tools are employed to tell the story of vulnerable subjects has a crucial ethical dimension that affects not only the person with dementia and the viewer but also the way caring for a person with dementia is (re)presented and provided. Amelia DeFalco points out the different meanings of care: "We give care, take care, care for, care about, have cares, and don't care. In its broadest sense, care is affection, devotion, responsibility; even obligation; it is action, behaviour, motivation, and practice: care feels and care 
does" (5). Within these meanings of care, these two films offer different cinematographic (re)presentations of people living with dementia and exemplify two different responses to and notions of "to care for" and "to care about" people with dementia.

\section{Documentary Film: The Ethics of Representation and the Ethics of Care}

Carol Gilligan's feminist concept of care ethics questioned the male model of moral reasoning and decision making. This criticism, Nel Noddings explains, opened an important path to understanding the ethics of care as not only gendered but also relational and interdependent, thus leading to the notion of interpersonal caring relationships. According to Christine M. Koggel, these interpersonal caring relationships are based on a recognition that the individual is part of different networks of relationships at personal, political and social levels, instead of an isolated entity. These two films certainly take different approaches to the ethics of care: while El Señor Liberto emphasises the personal and caring relationship between the filmmaker and the person with dementia, Tiempo suspendido highlights the roles played by the public and private figures of the person with dementia. That is, the purpose of each film is different: whilst Tiempo suspendido is mainly preoccupied with the public figure of Laura Bonaparte and the impact of her memory loss on her country's historical memory, El Señor Liberto is concerned with how the person with dementia continues to live, communicate, and enjoy life. Therefore, I argue that the purpose of the film influences the position of the persons living with dementia on screen, their potential vulnerability to psychological harm, and the cinematographic aesthetics employed.

The documentary mode selected to communicate with the audience shapes the response the viewer might have to the person with dementia on screen and has implications for real-world relations with people living with the condition. In the past few decades, the ethics of documentary film and the ethical responsibilities of filmmakers have been extensively debated. Among the issues at stake, two aspects are of relevance for the present analysis: firstly, consent in situations where filmmaker and subject are personally related and there is a clear intimacy between the two and, secondly, the harm to subjects that the interaction can cause. John Katz and Judith Katz have highlighted that in familial documentaries the intimacy of the family relationship is stressed from the beginning, which in most cases stops the viewers from thinking whether in certain circumstances the filmmaker is pushing ethical boundaries in relation to representation and consent. As G. Thomas Couser suggests for lifewriting, when people with dementia are the protagonists of narratives about them, their cognitive impairment may prevent them from consenting to their representation and from responding to it $(\mathrm{x})$. 
Documentary film endeavours to explore important social and cultural issues. There are two important and divergent approaches to documentaries depending on whether the emphasis is placed on the filmmaker's perspective or the object/film itself and its perception by the viewer. Bill Nichols suggests that documentaries inform or try to influence a viewer's opinion, but most importantly present the filmmaker's perspective on an issue. Distancing himself from Nichols' emphasis on the filmmaker's perspective presented in the film, Garnet Butchart characterises documentary film as a visual representation and a phenomenological perception that deepens "the sphere of the self-transcending gaze of cinematic perception in the presence of which any emergent object acquires identity and is thus made meaningful for a cinematic world" (437). Considering both perspectives, it can be argued that, despite the conscious, initial intentions of the filmmaker, the final product that reaches the audience attains first its own reality and materiality and is then perceived and interpreted by the viewer. Consequently, a film could hold a different meaning from the one originally conceived once it is interpreted.

The materiality and phenomenological nature of documentaries mean that the tools of production and what is presented on screen are equally key elements for both the reception of the film and the meaning that the viewer assigns, in the present case, to the person living with dementia. It is the phenomenological nature of the film that facilitates the encounter between private/personal and public/social dimensions of care: the private interpersonal caring relationship captured on screen ceases to be private (personal) to become public (social). In relation to journalism, Baastian Vanacker and John Breslin stress that Noddings' concept of interpersonal caring relationships, based on the idea that everyone wants to be cared for, is insufficient for addressing how care can be put into practice in the public world (203). They argue that, if the ethics of care is limited to personal relations (private sphere), it is unlikely that it can have practical applications or be a guiding principle in public institutions (203).

The film becomes an independent entity that is interpreted in different ways by different viewers through emotions, feelings and affects. Therefore, it is the new relationship in the public sphere between each viewer and its object of contemplation that may put the person living with dementia in a vulnerable situation. The film is a narrative composed of images and sounds that significantly influence not only the viewer's perception of the caring relationship depicted, but also our broader ideas about dementia, people living with dementia and care for people with dementia. As suggested by Susan Sontag in Regarding the Pain of Others with regards to photography and war, (re)presenting atrocity and violence suffered by others may generate diverse and opposing responses in terms of feelings, emotions and affects: repulsion, shock, pity, sadness, or fascination and attraction. Applying the same principle to people living 
with dementia (re)presented in a documentary film, there may be a wide array of viewer responses.

What is visually narrated in film embodies important notions of care that need to be carefully considered. Consequently, cinematographic language plays a key role in placing the person with dementia in relation to the viewer in certain ways (e.g., as a vulnerable subject or as a resilient one). Returning to the concept of the ethics of care, it is precisely the distance between film and viewer that has important implications for the notion of care, since the viewer cannot provide care for the person on screen. Viewers can respond in any of the ways Sontag suggests but cannot look after the person on screen; they cannot establish a "material" reciprocal caring (inter)action. How, then, could the spectators have a relational or reciprocal caring interaction with the subject-object of their gaze?

Leaving aside the various approaches that the "affective turn" scholars have to the concepts of affect, emotion, and feeling, ${ }^{2}$ it is important to note that images of old age and dementia predominantly have generated emotions of fear, sadness and impatience, as well as feelings of disgust and repulsion. ${ }^{3}$ If we follow Kristyn Gorton's notion that "feeling is negotiated in the public sphere and experienced through the body" (334), we can understand why erasing the traces of ageing from the body through cosmetics or surgery - or from the photographic image of a body - through Photoshop - is so important in a youth-centric society. Hence, gazing at older people living with dementia might cause emotions of fear and feelings of disgust. How can these socially and culturally preestablished and constructed emotional reactions and feelings about older people living with dementia be overcome? How can the moving image of film reverse these responses without erasing older persons living with dementia from the screen?

Affect and affective communication are core to care as relational practice. Teresa Brennan argues that the subject-object binary can be eliminated through affect, which makes possible the ethics of relationality. One affects others and one is affected by others; we "feel with others" (123). Moreover, she claims that in affect sight is no longer deemed to be the most important sense. If with sight the binary of subject (viewer) and object (person who is seen) is sustained, with affect the other senses of the body can interconnect and dissolve the binary. Within film studies, Laura Marks introduces the concept of haptic visuality, a visuality that functions like the sense of touch by activating physical memories of smell, touch and taste. Medina and Zecchi argue that hapticity "is evoked by certain formal strategies to represent the ageing body (extreme close-ups and long duration shots; video imagery; photographs in isolation or combination) and by affective imagery that triggers multi-sensorial experiences (caressing, smelling, hearing, and tasting)" (260). In this way, films that offer this type of multisensory experience work through affectivity to 
produce relationality between those within the film and the viewer and to weaken the object-subject binary.

Judith Butler aims to give answers to some of the ethical questions raised by Sontag in relation to vulnerability and our ethical response to suffering. Butler claims that "the way in which suffering is presented to us, and how that presentation affects our responsiveness" is important (951). How the presentation of suffering is framed can either trigger affective reactions or suppress responsiveness (955). Drawing on Butler's approach, the following comparative analysis illustrates how two radically different cinematographic (re)presentations of people with dementia solicit different affective responses and, in doing so, embody two different responses to and notions of "to care for" and "to care about" them. Furthermore, it argues that Tiempo suspendido and El Señor Liberto present very different modes of thinking about and visualising people with dementia, their personhood, and the ethics of care. Tiempo suspendido is rooted in static binaries: the self/the other, the able/the disabled, before/ now. This results in a film primarily focussed on forgetting as the major sign of dementia (the mind) and on the conceptualisation of the aged body without a mind as embodiment of an archaeological ruin (Dubois). Memory loss is used as a trope to discuss the national forgetting of atrocities committed by the Junta Militar in Argentina (1976-1983), and the need to create a prosthetic memory (Landsberg) that prevents those memories from disappearing. El Señor Liberto presents the perspective of Liberto and his experience living with dementia using the camera in a twofold distinctive mode: as the visualisation of Liberto's subjectivity and as the visualisation of other forms of communication which are paradoxically not visual. That is, while Tiempo suspendido reinforces in both content and form the Cartesian division between body and mind and between able and disabled, El Señor Liberto proposes a way to overcome this duality by portraying the continuum that exists between the self and the other not through reason and cognition but through the embodiment of affect. Finally, employing Teresa Brennan's approaches on affects and the ethics of relationality, this chapter evaluates how El Señor Liberto presents a different visual approach to the ethics of care. It does so by considering the film from a queer perspective and seeing it as a space of encounter in which affect is created by the filmmaker to communicate to and share with the viewer the lived experience of the person with dementia.

\section{Tiempo suspendido}

In Tiempo suspendido, Bruschtein presents a series of personal encounters with her grandmother, Laura Bonaparte. Bonaparte was an Argentinian psychologist and human rights activist whose former husband and three of her children (two sons-in-law and one daughter-in-law) 
disappeared during the Dirty War (1976-1983). In 1985, after having spent nine years exiled in Mexico, Bonaparte returned to Argentina and in 1986 co-founded a new strand of the "Mothers of Plaza de Mayo," an organisation that fought to preserve the memory of the 30,000 "desaparecidos" [the missing] and to bring the perpetrators to justice.

Bruschtein started working on this project in 2011, once her grandmother's Alzheimer's was rapidly progressing and after seeking permission from her uncle, Bonaparte's only surviving son, and cousins before she started filming (Medina, "Interview with Natalia Bruschtein"). When Bruschtein began shooting the film, Bonaparte was not able to recognise her, but nonetheless, some affective connection seemed to remain, because according to Bruschtein, Bonaparte felt at ease and safe with her granddaughter during the shooting of the film (ibid.). Bruschtein states that she was trying "to recover the last thing that remains of a woman I have always admired. I think that it is fair that she is the one who remains in the memory of the viewer" (ibid.).

The documentary was shot over the span of three years in different locations: the nursing home where Bonaparte had lived for the past few years and the family spaces she visited with her granddaughter, including those of Bonaparte's childhood and youth. The progression of Bonaparte's dementia in those years is reinforced by the time constrictions of the film and the structuring of the documentary as a sequence that constantly emphasises chronological contrasts in Bonaparte's life: before the disappearance of her family members; the time of her human rights activism against the atrocities committed in Argentina; and Bonaparte at the time of the narration. The repetition of this pattern generates a strong contrast between the "before" and the "now" of Bonaparte that seems to characterise her present as meaningless. The focus of the camera on her memory loss (made evident by her long silences and vacant stare) and her ageing and wrinkled body bolsters the notion of ageing and dementia as decline and loss of selfhood and presents a nostalgic perception of the past (see Figures 5.1 and 5.2).

The opening extreme close-up shots introducing Bonaparte at the time of the narration concentrate on her grey hair, wrinkled face and shaky, thin hands. The length of the shots pushes the viewer to look at Bonaparte for quite some time, with the camera focussing on her older body and vacant expression. The film soon reveals through an establishing shot that she lives in a nursing home. In clear contrast with this opening sequence, the following sequence shows a jubilant Bonaparte in her nursing home room, talking about having had a very happy childhood. The viewers are placed by the camera in the position of the camera itself, as if they were there with Bonaparte in the room. However, this is still an objective camera with the function of making the spectators sit back, watch and listen to the daily routine of this woman, her encounters with 

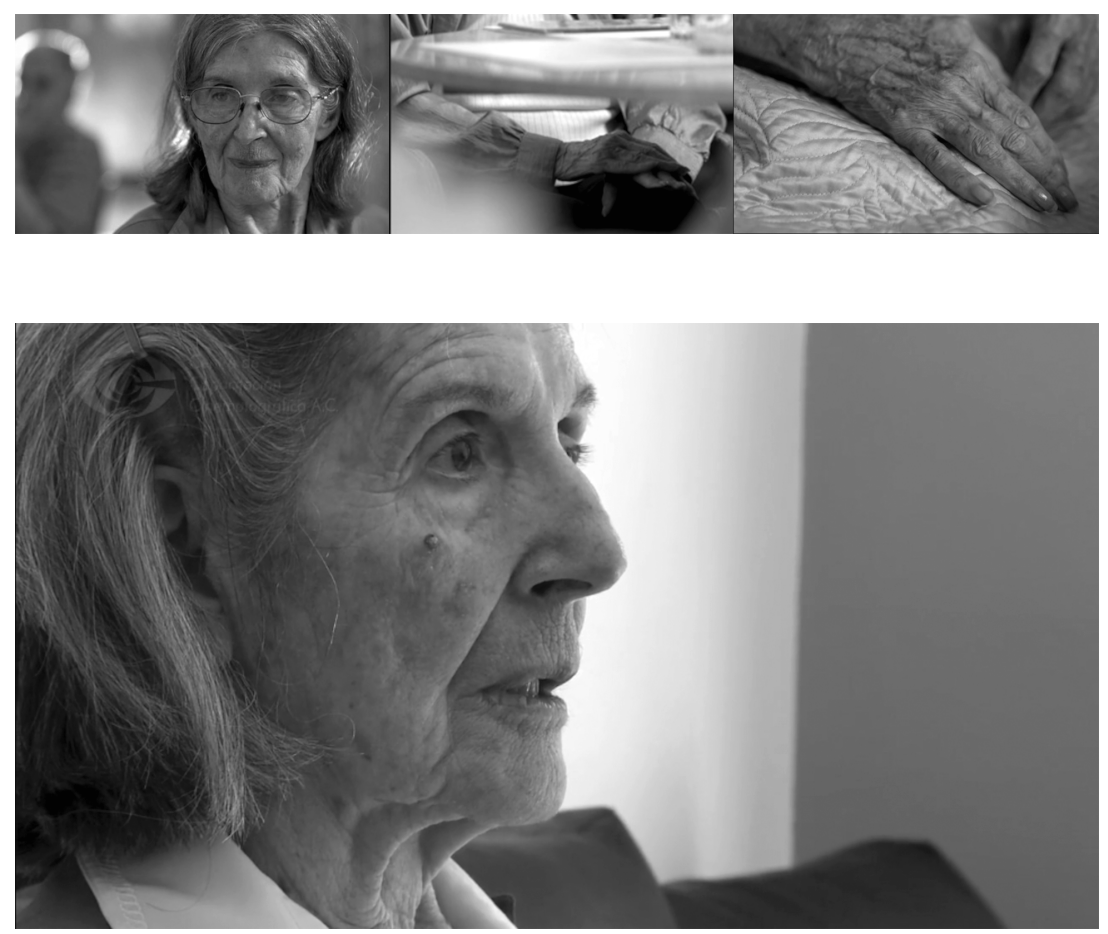

Figures 5.1 and 5.2 Tiempo suspendido. Natalia Bruschtein (dir.).

family members, the conversations with her granddaughter and, above all, the progression of her disease.

The sequence that shows for the first time both grandmother and granddaughter on screen together, sitting and looking at pictures, is composed of frames in which pictures occupy the full screen, close-up shots of Bonaparte and Bruschtein looking at photographs and talking about them, and medium shots that frame both women sitting at a table full of photographs. Each of these types of shots has a specific communicative function: photographs filling the screen allow the two women to talk about a past which no longer exists (Barthes) but also make viewers feel that they are looking at the picture as if they were part of the film; close-up shots that alternate photographs and the two people looking at them communicate at the level of emotions, immersing viewers into the action taking place and drawing them closer to both characters; and, finally, medium shots serve the purpose of pushing viewers back and out of the scene in order to emotionally distance them from what is about to happen. 
Bonaparte is constantly asked to name the people in the pictures shown to her. When Bonaparte tells her granddaughter that she does not remember their names, Bruschtein tells her the names of Bonaparte's children and discloses that three of them are dead. The revelation prompts Bonaparte to remember the death of her children, and her emotions are expressed through facial gestures that convey distress (see Figure 5.3).

Before analysing the viewer's position in this scene, it is important to offer the filmmaker's perspective on this specific moment, because she accepts that she too emotionally struggled with her grandmother's reaction:

She went through the same set of photos repeatedly. Whenever she got to that photo (which was an image that accompanied me all my childhood because I was at my grandmother's house and was with her through all the years of searching and struggling) sometimes she recognised them [her children] and sometimes she did not. The moment that remained in the film is a moment that for me was also very powerful, because at that moment I was not the director but the granddaughter feeling a lot of pain because she did not remember her own children, my father.

(Medina, "Interview with Natalia Bruschtein")

Despite Bruschtein's acknowledgement of her emotional involvement, the sequence does not show her reaction, only Bonaparte's. Leaving herself off-camera, Bruschtein stresses the split that the filmmaker makes on screen as filmmaker and granddaughter. Viewers are left to watch

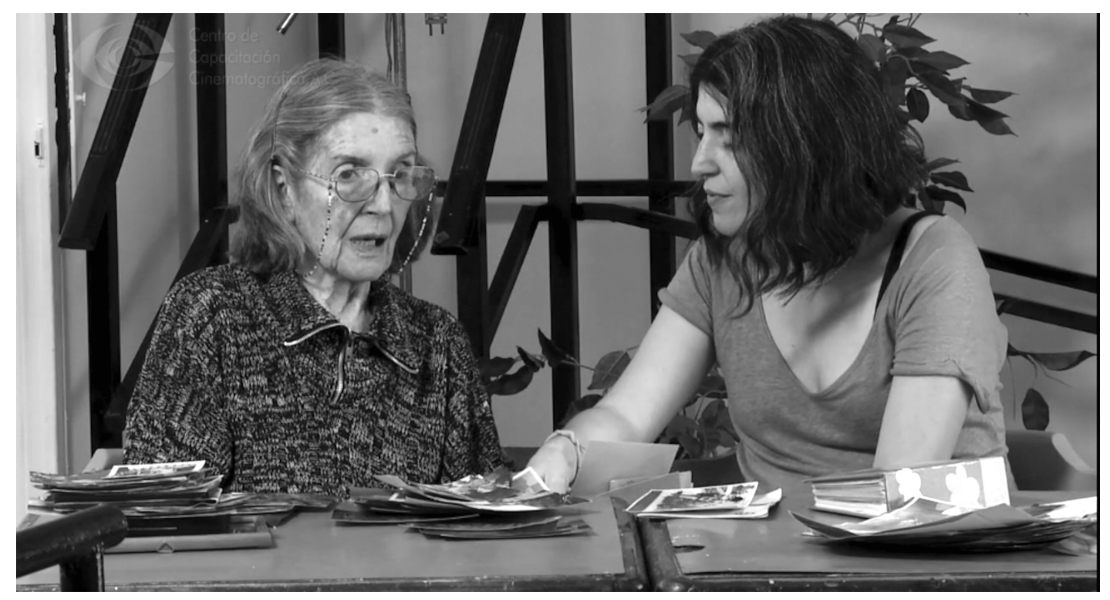

Figure 5.3 Tiempo suspendido. Natalia Bruschtein (dir.). 


\section{Raquel Medina}

Bonaparte's traumatic reaction through a medium shot placing them as witnesses who observe the moment when a traumatic event is recalled but where they cannot intervene (Sontag). Regardless of whether her consent was obtained or whether the filmmaker's motivation was disclosed, Bonaparte is pressed to involuntarily re-experience a traumatic event. In consequence, the subject (private Bonaparte) is transformed into the object of knowledge for both the filmmaker and the viewer: the public figure of Bonaparte as a well-known activist and, now, a person forgetting the past. The emphasis on this transformation may help to erase any traces of the emotional identification that Bonaparte's reaction may have initially triggered in the viewer.

Bruschtein's familial bond with her grandmother created the intimacy and familiarity necessary to facilitate filming with a person with dementia, as did Bonaparte's previous experience in front of the camera: "My grandmother never had problems with being in front of the camera; she was interviewed many times since the disappearance of her children.... So, she was not uncomfortable with our presence, on the contrary. Shooting with her was simple; we respected her times and moments" (Medina, "Interview with Natalia Bruschtein"). Although the filmmaker's words emphasise the duality of Bonaparte as both a public figure and a private citizen, it is Bonaparte's role as a public figure that takes centre stage, thus displacing/hiding Bonaparte's private self until the moment she no longer remembers her public past.

These recurrent encounters between Bonaparte and the filmmaker generate in the viewers a series of emotions and feelings that can range from pity and sadness to annoyance and shock at the filmmaker's insistent pressure to make Bonaparte remember a traumatic event. Karen Gerders elaborates on the differences between pity - condescendingly feeling sorry for someone; pitying someone in care settings might result in infantilising or shaming - and empathy - an initial unconscious and automatic affective reaction of the observer to another's emotional state, a reaction which may lead to a compassionate action. The encounters between Bonaparte and Bruschtein can certainly induce emotions and feelings that generate empathy towards Bonaparte in viewers, especially when they feel the suffering of private Bonaparte triggered by remembering the death of her loved ones. However, even if it was never the filmmaker's intention, the film also reinforces Bonaparte's physical and cognitive impairment as decline and therefore tends to evoke an emotion that may be closer to pity than to empathy. As a result, viewers cannot take any compassionate action; they can only remain mere witnesses of her suffering and therefore keep themselves emotionally distanced after an initial affective and empathic reaction.

The duality of Bonaparte's identity as a public figure and a private citizen in the film also affects the viewer's relation to her on screen. The dominance of her public figure throughout the film ${ }^{4}$ relegates the private 
citizen Laura Bonaparte to the background for most of it, thus presenting her as the object of a historical narrative or even as a historical figure. This dominance is reversed when her dementia rapidly progresses near the end of the film, with more scenes of Bonaparte's life at the nursing home shown on screen. Her initial humorous interactions with nurses have evolved into anger issues and a refusal to be fed or washed, all symptoms of dementia. This focus on the symptoms and deficits of the private Bonaparte is visualised through close-ups that concentrate on her wrinkled and thin hands and her unwashed hair; a focus that strengthens the "before/now" binary and may produce in the viewer the emotion of fear about the effects of dementia. These images create a great contrast with those documents shown early on that aim to provoke admiration for the public figure and, by contrast, lead viewers to feel pity for today's Laura Bonaparte. The viewer is constantly presented with TV segments and public speeches by an articulate Bonaparte that highlight the contrast with the forgetful and frail Bonaparte of the present, thus accentuating the decline narrative and the objectification of Bonaparte. The viewers may care about Laura Bonaparte's suffering in the past (the loss of her loved ones) and may care about her present frailty but cannot identify with her in ways that are meaningful for their own real-life experiences of care.

\section{El Señor Liberto y los pequeños placeres}

An opposite viewing experience and mode of representation are offered by Ana Serret in El Señor Liberto. Here Serret introduces what it means to live with Alzheimer's disease by highlighting the subjectivity and identity of the person living with the disease, as well as the possibility of affective communication through non-verbal language. In the same way, and by underscoring the artistic form and its means of production, the film suggests that aesthetic expression can reflect the experience of living with Alzheimer's.

The film documents the present of Liberto Serret, a retired engineer, widower and father of two daughters, who is in the final stages of Alzheimer's disease. He is not able to speak or walk and only moves his hands when music is played or in other limited circumstances. His daughter Ana, a filmmaker, moved with her two boys and her husband to Liberto's house after he was diagnosed and hired a Paraguayan carer, Luz, a year later. The documentary shows how the small pleasures Liberto had in the past have remained in the present: he loved and loves classical music, photography, reading, drawing, kissing, coffee and cakes.

In an interview, Serret acknowledges that she did not ask for Liberto's consent because at the beginning of the shooting sessions she had not planned to produce a film but just to create a testimony about the special relationship between Luz and her father (Medina, "Interview with Ana 


\section{Raquel Medina}

Serret"). That is, Serret's initial idea was to record the reciprocal caring relationship between the caregiver and the person cared for and to keep these recordings unpublished. In addition, Serret comments that the close relationship she had with her father had allowed them to maintain important conversations about moving to live with him and his opposition to being placed in a nursing home as he got older. She also relates that her father supported her artistic career and was always very keen on visual artistic expressions, as his home-made movies prove. Nevertheless, consent was not requested at any point, thus raising the issue of Liberto's vulnerability to the gaze of his filmmaker daughter and to the viewers of the film. However, it can be argued, as the analysis that follows aims to show, that all the tools of the film production, such as camera, editing, light and sound, are employed to highlight Liberto's ability to communicate and to support his ongoing personhood despite his cognitive impairment.

Dementia studies underlines the need to overcome the Cartesian duality and, in order to do so, some scholars employ Maurice Merleau-Ponty's philosophy of corporeality and of the lived body. For Merleau-Ponty, there is a relationship between the body and the outside world, and therefore sensory experience and thought are entwined: thought is the product of the interaction between the body and the world it inhabits. Therefore, the sensory perception of the body, according to him, allows us to communicate with the Other. Eric Matthews indicates that aspects of identity are sedimented in the body's habits and consequently persist even in the presence of severe cognitive impairment. Also drawing on Bourdieu's habitus, Pia Kontos and Wendy Martin consider the body as a place where discourse is inscribed and where subjectivity is constituted (290). They underline how gesture communicates more than verbal expression because it reveals the social and cultural movements that have developed into habits. Gestures are derived from the interiorisation of the sociocultural environment and thus define the subject's identity. Dressing, movements of the different parts of the body, the way of sitting down, for instance, are all features derived from socialisation. Consequently, individuality or identity can be found in these gestures, meaning that memory in the body, identity and social relations are interconnected. Moreover, all the elements attached to the body, such as clothing, makeup and food preferences, should be considered to constitute a type of communication that takes place through the body.

In El Señor Liberto, the subjective experience of the person with dementia shows the centrality that the body and its gestural communication acquire. The director's unequivocal intention is to place the experience and identity of the person with dementia at the centre of the film. Liberto's perspective is offered to the viewers through a narrative organised using a subjective camera, editing and diegetic sound. The narrative is articulated through long sequences captured by a fixed camera that 
on multiple occasions offers viewers extreme close-up shots of bodies or body parts that are in movement. Additionally, these sequences alternate with fragments of $8 \mathrm{~mm}$ home movies, photographs, and objects that are accompanied by a diegetic sound that captures the daily life of Liberto's family: conversations, ordinary noises, and music. By using all these elements, communication is threaded through the senses to stress the normalcy of the life with dementia that is observed on screen. In other words, Liberto is part of a whole that does not isolate him, that does not point him out as different or abject but that incorporates him into the daily life of the family. The supposed deficits and symptoms are indistinct and perceived within the parameters of normalcy through the embodiment of communication.

Sight, which is central to cinematographic representation, is also central to this film as a medium that expresses, both in form and on a semantic level, Liberto's identity and subjectivity. In this sense, the camera itself has a structural role, as Serret states:

I wanted to film from the perspective of my father, not to film my father. I wanted to keep his personality over the disease. That is why it is filmed using backlighting. I did not want to show his face for several reasons: to maintain his dignity and not focus on the deterioration but on the person himself. That is why we do not see him when Luz bathes him or walks [him] down the corridor. We always see him against a window. It was his place at the table, but I placed the camera to encourage backlighting. If he was communicating with his hands now, why shoot his face? It did not make sense. I just wanted to get inside his head and film from there.

(Medina, "Interview with Ana Serret")

To convey the perspective of her father, Serret uses a fixed camera that never moves, which allows the filmmaker firstly to document the family's daily routine and secondly to make the camera the eyes of the viewer by creating the illusion that the viewer is part of the film as another member of the family, sharing every moment of their daily life. Finally, the camera recreates Liberto's subjectivity by focussing on still and moving images from the $8 \mathrm{~mm}$ home movies that replace his memories about past events. Through the fixed lens, the viewers can perceive what is happening as if they were in a still body like Liberto's and are placed within Liberto's subjectivity, enabling them to think, feel and see as Liberto does.

The first sequences of the film already reveal Serret's intention to offer a visualisation of Liberto's subjectivity. On a black screen, Liberto's origins are written down: date and place of birth, his name and the opposition of the priest to that name (the name means "freedman"). This is followed by a home movie in which Liberto, now a mature man, is seen being filmed by his wife, to whom he talks. The transition between these two 


\section{Raquel Medina}

sequences is made by a jump cut to a black screen that lasts for some seconds. After the title, there is a shot of a window through which the branches of a weeping willow can be seen. This shot lasts 37 seconds, and the background sound is of someone walking around and then moving a chair; finally, the silhouette of a woman's head appears, who while sitting says "let's eat." Another jump cut leads to a close-up of a hand holding a spoon, a bowl, a mortar, a glass and a water jug. This woman's hand is feeding someone, of whom all we see is a napkin on his chest. The 46-second shot lacks sound and the light outside contrasts with the darkness inside the house. With another jump cut, the film moves to a group shot in which we see a dining room with a window in the background and two figures: the figure of an old man with white hair just in front of the window and a woman sitting next to him. The woman stands up, and the old man is left alone in the dining room. The backlight prevents us from seeing the face of this almost motionless man, whose only visible feature is his white hair. The sound in the background is a running tap, while the woman returns to the dining room and talks to another man. The shot lasts 42 seconds. Another jump cut leads to an extreme close up of a mortar in which the woman seems to be crushing medication; similarly, in this shot, we see the woman's hands and the white-haired man's hand on the table. The shot ends after 18 seconds, with a jump cut to a black screen on which the following text is written: " 7 years ago my father was diagnosed with Alzheimer's. He could no longer live alone, so my family and I went to live with him. A year later, we hired Luz to take care of him." With this text, the film has introduced its topic and main purpose: making the viewer perceive and share Liberto's subjectivity and the care he receives from all members of the household.

Liberto's subjectivity is also recreated through the repetition of the structure of long sequences of both present filmed images and past home movies. But as the documentary progresses, the $8 \mathrm{~mm}$ images, somewhat spoiled by the passage of time, take up more time in the film, thus making it increasingly evident that we are witnessing a recreation of Liberto's memories. The moments of confusion in Liberto's mind are also recreated through the superimposition of images. Barbara Zecchi argues that the materiality of film can be employed to blur the boundaries between one's past and present: memories that belong to one's past are evoked and incorporated through grainy texture, blurred images and extreme closeups. This is exactly what Serret does to present Liberto's memory: she uses old home movies and pictures to visually recreate Liberto's memories. Just like Liberto's memories, films and pictures also age with time, thus experiencing discolouration and acquiring a grainy texture.

Another two techniques that stand out to emphasise the permanence of Liberto's self are the constant link made between elements of the present and those of the past and the continuity of common aspects through the different generations of the family. These common aspects have an impact 
on the durability of experiences and emotions, which survive in interpersonal relationships and facilitate reciprocity. Drawing, reading, playing and listening to music, kissing and caressing are all activities shared at some point in life by all members of the household. As the home movies show, Liberto was a great drawer and sculptor and an avid reader, pleasures that are enjoyed by both his children and grandchildren. In fact, all are bodily actions filled with emotions that have passed from generation to generation thus validating that habitus remains in the body - hearing, touch, taste and smell - even when cognitive impairment is present.

The little pleasures of Liberto - eating cakes, drinking coffee (see Figure 5.4), listening to music and, above all, talking with his hands - are all linked to the four senses, which seem to remain intact despite the progression of the disease. He actively responds to music (hearing), caressing and kissing (touch) and to eating cake and drinking coffee (taste and smell). The diegetic sound of the film offers the spectator the possibility of perceiving sounds in the same way as any of the other inhabitants of that house and, especially, in the way that Liberto does. His pleasure in music is central to the affective communication depicted. His body's unconscious reaction to classical music is revealed through his bodily reactions, such as his ability to keep the rhythm with his hands or the caressing of his daughter's arm. The sense of smell is evoked in the documentary through the home movies and images such as those of flowers, mountains, the sea or coffee. Memories, then, remain and are experienced in the present by and in the body through the "memory of the senses" (Marks): sight, hearing, taste, smell and touch all play key roles in the film.

The senses are the vehicles that help to produce ethical responses to the person living with dementia in the viewer. They do so through the nonconscious and pre-personal quality of affect, as the filmmaker herself states

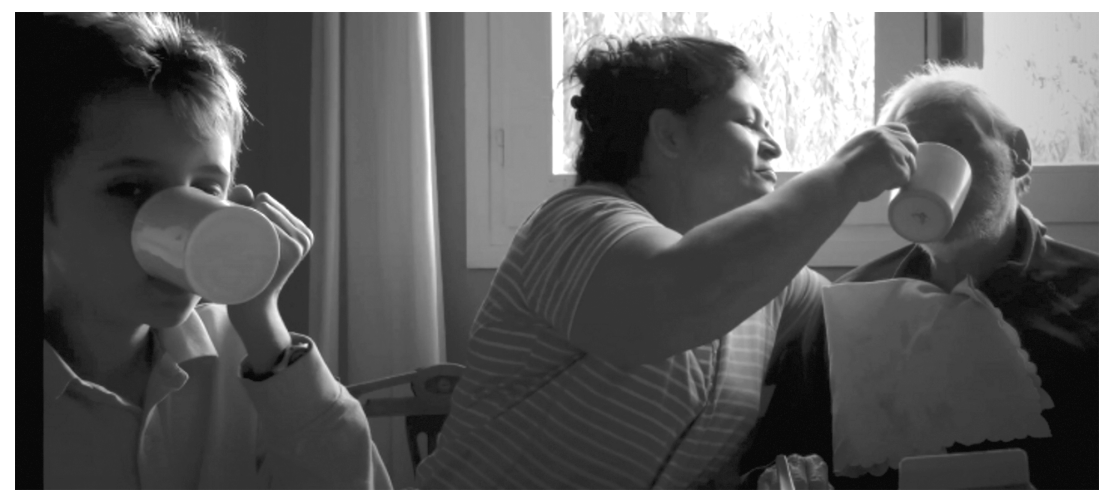

Figure 5.4 El señor Liberto y los pequeños placeres. Ana Serret (dir.). 


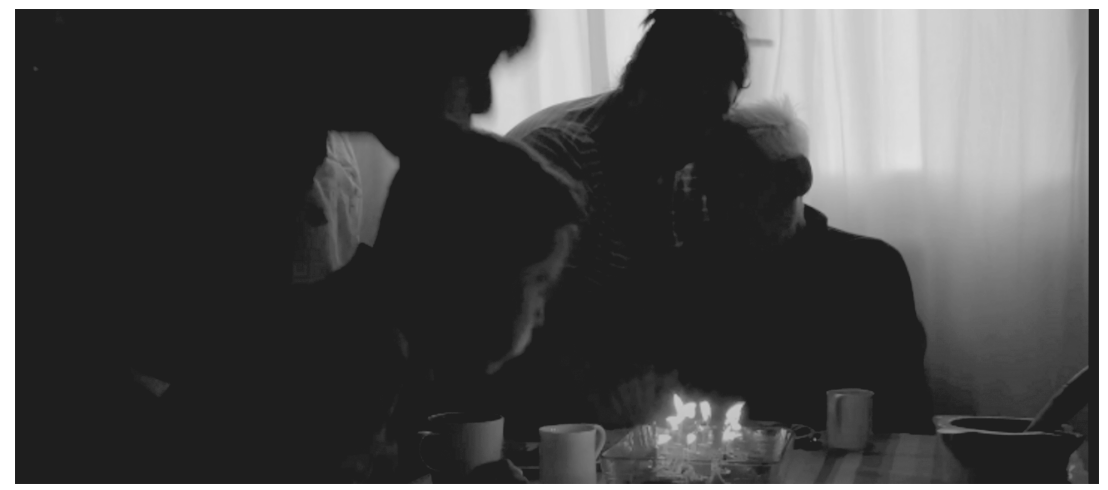

Figure 5.5 El señor Liberto y los pequeños placeres. Ana Serret (dir.).

(Serret). The camera leads the viewer to share and experience the same affects by creating "affective atmospheres" (Brennan) that generate understanding and empathy. Therefore, viewers cannot care for Liberto, but the film can make them feel as if they were part of the caring process. In these affective atmospheres, binaries such as able/disabled, body/mind and self/other are removed and replaced by sameness and continuity (see Figure 5.5).

Generating empathy in this way, the filmmaker practises an ethics of care, cutting across the limits of the film as an object to communicate with the viewer. Serret's film seems to reverse the socially and culturally constructed negative emotional reactions and feelings about people with dementia by making the viewer experience the subjectivity of the person. As viewers, we hear, see, touch, smell and taste with and through Liberto, and we perceive his nonconscious reactions. Because these types of affects are shown, emotions and feelings of empathetic caring about and for Liberto take centre stage, and the distance between the object (the film) and the subject (the viewer) seems reduced. The viewer gazes at Liberto and gazes at the world through Liberto, which ultimately draws the viewer closer to Liberto and his experience. Moreover, the viewer is made part of the household, sharing with other members their daily routine of caring for and about him. This transforms the public feature of the film into a private experience in which encounters between Liberto and the viewers are enabled, and dignified practices of care are supported.

Caring practices take place in this film within Liberto's home. Luz, the hired caregiver, becomes not only part of the family but also the most important pillar in the care Liberto receives. As Serret explains in the interview, Luz and Liberto became one, a unity that was based on trust:

He had never wanted a woman to take care of him, out of embarrassment. But Luz treated him with a lot of respect and dearly cared 
about him due to the trust gained in sharing with him her life and talking to him.... So, when my father, after some few years, little by little stopped talking, the two of them knew each other very well. My father felt safe with her and did everything she asked.

(Medina, "Interview with Ana Serret")

The sense of feeling safe clearly underlines two important issues: first, Liberto's acknowledgment and acceptance of his vulnerability and reliance on another person; and second, that feeling safe is strongly linked to trust. Dunn and Schweitzer define trust as "the willingness to accept vulnerability based upon positive expectations about another's behavior" (736). Furthermore, in the case of Liberto, the vulnerability of the person living with dementia is managed by the caring relationship adopted by Luz. Even when Liberto's cognition has deteriorated, Luz continues to communicate with Liberto by treating him as she did before in terms of identity and care. She talks to him in the same way as when he was still able to verbally respond to her. Luz anticipates Liberto's possible reactions and communicates with him through his little pleasures. As the film proves, care based on trust is not only assisting with the physical care of the person but also providing affective and emotional care, which highlights the importance of maintaining the identity and selfhood of the person living with dementia. Affective and emotional care needs to be linked to empathy: the emotion caused by the understanding of the suffering of another person. Therefore, empathy replaces pity and leaves the carer and the person cared for at the same level in the recognition of their own and mutual vulnerability.

\section{Conclusion}

Despite the fact that both films are characterised by a familial relationship between the film directors and the main protagonists, the comparison between these two documentary films has shown two different, almost antithetical, ways of presenting people with dementia in front of the camera. The comparative analysis of both films has shown that the harm to subjects that the filmic interaction can cause can be mitigated by the role assigned to the person living with dementia in front of the camera and the concept of care presented. Tiempo suspendido focusses on the dual nature of Laura Bonaparte as a private citizen and as a public figure and by doing so it patently emphasises the role of the public figure and relegates the private one to the otherness that ageing and dementia entail. It can be argued that Tiempo suspendido is rooted in the Cartesian notion of the mind/body: once cognition is impaired, identity is gone, and only the body remains. In contrast, El Señor Liberto shows that Liberto's identity has remained intact by focussing on his subjectivity and his lived experience instead of deficits. 
These opposite approaches to the object/subject of knowledge have an overarching effect in terms of the ethics of representation and the ethics of care. Each film presents a different concept of care ethics: while Tiempo suspendido focusses on the paradoxical quality of memory and its meaning within the political context of Argentina, El Señor Liberto documents embodied memory and how the individual is part of different networks of relationships (Koggel) that define both them and their counterparts. Regardless of memory loss, Serret's film tells us that the memory of the senses is what we all share, and therefore we can communicate through them when language is gone. By showing on screen how a person living with dementia is cared for, both films foreground key aspects of the experiences of dementia and care. For instance, in Tiempo suspendido, Laura's physical and mental deterioration becomes central, and it is stressed as the film progresses by increasingly introducing scenes where her daily routine at the nursing home is shown. In Serret's film, three generations of the same family live together and, although they hire a caregiver to carry out daily care for Liberto, they all participate in the same activities and daily routines that incorporate the person living with dementia. It could be said that Liberto is placed at the same level as any other family member, therefore simultaneously receiving care and being cared about.

Finally, the role that the camera plays and where it positions the viewer are essential for the ultimate understanding of the meaning of dementia at both individual and social levels and consequently can have a crucial part in shaping the social understanding of what living with dementia involves. Tiempo suspendido maintains the distance between the cinematographic object (those on film) and the viewers, who witness the harmful moment in which Bonaparte is pushed to remember the death of her children. Despite the possibility of initially generating a very brief and momentarily empathic response, the objective gaze does not allow any further affective engagement with the person living with dementia, beyond pity. From this point onwards, the viewers gazing at Bonaparte are likely to experience emotions of fear and feelings of disgust as a consequence of the film's emphasis on Bonaparte's decline. In contrast, El Señor Liberto deploys a cinematic language based on haptic visuality or visuality of the senses. Through this hapticity, the subjective camera allows the viewer to experience what Liberto feels, thus facilitating understanding and communication. This communication leads to a practice of care that could be considered reciprocal and interpersonal and goes beyond the filmic object per se, because the viewer becomes a participant in the network of relationships of which Liberto is part. In this film, Serret employs an original cinematic language to empathically connect with the person living with dementia through emotions and affects and to present embodied memories that are shared and lived with the viewer. This way, the notion that one affects others, one is affected 
by others and we feel with others becomes in this film the pillar of its ethics of care.

\section{Notes}

1. Small parts of the chapter have been adapted from two published articles: Medina (2020) and Medina (in press).

2. "Affective turn" scholars either do not differentiate between affect, emotions and feelings (Ahmed; Brennan; Ngai) or consider affect as pre-personal, nonconscious and autonomous from emotions (Massumi, Parables, Politics; Ross).

3. See Susan M. Behuniak; Hannah Zeilig; Aagje Swinnen and Mark Schweda.

4. The past of the public figure of Bonaparte is reconstructed through photographs, speeches, newspaper articles, interviews, TV programs and so on. The private past of Bonaparte is reconstructed through the questions asked of her and personal photographs. The documents pertaining to Bonaparte's public persona are all available at Argentina's National Library Archives; consequently, none of the questions she is asked aim to uncover an unknown truth since all facts are already known.

\section{Works Cited}

Ahmed, Sara. The Cultural Politics of Emotion. Edinburgh UP, 2004.

Behuniak, Susan M. "The Living Dead? The Construction of People with Alzheimer's Disease as Zombies." Ageing and Society, vol. 31, no. 1, 2011, pp. 70-92.

Braidotti, Rosi. Nomadic Subjects: Embodiment and Sexual Difference in Contemporary Feminist Theory. Columbia UP, 2011.

Brennan, Teresa. The Transmission of Affect. Cornel UP, 2004.

Buchart, Garnet C. "On Ethics and Documentary: A Real and Actual Truth." Communication Theory, vol. 16, no. 4, 2006, pp. 427-52.

Butler, Judith. "Torture and the Ethics of Photography." Environment and Planning D: Society and Space, vol. 25, no. 6, 2007, pp. 951-66.

Couser, G. Thomas. Vulnerable Subjects: Ethics and Life Writing. Cornell UP, 2004.

DeFalco, Amelia. Imagining Care: Responsibility, Dependency, and Canadian Literature. U of Toronto P, 2016.

Dubois, Philippe. "Photography Mise-En-Film. Autobiographical (Hi)stories and Psychic Apparatuses." Fugitive Images. From Photography to Video. Edited by Patrice Petro. Indiana UP, 1995, pp. 152-72.

Dunn, Jennifer R., and Maurice E. Schweitzer. "Feeling and Believing: The Influence of Emotion on Trust." Journal of Personality and Social Psychology, vol. 88, no. 5, 2005, pp. 736-48.

Gilligan, Carol. In a Different Voice. Harvard UP, 1982.

Gorton, Kristyn. "Theorizing Emotion and Affect: Feminist Engagements." Feminist Theory, vol. 8, no. 3, 2007, pp. 333-48.

Katz, John Stuart, and Judith Katz. "Ethics and the Perception of Ethics in Autobiographical Film." Image Ethics: The Moral Rights of Subjects in Photographs, Film, and Television. Edited by Larry Gross et al. Oxford UP, 1988, pp. 119-30.

Koggel, Christine M. Perspectives on Equality: Constructing a Relational Theory. Rowman \& Littlefield, 1998. 


\section{Raquel Medina}

Kontos, Pia, and Wendy Martin. "Embodiment and Dementia: Exploring Critical Narratives of Selfhood, Surveillance, and Dementia Care.” Dementia, vol. 12, no. 3, 2013, pp. 288-302.

Landsberg, Alison. Prosthetic Memory: The Transformation of American Remembrance in the Age of Mass Culture. Columbia UP, 2004.

Marks, Laura. The Skin of the Film: Intercultural Cinema, Embodiment, and the Senses. Duke UP, 2000.

Massumi, Brian. Parables for the Virtual: Movement, Affect, Sensation. Duke UP, 2002.

- Politics of Affect. Polity Press, 2015.

Matthews, Eric. "Dementia and the Identity of the Person." Dementia: Mind, Meaning and the Person. Edited by Julian C. Hughes et al. Oxford UP, 2006, pp. 163-77.

Medina, Raquel. Cinematographic Representations of Alzheimer's Disease. Palgrave Macmillan, 2018.

—. "Interview with Natalia Bruschtein." Gynocine Project, 2019, www. gynocine.com/interview-natalia-bruschtein.

. "El poder de los sentidos en El señor Liberto y los pequeños placeres de Ana Serret (2017): representaciones de la subjetividad e identidad en las personas con alzhéimer," Bulletin of Contemporary Hispanic Studies, vol. 2, no. 1, 2020, pp. 51-68.

—. "Interview with Ana Serret." Unpublished, 2020.

and Barbara Zecchi. "Technologies of Age: The Intersection of Feminist

Film Theory and Aging Studies." Revista de Investigaciones Feministas, vol. 11, no. 2, 2020, pp. 251-62.

Merleau-Ponty, Maurice. Phenomenology of Perception. Translated by Colin Smith. Routledge and Kegan Paul, 1962.

Ngai, Sianne. Ugly Feelings. Harvard UP, 2007.

Nichols, Bill. Introduction to Documentary. Indiana UP, 2001.

Noddings, Nel. Caring: A Feminine Approach to Ethics. U of California P, 1984.

Ross, Andrew A. G. "Coming in From the Cold: Constructivism and Emotions." European Journal of International Relations, vol. 12, no. 2, 2006, pp. 197-222.

Serret, Ana. "El señor Liberto y los pequeños placeres, 'Notas de la directora'." elsenorlibertoylospequenosplaceres.wordpress.com/notas-de-la-directora/. Accessed 2 Apr. 2020.

Sontag, Susan. Regarding the Pain of Others. Picador, 2003.

Swinnen, Aagje, and Mark Schweda, editors. Popularizing Dementia: Public Expressions and Representations of Forgetfulness. Transcript, 2015.

Vanacker, Bastiaan, and John Breslin. "Ethics of Care: More Than Just Another Tool to Bash the Media?" Journal of Mass Media Ethics, vol. 21. no. 2-3, 2006, pp. 196-214.

Zecchi, Barbara. "Gendered Aging and Sexuality in Audiovisual Culture." Encyclopedia of Gerontology and Population Aging. Edited by Danan Gu and Matthew E. Dupre. Springer, 2019, https://doi.org/10.1007/978-3-319-69892.

Zeilig, Hannah. "Dementia as a Cultural Metaphor." The Gerontologist, vol. 54, no. 2, 2014, pp. 258-67. 


\section{Filmography}

El señor Liberto y los pequeños placeres. Directed by Ana Serret. Rojo Films, 2018.

Tiempo suspendido. Directed by Natalia Bruschtein. Centro de Capacitación Cinematográfica, 2015. 


\section{Re-orientating Hesitantly}

\section{Approaching the Entangled Temporalities of Cinema, Dementia, and Hong Kong From a Decolonial Viewpoint}

\section{MaoHui Deng}

I open with a scene from Ann Hui's Summer Snow (1995, Hong Kong) that captures, in broad strokes, the overarching argument that this chapter puts forward. It is late at night. The Sun family is asleep, and the sound of a clock ticking permeates the whole household. Suddenly, from outside the house, the elderly Lin Sun begins to shout specific clock positions of enemies to his squadron in Mandarin so that they can pilot and shoot the planes down. His daughter-in-law, May, wakes up and finds him on the communal roof with a broken umbrella as a side stick. She rushes towards him and attempts, in Cantonese, to coax him back into the house. As May reaches him, their angry neighbours start throwing trash at them, and Lin Sun, seeing the flying rubbish, announces in Cantonese that the enemy is attacking them. He gets up, drags May, and runs off in the opposite direction to seek shelter. As they run, May points out to Lin Sun that the house is the other way before changing her claim, saying that they need to go to the bomb shelter to hide. Upon hearing her suggestion, Lin Sun agrees, and they both head inside the house.

Here, as Lee Carruthers might argue, the cinematic timeliness of the scene is heightened. For Carruthers, cinema's timeliness "encompasses our encounters with filmic ambiguity, as we read and respond to shifting temporal cues, and it retains the immersive appeal of cinematic time as we acknowledge our ongoing investment in it, as viewers" (16). This moment, like the rest of the film, is shot with Hui's typical social realist style. It is captured through a series of mid- and wide-angle shots by the observing camera, and it unfolds linearly through its editing pattern. Yet, despite the "real time" of the "now" that the scene seems to be rooted in, the succession of events appears to be far from temporally fixed or linear. First, the audience is encouraged to question the assumed function of clock time, as the ticking of the clock in the diegesis is punctured by Lin Sun shouting clock positions, imbuing the clock with a locational function. Second, though he is seated on the communal rooftop piloting an umbrella side stick, Lin Sun appears to be in a plane during the Second World War gunning down the enemy. Third, despite speaking in 
Mandarin while flying his plane, he switches to Cantonese when speaking to his daughter-in-law, even though he continues to insist that he is being attacked by the Japanese. ${ }^{1}$ And, fourth, in trying to get her fatherin-law back into the house, May switches between asking him to go back into the house and asking him to run into the bomb shelter to shield themselves from the incoming rubbish attack.

In paying attention to the minutiae of the film's narrative and form - as I do throughout this chapter - the seemingly straightforward temporal position in the scene becomes significantly more complex and hesitant. This scene, characteristic of Summer Snow and cinema about dementia in general, foregrounds the temporal mediation between the film and the audience, as the audience is invited to constantly (re-)assess and (re-) accept the temporalities that are embedded in the unfolding structure of the film. Through the timeliness of Summer Snow, the audience, like the characters in the film, is invited to continuously and hesitantly locate themselves temporally and positionally on multiple planes. In highlighting the constant temporal negotiations and refusing to pin any character or the audience members into a fixed temporal regime, films about dementia, I argue, offer and encourage a decolonial worldview that allows us to live with dementia without evaluating one's life course only in relation to the homogeneity of clock time, which, as I explain below, is a form of time that is associated with the project of colonial modernity. ${ }^{2}$

Such an argument is underpinned and furthered by the socio-politics of pre-handover Hong Kong, in which Summer Snow is contextually situated. Released in 1995, Hui's film was produced in a period of deep crisis and change, as Hong Kong cinema (and culture in general) re-examined its relationship with the colonial in all its manifestations. Hong Kong became a British Crown colony in 1842, at the end of the First Opium War, when the Qing Empire ceded Hong Kong Island, and the colony expanded to include the Kowloon Peninsula in 1860 at the end of the Second Opium War. In 1898, Britain signed the Convention for the Extension of Hong Kong, which allowed it to lease the New Territories of Hong Kong from China for 99 years, to expire in 1997. In 1984, mainland China and the UK signed the Sino-British Joint Declaration, and this set in motion the handover of the entirety of Hong Kong to China in 1997. The discussion of the handover occurred mainly at the top levels of governance, and this left the people living in Hong Kong with little agency and voice, consequently engendering a lot of anxiety and (re)consideration of what "Hong Kong-ness" might be or mean.

Set in a period contemporary to 1995 , where this rapid (de-/re-)colonial change is taking place, Summer Snow follows Lin Sun, the patriarch of an "everyday" Hong Kong family who lives with dementia, as he forges a new relationship with his family. Throughout the film, the characterisation of Lin Sun is typical of cinema about dementia: he regularly insists that he is still piloting airplanes in World War Two, shooting 
Japanese invaders down; he constantly wanders the streets of Hong Kong by himself; and he continues to rely heavily on the care of his daughter-inlaw, May, whom he rarely fails to acknowledge. Yet, despite the constant temporal and spatial disorientation that Lin Sun faces, the people around him never really renounce him for his out-of-place-ness and out-of-timeness but, rather, re-orientate themselves in relation to his worldview and changing sense of identification.

Focussing on the caring and interpersonal interactions between the person living with dementia and the person not living with dementia as encompassed by the social realist aesthetics and politics in Hui's film, I propose that Summer Snow, as a film about dementia, emblematically offers and invites a decolonial and hesitant encounter that in turn encourages a sense of re-orientation in the viewer. ${ }^{3}$ Drawing from Alia Al-Saji's understanding of hesitation as that which "suspends, for a brief interval, habits that constitute the normativity of the everyday" ("SPEP" 347), the chapter argues that to hesitate is to unfurl time and to allow for the simultaneous occupation of multiple temporal positions; to hesitate is to take into account an understanding of the interactions between people living with dementia and people not living with dementia as temporally relational; and to live relationally with dementia is to choose the option of living a decolonial way of life.

\section{Hesitation and Entangled Temporalities}

This atmosphere of uncertainty that permeates the film can be understood as an acknowledgement of a kind of temporal excess that explodes many of the strict boundaries set up by homogeneous, clock time. In such a way, in being hesitantly made mindful of the different temporalities in negotiation, the potential for a more relational kind of orientation is offered. To develop and add nuance to my suggestion, I turn to Alia AlSaji's philosophy of hesitation. She writes:

to hesitate is to delay and to make affect wait. The incompleteness, both of affect and of that to which affect responds, is here felt. To wait is to testify that time makes a difference for experience, that all is not given in the present. To open to a futurity that escapes prediction, but also to a past that can be dynamically transformed through the passage of events, and that grounds the creative potential of events.

(“A Phenomenology” 148)

Al-Saji's argument is complex and is predicated on a nuancing of the Bergsonian philosophy of time, which I will elaborate upon here. According to Al-Saji, to hesitate is to pause, and this in turn "suspends, for a brief interval, habits that constitute the normativity of the everyday" ("SPEP" 347). 
Habits, as understood by Bergson, are intimately tied to the sensory motor, as the body repeats the same effort over and over again. For Bergson, in a habitual act where, for instance, a body is orientated to expect that the clock will go "tock" after the "tick," the only shreds of the past that remain are "the intelligently coordinated movements which represent the accumulated efforts of the past" (Matter and Memory 93). This is to say, the past is contracted - flattened, in various iterations - in the present. The past is subsumed to the bodily and tied to movement, and it largely follows the body as it moves forward, linearly. The habitual, in other words, is tied up with the homogeneity of modern, clock time.

In momentarily pausing the bodily movement of time, Al-Saji posits, hesitation disorientates the body and opens up a space where "[u]seless memories, superfluous and aleatory remnants, steal in" ("SPEP" 347). Here, Al-Saji is referring to the ways in which the colonial project of modernity has closed off so many versions of living a life, consigned them to the past, and rendered them effectively useless (and not modern). As she writes, "useless memories are often witness to structuring conditions of nonlinear time" ("SPEP" 347; emphasis in original). When these useless shreds of the past re-enter the present through hesitation, the present is reconfigured and, simultaneously, the present's relationship with the past is also thickened. To hesitate, for Al-Saji, is thus to break "with the closure of the past and the predetermination of the future" ("A Phenomenology" 148). Put differently, to hesitate is to unfurl time and to open up the possibility of occupying multiple and different temporal (and spatial) planes.

We can see instances of such temporal hesitancy throughout Summer Snow. For example, just as May finally manages to get her father-in-law into bed after his earlier moment at the shared rooftop, Lin Sun sits up and attempts to leave the bed. May quickly announces that the enemy has retreated, and this proclamation stops him in his tracks. He nods at her - she nods back - and he lies back down. Suddenly, Lin Sun sits up one more time and points at what he believes to be two Japanese figures towards the off-screen. The film then cuts to a wide-angle shot of the bedroom: May and Lin Sun are in the foreground of the shot whilst Lin Sun's son and grandson are in the background looking concernedly at the situation. Lin Sun wants to kill the two Japanese soldiers while May insists that they are prisoners of war. She orders their execution, and the two men leave the room. This act satisfies Lin Sun, and he lies back down. As that happens, the film cuts to a two-shot, and this conversation ensues:

\section{MAY: Tomorrow I must}

LIN SUN: Fight again.

MAY: If not for you, I would have fought to the death with Isabelle

[a colleague she does not get along with].

LIN SUN: Sounds like a powerful foe. They shot a lot of our planes down.

Forget about me, get back out there. But be careful. 


\section{MaoHui Deng}

After he concludes the conversation, Lin Sun falls asleep. May, on the other hand, sits down and leans against the bedside drawer with a pensive look on her face (see Figure 6.1).

As observed by scholars like Hannah Zeilig and Janelle S. Taylor, the most common cultural fear that seems to be connoted by and associated with dementia is that a person living with dementia can no longer recognise you, and that their - and in turn your - futurity is thrust into an incomprehensible sphere of doom. Put differently, the cultural imagination of dementia is predicated on the fear of meaninglessness, as the sense of the self (embodied or not) is threatened. Yet, despite such a suggestion, something very different seems to happen in this moment from Summer Snow. Although Lin Sun's (mis)recognition of his son and grandson as Japanese soldiers/prisoners of war might feed into this sense of unknowable doom, no one in the room appears to articulate this fear or sadness. Instead, there is a wry touch of humour associated with the whole situation, as May orders the execution of her husband and her son in front of Lin Sun. Upon hearing the instructions, May's son calls out to his father and they both leave the room, and in this scene, through listening to May's interaction with her father-in-law, both husband and son are simultaneously prisoners of war and not prisoners of war. The audience, like the characters around Lin Sun, is invited to consider the multiple temporalities in negotiation.

Here, this interaction might be seen as echoing the ideas put forward by Lawrence Cohen who, writing about dementia as registers of voice, proposes that we listen ironically. For Cohen, the "senile deformation of

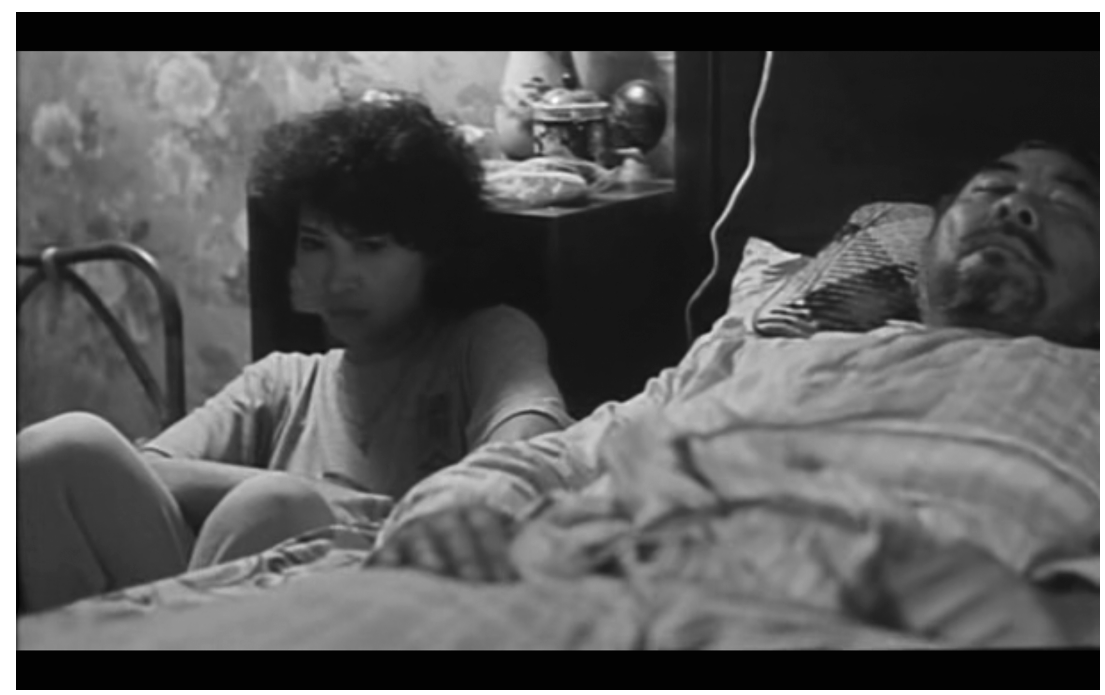

Figure 6.1 May and Lin Sun after their conversation. 
meaningful utterance is not necessarily a turn to meaninglessness" (125). Rather, dementia "does not so much turn the actual order of things inside out as trouble our desire for and identification with such an order" (125). According to Cohen, listening to people living with dementia is ironic because, within dementia, "words neither correspond to the expected referents of a shared history (that is, are coherent) nor are they necessarily radically beyond coherence" (127). In this sense, Cohen avers, dementia "heard ironically offers no redemptive or hidden speech, but neither does it of necessity reduce the voice" to that of nonsensical babble (127). Altogether, for Cohen, dementia heard ironically engenders a sense of "neither this nor that" and, consequently, challenges the hegemonic understanding of a certain idea without necessarily changing it.

In this respect, Cohen's argument finds affinity with my argument on hesitancy and films about dementia as characters regularly have to reassess their understanding of a particular idea or situation in order to accommodate the person living with dementia. However, I would suggest, this moment in Summer Snow goes one step further than Cohen's argument. Through this event, both son and grandson gain a deeper understanding of how to interact with Lin Sun, as they continue to be and not be for the remainder of the film. Similarly, the conversation between May and her father-in-law bears more elaboration. In this moment, Lin Sun appears to be talking about the Second World War and May about the workplace adversities that she is encountering. Despite the apparent cross-wiring between them, the conversation proves to be therapeutic for both because Lin Sun is finally able to fall asleep and May is able to process her feelings about her tense relationship with her colleague, Isabelle. Such an analysis is furthered by the cinematography and the use of music. As May lowers herself against the bedside drawer, the camera, following May, tilts down; this camera movement in turn reduces the empty space that was in the mise-en-scène before the start of the conversation, and both father- and daughter-in-law are framed more intimately. Likewise, as the camera moves, slow string music, in a minor key, enters the film score, adding to the scene's contemplative atmosphere.

Understood together, as encompassed by the film form, the multiple temporalities embedded in the scene become a way for the characters in the film to re-orientate hesitantly. For Sara Ahmed, the concept of orientation shapes "not only how we inhabit space, but how we apprehend this world of shared inhabitance, as well as 'who' or 'what' we direct our energy and attention toward" (3). Elaborating, Ahmed writes:

The work of inhabitance involves orientation devices; ways of extending bodies into spaces that create new folds, or new contours of what we could call livable or inhabitable space. If orientation is about making the strange familiar through the extension of bodies into space, then disorientation occurs when that extension fails. Or 
we could say that some spaces extend certain bodies and simply do not leave room for others.

Ahmed's thesis on orientation is an examination of the ways in which the body is phenomenologically disciplined by space, as the "body orientates itself by lining itself up with the direction of the space it inhabits" (13). To be in the Western world, for example, is not to be in the Global South, and to be straight is to experience a linear route of (reproductive) futurity and not to be queer. In other words, the notion of orientation is deeply enmeshed in the politics of space and the body.

By extension, Ahmed's ideas also have a temporal aspect. This is to say, bodies are oriented to a hegemonic understanding of space that is compliant with notions of expansion and linearity, and, here, we can begin to trace these space/time politics back to the burgeoning project of modernity. From the early voyages of Christopher Columbus, Ferdinand Magellan, and Amerigo Vespucci in the late fifteenth century, when a sense of cartographic colonisation and centring of Europe began to take place, to the rise of homogeneous, clock time across the world via the genealogy of the railroad and telegraph, when globalised space was standardised across the world in the eighteenth and nineteenth centuries, issues of the body and space are inexplicably coupled with questions of time. ${ }^{4}$ This time that is associated with modernity - described by Henri Bergson as "a juxtaposition in space" - is uniform and linear and has been the dominant way to orientate bodies into a particular mode of living which is completely entwined with the mechanics of capitalism (Time and Free Will 85).

Drawing from scholars like Bergson and Dipesh Chakrabarty, Bliss Cua Lim observes that "the world-historical project of modernity that hinged on colonialism" rests "on a temporal strategy in which radical cultural differences brought to light by colonial contact were framed as primitive or anachronistic" (13). According to Lim, heterogeneous temporalities - other modes of bodily orientations - are rendered untranslatable by the dominance of homogeneous, clock time, and that these varied attitudes towards time and temporality are subsumed by the overwhelming power of spatialised time. Writing about the aswang - malevolent shapeshifting spirits in the Philippines - in relation to the Philippines' socio-historical context, Lim observes that aswang narratives have flitted between history and story in the Philippines since at least the sixteenth century but, when the Spanish invaded and colonised the nation, the aswang and its narratives were relegated to the non-modern and premodern in favour of a Europeanised culture that was run on clock time and development. Such temporalities that do not fit with modern time are in turn disenchanted, understood as "a precursor to modernity," where "heterogeneity is translated into homogeneity in order to govern 
unsettling, radical difference" (Lim 18-19). Consequently, the Spanish invaders took over the Philippines, inhabited it, violently extended their bodies over the bodies of the indigenous people living in the land, and orientated the local people's heterogeneous understandings of time into the fold of homogeneous, spatialised time.

This understanding of a clock time that disciplines is thus associated with that of colonial modernity and Eurocentrism. As Enrique Dussel suggests, modernity's Eurocentrism, in defining those in the periphery who do not follow its myth of linear progress and development, "can be read as the justification of an irrational praxis of violence" (472). Briefly summarised, the myth of Eurocentric modernity casts Europe as the superior culture and takes it upon itself to educate those in the periphery, violently or not; in turn, as the victims of colonial modernity stack up like the growth of the Atlantic slave trade, like the institutionalisation and genocide of indigenous peoples, and like the plundering of resources from the lands of the colonised - Europe casts itself as the blameless, whereas the colonised are blamed and punished for not signing up to this form of modernity (Dussel 472-73). One way out of the modernity project that is overwhelmingly violent, Dussel argues, is to affirm "the alterity of the other (which was previously denied)" so that "modernity and its denied alterity, its victims, would mutually fulfil each other in a creative process" (473-74). ${ }^{5}$ In this sense, to decolonise from a Dusselian viewpoint is to put European ideas in conversation with non-European ideas on an equal ontological and epistemological ground.

Seen from this angle, and in light of the work by scholars like Nikolas Rose and James R. Fletcher, who argue that the biomedical treatment of dementia can be understood as a strand of twentieth-century neuropsychiatric imperialism in which Eurocentric psychiatric classificatory systems are privileged over all other forms of knowledge, people living with dementia, who are regularly proclaimed to be living out of time and thus medicalised, can be understood as having their bodies temporally colonised. Tests used by medical practitioners to diagnose forms of dementia, like the Montreal Cognitive Assessment and the Self-Administered Gerocognitive Examination, often seek to place the subject as somewhere in time or to see whether they are able to do something in a linear order (most analogously, perhaps, is the constant appearance of the Clock Drawing Test in these assessments, where the subject has to draw a clock set to a specified time so as to be located in a particularly homogenised temporal plane). ${ }^{6}$ Failing to do so, the subject is then diagnosed to be living with dementia and medical interventions are administered to help the body cope, and to slow down the (assumed) process of physical and mental disorientation. ${ }^{7}$ As Anne Davis Basting observes about the situation, the "ability to place ourselves in linear time is considered a mark of personhood and distinguishes us from primates who live only in the present" and, because of that, people living with dementia are often associated 


\section{MaoHui Deng}

with the irrational (135). Simply put, homogeneous time disciplines and others the person living with dementia, and from this viewpoint, synthesising Ahmed, Lim, and Dussel, to temporally understand dementia and the person living with dementia in such a way is to continue the colonial/ modernity project.

In this chapter, I propose that films about dementia, by highlighting the multiple temporalities under negotiation, can offer and invite a mode of hesitant encounter and that this form of engagement disorientates a colonial approach concerning dementia and re-orientates the characters and the audience towards environments that allow for more types of bodies to (co-)exist. In Summer Snow, such a diagnostic test can also be seen as Lin Sun, at the hospital, is asked questions about his age, the transportation he took to get to the hospital, his dinner the night before, and the year he got married to his wife. More often than not, Lin Sun gives an answer that is "wrong" or "out of time," and May, who sits behind him, has to nod or shake her head to indicate to the doctor whether Lin Sun is correct, or not. As the test begins, May confidently marks the veracity of Lin Sun's answer but, as the examination continues, she becomes increasingly uncertain of his answers and ends up, after pausing momentarily, just simultaneously shaking and nodding her head, quickly undercutting the seriousness of the diagnostic test.

Paradoxically, here, it is through the attempt to discipline and subsume the different temporalities that the plethora of temporalities are foregrounded and heightened. Borrowing from Lim, such a moment, in which Lin Sun and May sign up to/acknowledge the many different temporalities that might coexist with the assumed linearity of the seemingly singular life course, can be understood as hinting at - or pointing directly towards - "untranslatable times, that trace of containment and excess" (32). Through the timeliness of the scene, we are made aware of what Lim calls "immiscible times," or "multiple times that never quite dissolve into the code of modern time consciousness, discrete temporalities incapable of attaining homogeneity with or full incorporation into a uniform chronological present" (12). May's hesitant response, brought about by a confrontation with the person living with dementia's multi-faceted relationship with time, draws the audience's attention to the intersecting and heterogeneous temporalities that he (and she) lives with, as her concurrent shaking and nodding of head produces a comedy that unnaturalises the universalising effect of clock time, of the one "correct" way of living, poking at the structures of knowledge production of dementia in this moment.

\section{Time, Care, and a Decolonial Worldview}

Throughout Summer Snow, the hesitation engendered by the immiscible temporalities of the person living with dementia and enacted by the 
people around Lin Sun takes on a particular inflection that sees them refusing to pin him down to a particular temporal mode of existence. Instead, the characters choose the option to re-orientate relationally to him, and this in turn encourages a decolonial worldview that allows the character to live with Lin Sun's dementia without evaluating his life course only in relation to the homogeneity of clock time. In the earlier analysis, I have already highlighted how his son and grandson are simultaneously prisoners-of-war and not prisoners-of-war, and how May likewise is his fellow soldier and daughter-in-law. In another example, as Lin Sun's son, Bing, goes to the rooftop to look for his father, he finds Lin Sun cooing and throwing bird feed. Lin Sun explains that he is feeding the pigeons, and Bing pauses and hesitates. This exchange is captured via a wideangle shot, and throughout the moment, there are no visible pigeons in the mise-en-scène. Like the audience, Bing also notices that there are no birds around. Nonetheless, after hesitating, he points his father towards an area out of the frame, says that there are a few more pigeons there, and both father and son begin to feed the pigeons together. It is important to note that Bing's decision is not a patronising act where he is just "pretending" to placate his father or to get him to do things. Instead, I would suggest that his interaction can be understood as demonstrating a more developed and complex form of "relational citizenship," a concept preliminarily proposed by Pia Kontos, Karen-Lee Miller, and Alexis P. Kontos that, following the tradition of Tom Kitwood's person-centred dementia care, is "premised on the importance of interdependence, reciprocity, and the support of persons living with dementia as active partners in their own care" (182-183). That is, in this scene, we can think of Bing as carefully taking his father's agency into consideration and that he and his father are both agentically performing and performed by each other's actions and narratives. ${ }^{8}$

I will elaborate on my understanding of this caring relationship through that of performance studies. Janet Gibson, drawing from performance studies scholar Richard Schechner, proposes to look at dementia "as an action, event, or behaviour, with attention to the circumstances in which it has been created and is exhibited" (252), and this means that we reframe the behaviours of people living with dementia "as creative adaptations rather than just as deficit exemplars of insidious diseases" (256). This, Gibson argues, would demand an understanding of the performances of people living with dementia as inclusive of the embodied and an acknowledgement of their performances through the lens of "double negativity:”

their stories, as well as their identities, could be allowed to be both not true, but not not true. For example, through this lens people who are exhibiting symptoms of forgetfulness or changes in their personalities can be understood to be both who they are now and who they 


\section{MaoHui Deng}

are not now (i.e. who they were): still becoming selves, if also disappearing selves. They are not exactly "themselves", but this should not prohibit possibilities for being other selves.

In this sense, the person living with dementia, like the person not living with dementia, performs, presents, and manages a sense of embodied self "in front of others to whom the term 'audience' can be applied" (Gibson 250). ${ }^{9}$ In moving to think of the person living with dementia's performances as "still becoming selves, if also disappearing selves," Gibson puts forward an articulation of an audience who allows themselves to be dialogically performed by the actions and narratives of the person living with dementia, rather than just prescribing a set of interventions or medications to the people living with dementia so that they are living the "right way" - or, as I argued earlier, the colonial way.

Gibson's working theory of dementia as performance, then, is primarily concerned with the live, shifting and interdependent relationship between the performer and the audience, and her argument finds synergy with recent scholarship on care aesthetics. ${ }^{10}$ According to Amanda Stuart Fisher, the act of care too can be understood as performance, for "care can only be experienced as a live, embodied encounter" and "because it is comprised of repeated or 'restored' practices and behaviours" (12). From such a viewpoint, Stuart Fisher proposes, care should be understood "as becoming itself through the demands of the relationship that emerges between the caregiver and care receiver" (12). Concomitantly, James Thompson develops what he describes as "an aesthetics of care," which is "about a set of values realised in a relational process that emphasise engagements between individuals or groups over time" (437). Synthesising the ideas of Gibson, Stuart Fisher, and Thompson, to think of the caring relationship between the person living with dementia and the person not living with dementia through the framework of performance studies is to not just think of the semiotics (the acts and gestures) but to also consider the affects (the sensations and the feelings) that shape the interdependent and reciprocal relationships.

Throughout this chapter, I am interested in the ways time and temporality shape such caring relationships. ${ }^{11}$ As Summer Snow demonstrates, films about dementia invite a mode of hesitant encounter between the person living with dementia and the person not living with dementia, and everyone is performing and performed by everyone's actions and narratives. In one moment, for instance, as Lin Sun refuses to take off his clothes while his son and daughter-in-law bathe him, they end up washing the clothes at the same time to save time on doing laundry. In another, Lin Sun puts his son in an arm lock as he is accused of being a burglar, and to resolve the situation, both May and her husband insist that he is actually a good man who is returning the stolen money. Such 
a relational approach towards dementia, as evinced by the interactions between Lin Sun and the people around him, draws parallels with what Raewyn Connell describes as a "mosaic epistemology," in which multiple "knowledge systems sit beside each other like tiles in a mosaic, each based on a specific culture or historical experience, and each having its own claims to validity," and a "solidarity-based epistemology," where there is a "mutual learning on a world scale, in which different formations of knowledge are respected but enter into educational relations with each other" (30-31). Writing about the Westernised epistemology(ies) that colonise(s), Connell argues for a need to not only acknowledge the multi-varied types of knowledge formation but also, crucially, the ways in which these approaches are entangled and complementary so that no one framework can be centred and made universal. To decolonise, then, is to attend to the messiness of the structures that govern and to acknowledge a pluriverse, or a world that is plural.

A pluriverse, as defined by Walter D. Mignolo, "is not a world of independent units (as is the case with cultural relativism) but a world entangled through and by the colonial matrix of power" (xi). Developing this concept further, Mignolo and Catherine E. Walsh write:

the pluriversal opens rather than closes the geographies and spheres of decolonial thinking and doing. It opens up coexisting temporalities kept hostage by the Western idea of time and the belief that there is one single temporality: Western-imagined fictional temporality. Moreover, it connects and brings together in relation - as both pluri- and interversals - local histories, subjectivities, knowledges, narratives, and struggles against the modern/colonial order and for an otherwise.

(3; emphasis in original)

In other words, in a decolonial worldview, by situating ourselves in a pluriverse, heterogeneous temporalities that were subsumed by homogeneous time - made untranslatable, as suggested by Lim - are freed up. Accordingly, these different heterogeneous temporalities are positioned relationally to linear clock time; all these different attitudes towards time are entangled, and all temporal positions can be adopted and can unlock a more complex way of life. For one, specific to the chapter's central argument, it will allow us to live with dementia without othering the person living with dementia or evaluating their lives as relative to homogeneous, linear time. Films about dementia, in highlighting a kind of temporal excess, provide us with a decolonial worldview as an option that we might be able to hesitantly re-orientate towards, and this chapter serves as a provocation - as my opening exploration and invitation - to think through the complexities of such a mode of living with dementia in more detail. 


\section{MaoHui Deng}

\section{Summer Snow and the Decolonisation of Hong Kong}

This mode of living hesitantly as envisioned by Summer Snow, I suggest, extends beyond the individual to the national and the global. In my impressionistic and potted discussion of the socio-politics of Hong Kong earlier, I suggested that Summer Snow can be understood as a pre-handover film that was produced in a period of deep crisis. Before the British, Ackbar Abbas writes, Hong Kong did not have a precolonial history, and the handover to China was not simply a return to the "motherland" or a "Chinese-ness" that is associated with a version of Greater China:

Ironically, it is Hong Kong's colonial history, the only history it has known and a history that cannot be forgotten overnight, that has distanced Hong Kong culturally and politically from China and that will make their relationship not simply one of reunification.

Here, Abbas' claim can be understood in relation to the ideas I discussed earlier. Hong Kong, a city-body, has been orientated to know only one kind of history, a history that is predicated on a kind of colonial modernity. All of a sudden, as 1997 neared, the prospect of experiencing and reckoning with a future that was not necessarily reconcilable with Hong Kong became increasingly overwhelming. Confronted with this creeping expiration date, Abbas observes, "a culture of disappearance, whose appearance is posited on the imminence of its disappearance," paradoxically appears (7). As Victor Fan laments, pre-handover Hong Kong experienced an anxiety that compelled the people living in Hong Kong "to enjoy a present that had no future," and to focus on "the time it took for time to end" (114). Hong Kong cinema of this period, in turn, started to make films about the city that foregrounded an anxiety about time: in Chungking Express (Wong Kar-wai, 1994, Hong Kong), for example, individual frames are removed from the film or reprinted and inserted, and music plays on an eternal loop; in Rouge (Stanley Kwan, 1988, Hong Kong), the city is filtered through the viewpoint of a ghost and her ghostly temporalities; and in Song of the Exile (Ann Hui, 1990, Hong Kong), memories are layered upon memories to bring forward a kind of past and present that is organised in an expansively spatial manner. ${ }^{12}$ In these films, through the examination of time, the city of Hong Kong is disorientated.

Despite being a social realist dramedy, the exploration of time in Summer Snow is not too dissimilar to these films. In the film, Lin Sun wanders off on his own twice. In the first incident, he is chased by his daughter-inlaw on foot as he walks around his estate, and in the second occurrence, 


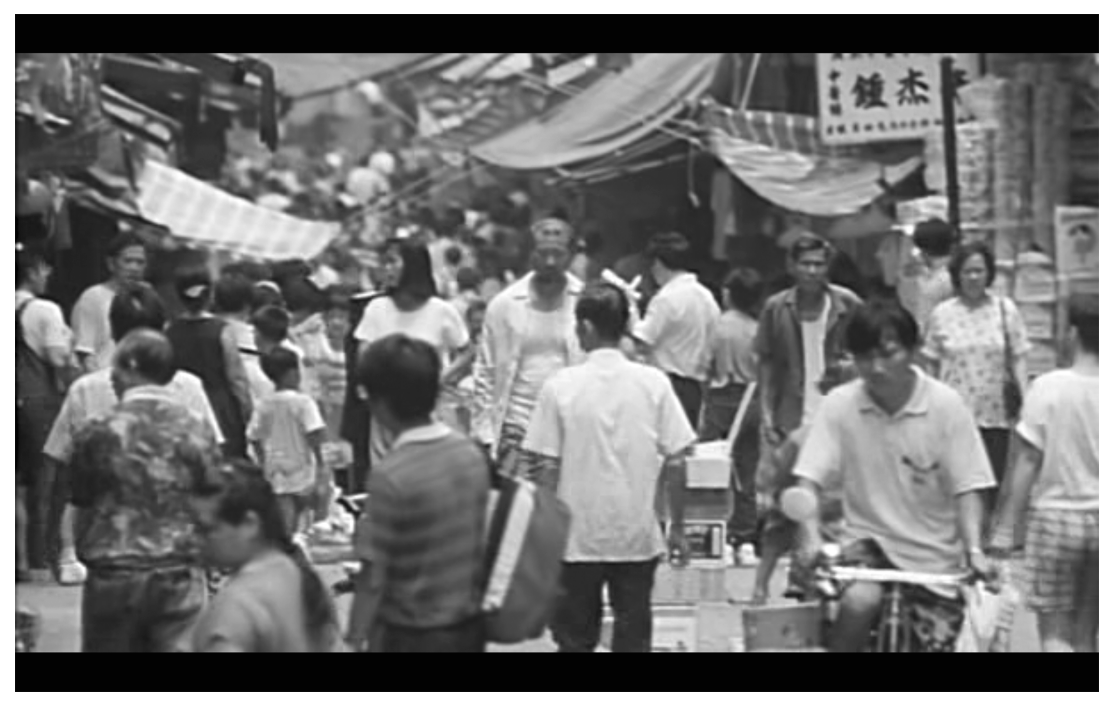

Figure 6.2 Lin Sun as part of the texture of Hong Kong's cityscape.

he walks beyond his immediate neighbourhood to traverse a wider portion of Tai Po, the area where the family resides. In the first example, he is wearing a white shirt that looks no different from the many white clothes that the people around him are wearing (see Figure 6.2), and in the second, he is wearing a blue shirt that blends in with the blue tint of the city's night lights.

In both instances, the wandering sequence is largely shot using a long lens, which flattens the mise-en-scène of the city, rendering it slightly claustrophobic and further embedding Lin Sun in the texture of the cityscape. The music that plays in the score when we see the city is martial, textured with drums and various brass instruments, and at once carnivalesque and whimsical, referencing Lin Sun's life as a veteran and flipping inside out the linear time in which he is supposed to live. Moreover, the area that Lin Sun wanders - Tai Po - is significant as the location where Britain raised the British flag and set up their first headquarters when they leased the New Territories, which is the territory that catalysed the handover of Hong Kong. All in all, as Lin Sun's dementia is inexplicably tied to the cityscape through the film's form, Hong Kong is imbued with a kind of temporal excess, and the audience is invited to hesitantly engage with the city.

There has been much debate about the status of Hong Kong and Hong Kong cinema, which, because of its history, is often talked about through the framework of the (trans-)national. As Vivian PY Lee observes, for 


\section{8}

many scholars, the politics of the local in pre-handover Hong Kong cinema

stood out as simultaneously an attempt to construct and consolidate a place/space-based identity on the one hand, and a tactic to destabilise and deconstruct narratives of identity associated with either the "empire" or the "nation," which are no less place/space-based regimes, on the other.

(66; emphasis in original)

Scholarship on Hong Kong and Hong Kong cinema, not least in relation to national and transnational film studies, is in other words firmly rooted in discourses of the space. Elsewhere, I have examined how such a focus on space in (trans-)national film studies relies on "the fixity of the nation as a geopolitical concept that is built on the notion of temporal continuity" (50). Such an approach, which is predicated on the linearity of time, continues the colonial project of modernity and does not fully account for the ways in which the "diverse pasts are often re-remembered (and re-forgotten) differently for the various purposes of the nation's present tense" (44). And, since the handover, such an understanding of Hong Kong cinema as attempting to comprehend its sense of self by turning to an imagined and linear historical development is becoming increasingly untenable.

In 1997, Hong Kong witnessed the Asian Financial Crisis and the H5N1 bird flu epidemic and, in 2003, the SARS epidemic. These events resulted in significant economic blows to the city and played a large part in the significant decline of the Hong Kong film industry. Through the signing of the Mainland and Hong Kong Closer Economic Partnership Arrangement (CEPA) in 2004, which allowed Hong Kong to co-produce films with mainland China, there has been an increasing "mainlandisation" of Hong Kong commercial cinema, as most of the films produced in the city today are predominantly CEPA films, as the past of Hong Kong cinema is folded into the wider history of Chinese cinema and culture. Concomitantly, politically there have been significant attempts by the mainland Chinese government to violently orientate Hong Kong into the outlook of the People's Republic of China, and this has been forcefully resisted by the local people in Hong Kong. In 2014, the Umbrella Movement, which is largely led by the younger people of Hong Kong, staged a series of protests that lasted 79 days, demanding full democracy. Since then, there have been continued largescale protests in Hong Kong, most recently, at the time of writing, the 2019-2020 protests against the creeping of mainland China's legal system into Hong Kong. Throughout these protests, spectres of the colonial continue to haunt Hong Kong as people variously call for a return to British governance and for America to step in and "Make Hong Kong Great Again" (Ruwitch and Pang). ${ }^{13}$ 
Throughout, then, the question persists: how might you access Hong Kong's temporalities, which are always at risk of disappearing or being subsumed to another colonial linearity? As I suggest earlier, films about dementia draw the audience's attention to the heterogeneous temporalities that intersect, engender a sense of hesitation that disorientates, and offer a decolonial way of life as an option that one might choose. In doing so, a worldview that is open to, and premised on, relational change and becoming is espoused. In Summer Snow, the family's experiences of living with dementia are inexplicably tied up with a sense of everyday "Hong Kong-ness" through Lin Sun's relationship with the city-body. As Lin Sun wanders around his surroundings, and as he is followed around by his family members, the film introduces the audience to shots of newer high-rise buildings, of mould and decay creeping into older buildings, of children playing with their latest toys, of adults playing mah-jong, of people taking naps outside of shops, of people carrying slabs of meat to sell, of people eating beef noodles, and of overflowing rubbish bins that have not been collected for days. Against this backdrop, as Giulana Bruno might argue, in showing glimpses of the often contradictory and disparate elements of everyday Hong Kong through the film's social-realist aesthetics and through Lin Sun's dementia, Summer Snow draws a cultural map of Hong Kong "as a metonymy of fragmentations" (4). In turn, the film about dementia offers a decolonial framework of temporal entanglement to shift the debate about the nation(al) from space to time so as to allow for an understanding of space as one where the past and the present are multiple and coeval (a pluriverse).

In this sense, to examine the temporalities of films about dementia is not just to think of the individual caring relationships that are formed between humans but to also think of the wider geopolitics that are structured by (the legacy of) colonial modernity, and Summer Snow offers the potential for a more nuanced examination of Hong Kong and Hong Kong cinema that is temporally entangled through and by the colonial matrix of power. Throughout the film, emphatically, the audience never sees Lin Sun actually feeding pigeons - nonetheless, as discussed above, this does not stop his family from feeding pigeons with him. At the end of the film, after Lin Sun has passed away, May goes to the rooftop to do some chores, where she discovers a rooftop full of pigeons. As she looks around ecstatically, proclaiming the existence of the pigeons, the film cuts to a freeze-frame of her face, and a woman's voice enters the score, singing about the importance of not crying or grieving, as life, like a morning dew, is ephemeral. With that, the film ends. In living relationally with dementia, in acknowledging and reckoning with the fleetingness of temporal change and becoming, the pigeons, which seemingly have not been present throughout the film, do appear. 


\section{Notes}

1. In mainland China, the dominant Chinese-language vernacular spoken is Mandarin, whereas in Hong Kong, it is Cantonese.

2. See Birth and Fabian on clock time and colonial modernity.

3. This chapter builds on the work on care, time, and cultural narratives about dementia by scholars like Sally Chivers, Martina Zimmermann, Raquel Medina, Sarah Falcus and Katsura Sako, and Rebecca Bitenc.

4. See Thompson, Nanni, and Sharma on time, modernity, and globalisation.

5. Dussel is critical of postmodernism and critical modernism as, according to him, these approaches continue to perpetuate the Eurocentrism that modernity is built on.

6. The Clock Drawing Test is also a test that examines one's spatial cognition, and this in turn furthers the link between homogeneous, clock time and spatial cartography.

7. On people living with dementia's time awareness, see Edwards; Eriksen et al.

8. See Boyle on the agency of people living with dementia.

9. Here, Gibson's understanding of the audience is drawn from Gareth White's definition of an audience, which is that of "a socially constructed practice," in which the audience comes into being as they perform and are performed by a set of social structures and beliefs (5). See, also, Kershaw, Santone, and Sedgman on the social construction of audience behaviour.

10. Scholarship on care aesthetics expands on the work done by care ethicists and philosophers like Joan C. Tronto, Eva Feder Kittay, Virginia Held, and Michael Slote, who insist on a politics of interdependency between the carer and the cared for.

11. See Deleuze and Massumi on time and affect.

12. See Eren, Lim, and Ma on the disparate temporalities in these films.

13. For John Nguyet Erni, post-handover Hong Kong exists in a state of "liminal postcoloniality." For Howard Y.F. Choy, Hong Kong has gone from the colonial to the recolonial.

\section{Works Cited}

Abbas, Ackbar. Hong Kong: Culture and the Politics of Disappearance. U of Minnesota P, 1997.

Ahmed, Sara. Queer Phenomenology: Orientations, Objects, Others. Duke UP, 2006.

Al-Saji, Alia. "A Phenomenology of Hesitation: Interrupting Racializing Habits of Seeing." Living Alterities: Phenomenology, Embodiment, and Race. Edited by Emily Lee. State University of New York, 2014, pp. 133-72.

- "SPEP Co-Director's Address: Hesitation as Philosophical Method Travel Bans, Colonial Durations, and the Affective Weight of the Past." Journal of Speculative Philosophy, vol. 32, no. 3, 2018, pp. 331-59.

Basting, Anne Davis. “'It's 1924, and Somewhere in Texas, Two Nuns are Driving a Backwards Volkswagen': Storytelling with People with Dementia." Aging and the Meaning of Time: A Multidisciplinary Exploration. Edited by Susan McFadden and Robert C. Atchely. Springer Publishing Company, 2001, pp. 131-49.

Bergson, Henri. Matter and Memory. Translated by Nancy Margaret Paul and W. Scott Palmer. George Allen and Unwin, 1911. 
Time and Free Will: An Essay on the Immediate Data of Consciousness. Translated by F.L. Pogson. George Allen and Unwin, 1950.

Birth, Kevin K. Objects of Time: How Things Shape Temporality. Palgrave Macmillan, 2012.

- Time Blind: Problems in Perceiving Other Temporalities. Palgrave Macmillan, 2018.

Bitenc, Rebecca. Reconsidering Dementia Narratives: Empathy, Identity and Care. Routledge, 2020.

Boyle, Geraldine. "Revealing Gendered Identity and Agency in Dementia." Health and Social Care in the Community, vol. 25, no. 6, 2017, pp. 1787-93.

Bruno, Giuliana. Streetwalking on a Ruined Map: Cultural Theory and the City Films of Elvira Notari. Princeton UP, 1993.

Carruthers, Lee. Doing Time: Temporality, Hermeneutics, and Contemporary Cinema. State U of New York P, 2017.

Chakrabarty, Dipesh. Provincializing Europe: Postcolonial Thought and Historical Difference. Princeton UP, 2008.

Chivers, Sally. The Silvering Screen: Old Age and Disability in Cinema. U of Toronto P, 2011.

Choy, Howard Y.F. "Schizophrenic Hong Kong: Postcolonial Identity Crisis in the Infernal Affairs Trilogy." Journal of Global Cultural Studies, vol. 3, 2007, pp. 52-66.

Chungking Express. Directed by Wong Kar-wai. Jet Tone Production, 1994.

Cohen, Lawrence. "Senility and Irony's Age." Social Analysis: The International Journal of Anthropology, vol. 47, no. 2, 2003, pp. 122-34.

Connell, Raewyn. "Meeting at the Edge of Fear: Theory on a World Scale." Constructing the Pluriverse: The Geopolitics of Knowledge. Edited by Bernd Reiter. Duke UP, 2018, pp. 19-38.

Deleuze, Gilles. Difference and Repetition. Translated by Paul Patton. Bloomsbury, 2019.

Deng, MaoHui. "Singapore as Non-Place: National Cinema through the Lens of Temporal Heterogeneity.” Asian Cinema, vol. 31, no. 1, 2020, pp. 37-50.

Dussel, Enrique. "Europe, Modernity, and Eurocentrism.” Nepantla: Views from the South, vol. 1, no. 3, 2000, pp. 465-79.

Edwards, Allen Jack. A Psychology of Orientation: Time Awareness Across Life Stages and in Dementia. Praeger, 2002.

Eren, Patricia Brett. "Crossing Borders: Time, Memory, and the Construction of Identity in Song of the Exile." Cinema Journal, vol. 39, no. 4, 2000, pp. 43-59.

Eriksen, Siren et al. "The Experience of Lived Time in People with Dementia: A Systematic Meta-Synthesis." Dementia and Geriatric Cognitive Disorders, vol. 49, no. 5, 2021, pp. 435-55, https://doi.org/10.1159/000511225.

Erni, John Nguyet. "Like a Postcolonial Culture: Hong Kong Re-Imagined.” Cultural Studies, vol. 15, no. 3-4, 2001, pp. 389-418.

Fabian, Johannes. Time and the Other. Columbia UP, 2002.

Falcus, Sarah, and Katsura Sako. Contemporary Narratives of Dementia: Ethics, Ageing, Politics. Routledge, 2019.

Fan, Victor. Extraterritoriality: Locating Hong Kong Cinema and Media. Edinburgh UP, 2019. 


\section{MaoHui Deng}

Fletcher, James R. "Positioning Ethnicity in Dementia Awareness Research: Does the Use of Senility Risk Ascribing Racialised Knowledge Deficits to Minority Groups?” Sociology of Health and Illness, vol. 42, no. 4, 2020, pp. 705-23.

Gibson, Janet. Dementia, Narrative and Performance: Staging Reality, Reimagining Identities. Palgrave Macmillan, 2020.

Held, Virginia. The Ethics of Care: Personal, Political, and Global. Oxford UP, 2006.

Kershaw, Baz. "Oh for Unruly Audiences! Or, Patterns of Participation in Twentieth-Century Theatre." Modern Drama, vol. 44, no. 2, 2001, pp. 133-54.

Kittay, Eva Feder. Love's Labor: Essays on Women, Equality, and Dependency. Routledge, 2001.

Kontos, Pia et al. "Relational Citizenship: Supporting Embodied Selfhood and Relationality in Dementia Care." Sociology of Health and Illness, vol. 39, no. 2, 2017, pp. 182-98.

Lee, Vivian P.Y. "Relocalising Hong Kong Cinema.” Wasafiri, vol. 32, no. 3, 2017, pp. 64-70.

Lim, Bliss Cua. Translating Time: Cinema, The Fantastic and Temporal Critique. Duke UP, 2009.

Ma, Jean. Melancholy Drift: Marking Time in Chinese Cinema. Hong Kong UP, 2010.

Massumi, Brian. Parables for the Virtual: Movement, Affect, Sensation. Duke UP, 2002.

Medina, Raquel. Cinematic Representations of Alzheimer's Disease. Palgrave Macmillan, 2018.

Mignolo, Walter D. "Foreword. On Pluriversality and Multipolarity." Constructing the Pluriverse: The Geopolitics of Knowledge. Edited by Bernd Reiter. Duke UP, 2018, pp. ix-xvi.

Mignolo, Walter D., and Catherine E. Walsh. On Decoloniality: Concepts, Analytics, Praxis. Duke UP, 2018.

Nanni, Giordano. The Colonisation of Time: Ritual, Routine and Resistance in the British Empire. Manchester UP, 2012.

Rose, Nikolas. Our Psychiatric Future. Polity Press, 2019.

Rouge. Directed by Stanley Kwan. Golden Harvest. Golden Way Films, 1988.

Ruwitch, John, and Jessie Pang. "Tens of Thousands of Hong Kong Protestors Plead for U.S. Help.” Reuters, 14 Oct. 2019, www.reuters.com/article/ushongkong-protests/tens-of-thousands-of-hong-kong-protesters-plead-for-ushelp-idUSKBN1WT039.

Santone, Jessica. "The Economics of the Performative Audience." Performance Research: A Journal of the Performing Arts, vol. 19, no. 6, 2014, pp. 30-6.

Schechner, Richard. Between Theater and Anthropology. U of Pennsylvania P, 1985.

Sedgman, Kirsty. The Reasonable Audience: Theatre Etiquette, Behaviour Policing, and the Live Performance Experience. Palgrave Macmillan, 2018.

Sharma, Sarah. In the Meantime: Temporality and Cultural Politics. Duke UP, 2014.

Slote, Michael. The Ethics of Care and Empathy. Routledge, 2007.

Song of the Exile. Directed by Ann Hui. Cos Group, 1990. 
Stuart Fisher, Amanda. "Introduction: Caring Performance, Performing Care." Performing Care. Edited by Amanda Stuart Fisher and James Thompson. Manchester UP, 2020, pp. 1-17.

Summer Snow. Directed by Ann Hui. Class, Golden Harvest, Harvest Crown, 1995.

Taylor, Janelle S. “On Recognition, Caring, and Dementia." Medical Anthropology Quarterly, vol. 22, no. 4, 2008, pp. 313-35.

Thompson, E.P. "Time, Work Discipline and Industrial Capitalism." Past and Present, vol. 38, 1967, pp. 56-97.

Thompson, James. "Towards an Aesthetics of Care." Research in Drama Education: The Journal of Applied Theatre, vol. 20, no. 4, 2015, pp. 430-41.

Tronto, Joan C. Moral Boundaries: A Political Argument for an Ethic of Care. Routledge, 1994.

White, Gareth. Audience Participation in Theatre: Aesthetics of the Invitation. Palgrave Macmillan, 2013.

Zeilig, Hannah. "Dementia as a Cultural Metaphor.” The Gerontologist, vol. 54, no. 2, 2014, pp. 258-67.

Zimmermann, Martina. The Poetics and Politics of Alzheimer's Disease LifeWriting. Palgrave Macmillan, 2017. 


\title{
7 Ghost on the Canvas \\ Glen Campbell's Musical \\ Narratives of Ageing, \\ Alzheimer's Disease, and Care
}

\author{
Simon Buck
}

In 1968, 32-year-old country-pop musician Glen Campbell released his chart-topping single "Wichita Lineman." Its B-side, "Fate of Man," told a sobering story about the life course: the naïveté of one's 20s, the "creeping of old age" up the spine at 50, and, finally, being rheumatic, frail, and "ready for the wreath" at 80 . "So, you can pity him as he goes up the line," Campbell sings, "As he wobbles on the spindle and is almost blind." In its veneration of "youth" and unease about ageing, Campbell's self-penned song reflected prominent age narratives in US culture in the 1960s but takes on new meaning in light of Campbell's diagnosis of Alzheimer's disease (AD) in 2011, at 75 years old. Between then and his death in 2017, Campbell opened up publicly about his illness, embarked on a "Goodbye Tour," campaigned to raise awareness of $\mathrm{AD}$, and generally resisted the kind of "pity" for older people articulated in "Fate of Man.” In 2012, his manager Stan Schneider told Billboard: “As long as the people are enjoying it and not coming out of pity, why not go out and say goodbye to the country?" (Graff). Yet Campbell's music during this period, if occasionally evocative of relatively complex ideas about ageing, $\mathrm{AD}$, and care, also reproduced a similar "decline" narrative to that found in "Fate of Man."

This chapter examines these narratives in Campbell's "late" music. It re-evaluates the career of one of the most popular anglophone musicians of the last six decades. Over Campbell's lifetime, the six-time Grammy Award-winner sold over 45 million records; in 1968, Campbell sold more records than the Beatles (Jones 191). This study demonstrates how ageing pop musicians like Campbell have musically responded to, and contributed towards, the increasing politicisation of $\mathrm{AD}$ in the US, signified by federal government legislation such as the National Alzheimer's Project Act (2011). In 2012, the Alzheimer's Association hosted "An Evening with Glen Campbell" at the Library of Congress in Washington, D.C., to "raise awareness of AD among members of Congress" (Alzheimer's Association). In 2013, Campbell's daughter Ashley testified at a Senate hearing on the National Alzheimer's Plan (Special Committee on Aging 3-10). Campbell's media appearances raised consciousness about 
$\mathrm{AD}$ and so arguably helped to put pressure on policy makers. Nearly 40 million viewers watched the visible effects of Campbell's dementia during his 2012 Grammy Awards performance. Campbell's story features in his daughter's and wife's bestselling autobiographies (D. Campbell and Bego 2014; K. Campbell 2020), other dementia-related memoirs (Sutton 60-63; O'Brien 37; Kapsambelis 4), advice manuals for caregivers (Snelling 456; Pulsford and Thompson 229-30), spiritual guides to dementia (Harrison 87), and textbooks on nursing (McCrae 509-10) and dying (Corr et al. 579-80). Campbell's music, similarly, both echoed dominant cultural ideas about ageing, illness, and care, and helped to shape discourses around these topics.

While increasing scholarly attention is paid to cultural narratives of ageing, illness, and care, musical narratives are often left out of this conversation, despite both the palpable influence of music on everyday life and growing scientific recognition of how "the quickening art" improves well-being (Basting 104-10; Bitenc 178-80; Baird et al. 2020). Some age studies scholars consider musical narrative, but usually only in passing (Gullette 113; Hartung 191) or in reference to other media (Chivers 89-91). This chapter maintains that music can conjure powerful ideas about ageing, dementia, and care in the minds of listeners. Songs, in Keith Negus' words, "mediate the human experience of time" (484) and so by their nature are narratological. Building on a Proustian understanding of age as "embodied time," Richard Elliott argues that because music is capable of handling considerations of time and experience, it is also well equipped to deal with ageing (11-58). Put simply, these and other authors (Gardner and Jennings; Cohen and Kruschwitz; Bennett; Whiteley; Buck) draw attention to how singers, listeners, and songs all age, the latter across performers' and audiences' lifetimes but also within their own internal temporalities; songs have beginnings, middles, and ends and are a means to reflect upon pasts, presents, and futures. Likewise, medical humanities scholars have dissected how music might narrativise experiences of health. As Arthur W. Frank argues, music is one way for those with illnesses to escape "chaos narratives" surrounding "deviant" bodies in popular culture. "Bodies need voices," Frank reminds us, and "music allows a direct connection to [the] body that speech can no longer provide," whether because of physical or cognitive illness or the culture of "muteness" surrounding illness (109). There is also much debate in the philosophy of music over the proposition that "music is caring" (see Stige 273). Marcel Cobussen and Nanette Nielsen claim that music, because of its social function and affective nature, can bind people in meaningful, "caring" relationships (158). References to music in dementia-care memoirs (e.g., Magnusson 276) testify to these ties between music and care. This chapter enters this debate by exploring whether music can do the work of both representing and enacting care. 


\section{Simon Buck}

This chapter concentrates on Campbell's recorded music. More could be said about ageing, dementia, and care narratives in Glen Campbell: I'll $B e M e$, a 2014 documentary about his experiences living with dementia, and how it sits within a subgenre of music documentaries about dementia, including Alive Inside: A Story of Music and Memory (US, 2014). Scott Selberg's study of media representations of Campbell's dementia, including I'll Be $\mathrm{Me}$, is a thoughtful deconstruction of celebrity selfhood discourse, but it nevertheless neglects to analyse Campbell's post-diagnosis music as a whole. By doing just that, some important thinking can be done about the historically problematic, but continuously evolving, relationship between the music industry and ageing and/or ill performers; the ability of music to articulate ideas about temporality, memory, loss, agency, dependence, and vulnerability; and how musical narratives might reinforce or challenge dominant scare/decline discourses surrounding dementia and ageing. This chapter begins by tracing the theme of age in Campbell's music back to his early career. It then charts how Campbell over time incorporated generational themes into his music and negotiated industry ageism, and finally it deconstructs the narratives about ageing, $\mathrm{AD}$, and care in his post-diagnosis recordings.

\section{Longhairs, Grey Hairs}

"Fate of Man" exemplifies how Campbell had sung about ageing and illness long before the onset of $\mathrm{AD}$. Assessing his earlier approaches to these topics helps to recontextualise his later music. Notions of "youth" were central to Campbell's start in showbusiness. He began his career as a child performer in his uncle's "hillbilly" band, before working as session musician in Los Angeles. Already in his 30s by the time he became a chart-topper in 1967, Campbell was nevertheless perceived as "young." Cover stories in "teen" magazines such as 'Teen ("Glen Campbell's Road") and Young Miss (Saunders) (see Figure 7.1) solidified Campbell's status as a teenage pin-up. Alongside his distinctive voice, virtuosic guitar skills, and cross-over country-pop repertoire, Campbell's “youth" embodied by his boyish good looks, perfect white teeth, blond locks, and wholesome personality - was a contributing factor to his popularity.

Unlike other 1960s musicians who propelled the era's "generation gap" discourse, however, Campbell used his fame to venerate "elders." This deference to age was born from a rural southern Baptist upbringing in Billstown, Arkansas. The self-described "Country Boy," if sporting longish hair in typical late-1960s youth fashion, nevertheless regularly invited his grey-haired parents as guests onto his CBS television series, The Glen Campbell Goodtime Hour. Teenagers constituted a significant proportion of Campbell's fan base, but he also attracted older audiences. Young Miss conceded that "Glen closes the generation gap nicely. This is probably because his music really says something, and he's such a 


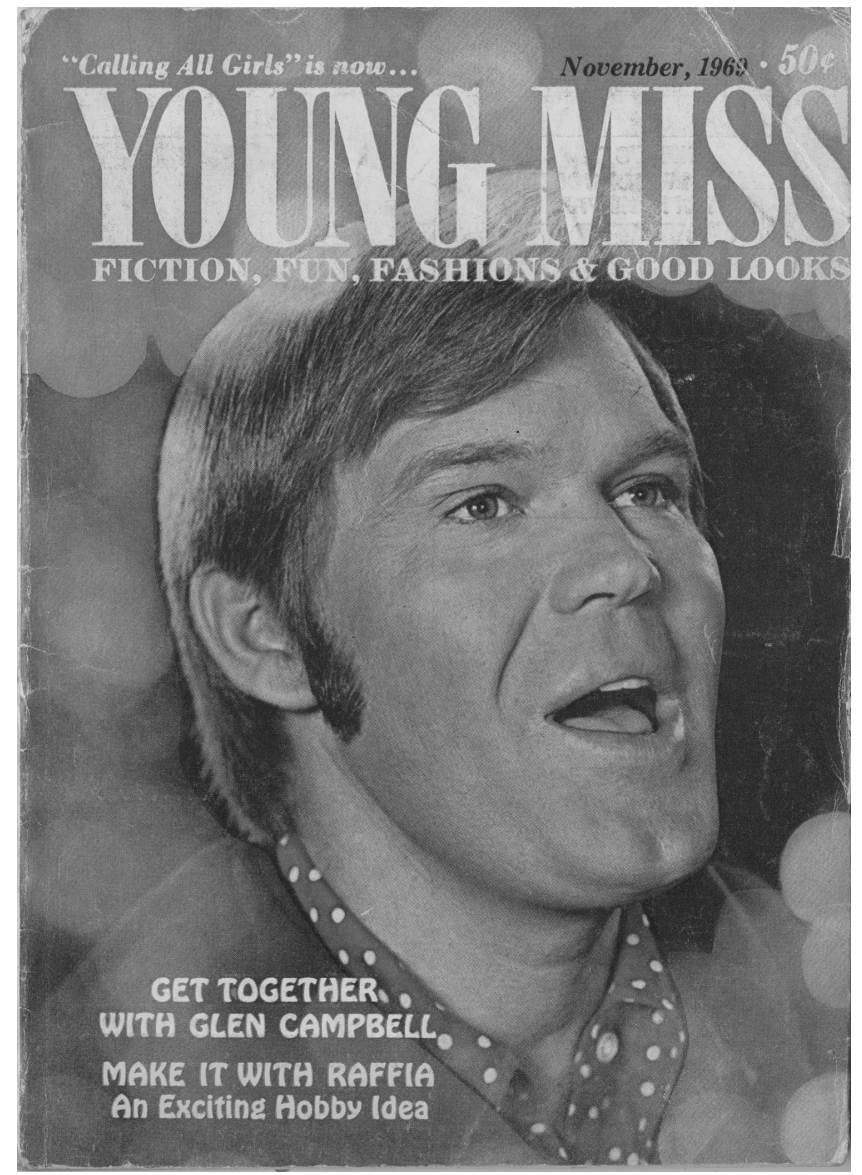

Figure 7.1 Glen Campbell on the front cover of Young Miss magazine, 1969. Author's collection.

good-looking guy that parents approve of their daughters going slightly out of their minds over him" (Saunders 22). In 1969, Florida Today reported that a "long line of little old ladies" had taken to Campbell: "At his concerts you see gray hairs lined up with the longhairs" (Botwin 20). Campbell attributed his cross-generational appeal to his avoidance of "controversy and politics" (20), but politics were never far away. In his first cinematic role, as a Texan ranger in True Grit (1969), Campbell portrayed the young counterpart to the film's grouchy, old-fashioned, and old antihero, played by ageing western cinema veteran John Wayne. Although set in the Wild West, the film's depiction of gender roles, racial hierarchies, and vigilantism resonated with contemporary audiences, 


\section{Simon Buck}

who felt anxious about women's liberation, race riots, and the anti-war movement. Garry Wills describes how, by True Grit's release, Wayne had garnered fans amongst conservative Americans for being a "living anachronism" (287). The politics that Wayne represented were yoked to his age. A reviewer for the Wisconsin Janesville Daily Gazette commented on the film's release: "In these critical days of constant turmoil, generation gaps, and panic in the streets, it is comforting to know that America still has John Wayne," even though the out-of-shape actor looked incapable of saving the "damsel in distress" and that most cinema-goers seemed more interested in seeing heartthrob Campbell on the big screen than they did Wayne ("True Grit").

Just as Campbell's repertoire drew from seemingly disparate musical wellsprings - from bluegrass to pop ballads - so too was his generational identity somewhat ambiguous. Another interpretation of Campbell's "middle-of-the-road" persona is as an "old man in a young man's body." As Dylan Jones argues, part of Campbell's appeal was the jarring idea that records such as "Wichita Lineman" and "By the Time I Get to Phoenix," with lyrics dealing in relatively complex, existential, or "mature" subjects such as time, memory, and loss, were sung by someone who looked like any other young pop star (23). This generational duality made it possible for Campbell to simultaneously appeal to both "youth" and "adult" audiences, much like how his twin rural-urban identity, captured in his 1976 song "Country Boy (You've Got Your Feet in L.A.)" (Rhinestone Cowboy), enabled him to straddle both "mainstream" and "country" music markets (Hemphill 223-34).

As his fame waned in the 1970s, Campbell increasingly had to deal with media perceptions of him as an ageing star but opted to take ownership of this narrative by including more "autumn songs" in his repertoire, including Charles Avenzoar's "Yesterday, When I Was Young" (Houston (I'm Comin' to See You)) and Stevie Nicks' "After the Glitter Fades" (Letter to Home), the latter of which implicitly criticised Hollywood and the recording industry for marginalising older performers. One of Campbell's most famous songs, "Rhinestone Cowboy," released as something of a "comeback" in 1975, reflects with ennui on the passing of time: "I've been walking these streets so long/Singing the same old song/I know every crack in these dirty sidewalks of Broadway" (Rhinestone Cowboy). The 1990s marked another transitional period. In 1994, after traversing alcoholism, drug addiction, and divorce, the 58-year-old enlisted a ghostwriter to co-write his autobiography (Campbell and Carter, Rhinestone Cowboy). Ironically, in his memoir Campbell lamented the industry ageism that had contributed to his initial fame: "That's a testament to the sad shape of country music today. A good-looking kid with an average voice can often get a record deal when a genuine legend cannot. The entertainment industry is like the athletic industry: Its youth will be served" (69). In the text, he also mourns his declining musical abilities, 
such as his narrowing vocal range (67), thereby treading the waters of what G. Thomas Couser terms "autosomatography" (2), a literary tradition of first-person life writing about illness and disability. Campbell's "late period" began in earnest with Meet Glen Campbell (2008), an album that featured material about ageing (John Lennon's "Grow Old with Me"), songs by younger contemporary artists (Travis, Green Day, the Foo Fighters), and sparse acoustic arrangements that spotlight Campbell's grainy yet recognisable voice. Campbell and his team likely hoped the record would recreate the success of Johnny Cash's critically acclaimed "American Recordings" albums. The album title's ironic "introduction" of the household Campbell name indicates how, by that point, he had attained that all-important yet difficult-to-negotiate industry label assigned to older acts: "legend."

\section{Rivers of My Memory}

If age was a recurrent and progressively prominent motif in Campbell's career up until this point, after his AD diagnosis in 2011 references to age in his music became more intimately entwined with illness narratives. Campbell released three age- and dementia-themed "concept albums" Ghost on the Canvas (2011), See You There (2013), and Adiós (2017) - and one soundtrack album, Glen Campbell: I'll Be Me (2015). The studio albums' titles, like his "Goodbye Tour" (2011-2014), present each record as a kind of "farewell." This sense of "departure" spoke to different, though overlapping, demographics of Campbell's predominantly older fanbase: "veterans" of "the Sixties generation," for whom Campbell's music was the soundtrack to their youth, and older conservative audiences who resented younger generational trends, including millennial-orientated movements such as Occupy Wall Street and Black Lives Matter. Like 1960s cinema-goers who enjoyed the elder, antihero protagonist of True Grit, many socially conservative listeners likely perceived these albums as reminders that "America still had Glen Campbell," even if just for one "last" go-around. However, for many listeners and reviewers (e.g., Deusner), this "farewell" message was closely associated with Campbell's AD. The albums' titles are just one example of how any possible distinction between ageing and dementia on the albums tends to collapse entirely. Campbell's "late" music thus reflects, and contributes to, what Paul Higgs and Chris Gilleard call the "Alzheimerisation" of old age in contemporary culture (176).

The backdrop to the albums' illness narrative is the potential threat of $\mathrm{AD}$ to Campbell's agency. Other famous musicians diagnosed with dementia, including Perry Como and AC/DC's Malcolm Young, withdrew from the limelight following their diagnosis. Campbell broke two industry precedents by continuing to perform after an $\mathrm{AD}$ diagnosis was made public and recording songs about dementia while living with it. The 


\section{0}

Simon Buck

very act of making these albums offers the music industry and audiences a new, if still problematic, mode of thinking about dementia and popular music. Campbell's story is a model for advocates of a "positivist" narrative for dementia, one that envisions individuals living "happy" or "functioning" post-diagnosis lives. Whilst challenging hegemonic decline/scare narratives about ageing and $\mathrm{AD}$, such counternarratives have nevertheless drawn criticism for marginalising care needs and responsibilities through a neoliberal idealisation of a "productive" later life (Latimer). Campbell's decision to continue performing may have contributed indirectly to these debates, but his reasons for doing so may have been more to do with his personal history and regional identity than any ambition to change perceptions of dementia. One reason for "going public" with the AD diagnosis was the fear that the media might assume that the alcoholic Campbell had fallen off the wagon (a drink-driving arrest in 2003 attracted unwelcome tabloid press). His wife Kim told People magazine, "if he flubs a lyric or gets confused on stage, I wouldn't want people to think, 'What's the matter with him? Is he drunk?" " (Champ, "Glen Campbell Has Alzheimer's Disease"). Longstanding cultural stereotypes about southerners and cognitive impairments may also have played a part. Dementia was one of the four D's (along with dermatitis, diarrhoea, and death) associated with pellagra, a niacin deficiency disease that for various socio-economic reasons became epidemic in the South when Campbell was still a child (Clay et al.). One etymology of "redneck," a derogatory label for white southerners, comes from pellagra's reddening of skin (Eisiminger 284). The fusing of pellagra to southern identity, one component of an enduring discourse about poor white southerners as imbecilic "hillbillies" (see Harkin 17), generated anxiety among southerners of Campbell's generation about being perceived as cognitively impaired.

The song-writing process behind Ghost on the Canvas (2011) confounds binary distinctions between music written by or about those with dementia and so, paradoxically, both challenges and conforms to stereotypical representations of dementia as a loss of agency. Only five of the album's 16 songs bear Campbell's name, and these are as co-writer with the album's producer Julian Raymond. Raymond drew inspiration for these songs from conversations with Campbell (Hattenstone). This "insider" perspective works to authenticate the album's narrative, even if Campbell did not claim sole authorship. Referencing Campbell's preceding album's title, one reviewer remarked that this process meant listeners "finally get to meet Glen Campbell" (Deusner). The rest of the album's songs were "tailor-made" for Campbell by famous songwriters: Paul Westerberg, Teddy Thompson, Jakob Dylan, and Robert Pollard. It is unlikely an explicit brief existed to encourage them to write dementia-themed material, but it is feasible that some informal guidance took place. Raymond told USA Today that all parties involved wanted 
to "craft a record true to the singer's personality and sound" but stressed that Campbell took an active role in the process: “Campbell doesn't just go in and perform a song. He puts his stamp on it. He treats songs the way a producer does. He speeds up the tempo. He's got cool guitar ideas. He makes changes in arrangements and lyrics" (Gundersen). Raymond's deferential tone captures how the project's marketing, if resisting cultural expectations about the loss of agency that accompanies dementia and, to a lesser degree, ageing, nevertheless deployed a defensive, somewhat patronising rhetoric in order to sell the album as a "genuine" Campbell record.

Relying on songs from other songwriters also alleviated the risk that singing too candidly or emotionally about ageing and dementia might pose to Campbell's identity as the rustic, masculine "Rhinestone Cowboy." A personal and vulnerable album like Ghost on the Canvas, like his ghost-written autobiography, was more palatable to audiences who bought into Campbell's "down-home" persona because other contributors were involved in its making. As Pamela Fox argues, cultures of "rusticity" in country music force musicians to negotiate "hero" and "antihero" modes of authorship in autobiographical songs and memoirs: they must present themselves as "exceptional" celebrities in order to justify the telling (or singing) of their life story yet simultaneously emphasise their "rustic" (rural, working class, and uneducated) credentials. This tension, Fox explains, "demands a collaborator or ghostwriter to ensure the celebrity author's rustic authenticity" (118; emphasis in original).

But Campbell's only partial role as composer neither delegitimises the authenticity of Ghost on the Canvas's story, nor indicates Campbell's lack of agency in the album's production. To the contrary, the writing process for the album is a continuation of a career characterised by collaboration. Campbell was adept at making other songwriters' material his "own" through subtle adaptions to a song's lyrics, arrangements, or "feel." Jimmy Webb, who wrote many of Campbell's hits, believed that these alterations helped make his songs commercially and critically successful (Webb 211-16). Drawing from his pre-fame occupation as a "hired-hand" session musician, Campbell possessed an extraordinary ability to live within the songs he performed, whether he had written them or not, and to attract songs that reflected his personality. The Larry Weiss song "Rhinestone Cowboy," Campbell believed, was his "autobiography set to song" (Campbell and Carter 136), so much so that he named his actual autobiography after it.

The lyrics on Ghost on the Canvas correspond with cultural tropes about dementia as a transitory state between life and death. In "Ghost on the Canvas," the "ghost" who cannot be seen but has "soul," is revealed to be Campbell himself ("I am the ghost on the canvas"). This depiction of those with dementia as "spectres" resembles the gothic modes that Marlene Goldman finds scattered across dementia writing (22-3) 


\section{Simon Buck}

and the wider sense of "invisibility" associated with dementia and ageing. The opening line, "I know a place between life and death for you and me," exploits related stereotypes of dementia as a "living death" (Behuniak). Conversely, Campbell hints in the song at a preserved feeling of futurity, "a place that we can grow," within the liminal existence of life with dementia ("between here and there"). The self-explanatory "A Better Place" reinforces this sense of "inbetweenness" by reproducing a centuries-old Christian theology of old age as an important, if necessarily painful, stepping stone to life everlasting (see Cole).

Ghost on the Canvas represents $\mathrm{AD}$ as "fragmenting" Campbell's memory and perception of time. In "A Better Place," Campbell confesses: "Some days I'm so confused, Lord/My past gets in my way." Like the use of literary techniques in $\mathrm{AD}$ life writing (Zimmermann 89), several musical techniques mimic this sensation of the past "disrupting" the present. Campbell performs a guitar break in "A Thousand Lifetimes" that evokes his iconic solo from "Wichita Lineman." An electronic beeping sound in the opening measures of "Ghost on the Canvas" quotes the faux-telephone-line noise from "Wichita Lineman." These are more than mere self-references: the blurring of past and present attempts to replicate the memory displacement experienced by those with AD. (More morbidly, the beeping recalls that of a life-support machine.) The insertion of six short instrumental interstitials between full-length songs interrupts the flow of the conventional long-play album format, thereby generating a narrative that $\mathrm{AD}$ "disrupts" the normative life course. The titles to these tracks reference places and moments from Campbell's past - his birthplace of Billstown, the date Goodtime Hour debuted - and so pulls the listener between different episodes in his life and provides insight into his "phased" temporal perception. The use of synth strings, pedal slide guitar, and piano arpeggios alludes to the sound of running water, placing the album in what Pamela J. Mittlefehldt describes as a long discursive tradition of water as a metaphor for memory (141-42). The water-like sounds also evoke a newly poignant metaphor from Campbell's 1967 hit "Gentle on My Mind:" "That you're moving on the back roads/By the rivers of my memory/And for hours you're just gentle on my mind."

See You There (2013) employed a different approach to Ghost on the Canvas but yielded similar narrative themes. Description of later life as a "temporary stop" in "I'm Waiting on the Comin' of My Lord" restates the central idea of "A Better Place." Most of the songs, however, are stripped-down versions of Campbell's hits. Reviving this old repertoire was an obvious choice, as Scott Selberg explains: "The tragic diagnosis of an older star with Alzheimer's promotes nostalgia for the youth-oriented media texts that made the star famous in the first place" ("Rhinestone Cowboy" 883). More than just nostalgia, however, See You There invites listeners to rehear these songs with Campbell's illness and care needs in mind. As well as the "rivers of my memory" line from "Gentle on My 
Mind," other older songs become heavy with dementia-related connotations: "The road of life is a long, long road when you walk alone" ("Hey Little One"); "I am so afraid of dying" ("Galveston"); "Cause I've left that girl so many times before" ("By The Time I Get To Phoenix"); and "One day, little girl, the sadness will leave your face" ("True Grit"). "Rhinestone Cowboy" takes on new metatextual meaning: "I've been walking these streets so long/Singing the same old song."

The reinterpretation of well-known lyrics into a decline narrative of dementia is facilitated by musical effects. The removal of original musical features, paired uncomfortably alongside the faithful replications of other sounds, simulates the oscillating flashes of clarity and confusion associated with early-stage dementia. The string arrangements for "Wichita Lineman" are removed, opening space for Campbell's ageing voice in the mix. The guitar solo, meanwhile, is reproduced note for note. In "Galveston," drums are stripped back to minimalistic percussion, the emptying of the song's "body" symbolising the challenges dementia presents to Campbell's sense of "self." On several songs, different slide guitars substitute for original instrumentation, with each serving a symbolic function: a dobro adds a "down-home" feel that anchors the listener to the rural Arkansas of Campbell's youth; a pedal steel guitar, another staple of country music, revives the "ghostliness" of Ghost on the Canvas; an electric slide guitar shakes with a fragility that stands in for Campbell's vulnerability. Tempos are slowed down, feeding into wider cultural narratives about the slower pace of later life. Campbell sings an octave lower than the original recordings, a lower frequency that signifies his age while also adding new gravitas to the songs. If Campbell impressively still reaches the high ends of the transposed melodies, there is less confidence in his voice in these reconfigured upper registers, causing him to perform some vocal "stretching." This vocal strain, what Roland Barthes calls the "grain" of the voice (179-89), reinforces the album's lump-in-the-throat "farewell" narrative.

Campbell's final album, Adiós (2017), although consisting mostly of covers, features snatches of lyrics that are difficult to unmoor from the context of his dementia: "Maybe someday I really will forget" ("Just Like Always"); "the memory of her lingers everywhere" ("She Thinks I Still Care"); and "Have I lost your love, or have I lost my mind?" ("Am I All Alone (Or Is It Only Me)”). "Everybody's Talkin',” perhaps unintentionally, conjures a tragic image of a confused old man with dementia that chimes with wider cultural fears about $\mathrm{AD}$ :

Everybody's talkin' at me,

I don't hear a word they're saying,

Only the echoes of my mind.

People stopping, staring,

I can't see their faces,

Only the shadows of their eyes. 


\section{Simon Buck}

"Funny How Time Slips Away," although ostensibly about catching up with an ex-lover, when sung by Campbell (as a duet with the song's composer, Willie Nelson) becomes an account of a temporal experience of $\mathrm{AD}$, or what scholars call "dementia time" (see Yoshizaki-Gibbons 182; Kafer 25-46). The original sardonic opening dialogue between reacquainted sweethearts takes on a new tragic pathos: "How I'm doing?/I guess that I'm doing fine." A "farewell" narrative consumes the song's lyrics about lost love: "Gotta go now/Guess I'll see you around/Don't know when though/Never know when I'll be back in town." By contrast, the Carl Jackson composition "Arkansas Farmboy" (Adiós), inspired by conversations with Campbell, departs from a "decline" narrative of dementia and ageing. It instead harks back to Campbell's early-career veneration of "elders." In the song, Campbell recalls the valuable role of older men in his childhood: his father, "the old man" who "grew wiser with time;" and his grandfather, who taught him to play guitar and sing traditional ballads. The song idealises old age as a purposeful stage of life, with older patriarchs positioned as repositories of family and community traditions. By reminiscing about how "elders" served important social functions in the past, the octogenarian singer implicitly questions whether his generation will achieve such a noble status in a more modern nation with an increasingly ageing population.

The dementia themes in Campbell's "late" music - that living with AD is a struggle for agency, authenticity, and selfhood; a state of "limbo" between life and death; and a fragmented encounter with time and memory - stitch together somewhat hackneyed dementia tropes, but they are nevertheless richly expressed using musical and lyrical techniques. An array of compositional and performative devices, including choice of repertoire, instrumentation, melody, and rhythm, and the revival and reinterpretation of songs, sounds, and stories from Campbell's past, construct a sonic dementia imaginary. This audio world is composed more from musical mood-making than straight narrative storytelling but is nevertheless redolent of some dimensions of Campbell's experience of AD.

\section{Need You More Than Want You}

Campbell's post-diagnosis music examines the topic of care from his own perspective, particularly as a religious, masculine celebrity, and from that of his familial caregivers (his wife and children). In the process, it also hints at the ethical ambiguities intrinsic to his "late" career. The most dominant care themes relate to his dependency and vulnerability. People magazine identified the lyric "I need the ones I love, Lord/More and more each day" from "A Better Place" (Ghost on the Canvas) as illustrative of Campbell's dependence on his wife Kim (Champ, "Glen Campbell Has Alzheimer's Disease"). On "Wichita Lineman" (See You There), the 
AD context reimagines the lyric "I need you more than want you" as a confession of a different kind of "need." "A Thing Called Love" (Adiós) discloses the gendered nature of Campbell's unease about dependency. Ostensibly about the "power of love" to bring a "giant of a man" to his knees, the song also subtly infers that AD unsettles Campbell's sense of his own rustic masculinity. In other songs, though, Campbell resists what Daniel Engster describes as the problematic tendency to treat vulnerability and dependency as synonymous (102). "Don't go to any trouble," Campbell sings on "No Trouble" (Ghost on the Canvas), "You know I won't be here long."

A Christian narrative about care, in which Jesus fulfils the role of caregiver, also features in Campbell's music, and provides the devout, masculine "cowboy" a more spiritually cohesive and culturally acceptable framework to understand, and accept, his own vulnerability. "Jesus take my hand," Campbell sings on "Waiting on the Comin' of My Lord" (See You There), "Guide me through the promise land." Campbell had long used spirituality to resist music industry ageism. In 1993, Cash Box asked the then-sexagenarian whether becoming an old, irrelevant "country relic" bothered him, to which Campbell replied, "I really don't worry about it anymore. That's what happens when you turn your life over to the Lord" (Wilson 18). His faith also helped neutralise the grief often associated with AD. In 2011, Campbell, who converted to Messianic Judaism two decades earlier, joked to People magazine that his AD was divinely ordained: "God just cleared a lot of things out" (Champ, "Glen Campbell: Living with Alzheimer's"). Significantly, Campbell's spiritual narrative about care has also made an impact with Christians: his story features in a 2019 self-help book on dementia caregiving from a "biblical perspective" (Gable 113).

In other songs, focus shifts from experiences of care to caregivers' experiences. "I'm Not Gonna Miss You" (I'll Be Me) posits that Kim, and not the forgetful Campbell, will deal with the memories and consequences of his dementia:

I'm never gonna hold you like I did,

Or say I love you to the kids.

You're never gonna see it in my eyes,

It's not gonna hurt me when you cry.

I'm never gonna know what you go through,

All the things I say or do.

All the hurt and all the pain,

One thing selfishly remains,

I'm not gonna miss you.

Margaret Morganroth Gullette argues that this Grammy Award-winning song reiterates "the standard 'dementia' trope" (the failure of memory 


\section{Simon Buck}

retrieval) (113), but its empathetic focus on Kim's challenges also reflects recent trends in $\mathrm{AD}$ narratives to centre caregivers' experiences (e.g., England 2017). If such narratives can risk sidelining the experiences of those with $\mathrm{AD}$ and disentangling "family caregiver-receiver mutuality" (Streck et al.), Campbell's songs instead stress the interconnectedness of caregivers' and care-receivers' experiences through a combination of lyrical content and emotive vocal performance. In "Am I All Alone (Or Is It Only Me)" (Adiós), the lyric "Do I hear you crying softly in your sleep?" communicates the emotional toll of Campbell's illness on Kim, while his sensitive vocalisation conveys his anguish at hearing her suffering. Similarly, the chorus to "All I Need Is You" (I'll Be Me) bluntly states Campbell's dependency, but its verses indicate how he reciprocates care: "I'm gonna hold you/Like there's no tomorrow."

While accounting for some of Kim's vulnerabilities as a caregiver, Campbell's music omits the emotional contexts that shaped her experience of providing care. Arguably, the real "ghost on the canvas" is Kim. None of the songs reference her philanthropic work raising awareness about caregiving, the care she provided her husband through his alcoholism and drug addiction (Campbell and Carter 188-202), or how their age gap affected her experience as a caregiver. Kim was 22 years younger than Campbell and dealt with the effects of his dementia while she herself was in reasonable health. If this made it "easier" for Kim to deliver everyday care, it nevertheless caused her emotional distress: first, by upsetting expectations about the "normal" age at which she might have expected to have become her spouse's carer (K. Campbell 191-201), and second, by deepening tensions around his care between her and Debby, Campbell's daughter from a previous marriage, who was older than Kim (see Campbell and Bego).

Three of Campbell's children - Cal, Shannon, and Ashley - joined their father as bandmates-caregivers for the "Goodbye Tour" and performed on his studio recordings. Their presence alone threaded notions of filial care and what Victoria Browne calls "generational time" (119-42) into his music, especially at live performances, where their practical care for their father on stage (reminding him of set lists, etc.) became part of the show's theatrics. The themes of filial care and generational time also translated to his recordings. Although "the caring female" archetype found in care narratives (Zimmermann 49-50) is a role primarily fulfilled by Kim in Campbell's lyrics, it is his daughter Ashley who embodies this role in his music. Ashley's banjo on "Gentle on My Mind" (See You There), if more or less similar to the original, sonically signifies both Campbell's rural genealogy and the care he receives from his daughter. Her quickfire picking establishes the tempo/pulse of the song and "carries" her father's voice along with the tune. Ashley's own composition, "Remembering," meanwhile, which she sings on I'll Be Me, describes the burden of memory as a caregiver's responsibility and joins 
a growing tradition of songs written and performed by (grand)childcaregivers, including Elvis Costello's "Veronica" (Spike 1989), Jessie J's "I Miss Her" (Alive 2013), and David Gilmour's "Faces of Stone" (Rattle That Lock 2015). Testament to the wider reverence for "elders" in country music (Buck), "Remembering” sits alongside the Chicks' "Silent House" (Taking the Long Way 2006) and Kenny Chesney's "While He Still Knows Who I Am" (Welcome to the Fishbowl 2012) in what can be described as a burgeoning dementia-themed country songbook. There are self-evident differences between songs composed by care-receivers and those written by caregivers, but the inclusion of both kinds of songs on Campbell's albums constitutes a hitherto unheard musical dialogue between caregiver and care-receiver. In "It's Your Amazing Grace" (Ghost on the Canvas), for example, Campbell acknowledges the care work that Ashley sings of in "Remembering:" "Everything I see in this world/I see it through you."

The ethics surrounding Campbell's family's and management's decision-making about his career, especially after his AD had progressed significantly, are anything but clear cut. Kim was aware that audiences might be critical of her. Announcing the tour to People magazine, she hoped that "people realize it's fulfilling for Glen to do music and feel all the love he gets from his fans. It really keeps him going" (Champ, "Glen Campbell Has Alzheimer's Disease"). Kim's claim that touring or recording were forms of "music therapy" was at best misleading and at worst neglectful of care responsibilities. Nevertheless, Campbell's music itself reinforces this narrative of music as therapy. I'll Be Me experiments with the idea that live performance is a kind of "care work." The album's two live recordings, taken from the "Goodbye Tour," represent the interactive and less-mediated environment of live performance as a "community of care" in which Campbell and his fans can support one another. After singing the line "Some days I'm so confused, Lord" during a live version of "A Better Place," Campbell laughs knowingly to his audience, telling them, sarcastically, "sometimes." Similarly, the content of Campbell's old material speaks to him and his audience in new ways when performed in public. On "Wichita Lineman," Campbell sighs/chuckles to himself/his audience after the line "I know I need a small vacation." After ending with an elongated vocalisation on the final lyric, "And I'm doing fine," the bated breath of the audience erupts into almighty applause, awakening joyful yelps from Campbell. These affects recall a similar moment in the I'll Be Me documentary, when Campbell forgets the lyrics to "Galveston" during a concert and so the crowd sings them back to him. As Ashton Applewhite contends, spontaneous audienceperformer interactions like these help us to imagine an ideal empathetic relationship between care-receiver and care-provider (66), wherein both parties engage with one another with openness, patience, and mutual appreciation. 


\section{Simon Buck}

Conversely, Campbell's final album, Adiós, recorded after his condition had progressed significantly, suggests that the controlled recording studio setting might be preferable to live performance in terms of care ethics. Campbell sang each song on the album line by line, as he was no longer able to complete entire takes (Dauphin). For the listener, the smoothness of modern digital editing masks these performance difficulties in a way that a live concert setting or documentary film cannot. This may explain why I'll Be Me received more critical attention than Adiós: audiences craved music that expressed the unvarnished "tragedy" of Campbell's illness. From a care ethics perspective, however, studio recording gave the increasingly cognitively impaired Campbell the ability to make music without the potential pressures, pitfalls, and indignities of live concerts. Many of Campbell's final gigs were dogged by moments of confusion, embarrassment, and anger that, if truthful to parts of his life with $\mathrm{AD}$, did not do justice to the talented musician and performer that he had once been (and could still be). The ethics of care in Campbell's music are highly contextual and sit with the need to preserve his identity and legacy as a musical legend.

Taking this debate in new directions, Campbell's daughter interpreted his late performances as acts of "care" towards his listeners. At an Alzheimer's Association event in 2012, Ashley suggested that Campbell's music connected emotionally with those with $\mathrm{AD}$ and their caregivers: "We decided to go on a farewell tour with him to keep his struggle public. ... We didn't want people to think they were going through this alone. This isn't a disease that just affects the person living with it - it affects their entire family" (Alzheimer's Association). Whether this was achieved at the expense of Campbell's dignity is questionable, but Campbell's songs, unsurprisingly perhaps, do not delve too deep into these more critical dimensions of the care ethics in his late career. Instead, his songs contemplate what Amelia DeFalco describes as the "ontological crisis" of care in contemporary Western societies (37): how care reconfigures his pre-established identity as a male head of the family.

\section{Fate of Campbell}

This chapter goes some way to re-evaluating how popular music reflects and shapes cultural attitudes towards ageing, $\mathrm{AD}$, and care. The possibilities and limitations of musical narratives warrant further study, considering that increasingly ageing populations in the Global North mean more older acts will likely opt to musically narrate their own experiences of dementia in the future (although Ashley Campbell's successful solo career suggests the caregiver narrator continues to be the dominant subjectivity in dementia song). Charting Campbell's age-related music from "Fate of Man" to Ghost on the Canvas indicates that a life course approach might help scholars to de-exceptionalise older artists' "late" 
careers. Campbell did not suddenly begin to sing about ageing once he entered his 80s. Throughout his career, Campbell at times resisted the ageist tendencies of wider popular culture but also reinforced "decline" narratives about ageing. Following his AD diagnosis, Campbell's music expressed mostly stereotypical, although occasionally challenging, narratives about $\mathrm{AD}$ and care, particularly regarding notions of agency, fracture, mortality, (co-)dependency, and vulnerability.

Moderately successful record sales notwithstanding (Graff), it is unclear what most listeners made of Campbell's age- and dementiathemed music. Clearly, the stories Campbell tells in his songs did not exactly correlate with his listeners' lives. Although Campbell came from a poor community and remained attached to his rural, working-class roots, he was a white, male, mansion-owning celebrity with access to private care. This begs the question: did listeners in Campbell's home state of Arkansas - a "stroke-belt" state that in 2015 had the fourth highest $\mathrm{AD}$ death rate in the nation, which in 2017 reported a total annual value of $\$ 2.5$ billion unpaid care - identify with his dementia- and age-themed music? For some audiences, it is likely that Campbell's songs were less important than his story. A 2019 Alzheimer's Society (UK) blog post written by British poet Tony Ward, who cared for his wife Sheila at home until her mild cognitive impairment progressed to AD in 2012, leading her to move into a care home, gives some insight into what Campbell's story could mean for those dealing with the consequences of $\mathrm{AD}$ :

Glen Campbell was one of our favourite country music singers. When Glen was diagnosed with Alzheimer's disease, he was determined not to "give up on life." He was also keen to share his Alzheimer's journey in order to raise awareness of the condition. He did this, in part, through a series of "no-holds-barred" documentaries. His example strengthened our own resolve. We were determined that the diagnosis of dementia would not drown out the music.

(Ward)

Tellingly, it was not Campbell's music about dementia, but his determination to continue playing music, and to tell his story in other ways, that inspired the Wards.

Music was just one of several narrative forms in Campbell's multi-textual career. The I'll Be Me documentary provides a different portrait of the "ghost on the canvas" than we find in Ghost on the Canvas. Campbell's music videos and album artwork also visualised other kinds of $A D$ narratives. Kim's recent memoir deserves a critical literary analysis as Campbell's music does a musical one. These "texts" contain nuanced, and potentially more influential, narratives about ageing, $\mathrm{AD}$, and care than those in Campbell's songs. If at times Campbell's music portrayed complicated sentiments about these topics, it generally reproduced well-trodden 
narratives and, revealing of the inherent limitations of popular musical narrative, omitted more uncomfortable topics relating to his condition. Apart from memory loss, no songs reference symptoms of Campbell's AD. More is revealed in Kim's memoir about Campbell's repetitive questioning, obsessive compulsions to complete domestic tasks, wandering away from home, snappy attitude, and sudden sexual desire (K. Campbell 183-265) than in his songs. No songs explore the later stages of Campbell's AD, after he entered a Nashville memory care community in 2014, when aphasia affected his ability to play (Gundersen). His music says nothing about his transition to institutional care; tensions between family members about his care and inheritance (legal disputes between Kim and children from his previous marriages continued until 2019); or the physical abuse Kim received from Campbell during the worst stages of his illness. Despite all this music, then, the "ageing," "cognitively impaired," and "vulnerable/dependent" Campbell still remains a "ghost on the canvas."

\section{Works Cited}

\section{Primary Sources}

Alive Inside: A Story of Music and Memory. Directed by Michael Rossato-Bennett. Projector Media, 2014, DVD.

Alzheimer's Association. "Glen Campbell Sings to Congress, Keeps Alzheimer's in the Public Eye." Alzheimer's Association, 23 May 2012, alz.org/blog/alz/ may_2012/glen_campbell_sings_to_congress_keeps_alzheimer_s.

Botwin, Carol. "Young World: Glen Campbell's Winning Ways Take Him into Movies." Florida Today, 16 Mar. 1969, p. 20.

Campbell, Debby, and Mark Bego. Life with My Father Glen Campbell. Omnibus Press, 2014.

Campbell, Glen. Gentle on My Mind. Capitol Records ST 2809, 1967, LP vinyl. _. "Wichita Lineman"/ "Fate of Man." Capitol Records 2302, 1968, 7" vinyl.

- Houston (I'm Comin' to See You). Capitol Records, 1974, LP vinyl.

- Rhinestone Cowboy. Capitol Records SW 511430, 1975, LP vinyl.

- Letter to Home. Atlantic 790 164-1, 1984, LP vinyl.

- Meet Glen Campbell. Capitol 34132, 2008, CD.

- Ghost on the Canvas. Surfdog Records 233444, 2011, CD.

. See You There. Surfdog Records 1-18013, 2013, CD.

CD.

. Glen Campbell: I'll Be Me. Big Machine Records BMRAGC0100, 2015, . Adiós. Universal 26500, 2017, CD.

Campbell, Glen, and Tom Carter. Rhinestone Cowboy: An Autobiography. Villard Books, 1994.

Campbell, Kim. Gentle on My Mind: In Sickness and in Health with Glen Campbell. Thomas Nelson, 2020.

Champ, Clark. "Glen Campbell Has Alzheimer's Disease.” People, Jun. 2011. 
. "Glen Campbell: Living with Alzheimer's." People, Jul. 2011.

Chesney, Kenny. Welcome to the Fishbowl. Blue Chair 88697-94866-2, 2012, CD.

Chicks. Taking the Long Way. Open Wide 8287680739 2, 2006, CD.

Corr, Charles A. et al. Death \& Dying, Life \& Living. Cengage Learning, 2018.

Costello, Elvis. Spike. Warner Bros 925 848-1, 1989, LP vinyl.

Dauphin, Chuck. “Glen Campbell's Final Album 'Adiós': How It Came Together.” Billboard, 2 Jun. 2017, www.billboard.com/articles/columns/country/7817455/ glen-campbell-final-album-adios-wife-kim-carl-jackson-interview.

Deusner, Stephen M. "Glen Campbell: Ghost on the Canvas." Pitchfork, Aug. 2011.

Gable, Dorothy. Dementia Caregiving from a Biblical Perspective: Your Guide for the Journey. Westbow Press, 2019.

Gilmour, David. Rattle That Lock. Columbia 88875123291, 2015, CD.

Glen Campbell: I'll Be Me. Directed by Trevor Albert and James Keach. PCH Films, 2014.

The Glen Campbell Goodtime Hour. Directed by Marty Pasetta. Shout Factory, originally aired 1969, DVD.

“Glen Campbell's Road: Paved with Glitter?” Teen, Jul. 1968.

Graff, Gary. "Midnight Cowboy." Billboard. 21 Jan. 2012, p. 25.

Gundersen, Edna. "For Glen Campbell, the Past Is a Present." USA Today, 25 Aug. 2011, www.usatoday.com/life/music/news/2011-08-24-glen-campbellalzheimers_n.htm

Harrison, James. Monday's Message: A Refreshing Word of Encouragement and Spiritual Direction from God Each Week! WestBow Press, 2012.

Hattenstone, Simon. “Glen Campbell: One Last Love Song.” The Guardian, 26 Aug. 2011, www.theguardian.com/music/2011/aug/26/glen-campbell-interview.

Jessie, J. Alive. Lava Music and Universal Republic 3752173, 2013, CD.

Kapsambelis, Niki. The Inheritance: A Family on the Front Lines of the Battle Against Alzheimer's Disease. Simon and Schuster, 2017.

Magnusson, Sally. Where Memories Go: Why Dementia Changes Everything. Two Roads, 2014.

McCrae, Niall. "Older People with Dementia." The Art and Science of Mental Health Nursing: Principles and Practice. Edited by Ian Norman, McGraw-Hill Education, 2013, pp. 502-20.

O’Brien, Greg. On Pluto: Inside the Mind of Alzheimer's. Codfish Press, 2018.

Pulsford, Dave, and Rachel Thompson. Dementia: Support for Family and Friends. Jessica Kingsley Publishers, 2012.

Saunders, Rubie. "Glen's Good Times." Young Miss, Nov. 1969, pp. 18-22.

Snelling, Sherri. A Cast of Caregivers: Celebrity Stories to Help You Prepare to Care. Balboa Press, 2013.

Special Committee on Aging. "The National Plan to Address Alzheimer's Disease: Are We on Track to 2025?" Hearing Before the Special Committee on Aging, United States Senate, 113th Congress, Serial No. 113-4, 24 Apr. 2013.

Sutton, Joan. The Alzheimer's Diary: One Woman's Experience from Caregiver to Widow. iUniverse, 2014.

True Grit. Directed by Henry Hathaway. Paramount Pictures, 1969, DVD.

“True Grit.” Janesville Daily Gazette [Wisconsin], 26 Jun. 1969, p. 43. 


\section{Simon Buck}

Ward, Tony. “Tony's Story: 'We Were Determined Dementia Wouldn't Drown out the Music.'” Alzheimer's Society (UK), 26 Sept. 2019, www.alzheimers. org.uk/blog/tony-ward-poem-farewell-tour.

Webb, Jimmy. The Cake and the Rain: A Memoir. St. Martin's Press, 2017.

Wilson, Jerry. "Glen Campbell: A Cowboy's Christmas." Cash Box, 25 Dec. 1993, p. 18.

\section{Secondary Sources}

Applewhite, Ashton. This Chair Rocks: A Manifesto Against Ageism. Celadon Books, 2019.

Baird, Amee et al., editors. Music and Dementia: From Cognition to Therapy. Oxford UP, 2020.

Barthes, Roland. "The Grain of the Voice." Image-Music-Text. Hill and Wang, 1977, pp. 179-89.

Basting, Anne Davis. Forget Memory: Creating Better Lives for People with Dementia. Johns Hopkins UP, 2009.

Behuniak, Susan M. "The Living Dead? The Construction of People with Alzheimer's Disease as Zombies.” Ageing \& Society, vol. 31, no. 1, 2011, pp. 70-92.

Bennett, Andy. Music, Style, and Aging: Growing Old Disgracefully? Temple UP, 2013.

Bitenc, Rebecca. Reconsidering Dementia Narratives: Empathy, Identity and Care. Routledge, 2020.

Browne, Victoria. Feminism, Time, and Nonlinear History. Palgrave Macmillan, 2014.

Buck, Simon H. The Aged South: Old Age and Roots Music in the US South, 1900-1945. 2020. Northumbria U, PhD dissertation.

Chivers, Sally. The Silvering Screen: Old Age and Disability in Cinema. U of Toronto P, 2011.

Clay, Karen et al. "The Rise and Fall of Pellagra in the American South." Journal of Economic History, vol. 79, no. 1, 2019, pp. 32-62.

Cobussen, Marcel, and Nanette Nielsen. Music and Ethics. Routledge, 2016.

Cohen, Elias S., and Anna L. Kruschwitz. "Old Age in America Represented in Nineteenth and Twentieth Century Popular Sheet Music.” The Gerontologist, vol. 30, no. 3, 1990, pp. 345-54.

Cole, Thomas R. The Journey of Life: A Cultural History of Aging in America. Cambridge UP, 1992.

Couser, G. Thomas. Signifying Bodies: Disability in Contemporary Life Writing. U of Michigan P, 2009.

DeFalco, Amelia. Imagining Care: Responsibility, Dependency, and Canadian Literature. U of Toronto P, 2016.

Eisiminger, Sterling. “Redneck.” American Speech, vol. 59, no. 3, 1984, p. 284.

Elliott, Richard. The Late Voice: Time, Age and Experience in Popular Music. Bloomsbury, 2015.

England, Suzanne E. "Private Troubles, Master Narratives: Dilemmas of Dementia Care in a Short Story." The Gerontologist, vol. 57, no. 5, 2017, pp. 963-68.

Engster, Daniel. "Care Ethics, Dependency, and Vulnerability." Ethics and Social Welfare, vol. 13, no. 2, 2019, pp. 100-14. 
Fox, Pamela. Natural Acts: Gender, Race, and Rusticity in Country Music. U of Michigan P, 2009.

Frank, Arthur W. The Wounded Storyteller: Body, Illness, and Ethics. 2nd ed. U of Chicago P, 2013.

Gardner, Abigail, and Ros Jennings. Ageing and Popular Music in Europe. Routledge, 2019.

Goldman, Marlene. Forgotten: Narratives of Age-Related Dementia and Alzheimer's Disease in Canada. McGill-Queen's UP, 2017.

Gullette, Margaret Morganroth. Ending Ageism, or How Not to Shoot Old People. Rutgers UP, 2017.

Harkin, Anthony. Hillbilly: A Cultural History of an American Icon. Oxford UP, 2005.

Hartung, Heike. Ageing, Gender, and Illness in Anglophone Literature: Narrating Age in the Bildungsroman. Routledge, 2015.

Hemphill, Paul. The Nashville Sound: Bright Lights and Country Music. U of Georgia P, 2015.

Higgs, Paul, and Chris Gilleard. "Ageing, Dementia and the Social Mind: Past, Present and Future Perspectives." Sociology of Health \& Illness, vol. 39, no. 2, 2017, pp. 175-81.

Jones, Dylan. The Wichita Lineman: Searching in the Sun for the World's Greatest Unfinished Song. Faber \& Faber, 2019.

Kafer, Alison. Feminist Queer Crip. Indiana UP, 2013.

Latimer, Joanna. "Repelling Neoliberal World-Making? How the Ageing Dementia Relation Is Reassembling the Social." Sociological Review, vol. 66, no. 4, 2018, pp. 832-56.

Mittlefehldt, Pamela J. "Writing the Waves, Sounding the Depths: Water as Metaphor and Muse." Interdisciplinary Studies in Literature and Environment, vol. 10, no. 1, 2003, pp. 137-42.

Negus, Keith. "Narrative Time and the Popular Song." Popular Music and Society, vol. 35, no. 4, 2012, pp. 483-500.

Selberg, Scott. "Rhinestone Cowboy: Alzheimer's, Celebrity, and the Collusions of Self." American Quarterly, vol. 69, no. 4, 2017, pp. 883-901.

Stige, Byrnjulf. "Practicing Music as Mutual Care." Where Music Helps: Community Music Therapy in Action and Reflection. Edited by Byrnjulf Stige et al. Ashgate Publishing, 2013.

Streck, Brennan P. et al. "Family Caregiver-Receiver Mutuality: A Concept Analysis." Advances in Nursing Science, vol. 43, no. 2, 2020, pp. E71-E79.

Whiteley, Sheila. Too Much Too Young: Popular Music, Age and Gender. Routledge, 2005.

Wills, Garry. John Wayne's America. Simon and Schuster, 2013.

Yoshizaki-Gibbons, Hailee M. "A Call for the Greying of Critical Disability Studies." Manifestos for the Future of Critical Disability Studies: Volume 1. Edited by Katie Ellis et al. Routledge, 2019, pp. 179-88.

Zimmermann, Martina. The Poetics and Politics of Alzheimer's Disease LifeWriting. Palgrave Macmillan, 2017. 


\title{
8 A Glut of Slippers \\ The Chronotope of Older Age in the Contemporary North American Short Story
}

\author{
Elizabeth Barry
}

The subjective experience of advanced old age is overshadowed - whether the shadow cast is felt negatively or not - by the sense of imminent ending. Wilma, the protagonist of Margaret Atwood's short story "Torching the Dusties," contrasts her residential home with a "maternity hospital:" "About the opposite, she thinks caustically: it's an exit from life, not an entrance" (238). One's sense of time constitutively changes in this period of life. And so there is, in this respect, a particularly good fit between this changed apprehension of time and the short story form. Mikhail Bakhtin observed that every genre is defined by its chronotope, generic conventions that disclose the "intrinsic connectedness of temporal and spatial relationships that are artistically expressed in literature" (84). In this respect, the short story as a genre is particularly well placed, as Rachel Falconer has argued in a different context, to "capture [the] sense of time foreshortened, or already run out" (699) that habitually attends the cultural understanding - and to some extent the lived experience - of advanced old age.

Falconer is not talking explicitly about age here, but the apocalyptic sensibility that attended the millennium - and arguably is even more prevalent since then, in the wake of a financial crash and at a catastrophic tipping point in relation to climate change (not to mention, most recently, a global pandemic). The short story is already primed by its very form to "net" what Falconer calls "our culture's apocalyptic sense of impending crisis" (699). And this culture figures old age as part of the crisis, invoking the "grey tsunami" of boomer retirees and their expensive care needs. The contemporary short story has responded accordingly, making a direct connection between this sense of time in older age and the widespread cultural sense of foreshortened horizons. In one of the short stories this chapter will consider, John Barth's "Peeping Tom," the ageing narrator aligns his perspective on contemporary society with the internalised perception of the prospects of his age group: the world going "downhill, at least on balance, despite there having been no world wars lately. Nor are we-all what we used to be, either" (Barth 6). In all of the literary examples I will consider - Barth's 2008 short story collection

DOI: $10.4324 / 9781003058618-9$ 
The Development, in which "Peeping Tom" features; Margaret Atwood's 2014 story "Torching the Dusties;" and Joy Williams' 2016 "Stuff" - the form of the short story converges with the sense of ending encountered in old age and a contemporary sensibility in which temporal horizons are foreshortened by the threat of economic and environmental disaster. In Falconer's words, "generic chronotope and contemporary Western time sense" - and to these we might add a seemingly bleak perception of old age - "converge upon a shared premise that [in the words of Melissa Clark (153)] 'time and space are condemned entities" " (706).

Our expectations, then, of these stories might well tend towards the dystopian. The idea that life has all but already ended in older age is both symbolised and exacerbated by the confined, controlled and marginalised locales to which older people are consigned. The old people's home in the popular imagination is seen as an institution tending more towards an archetype of prison than any recognisable definition of "home." Dystopia is often identified, as Urzula Terentowicz-Fotyga has argued, with the destruction of privacy, "a critical representation of different forms of communal living and the ubiquity of surveillance systems" (17), all of which are also seen to characterise representations of care homes or security-conscious retirement communities (with a vested interest in policing those distracted residents who might wander, as well as those who might intrude and prey on vulnerable inhabitants). Barth's narrator, Tim Manning, remarks upon the incongruity of "roundthe-clock gatekeepers" and "phone-ahead clearance for visitors" in his low-crime area (5), but deals from the opening story onwards with the heightened sense of risk that older age itself can confer. Care home stories, as Sally Chivers and Ulla Kriebernegg have observed, can take the form of jailbreak narratives: uplifting tales, but at the same time narratives of individual freedom versus institutional control that leave the negative associations of care homes intact. And the world of these stories is likewise no utopia; there is little faith in the future in an environment showing the signs of decline and even imminent collapse. Old age seems to serve in this context as a metaphor for a contemporary society on the brink of financial implosion or environmental extinction. When we pick up a care home story by Margaret Atwood, in particular, what else could we expect?

Yet what emerges in these stories is a counter-intuitive distance between the older protagonists and the fate of their ageing world. They find a means to defy expectations of their life stage and retain agency and selfpossession. Not only this, however, but if the "homes" that they inhabit are far from the positive archetype of "home," this distance can in some respects be a liberating one. Even the apprehension of the end being near can galvanise as well as disillusion. Terentowicz-Fotyga has argued that "dystopian society either discourages or firmly forbids the forms of social interactions that might promote privacy, intimacy and individualism" 
(17), qualities that are likewise seen to be negated by the managed spaces and intrusive personal care of the assisted living facility. The fiction in question, however, presents a variety of kinds of intimacy developing rather than declining in such environments, and in relation to an experience of crisis, and thereby offers a more nuanced understanding than might be envisaged of the life possible in "elder" spaces.

\section{Space, Time and Genre in Stories of Older Age}

The geographical and institutional silos in which advanced older age often finds itself "contained" - the nursing home, the assisted living facility, the retirement community - are often perceived, in Simon Biggs' words, to have been "charged to manage the difficulties circumscribed within" (147). Glenda Laws has examined the relationship between age and space, observing the factors determining and limiting the space occupied by older people: namely, accessibility, mobility, motility (how far we can move), scale (how far we are allowed to move) and segregation. As we age, we are confined to a "discrete location," whereas "youth," in contrast, "is everywhere" (Laws 93, 91; cited in Snaith 125). Helen Snaith, reading Atwood's story "Torching the Dusties" in line with Laws' ideas, observes that it is easier for the young to (literally) besiege and attack older people in that dystopian story because of the latter's concentration and static location in care homes (124).

The discrete locations of older-age care as they are described in these stories are not only an indictment of the marginalisation of older people, however, but also the occasion for a particular aesthetics that makes creative play with the tensions between inside and outside, private and public, care and control. I read these spaces here in line with the logic of Mikhail Bakhtin's chronotope, which as noted earlier is a feature of narrative that brings time and space into explicit relations; where, in Bakhtin's words, time "thickens, takes on flesh, becomes artistically visible" (84). The spaces of the stories in question institute and impose their own temporal laws and rhythms. They are often the starting point for a reimagining of older age allowing for a critique of structurally ageist practices, "an optic," in Bakhtin's words, "for reading texts as x-rays of the forces at work in the culture system from which they spring" (427). In these particular narratives, however, they also have the potential to be a subversive world-within-a-world.

Perhaps the chronotope most often invoked as the archetypal locus of time and space is the home, and it is this concept that will be a focus for the discussion. I also want to follow one of the most well-known applications of Bakhtin's idea: that in the film studies work of Vivian Sobchack. Her reading of locations in film noir and neo-noir, in connection with (or more often contradistinction to) the idea of home, serves as a model for reading the care home and the retirement development in this chapter. In 
her classic essay on the chronotope in film, "Lounge Time," Sobchack talks of the "material premises" of film noir (130). It isn't clear whether or not the pun is intended, but it serves her argument and ours. The physical premises - the built environments of film noir, the "non-places" of transient social interaction (the cocktail bar, the hotel room, the boarding house, the bus or train station) - are also the logical premises for the narrative operation of noir storylines: the basis for the operation of spatial and temporal coincidence or disjunction, and the luck or misfortune these chance encounters or missed encounters represent.

What, then, if we think of care settings and retirement communities in a similar way? They are ostensibly places of stasis rather than movement: for some residents, at least, the interaction will effectively be one-way, an arrival without a departure. In one sense, then, this residence is permanent, none more so. In another, of course, it is the definition of transient. These are the waiting rooms for le grand départ. Like Sobchack's transient environments, they too represent a kind of limbo, characterised by generic institutional rooms and relationships that begin, at least, through no more than physical contiguity and temporal coincidence, "real" family relegated to the status of visitor. Sobchack describes the dissonant relationship between bars and hotel rooms and the chronotope of "home:" both provide food, shelter and a resting place, but in the former locales, these are only fractured and alienated substitutes for the "nurturant functions" of home (156-67). Even more pointed, of course, is the uncanny disjunction between the nurturant functions of the care "home" and the (forsaken) environment that one once called home.

It might seem an unlikely comparison, but the dystopian spaces, dark humour and often terse and ironic style of the contemporary American short stories of old age can be seen to negotiate space and its relationship with time in ways comparable with the film noir of Sobchack's argument. Both deal in environments that represent a kind of "non-space" that denies their inhabitants existential agency or fulfilment. Dana Polan in Power and Paranoia coins the idea of a "negative existentialism" (Polan 208 qtd. in Sobchack 138), observing that in American films of the 1940s, "environments . . . don't reflect back to a character his/her personality or values - that is, his/her freedom to shape externality according to individual desire - but, quite the contrary, rather demonstrate the radical externality and even resistance of environment to the imprinting of a self upon environment" (Polan 253 qtd. in Sobchack 138). The care home room, and its curation by the institution's staff, can also be seen to be a space particularly obdurate in its resistance to the imprint of the self. In Joy Williams' "Stuff," the care home where the protagonist Henry's mother lives puts stock photographs of generic "happy families" in the photo frames that decorate the rooms, in place of the residents' own families (par. 27). This simulacrum of family is intended to ward off suicidal thoughts: either the cognitively challenged resident will not 
distinguish these photogenic figures from her own family, the thinking seems to run - or if she does, the photos will serve as a form of minimal company. The rupture with the idea of home as an extension of self is exacerbated in this story by the fact that Henry's mother, along with a number of other residents of the generically named "Ambiance" home, lost their original possessions in a catastrophic flood at their former care home. This disaster precipitated the current move and has meant that the space of their new institution is a kind of tabula rasa which they are unable to furnish with a link to the past, let alone the future. The name "Ambiance" itself is suitably an empty signifier which reinforces the impression of a perpetual present, a free-floating atmosphere that has to be constantly refreshed rather than having an organic relationship to past memories or future projects. In the home, or at least the idyllic archetype of the American home, quotidian functions such as sleeping, eating and drinking "are secured and transfigured into intimate social communion" (Sobchack 138); in the care home, they can be routinised, rendered "public" and remain only functional.

The cocktail lounge or hotel room, furthermore, "spatially rend and break up the home - and, correlatively, family contiguity and generational continuity" (Sobchack 158). The same can be said for care homes - the eating, drinking and sleeping functions are more contiguous than in the streets of late noir (or the strip malls seen in more contemporary cinema) but less than in the home proper. Wilma, Margaret Atwood's protagonist in her story "Torching the Dusties," prepares her own breakfast in her "kitchenette" at Ambrosia Manor. As Biggs observes of space in care homes, there is a "degree of privacy and autonomy" (147) here, while it remains - as Helen Snaith comments - also "safe space" (122) for the increasingly vulnerable Wilma. She has a degree of autonomy, but this is far from home territory. The "dry breakfast cereals" (Atwood 232) are provided for her, and she is at the mercy of the limited and institutional provisions - Tobias, for whom she makes breakfast, laments the lack of croissants. Other meals are taken in the communal dining room, residents guarding their share of the best bread rolls. Wilma's assistant, Katia, is somewhere between a domestic servant, a care assistant and a hotel chambermaid: the chocolates left on the residents' pillows ("it's the details that differentiate Ambrosia Manor from its rivals, said the brochure" [Atwood 253]) allow them to appreciate the luxury of their circumstances, but also remind them that this is far from being a true home.

Time is also a factor in Polan's "negative existentialism." He argues that "if the project (to use the existentialists' term) is a narrative activity through which human beings work to come to terms with an environment and make it their own," the environment of a film noir can be a "disruption, subversion, dispersion of projects," representing the gap between an enduring "intention" and the abandoned or foiled "realization" (209). In care home narratives, there are few projects in evidence. 
Time is almost always felt, it appears, in relation to an imminent end which makes any sustained existential project futile. Just as leisure in noir is reframed as idleness, waiting and underemployment (Sobchack 158), in the absence or frustration of a project, activities and even socialising in care settings can be experienced as filling time or manufacturing a sense of purpose that can only feel contrived. In "Torching the Dusties," Wilma reflects acerbically on the role of the therapist Shoshanna and "the fingerpainting or pasta necklace making" she has "cooked up to give them all a reason for staying on the planet for another sunrise" (Atwood 243). It is not so much that life is felt to be uneventful, but that the one big event on the horizon will serve to terminate it. Life in this last phase is also often framed in terms of losses - of friendships, of responsibilities, of functions. Finally, this period can be seen in terms of risk. While the care home is designed to minimise risk, this very preoccupation forces attention to it. Every day can seem an exercise in short-term goals - the evasion of accident, over-exertion or simply the bad luck of a medical event - leaving little time or space for the realisation of larger plans.

The gap between home and care home, project and pastime seems to open wide, even in these stories, and their characters do not forbear to comment acerbically on the circumscribed motility and scale, in Laws' terms (93), of their existence and the limitations imposed upon their future in terms of both space and time. The scope, structure and point of view of the stories provide, then, Bakhtin's "optic" on the "forces at work" (427) in the social system in relation to the experience of ageing. In each case, however, the protagonists find intimacy even in their managed spaces and enjoy a new sense of shared purpose in the absence of Polan's individualistic existential project. In "Torching the Dusties" and Barth's "Peeping Tom," this comes in response to an outside threat quickening the pulse; in Williams' "Stuff," the project is death itself and a programme of collective spiritual and mental preparation. The limitations of the situation are surpassed in all cases, whether the process is literal, psychological or metaphysical in nature. And it is the sense of impending catastrophe itself that is the catalyst for renewed energies and intimacies. Despite their acerbic tone, these stories assert the ingenuity, agency and, on occasion, sheer fun both conserved and spent in older age, in the face of both an immediate environment and also a world depleted of such resources.

\section{"Stuff"}

It was December, and he was in the windowless consultation room of his doctor's office. A young man with a stunningly high forehead was informing him that he had lung cancer and would die - the certainty of this being considerable - soon. 


\section{Elizabeth Barry}

The story opens with brutal directness. Even the symbol is direct here. The windowless consultation room in which the protagonist, Henry, is given a terminal diagnosis - a perfect chronotope of temporal and spatial equivalence - sends an unequivocal message: No Way Out. Henry is a middle-aged man - young to have this news - who still works in his local community, albeit feeling increasingly estranged from it by his advancing age. He has little family other than his ageing mother, whom he visits in her care home, and this unsparing opening makes it clear that he is likely to predecease her, upsetting the expected order of things and resetting the relations between generations in the story. The language of this passage is direct, but it is also unsatisfying. What is "considerable" certainty? What, indeed, is "soon"? But the outlook is clear. The story continues in a similar vein, full of wounding counterpoint but delivered baldly and without preamble. Henry employs a precautionary seat belt: he can "harness himself" into his car but not his life. He thinks back to the record he bought as a child, "How to Teach Your Canary to Sing" (par. 7) - but there had been no warning in this case. He "hadn't even had a canary" (par. 9), and lo, his "canary record" (in another sense) is still deficient. He has found out too late.

The directness of the diagnosis and the prognosis will not, the narration suggests, be replicated when Henry tells his mother: "He'd never been able to tell her anything straight out, and this was no exception" (par. 12). He cannot even contemplate the scene directly, but sets it at a distance by imagining it via the column he writes as a journalist on a local newspaper: "He'd write a column about buying a last Christmas tree and then show it to his old mother in that frightful home she was in, and, in that way, inform her that he was about to die" (par. 12). The emotion that he might be feeling - must be feeling - is displaced into ironies, aperçus that he might be noting for a future column. He observes the unlikelihood of his parking fee being waived on account of the news with a similar strategy: "[i]f the recently condemned weren't required to pay their fair share, the lot would bring in no money at all" (par. 10). Even the internal focalisation, his thoughts conveyed in the third person, registers itself an ironic device, we might almost imagine willed on his part, whereby his own perspective all but converges with the aesthetic effects he desires to create for his readers. Rather than simply bringing us closer to Henry's thoughts and feelings, this narrative point of view (designed for intimacy) in fact makes us doubt the authenticity of these feelings: they are not fundamentally different from his "real" feelings, perhaps, but are always already being edited. Ironically (again), a more omniscient narration would produce the effect of a "realer" set of feelings. As it is, his whole life is lived at a distance, as a character, something capitalised on by his newspaper columns about local life and his role as face of the town - the living focaliser of its point of view - on the front of the telephone directory. 
This distancing strategy translates into a lack of empathy, as when he describes the open sore on the receptionist's face at the care home as risking opening up and offering a glimpse of the "preposterous fundamentals, rather like the truth window in a straw house" (par. 29), the artful metaphor taking precedence over any sympathy for the man's plight. Henry seems to want to preserve a Wildean reversal of priorities in the story, life subservient to art. Indeed, reality is presented as so "preposterous" that a sense of normality must be constructed with pictures of fake relatives, or the "artist's impression" of the town's new windfarm: “[g]reen pastures, sleek white blades, blue sky" (par. 8). Yet everywhere that Henry goes, he is faced with the fundamentals that he can no longer ignore.

Indeed, the windfarm seems idyllic, an ecologically progressive new version of the pastoral, but there are darker undertones to the environment of this story, even beyond the world of the care home (which is, in this story, a haven of sorts, if not exactly home-like). Henry's mother has moved to her current residence from another care home, however, one which was destroyed by floods, as touched on above, and in which many residents were left for dead. The windfarm seems to have come too late, the artist offering in his or her vision of elemental harmony only a partial impression of the reality of Henry's surroundings.

In a twist familiar for readers of Williams' work, and in line with the argument I am making about the subversive potential of the time and spaces of older age, the story does not play out as we expect. Old age does not serve as a memento mori, and Henry's mother recovers her aplomb after her brush with apocalypse, in a way that Henry himself seems ill-equipped to do. He will die before his mother, the relatively young receptionist has the unhealed wound, not the aged residents, and the home itself comes to seem more a serene religious retreat than a place of incarceration or moribund decay. Here, Henry's mother at least has a space in which to prepare herself for death and companions with whom to talk about mystical philosophy. Neither is this simply a colloquially " "philosophical" approach to death in old age - an equanimity synonymous with resignation. Instead, she has an existential project of sorts: a programme of engagement with an ancient and arcane branch of philosophy, Gnosticism. She is removing herself in all senses from Henry's world, but as well as a departure, this is an arrival somewhere else - an arrival that excludes him. She is in control of the process whereby she can gradually remove herself from worldly concerns. Henry, on the other hand, is summarily dismissed: from life by the doctor's terse sentencing, and from any support or guide to the transition by his mother's abrupt discharge ("'Goodbye, Henry.'/'But I just got here,' he muttered” [par. 52]). $\mathrm{He}$ is also dismissed from his role as a storyteller and interpreter (albeit a studiedly folksy one) of his environment. His role in life as a local journalist seems displaced by the "monitor" in the care home lobby on which "news of the weather scrolled by" (par. 54). The news may just as 


\section{Elizabeth Barry}

well remain confined to the lobby: this care home is not, in fact, simply a poor facsimile of a "real" home, as the logic of the chronotope might suggest. It is a closed community with its own impenetrable language and conventions, and this - it is suggested - is at least in part by choice. The assumptions about age and its spaces - that it is excluded, confined, erased - are challenged here. This is a "little world" that has turned its back on the larger one, rather than the other way around.

Williams creates a form of anachrony by catapulting the middle-aged, or at least "young-old," character over the heads of the much older care home residents in life course terms. He faces an imminent death before or at least more certainly than they do. The residents of the care home are not only more robust than he is in outlook and even in health, but they are also more connected to contemporary culture than he. His mother's room-mate, Debbie, is "into dystopian video games" and is "very, very good" (par. 33). Henry has neither the knowledge of the older generation, nor the abilities of the younger. He has no connection with the youth he met earlier in the day: his love for the A. E. Housman lines the boy has tattooed on his arm a nostalgia for already nostalgic art; the young man's a tribute to a more immediate loss, the untimely death of a friend (par. 20). The reference underlines, in fact, the disordering of the expected narrative in this story, one in which the younger generations are dying sooner than those who are very old. There is the sense of an ending, but that ending is an indiscriminate one.

We are not unsympathetic to Henry's plight. Indeed, the reader might well also regret the vanished days to which Henry is attached: the direct connection to place and nature that his role as town reporter once gave him; the idea of a shared repository of consoling poetry (in contrast with his mother's rebarbative mysticism). Henry's writing - and his reading keep him sealed from the present, however: striking attitudes rather than feeling. The residents reach back to Gnosticism, an ancient system of thought, and forward to the skill of playing video games. They move in a mentally mobile way between different forms of reality, different touchstones of cultural history, in a way that he - trapped in an outmoded analogue world - cannot. Here the form of the short story not only compresses the life course but plays with the expectations of its shape and order. It challenges norms of age-appropriate behaviour, as well as the expected ordering of genealogical succession. In this "home," the parental figures are behaving like young people, and the figure of middle age rejected as child but unrecognised as adult, without child of his own or forward-moving career - cannot find a place.

Yet in one sense this is a belated coming-of-age story, the protagonist dismissed from his mother's care (in all senses) to navigate the future of his life on his own. He is birthed almost into death, and the story is full of these savage twists on the usual symbolism of life transitions. Exiting his mother's room into the "cruelly illuminated" hallway seems akin to 
a birth, and the mother's room as womb is also an ante-room to death. Old age is not the foreign country to discover, but a haven (at least in this affluent context) - a time and space of preparation and reflection of which Henry has been robbed. Leaving the home is not escaping, but being forcibly delivered to one's fate. Nonetheless, Henry steps out in touch with his future, however short this will be, rather than living his present in the third person and as a kind of constantly edited past. Of necessity, now, he is ignorant of what comes next - but open to it; he has, as in the last line of the story, to "brave the outside, where there would be darkness and steps to navigate" (par. 53). For this visitor, the care home cannot be a space that encloses and protects, a "nurturant" home in Sobchack's terms, but it does offer a chronotopic threshold or a series of thresholds - the reception desk, his mother's room, the steps of the building - that make a new future of the imminent end.

\section{“Torching the Dusties"}

Atwood's story similarly depicts a 'home' which deconstructs the "nurturant functions" of the domestic home in ways other than we might expect. The (cruel) joke here is on not one individual, stranded without the knowledge of either the generation above or below him, but a whole generation, besieged in their mock mediaeval fortresses. The protagonist Wilma observes at one moment: "We have to be kind to one another in here.... We're all we have left" (Atwood 227). The idea that Wilma and her generation are under siege is, indeed, a literal one in Atwood's story. Wilma and Tobias, residents of an exclusive retirement home, Ambrosia Manor, are - along with their fellow inmates - trapped in the building by the mob of young rioters at the gates, threatening to set fire to the home and remove the economic burden of the "selfish" old. Wilma and Tobias escape; many of their fellows, the implication is, are not so lucky. There is not even this space, this silo left to them.

In one sense, elders are the victims in this story - or the underdog heroes. But in another, they are implicated. The problem here is at least in part money: systemic inequity, yes, but also tensions internal to one's class. This is a society in which relationships between generations are dominated by transaction and transfer (and withholding) of funds. The older people are holding onto wealth, the younger want to enjoy it; neither can see beyond it. There is a critique here, as Ulla Kriebernegg has argued, of ageism concentrated in an intergenerational conflict fuelled by the "burden narrative of old age" (49-51). And yet the message of the narrative is also more ambiguous than that implies. Elders participate in the materialism that contaminates the society Atwood presents. The "little world" of the residential home enshrines, memorialises and replicates a history of privilege, from the tiny feudal characters dancing at the edge of Wilma's eyeline (her visual hallucinations) to the figure of domestic 


\section{Elizabeth Barry}

service (explicitly costumed as Victorian in Marlene Goldman's film of the story) to the fine-grained late capitalist differentiation of luxury foodstuffs. The home, Ambrosia Manor (its name at once rank cliché and all-too-plausible brand), is a shrine to past wealth. Its fountain references the statue of the peeing Belgian boy (the Manneken Pis of Brussels): an in-joke, a shibboleth between those rich enough to have travelled in Europe, privileged enough to know (mockingly) what the clichés of the European Grand Tour might be. The gates are adorned by "ostentatious, depressed-looking stone lions" (Atwood 234) that likewise speak of the Old World and money that knows that it cannot reproduce itself, let alone grow. The home is a whited sepulchre not because its inhabitants are old but because their money is old and their claim to it superseded. There is also a more fundamental sense of belatedness and dissipation: "The Manor was once a mansion in the countryside, back when people built mansions, back when there was a countryside" (234). The narrative hints at a landscape in which industrialised farming has destroyed the countryside as such and hence discouraged the building of such mansions there. In making money this way, the value of what it might buy has been squandered. If culture is the taming of nature, what is culture when there is no more nature to tame?

This dystopian sense that the countryside has already disappeared, that human society is already post-nature, registers subtly but pervasively in Atwood's story. We are not only in the era of the Anthropocene, but this is an era that will itself be - inevitably - short-lived. This underlying condition makes sense of the unsettling stylistic gesture we see deployed in Atwood's writing in this tale, whereby the texture of Wilma's daily life is described as both aesthetically pleasing and deeply unappealing. Wilma's sight being limited, she encounters the world via sound, but the sounds she hears are connotatively unstable and disconcerting for her and for the reader. She likens them to the natural world in comforting metaphors recognisable from a standard cultural repertoire. The sound of the cereals she and Tobias crunch are "crisp snow underfoot" (233); the voices of the other residents "sudden gusts of autumn leaves" (248). Yet at the same time, these sounds are described in much less comforting terms. Crisp snow underfoot turns out to sound like "Styrofoam packing peanuts" (233); the voices that eddy around her like gusts of autumn wind are also heard at the same time and in the same sentence as "squawkings, or cluckings, or wheezings" (248). What she does see, when she "escapes" outside towards the end of the story, for example, is similarly equivocal, and similarly suspended between the wonders of nature and the prosaic realities of her impaired condition: the sparkling light either "fireflies" or symptoms of her brain short-circuiting "like a toaster dropped into the bath" (265). The natural order is not only upset, its creatures struggling to survive, but it can be - and perhaps is being - displaced or replaced by unnatural, manmade alternatives. 
Old age appears, in a sense, a symbol as well as a theme here. In presenting older people as a generation whose time has passed, Atwood paradoxically hints that they also represent the whole of humanity, in the process of extinguishing itself by gobbling up all resources; cannibalising past culture and colonising the natural world. Their self-interest, as that of the younger generation, not only brands this society as ethically damaged but has also wrought physical damage and threatens its very survival. They are not so much on the margins of society, then, as a symptom of its "ruined public sphere" (Clark 150); not so much an extinguished generation as a symbol of universal global extinction.

Atwood's scenario in this story is described, in line with the genre she is perhaps most known for, as "dystopic" and its intent "satiric;" Kriebernegg suggests that it is also "bitter" (50). Wilma and Tobias enact an escape narrative familiar in care home fiction that likens such residences to the disciplinary institution of prison (and Ambrosia Manor, for all its luxury, has the locked doors, security detail and "perimeter wall" [Atwood 262] - a "high brick wall" - reminiscent of such a space). Marlene Goldman, in her stylish recent film version of the story, even picks up the nod to this genre of prison escapes in the original story, expanding the detail about the police letting through the laundry van to have her protagonists (the visually impaired Tobias being led by Wilma in a smart gender reversal) make their escape under a pile of clothes and bedding in the laundry trolley. Atwood's ending is hardly redemptive, however. Wilma and Tobias settle down to watch the show of the Manor's torching with their peanuts, seemingly sanguine about their fellow residents' deaths. Not only the effect of the previous injunction to be kind to one another, but also the solidarity felt in that earlier "we," seems to have evaporated. If this narrative ending is troubling, the final cadence is still more so, Wilma seeming to retreat into the world of her malicious little people, who accompany the spectacle of the burning home with their "singing" (268).

There are hints earlier in Atwood's story, however, that the destruction of this home is not straightforwardly the tragedy that her reader might conceive it to be - or not just this. The regret for Wilma is not so much that her life is nearing its end but that the flavour has gone out of this life in living it under its present conditions. Wilma has a "glut of slippers" (234), sent by a daughter careless of her true situation: not only a symbol of her circumscribed existence, in which day and night are interchangeable, but of an existence so static that even this footwear does not wear out. She lacks purposive activity, then - until the end, when she makes ready for a journey to the outside, generating a sense of purpose, however finite and whatever its chance of success (and hers of survival). In fact, the siege quickens the pulse of this existence in not only her and Tobias but also many of the other residents. With the enemy at the gates, there is a carpe diem quality to their living: "The evening's dinner is more 


\section{Elizabeth Barry}

vivacious than usual" (247). They go on to organise themselves to gather food and warn other residents (though the doors of the "Advanced Living" wing are - ominously - locked). Wilma herself has a complicated reaction, but it is certainly not ambivalence:

She can't pinpoint exactly what it is she is feeling. Not despair, not at all. And not hope. She only wants to see what will happen next. It certainly won't be the daily routine.

A dramatic ending is perhaps not the worst fate imaginable.

If Wilma is not bitter, it is hard to say the same of Atwood at moments such as the one when Wilma imagines the other residents, or at least herself in their place, "just giv[ing] up" (268) rather than trying, however ruinously, to escape. In the main, however, as has been suggested, the older residents respond with ingenuity and energy to the prospect of impending crisis. And if Atwood seems at times almost complicit in the view that it is "Time to Go," offering neither despair nor hope herself at the spectacle she creates, it is part and parcel of the fact that dystopia and utopia have been conflated in the world in which "Ambrosia Manor" is located. This affluent setting is the best care available in the neoliberal system, but life, like the breakfast cereals, is still dry to the taste and that goes equally for a world outside the home, a world where all progress has meant is that there is no more "countryside," nothing left to buy. Neither the under-twenty-fives the radio commentator mentions nor this generation are fully the victims of the current "shambles, both economic and environmental" (257); both are complicit, unable to see outside the system. In this context, images of ending can be enlivening. Atwood imagines in the Manor's destruction not the sweeping away a troublesome older generation but the putative end of an unequal system itself.

\section{The Development and "Peeping Tom"}

The Development, the title of John Barth's short story collection, is a loaded one. The land is "developed," but the lives of the protagonists (all residents of the same area and appearing across the connected stories in the collection) are caught in a different, even opposing, dynamic. They are at best holding the line against the depredations of ageing, but sooner or later move in a direction that is almost universally seen as downwards towards dependency. The different areas of the development likewise chart the stages of older age, the design and function of their accommodation reflecting the increasing levels of dependence from autonomy to "assisted living" to full-time nursing care. We see here the monetisation of Sobchack's "nurturant functions," not only in the homes themselves, 
and provision of food, but in the services allied to health and the (already euphemistic) care that are built into such environments.

In the first two of Barth's stories, Tim Manning, the collection's main narrator, lives in Oyster Cove, an area of the Heron Bay development that represents a kind of midpoint both in terms of house price and life stage. His locale, while not strictly speaking a retirement community, is populated by the retired or semi-retired and the late middle-aged to the "early" old. His duplex is a "halfway house" between mansion and condo, then; the community a halfway house between active adult life and the seclusion and dependency of old age. Margaret Atwood's residential home in "Torching the Dusties" - and countless others like it in life and literature - also mark out these stages physically, and Atwood's text mines the same euphemistic commonplaces:

[Residents] have their breakfasts in their own apartments; those of them in the Early Assisted Living, that is. In the Advanced Living wing, things are different. She hasn't wished to imagine how different.

As living becomes more "advanced" in chronological terms, it risks becoming more reduced, more basic in terms of scope, activity and agency. The stories that involve Tim Manning also follow this trajectory within Barth's collection. The title of a late story, "Assisted Dying," reflects an assumption that "assisted living" (where Manning, now a widower, has moved, in the early stages of dementia) is the point at which living becomes synonymous with dying, an existence lived in the shadow of its end, although Manning is still able to reflect acutely on his own existence here.

We will concentrate in this chapter, however, on the story that begins the collection, "Peeping Tom." This story, like Atwood's "Torching the Dusties," suggests an external threat to the affluent community living behind its protective gates. The idea that there is a voyeur, a "peeping tom," spying on the late middle-aged characters in their bathrooms gives rise - in much the way of the squarer threat of siege in Atwood's story to a complex mixture of fear and something like excitement. What the phantom voyeur represents, however, at least among other things, is the fear of old age itself. The anxiety is one of exposure to an external gaze that confirms these characters in their ageing. The resident academic in the community, tilting the story towards the metafiction for which Barth is so well known, suggests that their fears represent a form of what the narrator calls "projection" - they are the peeping tom seeing themselves, both literally in the window and symbolically as an embodiment of their own "fears, needs, desires" (17).

Taken together, it might be argued, these fears can be read as a kind of projection of the community's anxieties about ageing. The 


\section{Elizabeth Barry}

voyeur is for the most part observing not sexual activity but other bodily functions: they are "peeped at on the potty" (17), as one resident puts it. The implication is that such functions are already a preoccupation of the protagonist, who sleeps naked from the waist down, "originally for romantic reasons, latterly out of long habit and urinary convenience in our three-pees-a-night old age" (10-11). The discussion between the narrator, his wife Margie and their friends Matt and Mary Grauer of the intruder interrupting Margie on the toilet ("mid-urination") seems excessively, ostentatiously concerned to speak openly about these bodily processes and fear of their exposure or loss of control. Mary remarks: "If it'd been me, he'd've gotten a different kind of eyeful: I'd've wet my pants" (11), and they go on to discuss fecal incontinence via the expression "it scared the shit out of me." This insistent emphasis on private, shameful processes and the threat of their impaired function in older age seems to bespeak an anxiety about the body and its gradual dysregulation. The fear is not so much that their bodies will arouse sexual desires in an onlooker as it is that they will not.

Just as Manning and his friends exhibit their fearlessness in talking of incontinence, one resident appears to face down, or perhaps aggressively play down, the fear of sexual impotence. Spied on while urinating, he reacts by unzipping his trousers again and exposing himself to the voyeur (or the darkness that he believes to contain him) in a display of machismo. He not only "marched to the by-then-dark window saying 'Eat me, cocksucker!'," but "afterward boasted openly of having done so" (18), both actions an exhibition of potency - physical and discursive - that respond to a masculinity threatened in more than one way. That the women are more sanguine about the intruder, even joking repeatedly about the allure of being observed as a marker of continuing sexual attractiveness (one suggests it is a "turn-on," another that she checks "her hair and makeup" [17] before undressing), is - it is implied - not assuaging the men's complex reaction to this threat.

The story never resolves the question of who the voyeur is or, indeed, if there is one. The idea that he (for it is assumed without question that it is a "he") is one of their own is floated, but the further idea that it may be a figment of their collective imagination is only approached obliquely. One of the residents, "catch[ing] sight of some movement just outside the picture window" does have a revealing experience, however:

I cross the room to check it out - in my robe and PJs, same as now? and the guy comes at me from out there on the porch as I come at him from inside, and I'm thinking, Isn't he a brazen bastard and traipsing around there in his nightclothes too! 
The realisation that it's "my own reflection I'm looking at" is a humiliating one: "So I stand there contemplating myself in the picture window and feeling foolish while my pulse calms down" (15). The sense that it is advanced old age itself that these residents are fearing gains more support with this incarnation of the peeping tom as an older man "traipsing around in his nightclothes," embodying the wandering that is another familiar fear linked to dementia. These fortified spaces - represented in the elaborate rituals of entering and leaving in Williams' "Stuff," the locked doors and high gates at Atwood's Ambrosia Manor, and the gated developments and security patrols in Barth's Oyster Cove - mark the silent transition of the idea of "security" from keeping an external threat out to keeping the residents in; the threat is within oneself, an incipient danger that awaits one and which one cannot dislodge or eradicate. Manning himself comes to embody this fear, going to search for the voyeur in his "PJs" and hiding in the bush when the security patrol car goes past changing places with the peeping tom whom he and his friends frequently speculate is "one of us," a figure that itself blends seamlessly with the spectre of an aged escapee from a dwelling that has become more prison than home.

Nonetheless, this episode, like the torching of Ambrosia Manor, might be seen as one that quickens the pulse - literally and figuratively - of the residents of this halfway house in the journey towards "assisted dying." If it projects their fears about ageing, it also - temporarily - provides a way of forestalling them. Manning and his wife come together "more passionately" (21) than for a long time after he briefly incarnates the peeping tom himself. The neighbourhood is also "agreeably more bonded" by this "common concern" than they had been before. "He" eventually departs without drama, the story "petering out," in Manning's words, "like most folks' lives" (22). This ending is not entirely downbeat, however: the incident leaves a memory of the quickened pulse, the briefly reignited sexual mettle of these early-old characters that is later missed but fondly remembered. The next incarnation of the night wanderer, a future exposure to "potty"-related shame, may indeed be one of them and represent a more genuine fear - that of old age itself; but, for now, that fear has been allayed.

\section{Conclusion}

Barth ends his collection - or starts the beginning of the end, as it were - by providing a narrative crisis of sorts: the arrival of a hurricane that destroys many of the homes in the development. The names of the different areas of the development - its bays and shoreline drives have advertised its coastal position, and that of the real estate company responsible for it, "Tidewater Communities," underlines the fact 
of this as reclaimed land, an appropriation of nature that might one day be reversed. The greedy developers respond to the disaster in a final chapter ("Rebeginning") with plans to rebuild bigger and better, while other voices point to the future that global warming is preparing and counsel a visionary "green" development. The competing visions both seem hubristic and short-sighted, however, in the face of the implacable planetary changes: the tides of ill fortune that await these affluent Americans and all the defences they construct against their own vulnerability.

Even before this narrative development, the tidewater lurks in every story in Barth's collection as a reminder of the reversibility of the development of Oyster Cove and the whole Heron Bay estate - as of every human "development;" the potential undoing of society's Enlightenment project of progress and perfectibility (as well as the precarious security of every family's instantiation of the American Dream) by the larger forces of climate change. This corresponds to the incipient sense of crisis in so much of this contemporary fiction. Even the security of the care home is upended in Joy Williams' "Stuff:" as has been seen, Henry's mother arrives at her current residence because her last "home" was flooded and destroyed, the residents left for dead by the staff but surviving against all expectation, found dehydrated but alive a week later. Older people are expected to die, whether in this catastrophic situation or just in the course of life; their survival does not generate "joy, just troubled amazement" (Williams 26). As with everything in Williams' story, the expected ordering of events is not followed, however: the form of genealogical succession is overturned, and elders exhibit a tenacity at odds with the apocalyptic tenor of the setting. And if Atwood's "Torching the Dusties" ends with fire rather than flood, the world into which its own indefatigable elders escape is also a world where both natural resources and reserves of compassion have been privatised and developed to the point of exhaustion. The crisis is not located in the dystopian spaces of commercialised "care," but in the larger system that creates them.

These examples can be seen to demonstrate, then, that the short story as a genre is a natural place for this sense of an ending. And in the contemporary short story, this is not just on an individual level but in finding as its locale what Miriam Clark has called the "ruined public sphere" (150). Despite the affluence of these locations, the characters and the world they inhabit have this dimension: there is no more countryside; resources are finite even for the young. The chronotope of an old people's home is a metonymic representation of a world exhausted of its capital. The older people themselves, however, are as likely to be tenacious as vulnerable to its incursions. The form of the short story, therefore, is itself also a fitting narrative chronotope. Norman 
Friedman has suggested that "it is the imminence of the end," that is, "its relative closeness to the beginning," which differentiates the "effects" of short fiction from those of "longer works" $(29,26)$. If these authors' stories reflect the dominance of the idea of looming closure as the defining chronotope of the contemporary short story, it is not so much that they have older characters as it is that the world they are writing about is facing the prospect of its own imminent ending. The older protagonists are simply waiting to see "what will happen next" (Atwood 255).

\section{Works Cited}

Atwood, Margaret. “Torching the Dusties.” Stone Mattress. 2014. Virago, 2015, pp. 233-308.

Bakhtin, M.M. "Forms of Time and of the Chronotope in the Novel: Notes toward a Historical Poetics (1937-38)." The Dialogic Imagination: Four Essays. Edited by Michael Holquist. Translated by Caryl Emerson and Michael Holquist. Austin, 1982, pp. 84-258.

Barth, John. The Development. Mariner, 2010.

- "Peeping Tom." The Development. Mariner, 2010, pp. 1-24.

Biggs, Simon. Understanding Ageing: Images, Attitudes and Professional Practice. Open UP, 1993.

Chivers, Sally, and Ulla Kriebernegg. Care Home Stories: Aging, Disability, and Long-Term Residential Care. De Gruyter, 2017.

Clark, Miriam M. "Contemporary Science Fiction and the Postmodern Condition." Studies in Short Fiction, vol. 32, 1995, pp. 147-59.

Falconer, Rachel. "Bakhtin's Chronotope and the Contemporary Short Story." South Atlantic Quarterly, vol. 97, no. 3-4, 1998, pp. 699-732.

Friedman, Norman. "Recent Short Story Theories: Problems in Definition." Short Story Theory at a Crossroads. Edited by Susan Lohafer and Jo Ellyn Clarey. Louisiana State UP, 1989, pp. 13-31.

Kriebernegg, Ulla. "'Time to go. Fast not slow': Geronticide and the Burden Narrative of Old Age in Margaret Atwood's 'Torching the Dusties'." European Journal of English Studies, vol. 22, no. 1, 2018, pp. 46-58.

Laws, Glenda. "Spatiality and Age Relations." Critical Approaches to Ageing and Later Life. Edited by Anne Jamieson et al. Open UP, 1997, pp. $90-100$.

Polan, Dana. Power and Paranoia: History, Narrative and the American Cinema, 1940-1950. Columbia UP, 1986.

Snaith, Helen. "Dystopia, Gerontology and the Writing of Margaret Atwood." Feminist Review, vol. 116, 2017, pp. 118-32.

Sobchack, Vivian. "Lounge Time: Postwar Crisis and the Chronotope of film noir." Refiguring American Film Genres. Edited by Nick Browne. U of California P, 1998, pp. 129-70.

Terentowicz-Fotyga, Urzula. "Defining the Dystopian Chronotope: Space, Time and Genre in George Orwell's Nineteen-Eighty-Four." Beyond Philology, vol. 15, no. 3, 2018, pp. 9-39. 
Torching the Dusties. Directed by Marlene Goldman and Philip McKee, cinematography by Henry Sansom, performances by Clare Coulter, Eric Peterson, Aris Tyros, Filmcoop Inc., 2019.

Williams, Joy. "Stuff.” New Yorker. 25 Jul. 2016, www.newyorker.com/maga zine/2016/07/25/stuff-by-joy-williams. Accessed 19 Jan. 2021. 


\title{
9 Old Friends
}

\section{Reimagining Care Relations Through Helen Garner's The Spare Room}

\author{
Sally Chivers
}

\section{Introduction}

Long before a global pandemic made the social isolation that follows from physical distancing a widespread concern, myriad research funding calls, most age-friendly discourse, and much of social gerontology had been raising a clarion call about the accelerating risks of social isolation. Along with such calls, heartwarming human-interest stories would appear in the popular press, often featuring students treating a nursing home as their dorm, women collectively creating their ideal late-life housing settlement, friendly visitors going door to door to check on older adults, and buses arranged to take older adults to do their shopping, offering the side benefit of social connection. I refer to these as curated friendships which offer a seeming solution to a problem that goes far beyond a lack of companionship, often to a lack of adequate care support for people who need it. Of course, these curated friendships are less possible when in-person contact causes grave danger. The pandemic has amplified how these programmes individually promise important social connections to otherwise lonely older people, but a collective reliance upon them is worrying. Not only do such stopgap approaches push longer lasting and more genuine friendships into the shadows, they also fail to recognise, let alone address, the broader structural problems that were already contributing to the social isolation of many older adults, even prior to COVID-19.

A humanities-based focus on meaning-making separate from stark use-value provides a much-needed vantage point from which to offer a hopeful yet sobering vision of late-life friendship rife with possibilities for creativity and empathy, particularly when care is involved. I argue in this chapter that questioning the social practices and cultural politics of friendship through fictional analysis exposes productive tensions and complicated connections at the heart of care relationships, opening up new ways of addressing social isolation as well as loneliness. I draw on team-based ethnographic research conducted to find practices ${ }^{1}$ that hold the promise to expand or even move beyond age-friendly to what we call 


\section{Sally Chivers}

age equity. Findings from the Imagine Aging team's fieldwork in Toronto at organisations that serve so-called marginalised older adults provide context for my analysis of Helen Garner's 2008 Australian novel The Spare Room. I turn to that novel as an example of how fiction that centres friendship can broaden what we imagine to be possible within social relations and can portray multiple perspectives simultaneously. My reading of the novel exposes how friendship can illuminate as much as it can assuage loneliness, especially during acute illness. Caring for a friend can be isolating too, so friendship is not an antidote to the slippery combination of loneliness and social isolation, no matter what other benefits it yields.

Noting the implications of aforementioned curated friendships, such as through paid companions hired by family members to visit their loved ones in long-term care, dementia "friend" programmes, and "friendly" visitors that organisations arrange for those they deem to be dangerously lonely, I concentrate on how "friendly" terminology, such as the dead metaphor behind the age-friendly movement, ${ }^{2}$ feeds on the significance of genuine, voluntary social connections; on how real friendships shift, develop, deepen and weaken with age, especially when care is needed or desired; and on what literature and film have to tell us about both.

\section{Why Friendship?}

By friendship, I invoke a Western conception entailing voluntary social connections outside family and romance, based on mutual affection, interests, values, trust, and respect.

Of course, I am far from the first person to consider the role of friendship throughout the life course, in old age, or in relation to care. Indeed, the ethic of care was pushed forward because of feminist philosophical considerations of the friend relationship, such as Carol Gilligan's analysis of 11-year-old friends in In a Different Voice (6-9) and Emily K. Abel and Margaret K. Nelson's discussion of friend carers in "Circles of Care: An Introductory Essay" (11). Though they do not explicitly mention it, they appear to share influences with feminist literary theory, especially the renowned exchange between Elizabeth Abel and Judith Kegan Gardiner.

Elizabeth Abel and Gardiner explore the reciprocity within femalefemale friendships as a way to articulate what literature does in the world as well as how readers are positioned. Their conversation, published in Signs in 1981, offers an exchange in which Elizabeth Abel, who focuses on how the literary imagination shapes women's friendships (413), argues that

female bonding exemplifies a mode of relational self-definition whose increasing prominence is evident in the revival of psychoanalytic interest in object-relations theory and in the dynamics of transference 
and countertransference, as well as in the growth of literary emphasis on theories of influence and intertextuality.

She concludes by claiming that studying female friendship reveals "the sketchy pattern of the intersubjectivity that permeates the framework of recent humanistic inquiry" (435). Gardiner challenges Elizabeth Abel to think of commonality and complementarity within female friendships as fluid processes (436), a point with which Elizabeth Abel agrees. Gardiner suggests an interpretation that attends more closely to the fictionality of the novels studied so as to "understand the meaning the authors give to the social contexts within which the women's identities are formed" (442). The exchange between these two scholars not only illuminates the reciprocity of friendship, but also demonstrates that the approach to a literary text affects how it might contribute to understanding social relations.

My own approach benefits from existing theoretical work that idealises friendship as a model for a broader social and political world, such as Jacques Derrida's connection between friendship, democracy, and the future, upon which Leela Gandhi builds to develop an antiimperialist theory of transnational collaboration, and Michel Foucault's contemplation of male-male non-sexual relationships as harbouring the potential to challenge social norms. However, like Elizabeth Abel and Gardiner, I situate my work in a feminist tradition that considers friendship a means to make up for the limits of existing social and institutional relations, rather than as a figure for broader social and political structures. I remain attentive to the potential for literary fiction to add to our understanding of the social context that bears upon friendship. Like Gardiner, I want to go beyond considering the figurative resonances of friendship. I am most interested in safeguarding lived friendship from cooptation into a system that cannot properly allow it to thrive, and I aim to do so by exploring what literary fiction has to offer that process.

\section{When Friends Care}

The friendships I am considering - in literary depictions, film, popular media, and empirical research - emerge because of a combination of similarities and differences tied to often-serendipitous circumstances that allow for mutual learning that can be transformative. As Marilyn Friedman puts it: "No particular people are assigned by custom or tradition to be a person's friends" (208). Comparing friendship to reading novels, biographies, and autobiographies, Friedman demonstrates how narrative contributes to the potential positive outcomes of friendship when she argues that by listening to our chosen friends' differing life stories that 


\section{Sally Chivers}

come from disparate moral vantage points, we open ourselves to potential moral change that could lead to broader social change (199-206).

But care changes and is changed by friendship. Emily Abel and Nelson pose a pivotal question: "Because friendships are established voluntarily and are anchored in equality, are they more likely to provide the basis for reciprocal care?" (11). Friedman argues, "In countless ways, from the trivial to the monumental, friendship invites us to marshal the greater part of the scarce resources of our care, attentiveness, and trust in the selective support of our friends, even though other human beings have similar needs or qualities" (190). Because friendship differs based on the individuals in the relationship, arguably making no two friendships alike, it pushes care beyond repetitive, mundane task-based care work: "a friend is supposed to show not simply the mechanical features of caring behaviour but positive concern as well; not simply the techniques of loyalty but also personal commitment" (214). Indeed, as Friedman argues, "to fail to provide the care, assistance, or support needed by a friend is to fail to be a genuine friend, a friend indeed" (216). Nonetheless, when it comes to what she refers to as "dependent children, elderly persons, and all other individuals whose lives and well-being are at great risk," Friedman insists on the need for "social relationships whose other members do not or cannot choose arbitrarily to leave" (254). Friedman thereby expresses that the voluntary and variable nature of friendship means that family members are better suited to care when it involves intimate physical work. To her, friends require a caring affect but, for the grittier and enduring care work, friends remain Friedman's alternative.

For a significant minority, friends are not the alternative but rather the obvious option, even for late-life care work. With this in mind, Sasha Roseneil draws on queer theory to centre friendship. She argues that, in fact, social science research should "care about friends" because of "the importance of thinking beyond the conjugal imaginary," not only for queer seniors but for all (411). She brings together affect with care work, arguing, "If we take friendship seriously we will have to confront the question of how care may be given and received by equals, without violating individual autonomy, without self-sacrifice and subservience, and maintaining the affection which constitutes the relationship" (414). Friendship, for Roseneil as for Emily Abel and Nelson, has the potential to allow for reciprocity rather than the unequal relations that often proliferate in familial caring. For Roseneil, friendship is both everyday life and a broader model for care relationships as it can tackle the thorny desire for autonomy in community. Centring friends, Roseneil argues, offers a way to reassert autonomy without losing connection.

Friendship shifts everyday practices of care, especially as older adults increasingly turn to friends for practical support (Roseneil; La Pierre and Keating). In their chapter "Towards a Feminist Theory of Caring," Berenice Fisher and Joan Tronto elaborate on how the equality and choice that 
characterise friendship pose challenges to considering the parts of care that hinder choice and are not based on mutual advantage. I build on these feminist approaches to friendship to contend that much of what makes care among friends desirable also risks cooptation in an era of austerity. The austerity-driven process of devolution, whereby responsibility to care is downloaded onto the individual, as Wendy Brown aptly argues, is profoundly and deliberately isolating: "neoliberal practices of devolution and responsibilization produce a structure of isolation, weakness and sacrifice in the figure of the putatively democratic citizen" (4). While many people are then pushed to rely on family members for care that could have been provided through a well-funded, supportive social system, those without the appropriate family connections must turn to others. It is this reliance on informal social connections that risks cooptation in an austerity framework, since funding for adequate care is threatened by austerity's scarcity approach. Friends, rather than being the alternative as Friedman implies, become part of the essential care structure for many older adults separated from expected family structures. And when friends care, the state ostensibly doesn't have to.

Keeping in mind Roseneil's ideal that the equality that underpins friendship also mitigates the self-sacrifice and subservience that can occur in care relationships, I consider how the "discretionary, and perhaps unreliable" nature of friend and neighbour relationships emphasised by Tracey La Pierre and Norah Keating, for example, could be advantageous when friend relationships are not set up as simply replacing familial and institutional care relationships (1443). Their very difference from those relationships offers the opportunity to expose and hopefully change care relations. What is more, fictional accounts of friendship and care can generate ambiguity and embrace contradictions while imaginatively offering a way to perceive another way of being. As such, they hold the potential to challenge the conjugal imaginary without replacing assumptions about familial care with similarly troublesome assumptions about friend care. Thus, turning to a literary example offers me a new way to theorise relations in the "care economy." ${ }^{3}$ In this chapter (and hopefully beyond), I want to make friendship matter without making it count, or be counted.

\section{Bill Is No Golden Girl}

Roseneil's hopeful vision of mutual equals joining forces to create new bonds in late life has enormous popular appeal to an extent that risks removing its more radical potential. For example, news media adores the notion that women who outlive men might address the economic and social crises supposedly created by an ageing population through a creative return to the communality of the dorm room. They dub such arrangements and groups "Golden Girls," indicating widespread recognition of 


\section{Sally Chivers}

popular culture's influence. For example, a December 2018 Canadian Broadcasting Corporation (CBC) piece portrays three white "baby boomers and long-time friends," two widowed and one divorced, who have pooled their considerable resources since their offspring have grown up and moved away (Roussy n.p.). Though they talk about the specific benefits of the companionship they receive, they mostly value the independence it allows them, and yet the story emphasises the communality of their situation.

The CBC piece relies on an assumption that living together is preferable to living alone because it returns people to a seemingly more natural state of community. The story outlines the pragmatism of the arrangement, together with the oft-cited loneliness that it seemingly remedies. Indeed, "Golden Girl" Phyllis Bradley summarises the women's motivations in seemingly ranked order: economy, safety, and companionship. Importantly, none of these "old friends" have serious care needs, so the "sacrifice" that Wendy Brown situates in the putative democratic citizen turns into an accounting of possessions they have chosen to relinquish. An array of similar media articles displays similarly relatively well and well-off white women who decide to travel "down the road and back again" 4 together. There is also great media interest in mutually beneficial intergenerational housing solutions wherein students in search of housing bunk in with seniors who need a few chores done around the house or some company, but mixed income and cross-cultural arrangements have not yet entered this popular discourse. ${ }^{5}$

The collaborative, international, interdisciplinary research team I am part of, colloquially titled "Imagine Aging," seeks to understand the experiences and needs of people missing from these dominant stories of late-life communal living. As part of our catalytic ethnographic method, we produce what we call digital cues - short videos drawn from interview transcripts to illustrate central issues and ideas. Our original plan was to take the videos from one city to the next, as we travelled to 12 cities in 6 countries to conduct fieldwork (we are working on a COVID19-adjusted alternative plan). These videos help to share our research findings, but they also help us to reach out to interested participants and to think through our collective ideas and findings. Most importantly, they are essential to the catalytic validity of our research, which seeks to change the conversations about and practices of age-friendliness to focus on and create age equity and hopefully age justice.

From our first site, the Canadian city of Toronto, the team created a digital cue, "Less Lonely," 6 based on interviews with Bill and his friend Rupert (names changed to preserve anonymity) (Braedley, Less). Bill's story offers a vital counterpoint to the CBC's Golden Girls story. Bill is poor, gay, and lonely. He cannot be a Golden Girl - not because of gender, but because his friends are dead, and were they alive they would not have the resources, even collectively. A local organisation focussed 
on the needs of queer seniors (the organisation cannot be named due to Research Ethics approval) intervened through a programme that provided a "friend" to Bill, in this case very successfully. The key to that success goes beyond ticking a box affirming that Bill receives weekly visits or phone calls, somehow measurably reducing his presumably immeasurable isolation. As the video explains, Rupert and Bill connect because of shared interests, in art especially, and being willing to develop new interests together, such as Rupert learning about architecture from Bill. Rupert is helping Bill, yes, but there is an unquestionable mutuality as well as commonality that transcends the complementarity brought on by the generational difference, ${ }^{7}$ made more poignant by the HIV crisis Bill survived when so many of his friends did not. The story became even more resonant during COVID-19, as so many other people who weren't directly affected by AIDS discovered the devastating effects of a global pandemic. Lest we forget, COVID-19 was not the first time some people have experienced the isolation, the loss, the fear, and the stigma that come with mysterious contagion.

Certainly, Bill's story showcases how important meaningful social connections, including friendships, are to the people our team wants age-friendly resources to better support. At the same time, curated friendships - such as those offered through programming - risk misuse under austerity because they can so easily become the target of responsibilisation whereby the individual becomes responsible for arranging care and turns to friends when family don't suffice. This heartening individual story shows the enormous promise of these programmes, but the connection between Bill and Rupert doesn't solve the broader problems Bill has faced, problems that led to him being isolated and lonely, having had most of his friends die. As such, the curated friendship between Bill and Rupert, one that appears to have blossomed into a deeper and truer friendship, is - on the part of the organisation - a helpful individualised intervention that still cannot address the devastating sociocultural context as well as personal circumstances that led to Bill needing a new friend late in life.

The video stories of the CBC Golden Girls and of Bill and Rupert illustrate the growing trend to manipulate and even fabricate friendship as a way to offer older adults what they do not find within the structures currently set up to support them. They both lean on what is becoming a popular refrain about the dangers of loneliness to offer encouraging suggestions about ways to alleviate it frugally. They show there is much promise in this approach. To be clear, I am happy these people have found each other, moved by how significant a very simple social connection can be, and want to support the programmes that allow such friendships to develop. I also sincerely hope people in similar situations found ways to connect during COVID-19. But I worry about the interlocking factors that make such programmes necessary and even normative, as 
well as what essential elements of friendship - its changeability and flexibility especially - these examples miss while still relying on uncomfortable happenstance. I especially worry that they do little to edge out the unreliable default reliance on family for which these curated friendships always only compensate.

\section{The Spare Room}

Narrative fiction invites deeper, multifaceted ways of thinking and feeling about late-life friends, loneliness, and isolation in context than these video vignettes can offer. Helen Garner's novel The Spare Room offers a compelling example of the role, obligations, and limits of friends who want to care and who have the means to drop their other obligations to do so. Alternately criticised and praised for its spare prose, with the pun usually intended, the novel offers an almost journalistic account of a semiautobiographical experience (Dessaix; Coslovich; Carr). Garner paints a portrait of 65-year-old Nicola, who, having exhausted other treatment options for stage-four bowel cancer, arrives from Sydney to stay in her 63-year-old friend Helen's spare room in Melbourne while she undergoes costly alternative therapy at the dubious Theodore Institute. The ensuing narrative exposes how a friend relationship is permissive, in that a friend can support someone making daring care decisions without the personal consequences that might fall on a family member with genetic links and legal duties. But it also draws sharp attention to how a friend, though she is free to be more openly critical as well as to walk away, lacks the power to intervene officially when choices turn out to cause harm. This is a thorny autonomy, limited by the prevailing social prioritisation of the family and familial links for care.

The novel rides waves of alternating tenderness and rage tempered by fear, offering the relatively rare perspective of a fictionalised caregiver but, in this case, one who can choose to walk away with relative impunity, having already done more than anyone would ask of someone unpaid and outside the family. Host-cum-carer Helen boils with anger and resentment at the shoddy establishment ripping her friend off while offering devastatingly false hope. But she also rages at Nicola for her everpresent, maddening grin and refusal to face surely looming death. Feeling trapped after just three weeks, Helen lashes out to express her frustration and pushes Nicola to acknowledge death, neither of which (being so frank nor acknowledging death) Nicola's niece in Sydney has managed. For a time, Helen eases her anger by intervening to take Nicola to a conventional doctor: "What was all this anger? I needed to be kinder to her. Dying was frightening. But it was easier to imagine being tender when I had a packet of slow-release morphine capsules in my bag" (74). The tenderness peaks when Helen refutes Nicola's worries about a wasted life by offering a list of Nicola's accomplishments and contributions, from 
her grudge-free character through her generosity to the way she makes people feel free (143-144). But when Nicola tries to stay even longer, this time to pursue now-essential surgery, Helen finally explodes saying "Will you fucking listen to me? .. . I. Can't. Do it" (183).

Having cancelled all work and personal obligations for what was to be Nicola's three-week stay, Helen is nonetheless surprised to find herself cleaning sheets, mopping up sweat, and cuddling with Nicola to warm her up. In her extended review of the novel, Martha Holstein draws attention to the extraordinariness of the situation, asking, "What are we to do if we find ourselves in Helen's position? I don't know. I have watched friends die. I have tried to be attentive, but I've never had to clean up after them or take them to the bathroom" (459). Though Helen had not anticipated this shift from hospitable pillow fluffing to intimate care work, the menial work is not what angers or exhausts her. As she puts it, "This was the part I liked, straightforward tasks of love and order that I could perform with ease" (48). But she cannot (but must) abide sharing in the self-deception about the charlatan treatment regime, what she calls "the sick air of falsehood" (59). Her anger arises from the emotional work of playing along and then later, contradictorily, having to be the one to refuse to play along with the "cloudy hope" Nicola seeks at the Theodore Institute (93).

The novel's retrospective last lines "It was the end of my watch, and I handed her over" (195) signal Helen's refusal to remain centrally responsible for Nicola's care. They thus expose the broader network involved in friend-based care as well as the limitations of friend-based care, leading to the need to acknowledge the multiple but limited roles that friends can play. As Bernadette Brennan explains, "Nicola is a bohemian and part of the bohemian ethos ... involved forming new configurations of family among friends and lovers. Helen's care for Nicola affirms the legitimacy of those youthful aspirations. But only to a point" (242; my emphasis). Helen's fortitude comes from knowing this period will end and that there are others to take her place:

I was her friend, yes, and I loved her, but I was a recent friend: I had known her for only fifteen years. Surely her dearest, her oldest friends were Sydney people. In a couple of days, when her three weeks with me were over, she would fly home to them, and to her family: they would take over, and I would go back to my role as darling $\mathrm{Hel}$ in Melbourne, the practical type with a handy authoritarian streak, who had work to do and a ticket to Vienna in December.

(162; original emphasis)

Once Helen makes clear her hospitality will run out, Nicola imagines "dozens of darling old school friends who live in Melbourne" who will "take [her] into their homes with all their hearts" (184). Nicola instead 


\section{Sally Chivers}

has to fly friends from Sydney to Melbourne to assist during the surgery, after which she returns to Sydney to be cared for by friends and family, including Helen at times. Though Helen ends her solo watch, she still subsequently "[learns] to wash [Nicola's] arse as gently as [she] had washed [her] sister's and [her] mother's, and as someday someone will have to wash [hers]" (191). The collective strength of Nicola's friend network enables Helen to both exit care and yet continue to participate in even the grittiest of care work, while staying free from the obligation she faced when Nicola was staying in her home, away from her other sources of support.

The Spare Room promisingly tells the story of a person outside the "conjugal imaginary" drawing on a circle of friends to create the care an ill woman desires at the end of life. It offers a decidedly middle-class fantasy wherein a terminally ill older woman can travel about Australia to pursue varied treatment options with a seemingly inexhaustible supply of friends who themselves have time and means to assist and even do care work. Helen represents a freedom not often available to family caregivers, since she is able to walk away, but the velocity with which she reaches a breaking point also emphasises how the intricate demands of care compromise friendship.

The human connection represented by this central friendship initially appears to resist inhumane care structures. Nicola bumps up against a callous medical system that, though it offers pretty remarkable two-tiered care of which she appears able to afford the top tier, refuses to offer her the hope and caring affect she desires. When it turns out that the appalling Theodore Institute also couldn't care less, that too is left to her furious friend to deal with. But the support of one friend as replacement for the family assumed to be responsible for care is of course insufficient. During Nicola's brief stay, she and Helen are wedged into an isolated dyad, with Helen cut off from her infectiously flu-ridden family who lives next door, reaching desperately out to other friends for advice and support. The shift from a limited view of Helen and Nicola to the broader view of Nicola cared for by a range of friends demonstrates how friendship's changeability is not its weakness but rather its strength. Nicola's bevy of other friends becomes essential to understanding how utterly different friends can be from family as well as to exposing the ironic inhumanity of how care works, or doesn't. They are, in essence, a renewable resource, which is promising, and yet that renewability contributes to my concern that friendship is especially vulnerable to cooptation by a neoliberal system.

Beyond its roots in lived experience, The Spare Room's fictionality disallows the societally unnoticed reduction of friendship to a function that solves a social problem, revealing instead the possibilities and impossibilities of relying on friends for care and the limits of considering friends to be a cure for social isolation. As mentioned earlier, in their 
classic 1981 Signs debate, Gardiner pushes Abel's psychoanalytic reading of commonality over complementarity in female-female friendships depicted in literature further by emphasising the role of fictionality which helps illuminate social context (442). Indeed, as my analysis shows, the invention of fictive friendships can evoke contexts such as the relative wealth required to access top-notch medical care. Such friendships can illuminate how such access does not render anyone immune to the hope, fear, and anger that accompanies many diagnoses and realities of terminal illness. Their depiction can also uphold in a generative tension the conflicting perspectives of Helen and Nicola, not to mention the conflicting perspectives within Helen alone.

Helen and Nicola's fictional friendship offers a way to imagine beyond, without rejecting, dyadic care relations that trap caregivers and care receivers alike in their narrow perspective on who does the work of care and of what care work comprises. But it also disallows the simple replacement of family with friends. Garner's novel demonstrates the potential for deliberately imagined real, true, and old friends to mitigate the possible harm embedded in considering curated friendships to be a solution for social isolation of seniors. It perhaps offers a means to resist the devolution of responsibility for care to the individual via the family. The very fallibility of Helen's care turns out to be its strength. Her refusal offers a way not out of but into the care that Nicola needs and desires.

\section{Conclusion}

The current research and policy focus on social isolation obliges cultural scholars to push the conversation beyond finding friends for poor old people or coming up with cute interim solutions that emulate dorm life. COVID-19 made doing so all the more urgent. Rupert, Bill, and the reallife Golden Girls develop friendships that nonetheless expose shortcomings in the care and broader social systems while revealing the contextual determinants of both loneliness and social isolation. Similar to fiction, their stories offer viewers a "what if" scenario that allows them to imagine solutions to problems associated with population ageing. Indeed, they each seem to offer uplifting solutions. But the need for these fabricated connections speaks to the scarcities that make population ageing a potential problem, especially an undesirable long-term care system. More deliberately imaginative fictional friendships, such as that of Helen and Nicola, help to expose the shortcomings of contemporary curated friendships, which tend to be dyadic, by showing the tenacity and long-term commitment required to do the grittier work of care, best taken on by a broader network of people. I especially don't want already overburdened and under-supported service providers put in the position of counting or tracking friends, let alone finding them, when what they need is better funding. As Garner demonstrates, the trouble with and the beauty of 


\section{Sally Chivers}

friendship is its changeability, its ineffability, its individuality, and not its seeming affordability nor seeming capacity to solve simplified problems.

The disproportionate effects of COVID-19 on older adults have meant they faced even greater (and understandable) pressure to socially distance, shield, shelter-in-place, physically distance, and/or self-isolate as well as considerable pressures to find ways to be "Together, Apart," in other words, to find social connection without physical proximity. Opportunistic approaches to alleviating the perceived demographic burden become even more threatening, and the role of genuine friendship even more elusive. The time is thus riper than ever to draw on what humanities scholars know about friendship to emphasise "what friends are [and are not] for" in late life, especially in care situations, to play on Marilyn Friedman's book title. Although social bubbles or circles or cohorts became a way of understanding primary social connections in some jurisdictions during COVID-19, they typically referred to the ability to extend one's physical contacts to include extended family or to join two families together. The dominant emphasis throughout the pandemic was, as ever, on the role of families rather than on broader understandings of the way in which humans need to relate in order to thrive, well beyond the conjugal imaginary. It remains up to humanities scholars to ask and answer: who or what do we leave out when we fail to take true friends seriously?

\section{Acknowledgments}

This work was supported by the Social Science Research Council of Canada, grants numbered 435-2015-1787 to S. C. and PG 895-2018-1013 to T. D. I am grateful to Janna Klostermann's highly original dissertation research on leaving care, which influenced what I noticed when coming back to this novel; she offered helpful comments on earlier versions of the chapter. I thank Susan Braedley for her work on Bill and Rupert's story. I thank Tamara Daly for her framing and leadership of the Imagine Aging Research project. Finally, I thank the organisers of and participants in the important conference that was the inspiration for this timely book, especially Sarah Falcus and Katsura Sako.

\section{Notes}

1. The terminology "promising practices" is meant to build on but also resist the more corporate "best practices" that disallows a thorough consideration of context.

2. In my article “'With Friends Like These': Unpacking Panicked Metaphors for Population Ageing," I build on the argument of Amanda Barusch that we need a new metaphor for population ageing to explore how the seemingly benign metaphor of the "friend" as a way to make environments suitable for growing older in - that is, the metaphor that undergirds the age-friendly movement - is 
at once a pleasant counterpoint to the odious metaphor of the silver tsunami and a misnomer that props up the neoliberal focus on activity that drives the WHO's age-friendly movement. Although "age-friendly" connotes a pleasant response to an ageing population, it is decidedly an aspect of friendliness - the politesse of the service industry, for example - rather than friendship based on meaningful relationships.

3. Amid circulating usages, Susan Braedley helpfully describes the care economy "as the constellation of social relations through which care needs and wants are met, including market, household, familial, community and state actors" ("Pulling" 265).

4. This is a line in the opening theme song to the popular television show The Golden Girls (Harris; 1985-1992).

5. One such program in Toronto (set to expand beyond to include other Ontario cities) can be explored here: www.torontohomeshare.com/.

6. The digital cue can be viewed here: www.youtube.com/watch?v=YuTiAOZj1wg and here: https://imagine-aging.ca/digital-stories/.

7. We do not collect demographic information in our interviews, but it is safe to assume there are about 30 years separating Bill and Rupert in age.

\section{Works Cited}

Abel, Elizabeth. "(E)Merging Identities: The Dynamics of Female Friendship in Contemporary Fiction by Women." Signs: Journal of Women in Culture and Society, vol. 6, no. 3, 1981, pp. 413-35, https://doi.org/10.1086/493815.

Abel, Emily K., and Margaret K. Nelson. "Circles of Care: An Introductory Essay." Circles of Care: Work and Identity in Women's Lives. SUNY Press, 1990, pp. 1-34.

Barusch, Amanda S. “The Aging Tsunami: Time for a New Metaphor?” Journal of Gerontological Social Work, vol. 56, no. 3, 2013, pp. 181-4, https://doi.org/ 10.1080/01634372.2013.787348.

Braedley, Susan. "Pulling Men into the Care Economy: The Case of Canadian Firefighters." Competition \& Change, vol. 19, no. 3, 2015, pp. 264-78, https:// doi.org/10.1177/1024529415580259.

—. Less Lonely. Imagine Aging Project, 2019, www.youtube.com/ watch?v=YuTiAOZj1wg.

Brennan, Bernadette. A Writing Life: Helen Garner and Her Work. Text Publishing Company, 2017.

Brown, Wendy. "Sacrificial Citizenship: Neoliberalism, Human Capital, and Austerity Politics.” Constellations, vol. 23, no. 1, 2016, pp. 3-14, https://doi. org/10.1111/1467-8675.12166.

Carr, Richard. “All That Beauty, All That Wealth e'er Gave.” Antipodes, vol. 24, no. 1, 2010, p. 112.

Chivers, Sally. “'With Friends Like These': Unpacking Panicked Metaphors for Population Ageing." Societies, vol. 11, no. 3, 2021, p. 69. https://doi. org/10.3390/soc11030069.

Coslovich, Gabriella. "Playing against Type: Approaches to Genre in the Work of Helen Garner and Kate Jennings.” Hecate, vol. 41, no. 1/2, 2015, pp. 139-55/191-2.

Derrida, Jacques. "The Politics of Friendship.” The Politics of Friendship. Verso, 2005. 


\section{Sally Chivers}

Dessaix, Robert. "Kitchen-Table Candour: Helen Garner's Spare Room." The Monthly, Apr. 2008, www.themonthly.com.au/books-robert-dessaix-kitchentable-candour-helen-garner-s-spare-room-869.

Fisher, Berenice, and Joan Tronto. "Toward a Feminist Theory of Caring." Circles of Care: Work and Identity in Women's Lives. SUNY Press, 1990, pp. 35-62.

Foucault, Michel. "Friendship as a Way of Life." The Essential Works of Michel Foucault 1954-1984, Volume One - Ethics: Subjectivity and Truth. Edited by Paul Rabinow. Translated by Robert Hurley. The New Press, 1997, pp. 135-40.

Friedman, Marilyn. What Are Friends for? Feminist Perspectives on Personal Relationships and Moral Theory. Cornell UP, 1993.

Gandhi, Leela. Affective Communities: Anticolonial Thought, Fin-de-Siècle Radicalism, and the Politics of Friendship. Duke UP Books, 2006.

Gardiner, Judith Kegan. "The (US)Es of (I)Dentity: A Response to Abel on '(E) Merging Identities.' ' Signs: Journal of Women in Culture and Society, vol. 6, no. 3, 1981, pp. 436-42, https://doi.org/10.1086/493816.

Garner, Helen. The Spare Room. Anansi, 2009.

Gilligan, Carol. In a Different Voice: Psychological Theory and Women's Development. Harvard UP, 1993.

Harris, Susan, creator. The Golden Girls. NBC, 14 Sep. 1985-9 May 1992.

Holstein, Martha. "The Spare Room: By Helen Garner, Henry Holt, New York, 2008." Journal of Aging, Humanities, and the Arts, vol. 4, no. 4, 2010, pp. 457-61, https://doi.org/10.1080/19325614.2010.537965.

La Pierre, Tracey A., and Norah Keating. "Characteristics and Contributions of Non-Kin Carers of Older People: A Closer Look at Friends and Neighbours." Ageing and Society, vol. 33, no. 8, 2013, pp. 1442-68, https://doi.org/10.1017/ S0144686X12000736.

Roseneil, Sasha. "Why We Should Care about Friends: An Argument for Queering the Care Imaginary in Social Policy." Social Policy and Society, vol. 3, no. 4, 2004, pp. 409-19, https://doi.org/10.1017/S1474746404002039.

Roussy, Kas. "Seniors Co-Housing Antidote to Loneliness for 'Golden Girls' I CBC News.” CBC, 21 Dec. 2018, www.cbc.ca/news/health/seniors-cohousing-babyboomers-loneliness-mental-health-1.4952142. 


\title{
10 Care, Generations and Reciprocity in Children's Picturebooks in Japan
}

\author{
Katsura Sako and Sarab Falcus
}

\section{Introduction}

The COVID-19 pandemic brought into sharp focus questions about care, dependence and relationality. It highlighted, in particular, the generational relationship as something that is critical to the care and health of populations. As age was identified as a marker for vulnerability to the virus, yet resources for care were often severely limited, the question of which generations to protect and care for had ethical, political and social implications. Generational connection, however, has long been a critical issue in debates about care in Japan. Anxieties about care in the country connect the oldest and the youngest in the population through the twin drivers of demographic change: increased longevity and low fertility rates. Long life expectancy and the low birth rate combine to create a "super-aged population" (Kavedžija 215), pushing up the country's oldage dependency ratio and the demand for health and social care. ${ }^{1}$ More broadly, generational connection is a grave concern, because the country has long relied on families in the provision of care for older generations, and yet demographic, cultural and social changes have made such family-based care increasingly unsustainable. While social and publicly provided care remains inadequate, there is also a growing concern about the neoliberal individualisation of care responsibility. Chizuko Ueno, one of the leading feminist scholars on the family and care in Japan, therefore argues that "the myth of 'familial care' must be deconstructed" to realise a social security system that better responds to the varied circumstances and care needs of older people (Kea 104; translation by Sako).

To explore the cultural discourse of ageing, illness and care through the lens of generations, in this chapter we analyse post-1980 Japanese picturebooks that depict generational relations and care in a familial context. Children's literature is a genre in which the adult-child relationship is ingrained. Children's texts are produced largely by adults; are then often bought by adults; and even, in the case of books for the youngest, read by adults to children. Though there is a small but growing body of scholarly work on children's literature and ageing (see for example 


\section{Katsura Sako and Sarah Falcus}

Henneberg; Joosen, Connecting Childhood and "Second Childhoods"), studies that explore ageing, old age and intergenerational relationships in Japanese children's literature are very limited (Aoyama; Oomachi). The present study rectifies this by examining the relationship between the child and the older adult (usually a grandparent) in contemporary Japanese picturebooks. Our analysis is informed by Japanese, AngloAmerican and European scholarship. We heed the warning that Western perspectives are "often uncritically presumed to be culture-free and universally valid" (Lamb 37). We hope, however, that our eclectic intellectual basis enables a contextually informed reading that may also have relevance for similarly neoliberal, capitalist societies with ageing populations and increased demands for care.

There are debates and concerns among scholars over the power imbalance inherent in a literature (largely) written by adults for children (Nikolajeva; Nodelman) and the disempowerment of the child in many approaches to that literature (Gubar; Rudd). Nonetheless, in this chapter, we deliberately approach these books from the perspective of the adult. This approach recognises the significant role that picturebooks, or more generally children's literature, have played as an educational tool for children in Japan, a role that may extend to shaping the cultural discourse of family care. From the late nineteenth century through to the end of the Second World War, Japanese children's literature in its modern forms developed in close relation to the state's official policies and efforts to bring about modernisation and development, meaning that the books still often carry a strong instructive force (see for example Karatani Ch. 5; Torigoe, "Sengo"). Didacticism has characterised many picturebooks, too, since their modern forms began to be published in the early twentieth century (see for example Honda, "Ehon" 124-27 and Kodomo 201-08). This tendency continued even as picturebooks moved away from the militarism of the previous decades, and throughout the "golden age" of the genre (the 1960s through to the 1990s), which witnessed its expansion and diversification (Torigoe, Hajimete 146). The Ministry of Education, Culture, Sports, Science and Technology's 1956 guideline recommended the use of picturebooks for education at kindergarten; picturebooks were widely circulated through school and community libraries (Takahashi 147-51); the School Library Association (SLA) and other educational bodies began - and continue - to issue lists of recommended picturebooks; tied to these lists, various reflective writing competitions for children have been held locally and nationally (Miura 188-9; Torigoe, "Sengo" 14). ${ }^{2}$ This instructive impulse is reinforced by the way in which the adult's voice is felt in the books, because the act of address as well as the age and the gender of the addressee and the addressed are often clearly indicated in the modern Japanese language (Karatani Ch. 2). Therefore, there may be more 
explicit didacticism in Japanese picturebooks than in those produced in other cultures.

We present in this chapter our findings from a survey of 46 Japanese picturebooks, chosen from a larger corpus of 75 picturebooks about intergenerational, primarily (great) grandparent-grandchild, relationships. ${ }^{3}$ We explore the various ways in which these books promote the traditional - generational and gendered - form of familial care. These books depict two types of care: one is emotional, practical and affective care, and the other is what Eva Feder Kittay, Bruce Jennings and Angela A. Wasunna call "dependency care," in which a person (young or old) needs support in the daily activities of self-maintenance (443-4), a type of care that is central to policies and debates about care in Japan. But we are less concerned with exploring different types of care in the books than with the way that care is both realised and anticipated, underpinned by notions of duty, responsibility and reciprocity. As our analysis demonstrates, these notions are often expressed through narratives of generational succession that link care to intergenerational reciprocity, something that may reflect the adult's desire to secure care in the future. Akiko Hashimoto describes this generational exchange of care in Japan in her 1996 study: "The expectation that succeeding generations face the same predicaments creates the basis for reciprocal helping arrangements that extend over generations: The young person is more likely to pay the price of old age willingly at an early age, if he or she also expects need is inevitable and wants to guarantee his or her future support" (150). These books are then a medium that perpetuates rather than deconstructs what Ueno calls "the myth of 'familial care"" (Kea 104).

The family care depicted in these picturebooks can be read in the light of the ideas of relational care and self associated with feminist ethics of care (Gilligan; Kittay; Noddings). The focus on relationality in this scholarship derives from a feminist rethinking of the conception of the human subject as an autonomous self in the Western liberal tradition, a conception that does not accommodate conditions such as vulnerability, disability and resultant dependency. Scholars such as Kittay have argued that dependency must be considered as an inevitable and shared condition of human subjects. This approach resonates with age studies critics who question discourses of successful ageing that are founded upon ideals of "individual choice, agency, and lifestyle" (Katz and Calasanti 28). On one level, these picturebooks suggest a relational model of care, one that accommodates rather than stigmatises dependency and an embodied, potentially vulnerable self. The integration of care responsibility into the family as a self-sufficient unit means that the books tend not to stigmatise the receipt of care. At the same time, however, the books contribute to a social imaginary that idealises gendered care. As feminist care ethics scholars have noted, social structures can create and amplify the vulnerability of certain people, including carers, most of whom are women 
(Kittay et al. 462). Furthermore, some books also suggest a paradox at the heart of familial relationality: that it can lead to anxieties around dependency on others and can restrict the ways in which autonomy is exercised.

The relationality of care and self that we find in these books in many ways echoes existing scholarship on subjectivity and autonomy in Japanese culture. ${ }^{4}$ For instance, John Traphagan explains: "in many respects it makes more sense to talk about family autonomy than individual autonomy in Japan" (Rethinking 77). There are also suggestions that a specific form of individualism underlies the collectivist fabric of Japanese society. ${ }^{5}$ These suggestions indicate the complex positionality of self in relation to others and groups in Japan, and we certainly do not deny the similarities between this scholarship and some of our conclusions about the books we examine. Indeed, the specific ways in which autonomy and reciprocity are exercised in these books do suggest that the impact of local culture cannot be ignored when we think, read and write about care, reminding us of Lamb's caution about the non-universality of Western theorisations. Nonetheless, it is not our aim in this chapter to participate in the debates about contemporary Japanese selfhood. Our primary concern is to explore the role of children's picturebooks in the discourse of care in Japan and how they depict the familial relationality that sustains reciprocal care.

\section{Familial Care in Japan}

Ueno defines family care as that in which the primary carer is kin to the cared-for, which is unpaid and which takes place in the residence of the cared for ("Family Strategy" 31). There is the popular belief in and outside of Japan that family care - especially that based in a multigenerational household - is part of Japan's cultural tradition. Scholars have shown, however, that this belief is a product of official policies and political discourses. Merry White explains that "the family" is a state construct invented by the Meiji government (1868-1912) to achieve rapid industrialisation through the gendered division of labour ("Introduction"). In this system, care responsibility was located in each family and fell to female members, especially daughters-in-law, in cases of elder care. Studies have also identified the "contractual quality" (Coulmas 64) of family care that undermines the view that it is sustained solely by filial piety. Misa Izuhara notes, for instance, that inheritance practices in Japan, although changing, have traditionally been linked closely to the care that the child has provided for the parent. Looking at care relationships in both Japan and America, Hashimoto also describes the "social contract" that underpins care relationships as "a reciprocal arrangement to give and receive gifts in turn, based on a tacit standard of evaluation that defines their symbolic equivalence" (17). She argues that in Japan 
there is greater expectation of the need for care, and this leads to the involvement of the family in planning for future care needs. This expectation of the need for care also shapes relationships among generations as "intergenerational equity means taking turns in giving and receiving support according to differential abilities in different life stages" (Hashimoto 154).

Despite the continued emphasis upon familial and intergenerational responsibility in cultural discourses and in practices of care, the reliance on gendered and generational care has come under increasing pressure in the decades since the end of the Second World War. This is due to various factors: growing female participation in higher education and the labour market; the reduction of multi-generational households and an increase in nuclear households as a result of ongoing rural to urban migration; ${ }^{6}$ and the decline of secure and stable employment in post-recessionary Japan (Aoyama et al. 1-2; Sasaki), contributing to the increase in single-person households and late marriage; and a growing segment of the population who never marry. Alongside these changes, there have been debates over and reform to the social security and welfare and healthcare systems for older people since the achievement of basic universal healthcare coverage in the 1960s (Nakagawa and Gondo). The Act on Social Welfare for the Elderly in 1963 was a response to the ageing population and the associated idea of care as a "social problem." Public care provision, however, was limited and only available to those for whom familial care was not available. There were further reforms to welfare, healthcare and the pension system throughout the seventies, eighties and nineties, as demographic change continued. The Long-Term Care Insurance (LTCI) system, introduced in 2000, marked a significant milestone, combining social insurance and tax to provide more public care (Nakagawa and Gondo 57). LTCI has, however, contributed to the rapid marketisation of care and the individualisation of care responsibility, leaving many older people unable to afford the care they need (Nakagawa and Gondo; Thang). ${ }^{7}$ More significantly, the system has been criticised for assuming family involvement in care, making it "a useful tool to keep the family involved in the care of older people" (Tokoro 68).

Despite expanding social and private care, therefore, many families continue to cope with care responsibilities. Yet, signs of the limits of familial care indeed abound: a rising poverty rate among older populations; the rising number of older people who live and die alone in their homes; ${ }^{8}$ continuing incidents of abuse and violence against older people by family carers, despite the 2006 Law for the Prevention of Elderly Abuse and Support for Caregivers; and cases of "old-old care" (ro ro kaigo), where carers themselves are old and are often caring with severely limited resources (see Kasuga). Care also remains a gendered issue. Although forms of family care have diversified, with more men caring for spouses and parents, care is still predominantly undertaken by women, as wives, 


\section{Katsura Sako and Sarah Falcus}

daughters and daughters-in-law, ${ }^{9}$ in many cases making them financially and emotionally vulnerable (Ueno, Kea 112-15).

These recent changes have unsettled the generational exchange of care, confirming Hashimoto's claim that "intergenerational equity is not set in stone" (155). Furthermore, to suppress care costs, governmental discourses and initiatives place increased emphasis on the prevention of care needs and support for independence (Arichika et al.). Ethnographical works confirm the impact of these changes in the lives of older people. For instance, Jason Danely emphasises how some older people now live with the fear of falling out of the circles of care within families and communities and being abandoned (Ch. 6); "If Japan was never a genuine geriatric utopia," he states, "then it is not currently a paradise lost" (17). The generational care in the picturebooks we examine, however, remains largely anachronistic and nostalgic, suggesting a desire to sustain a discourse of familial care, even in the face of social change.

\section{The Picturebooks: An Overview}

Our corpus contains 46 books published between 1982 and 2015. Many are published by well-known or established publishing houses specialising in children's literature, and some are widely circulated. ${ }^{10}$ The readership age groups for these books are judged to be up to around eight years old. ${ }^{11}$ The narratives in the corpus are predominantly realist, although there are exceptions, such as the fantastic elements in Obachan to warabeuta [Grandma and Nursery Songs] (Nakajima, Takagi and Ikeda, 1997) and Maho ha naishode kakeyone [Let's Secretly Cast a Spell] (Sueyoshi and Makino, 1984). ${ }^{12}$ The illustrations in the books are similarly realist, but they do include symbolic and carnivalesque elements, for example, in Bachan no onaka [Grandma's Tummy] (Kasai and Yoshinaga, 2010).

One-third of the books in the corpus are clearly set in multi-generational households, and this proportion does not change significantly in the books from the twenty-first century, despite the rise in nuclear families and single-person households in Japan. Grandparents are most often widowed and are rarely seen in couples, a feature that may be a reflection of Japanese households as well as a conceit to allow for an intimate child-grandparent relationship. Some narratives employ what Vanessa Joosen (Connecting 17) calls the "seesaw effect," omitting the middle generation (the child's parents) in order to exploit the child-older person bond for narrative effect. In 14 books, grandparents are seen at home in need of care because of injury, impairment or illness; in 4 books, grandparents receive medical care at hospital. Significantly, the middle generation is typically present in the narratives in which dependency care for grandparents is required and the child's parents (predominantly mothers) are seen to have a caring role within the family. Only two of the books contain representations of day-to-day professional, non-medical care at 
and outside of the home. ${ }^{13}$ This means that these books largely ignore the recent increase in professional care and diversifying forms of familial care in Japan mentioned earlier.

Grandparents are not always care recipients, and both grandfathers and grandmothers provide care for children in these books. Nonetheless, representations of older people are strongly heteronormative and gendered, despite the diversification of gender representations in Japanese picturebooks in recent decades noted by scholars such as Kyoko Takeda ("Gender"). Most books are centred on (great) grandparent and grandchild relationships, with same-sex pairings the most common: 17 books feature (great) grandfather/grandson relationships and ten books feature (great) grandmother/granddaughter pairings. Where the relationship is of mixed sexes, grandmother/grandson pairings appear most frequently (ten books), with only one book featuring a relationship between a granddaughter and grandfather. Although the gender balance of grandparents is almost equal, in our sample, grandfathers are very rarely seen with and caring for female children. Grandmothers are depicted with white hair, wrinkles and round bodies; they are tied to domestic environments and undertake tasks such as cooking and childcare. In earlier books, they are often depicted as physically frail (Yukkurayukkura yotayota [Slowly, Slowly, Titter, Tatter] (Watanabe and Kajiyama, 1982); Obachan no engawa [Grandma's Deck] (Nomura, 1983)). Later books offer stronger grandmotherly figures - even to a baseball-playing grandmother in Obachan ga obachan ni nattahi [The Day Grandma Became Grandma] (Nagano, 2015) - but this strength is exerted within the parameters of the maternal and domestic role. Grandfathers, on the other hand, are more varied. They range from stern, blue-collar figures (Jishinkaminarikaji jichan [Earthquake, Lightning, Fire, Grandpa] (Okada and Shinohara, 1987); Jichan to naishonaisho no yamanobori [A Secret Secret Mountaineering with Grandpa] (Watanabe 2007)) who speak in a rough, masculine language and rarely smile, to more caring (It's Okay, It's Okay) and imaginative figures (Let's Secretly Cast a Spell; Futari ha dadakko [Two Spoiled Children] (Imamura and Furiya, 1995)). The trend overall is, nevertheless, to stress the masculine role and to locate grandfathers outside the home, very often connected to rural and even wild places. These findings may not be statistically significant because of the small size of our sample, yet they are suggestive of the persistence of the link between gender and familial care.

\section{Care, Duty and Intergenerational Reciprocity}

Care in these books is embedded within gendered generational structures and is presented as a duty that is tied to one's position in the family. Many of the books offer a clear moral lesson about a child's responsibility to care and depict the obliging child who matures through care. This 


\section{Katsura Sako and Sarah Falcus}

is facilitated by presenting care as a challenge to the child but also as an opportunity for their growth. Most of the books that depict the illness of a grandparent present this as an acute or temporary rather than chronic condition, which ends with the grandparent's recovery or death. A grandparent's illness is therefore an event that clearly marks the exchange of caring roles between the generations, emphasising the development of the child. The narrative of reciprocal generational care in these books therefore aligns with Miyuki Hisaoka's observation in a comparative study of Japanese and Australian picturebooks that Japanese texts envisage subjectivity based on "identity-with" rather than "different-from" as their Australian counterparts do (71). This distinction may be cultural, as Hisoaka suggests, and rest on the idea that Japanese subjectivity "tends to be formed in wider society through the child's early joining into social practices," practices that encourage their "assimilation ... into society" (76). The books we examine certainly support a vision of personhood and child development that is based upon relationality and obligation. What is important for our discussion, however, is that this relational model of subjectivity is embedded within a narrative of development that teaches the child about the duty to care.

In Yuko to Fumi bachan [Yuko and Grandma Fumi] (Miyakawa and Ishikura, 1983), the acceptance of a generationally defined role and gendered care responsibility is powerfully depicted through mirrored generations. Grandma Fumi relates to her grandchild, Yuko, a story about caring for her own mother, Yuko's great-grandmother, when she was ill. Grandma Fumi goes to great lengths to find snow on the mountain and brings it to cool her mother's fever. Grandma then falls ill, and Yuko undertakes the same task, travelling far into the mountains to find snow. The repetition of this story is reinforced by the mirroring of images within the text. In a double spread, a red-clothed, young Grandma Fumi kneels beside her mother's futon (see Figure 10.1) and, in a later image, walks in the mountains, small against the landscape. Similarly, Yuko is seen as a figure in a red skirt kneeling next to her grandmother's futon (see Figure 10.2) and then as a small figure against a mountainous background. Grandma recovers, just as her own mother did, as a result of the care of the child. Grandma, like her mother before her, praises this care when in the company of other members of the community, making clear the social value of familial care and responsibility.

Children travelling to and visiting older relatives alone is a repeated trope in the books that reinforces the moral education of the child through the fulfilment of a caring role (Grandma's Tummy; It's Okay, It's Okay; Obachan no shima de [On Grandma's Island] (Furiya, 1995); Hitoride omimai [A Visit Alone] (Kimura and Kimura, 1991); Sayonara, obachan [Goodbye, Grandma] (Nishimoto and Karino, 2010)). In her study of the long-running series of stand-alone picturebooks, Kodomonotomo, Takeda argues that nuclearisation of families "ha[s] detached the presence 

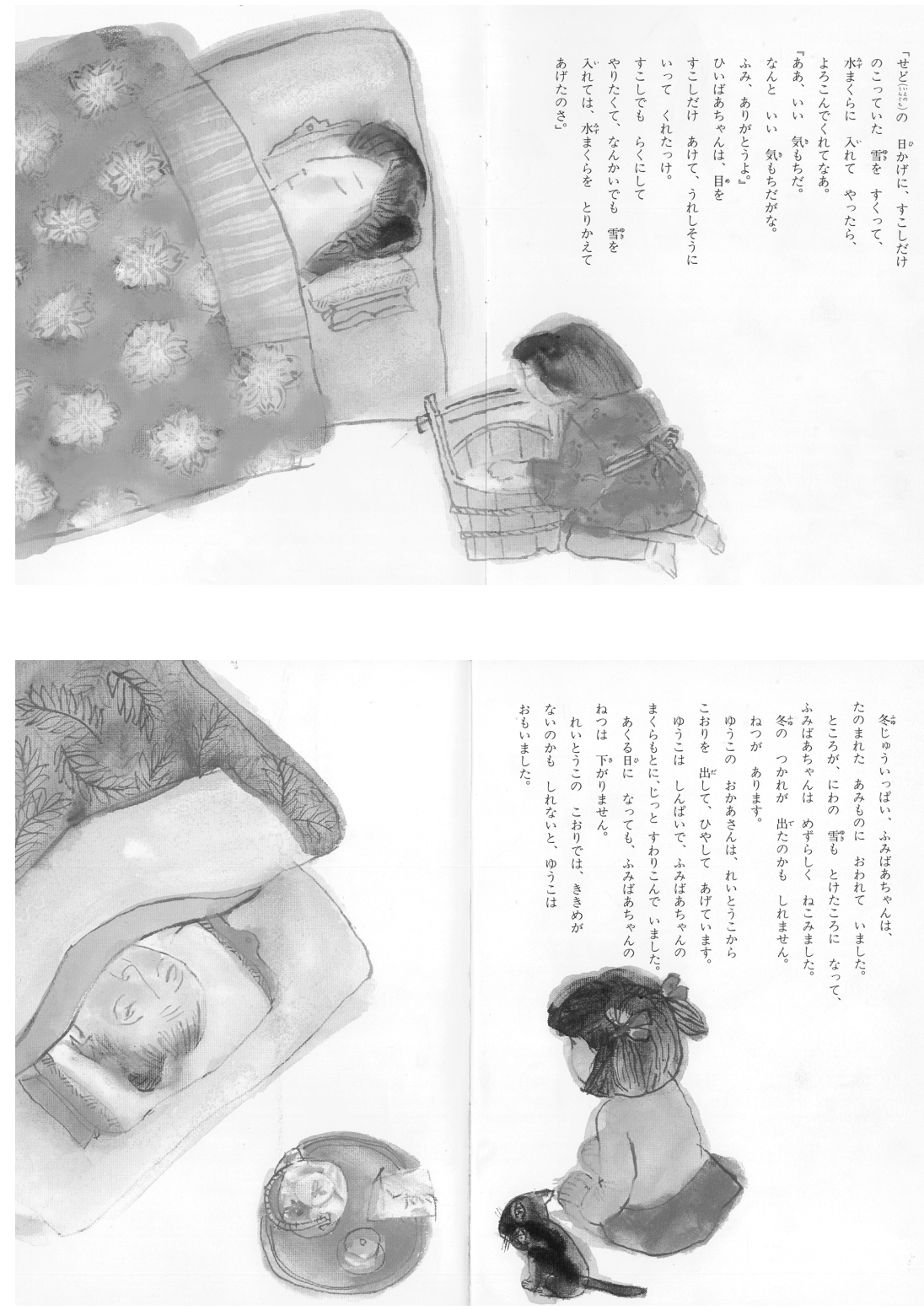

Figures 10.1 and 10. 2 Yuko and Grandma Fumi [Yuko to Fumi bachan], reproduced with permission of Akane Shobo.

Source: ( Hiro Miyakawa and Kinji Ishikura. 
of grandparents from children's daily life" ("Ehon" 526), noting a growing number of books where grandparents live alone, or where a child visits a grandparent during long school holidays (ibid. 527). The journey narrative may reflect changing household structures in Japan, which means generations are geographically separated, with grandparents living in rural or remote areas in some cases. Nonetheless, as a device, this trope effectively represents a journey to maturity and emphasises the child's responsibility for care within a generational structure.

In the more recent picturebook Obachan ha kaguyahime [Grandma is Kaguyahime] (Matsuda and Karino, 2013), Saki-chan visits her father's childhood home to stay with her bamboo-farming grandparents alone for the first time. This indicator of child development is tied closely to generational responsibility, as Saki-chan's father tells her that "Grandpa and Grandma are both old now. It's crucial that you dig up bamboos every day" (3). He worries that the child will not "be enough help" (ibid. 3.). The bamboo functions as a symbol on a number of levels: it ties the grandparents to a traditional occupation, it represents their livelihood and independence, and its encroachment is a danger associated with lack of care. This is made clear in the example of a neighbour's house where the bamboo growing out of the floor is explicitly connected by Grandpa to the lack of family and, implicitly, to the lack of care and support. As Grandpa says, "Apparently there's bamboo growing out of the floor at Ueda-san's house. They don't have any kids and they can't take care of the house nor the mountain, only bamboo's growing” (20). The book uses temporary illness as a plot device in order to enable the child's development through responsibility and duty. The care that the grandparents are seen giving to Saki-chan is reciprocated when her grandmother injures her foot and Saki-chan is seen in the image bending down to her seated grandmother, trying to help. A later image depicts Saki-chan stooping to touch her grandmother's injured foot. These images of care are supplemented by a narrative that describes Saki-chan helping her grandfather to dig bamboo shoots in order to make her grandmother happy. As in many other books, illness necessitates the reversal of the caring role, tying the development of the child to their place in a generationally defined structure of care and responsibility.

Significantly, this generational responsibility is gendered in distinctive ways. One example is the way that Grandma is Kaguyahime alludes to the traditional literary tale of Kaguya-hime [Princess Kaguya], a story about a girl who is found in a bamboo stalk, raised by an old couple, and grows into a beautiful woman. Grandpa tells Saki-chan that Grandma was known as Kaguya-hime as a young girl, and that Saki-chan is their Kaguya-hime. The allusion to Kaguya-hime connects Grandma (as child) and Saki-chan through their appearance (emphasised in Grandpa's words and in the large image of Kaguya-hime centred on the page), their affinity with bamboo, and their status as a source of happiness for older adults. 
This connection is embedded within the familial unit when Saki-chan's parents return and her father joins Grandpa in cutting bamboo. The double spread presents the active masculinity of the grandfather and the father as they climb the mountain carrying tools, in opposition to the stasis of the three women. In the image, the mother supports a slightly stooping Grandma as Saki-chan raises her hands towards the men above her. The sense of generational succession that is evoked by the Kaguya-hime tale is reinforced by the narrative of generational responsibility and emphasised by images that depict gendered, generational structures of care.

The moral lesson is particularly strong in books that depict a child's resistance to care and to their familial obligations. In a number of books, the child protagonist is seen to struggle with the role expected of them in relation to an older relative (for example, Grandma and Nursery Songs). In Chiko-chan no akai chokki [Chiko-Chan's Red Vest] (Furiya, 1987), a grandmother's illness marks the shift of her role from the provider to the recipient of care, and granddaughter Chiko-chan initially struggles with the repercussions of this. Chiko-chan's relationship with her grandmother is established in an image of them planting bulbs together, both active and smiling. The garden and the cycle of the seasons then provide the temporal framework and symbolism for the narrative of their changed relationship. The outdoor space proves to be a space of risk for the grandmother: her two falls - one in the garden and the other through the bedroom window - cause her confinement to her futon. The indoor space then becomes one of illness and, therefore, of care. After her collapse, the grandmother is primarily depicted indoors, and Chiko-chan, coming back from school, sees her bedroom window curtained. The grandmother is then seen in bed or looking out from her bedroom window, symbolically representing her changed relationship with the world around her, including both the garden and her granddaughter.

Care is heavily gendered in Chiko-chan's Red Vest. Published in 1987, just two years after the passing of the Equal Employment Opportunity Law in 1985, the book contains a rare representation of a working mother. Nonetheless, though both parents discuss the burden of care, it is the mother in this multi-generational household who leaves her job to provide care for her ill mother-in-law. Many images show her smiling whilst providing practical support with feeding and other daily activities (see Figure 10.3).

Yet Chiko-chan is also still in need of the mother's care, as suggested by an image of her trailing after her mother, holding onto her apron. Chiko-chan is depicted as an observer in the images of her mother caring for her grandmother, looking askance and at times shocked by her grandmother's changed behaviour and inability to care for herself. In one image, Chiko-chan is seen holding her nose and the text describes her complaining about the smell of the room. However, as a narrative of growth and development, the picturebook sees Chiko-chan learn to relate 


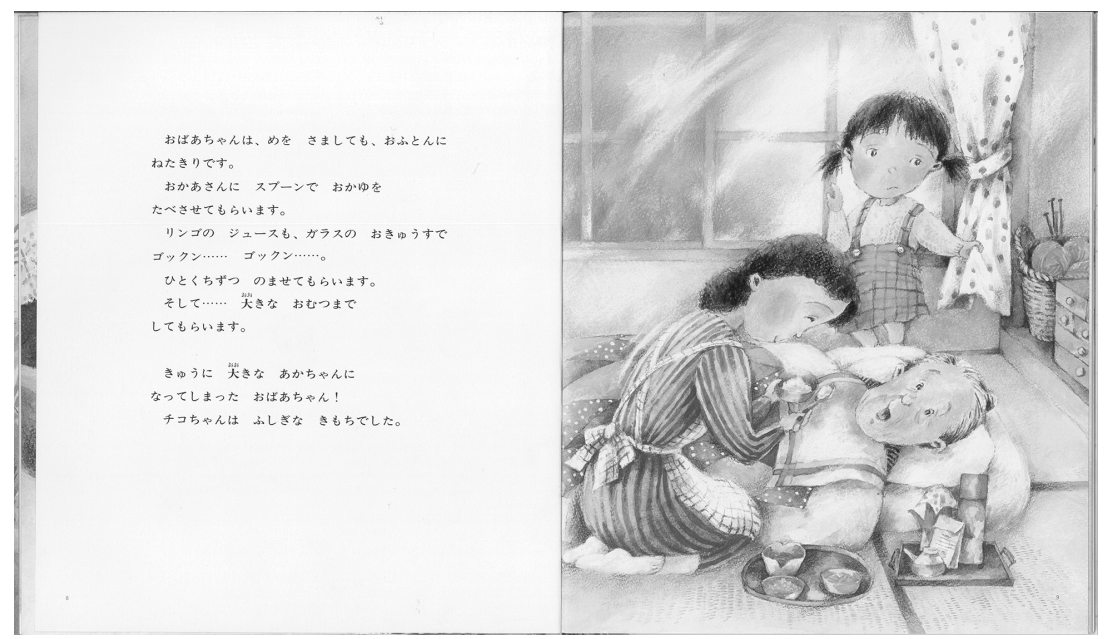

Figure 10.3 Chiko-chan's Red Vest [Chiko-chan no akai chokki], reproduced with permission of Kayoko Furiya.

Source: (c) Kayoko Furiya.

to and care for her grandmother. This is symbolised by the first image of the grandmother outdoors after her collapse: she is seen sitting making flower crowns and necklaces with her willing granddaughter. Spring has arrived, and in the following double spread the hyacinths planted by the pair have bloomed, linking generational succession (and the human life course) to the cycle of the seasons. The child reader is encouraged to empathise with and relate to Chiko-chan's initial struggles and her final, and inevitable, acceptance of her gendered caring role. The gendered nature of this role is emphasised in an image in which a male doctor and Chiko-chan's father are depicted sitting next to the dying grandmother, with the mother and Chiko-chan sitting behind them. The book's narrative of generational succession is then reiterated after the grandmother's death when the mother completes a red vest that the grandmother had been making for Chiko-chan, symbolically taking on the grandmother's role and linking the three generations of women through a domestic skill. Chiko-chan is currently the recipient of her mother's care, but the text implies that she will, in her turn, become the provider of care to both her elders and to the next generation.

In contrast to grandmother-granddaughter relationships, relationships between grandfathers and grandsons are often marked by active, commonly outdoor pursuits that enable the succession of traditionally masculine skills and knowledge through generations. Care, in this trope, 
is not practical support for daily life, but embodied in the assumption of intimately shared masculine knowledge and skills as familial assets. Furthermore, what is notable about these books is that the vision of masculinity being passed on to the child is one under threat, but this threat is contained through the male lineage. The sense of anxiety that emerges in some of these texts intimates that changes in Japan are unsettling the vision of familial care promoted by the books. In Earthquake, Lightning, Fire, Grandpa, for example, a grandfather teaches his grandson the traditional family trade, bamboo weaving, and this functions as a compensation for the loss of the family bamboo grove (sold to provide the family with money to modernise their house). Samojiro Watanabe's A Secret Secret Mountaineering with Grandpa offers a similar narrative of male inheritance in the face of loss. Grandfather and grandson engage in a kind of initiation rite in the absence of Kenta's parents. They leave the domestic space of the family home to walk in the mountains in search of the char that adventurous Grandpa rescued and put into a high river years ago. Finding the fish, Grandpa acknowledges that he can no longer monitor them and passes the responsibility to his grandson. Having undergone the initiation rite and learned how to cope with danger and the unexpected, Kenta accepts his familial role, symbolised through his care for the fish. The positions of grandfather and grandson in the images makes this clear: Kenta is initially positioned as subordinate to his grandfather (below, behind or being carried by him) (see Figure 10.4), but after they find the fish, they are seen from behind standing close together, and Grandpa has his arm on his grandson's shoulders (see Figure 10.5). This book hints at a changing world through the threat to the fish (they have been overfished for fun, not food), which is tied up with Grandpa's increasing frailty. Nonetheless, the book seeks to overcome this threat, symbolically, by a successful exchange of caring roles, rooted in a masculinity associated with danger, strength and protection of the vulnerable.

A narrative of male lineage is also central in Jibun no ki [One's Tree] (Mogami and Matsunari, 2009), in which the illness of a greatgrandparent necessitates the development of the child. Set in a remote, depopulated village, One's Tree depicts the connection between Wataru and his 93-year-old great-grandfather. Wataru listens to the great-grandfather's past as a bear hunter and his love for the mountainous environment in which they live, especially Mt. Asahidake. This environment is depicted in vivid colours in thick brush strokes throughout the book. As in many other books, the middle generation is entirely absent, isolating the child and great-grandfather to emphasise their intimacy. The trope of travelling alone features in this book, too, as the great-grandfather's illness forces his move to a hospital in the nearby town, meaning that Wataru has to travel for an hour to see him. Images of Wataru on his bicycle, a tiny figure in the lush green surroundings, and later his anxiety in the unfamiliar space of 

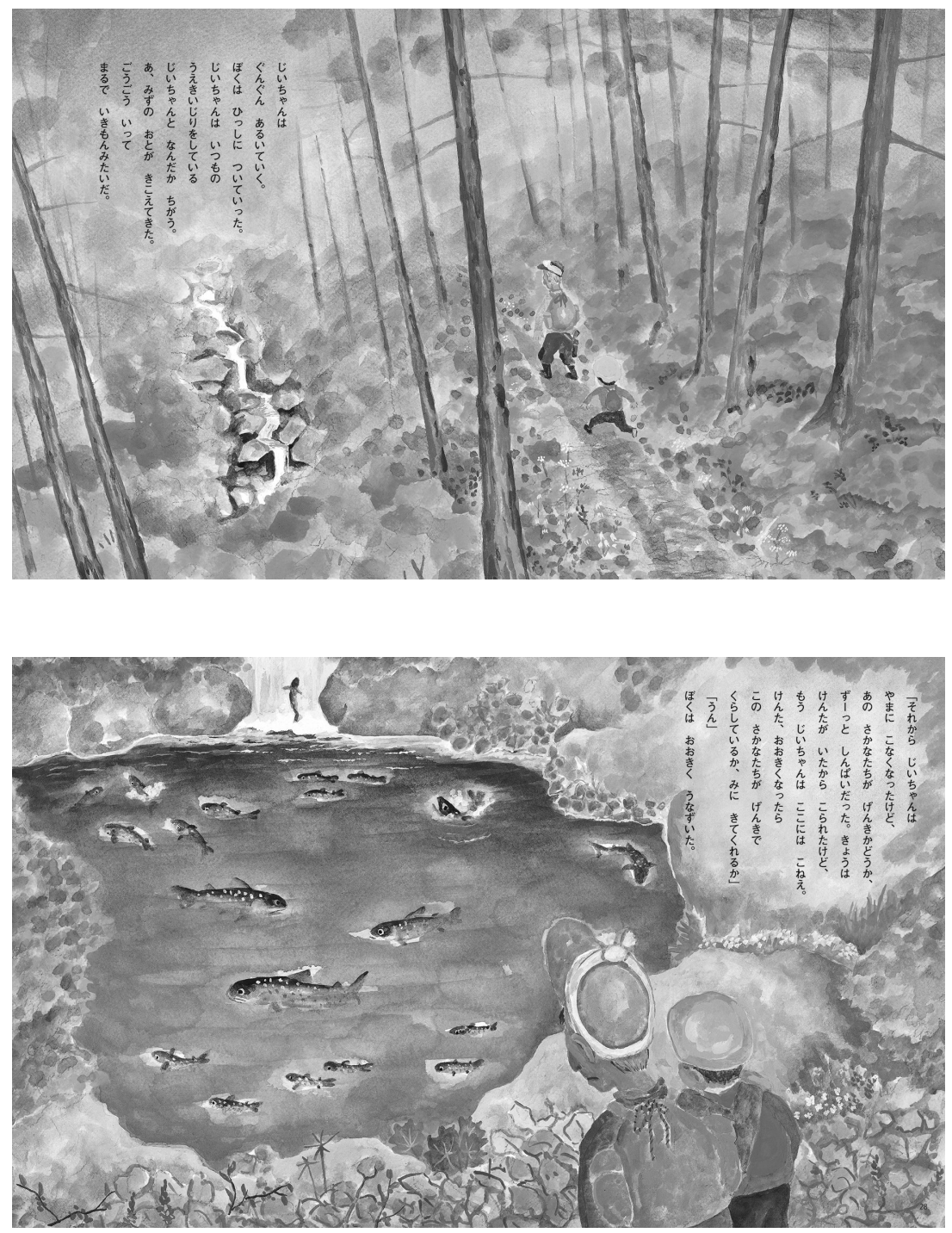

Figures 10.4 and 10.5 A Secret, Secret Mountaineering with Grandpa [Jiichan to naishonaisho no yamanobori], reproduced with permission of Suzuki Publishing Co., Ltd.

Source: () Samojiro Watanabe.

the hospital, painted in pale colours, suggest the challenges he faces in order to mature. One episode then clearly marks the exchange of care between the two generations: to fulfil his great-grandfather's wish to see Mt. Asahidake once more, Wataru gazes at the mountain so as to 

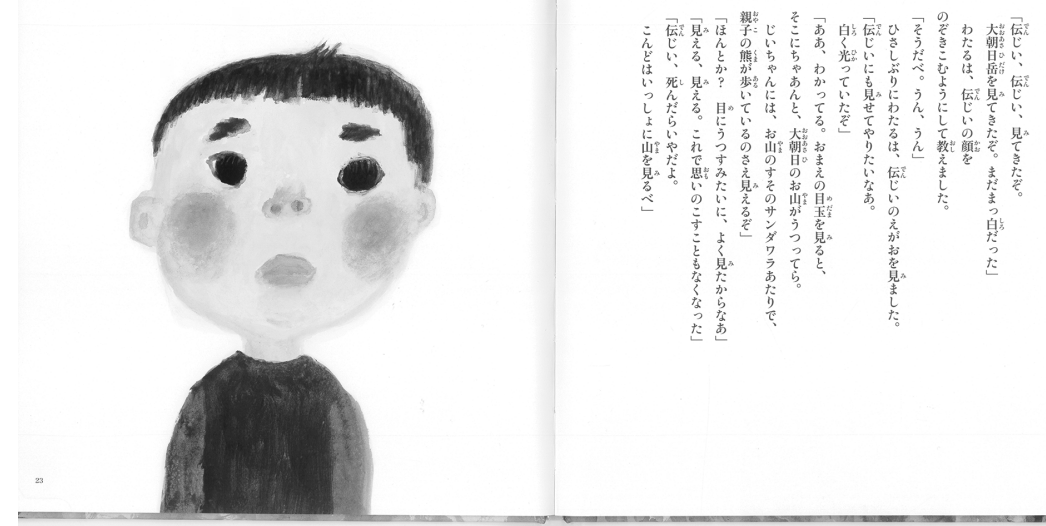

Figure 10.6 One's Tree [Jibun no ki], reproduced with permission of Iwasaki Shoten.

Source: ( Ippei Mogami and Mariko Matsunari.

"print it on my [his] eyes" and delivers the image to his dying greatgrandfather (22). On the right page of a double spread, we see the conversation between the two, in which the great-grandfather confirms that he can see the mountain in Wataru's eyes (22). The illustration on the left page (23) shows Wataru alone, his eyes large and black against a blank background (see Figure 10.6). Depicted from the perspective of the great-grandfather, the child looks sad, and his pink cheeks exaggerate his childishness. Nonetheless, this is also an image of a child who is called upon to be strong, an image that stares back at the child reader as much as at the great-grandfather. ${ }^{14}$

\section{Vulnerability and Dependency of Grandparents}

Promoting reciprocity and duty in relation to familial care, the picturebooks present a model of care that is premised upon the relational understanding of self and dependence but that relies upon gendered responsibilities. There are also signs in these books of the paradoxical impact that strong relationality and familial reciprocity may have. Though the books do not stigmatise the receipt of care in older age, some texts depict the individualisation of responsibility and shame about dependence as the result of strong intergenerational duty and responsibility. 


\section{2}

Katsura Sako and Sarah Falcus

The centrality of obligation in generational relationships in these books means that grandparents' receipt of care is naturalised and is rarely represented as a threat to their sense of self, as the stories of mirrored generations in Yuko and Grandma Fumi make clear. Generational care is explicitly endorsed in books that point to the moral and social value of the child's caring through praise voiced by a grandparent or other older character, as in Yuko and Grandma Fumi and other books, such as Ojichan no machi [Grandpa's Town] (Nomura, 1989). At the same time, some books signal that, though reciprocity may be assumed, dependency is something that should be avoided. In these books, grandparents apologise and feel guilt because illness means that they are dependent on others' care and/or they become a "burden" to their families. This can be seen in stories like Grandma is Kaguyabime, where the grandmother apologises after hurting her foot and being unable to cut bamboo (see also Grandpa's Paradise, Paradise and Daisukina obachan [My Dear Grandma] (Koyama and Fukuda, 1991)). These books then depict autonomy itself as relational and secured by taking responsibility for the impact of one's own actions on others, in this case, primarily family members. This model of autonomy may be culturally inflected, as we suggested earlier. The shame expressed about dependence in these books may also reflect the impact of neoliberalism in Japan in recent decades, where older people are under increasing pressure to "become (self) disciplined bodies" (Traphagan, "Being" 271) to spare society the burden of their care. Either way, it is significant that these books, while instilling a duty to care for older people in children, also indicate independence as a norm. This seemingly paradoxical attitude towards autonomy and dependence may be cultural, but it may also be an expression of anxieties about the impact of care needs on subsequent generations.

Ojichan no dobutsuen [Grandpa's Zoo] (Asano and Asano, 2002) clearly illustrates the paradox of the strong relationality at the core of family care. In the book, a grandchild narrates the story of his grandfather's realisation of a long-held dream to live with many animals. After his retirement, Grandpa moves to a rural area to run a farm and menagerie. He is eventually joined there by his grandchildren and family. Colourful images stress the active nature of farm life. But as Grandpa brings in more and more animals, the images show the other family members to be dismayed, rather than pleased, and a sequence of images and text describes the tasks involved in caring for so many animals. Grandpa eventually falls ill immediately after nursing a monkey back to health, implying that his illness and associated need for care are a direct result of his animal ownership (and, therefore, his individual dream). The animals are then a burden on the other family members, and the text describes Grandpa's sadness and worry about this. Specifically, he relates this to his own future frailty: "As I grow even older, and my body stops working, what will happen?" (19). This link makes clear that the "burden" 
of caring for the animals is inherently linked to the "burden" of caring for older relatives. Upon his recovery, Grandpa begins to free some of the animals, recognising the need to curtail his own desire because of the impact of his decisions on other family members. At the same time, Grandpa's family decides to distribute roles more equitably and work together. It is therefore through turning Grandpa's individual dream into a familial project that the book de-stigmatises his choice to follow his own dreams. A further community-based responsibility is fulfilled when "Grandpa's zoo" is opened to visitors, and Grandpa educates them about animal welfare. Picturebooks like Grandpa's Zoo then present a model of relational care that may ensure reciprocity but also restrict individual autonomy. They not only emphasise the duty to care embedded in generational relationships, but also suggest that there is a complex relationship between duty, responsibility and reciprocity.

\section{Conclusion}

These books about grandparents, grandchildren, illness and ageing are in many ways anachronistic, conservative and idealistic. They support the cultural discourse of familial and gendered care, inducting young children into a vision of intergenerational responsibility that is now very often unattainable. Espousing the duty of a child to care for older generations, they present the route to maturity (growing up) as one of relationality and the acceptance of familial obligation. Some books do express what we might call "hidden adult anxieties" about the threats to the very care and generational system they celebrate. Geographical separation and depopulation, for instance, signify these threats, as does the very force with which the texts assert a familial ideal that may be a long way from the reality of the lives of many families in contemporary Japan. The books contain these threats through the narrative of generational inheritance. They are evidence of both the persistence of the ideal of familial care in Japan and the desire to secure the future of that ideal in the next generation.

At the same time, these books contain signs of limitations to the ideal of reciprocity at the heart of familial care. The complexity of what Hashimoto calls "symbolic equity" in generational economies of care is indicated in those books where older people feel guilt about their own dependence and the associated need for care from family members. Although relational care has been considered in positive terms in recent decades as an antidote to harmful individualism in Western societies, the intergenerational familial care in these Japanese books suggests that relationality works in complex ways, ways that are also culturally conditioned. Furthermore, the shame attached to dependency may also reflect the neoliberal individualisation of care responsibility. In June 2021, the Japanese government passed a bill to oblige more 


\section{Katsura Sako and Sarah Falcus}

people over 75 to contribute $20 \%$, not the current $10 \%$, towards their medical costs. The official justification for this change - that it would lessen the burden on younger generations - has been questioned by estimates suggesting its limited impact on younger people, and concerns have been raised that yet more older people would be left unable to pay for their healthcare. The idealisation of family care in these contemporary picturebooks is therefore a reflection of a society that struggles to find new ways to care.

\section{Acknowledgements}

Research for the present study is supported by the Japan Society for the Promotion of Science (KAKENHI: 17KK0030). The authors are also grateful to the three bilingual students from Sako's cultural gerontology class who translated the picturebooks into English.

\section{Notes}

1. In 2019, Japan's total fertility rate was 1.36 (Ministry of Health, "Reiwa" 4 ), and life expectancy at birth was 81.41 (men) and 87.45 (women) (Ministry of Health, "Abridged" 1). Among countries in The Organisation for Economic Co-operation and Development (OECD), Japan has the highest old-age dependency ratio at over 50 people aged $65+$ for every 100 people aged 20-64 (OECD).

2. The SLA's annual writing competition, which began in 1956, now attracts 4 million submissions every year (School Library Association).

3. From a reference book of children's picturebooks published in Japan 19582010 (DB Japan), we selected texts published in Japanese after 1980 that focus on older adult/child relationships (usually grandparent and grandchild). Adding more recent publications to the selection, we had 75 texts translated into English by three research assistants. Following more detailed analysis, we selected 46 texts that most prominently explored ageing and care in the context of intergenerational relationships. Translations of the picturebook titles and texts in this chapter are either based on or modified from those produced by the assistants.

4. See Traphagan (Rethinking Ch. 3) for a useful overview of these scholarly works.

5. Cases of harassment towards those with COVID-19 in Japan seem to highlight this individualism. In an interview, historian Jun Yohana connects the harassment to "negative individualism" (funo kojinshugi) that makes it a moral norm not to trouble others ("Kansensha;" translation by Sako). Similarly, an online survey in March/April 2020 found that $11.5 \%$ of respondents in Japan, in contrast to $1 \%$ in the US and $1.5 \%$ in the UK, agreed with the statement that "I think anyone who gets infected with the Coronavirus (COVID-19) got what they deserved" (Hirai et al.).

6. According to a 2019 survey by the Ministry of Health, Labour and Welfare, $5.1 \%$ of households in Japan include three or more generations (down from $15.3 \%$ in 1986$), 19.6 \%$ of people aged $65+$ live alone, $40.4 \%$ live with a spouse and $35.9 \%$ live with a child/children ("Summary" 3, 6). Ueno also 
makes the point that multi-generational living is not simply cultural but is also socio-economic (Kea, 95).

7. The monthly contribution for those aged $65+$ doubled by 2020 and is expected to continue to rise (Yamamoto).

8. The number of these deaths among people aged $65+$ in Tokyo has increased from 1,441 in 2003 (Kaneoke et al.) to 3,176 in 2019 (Bureau).

9. In a 2019 survey, $72.7 \%$ of primary co-resident caregivers who provide care "almost all day" were women (40.9\% were spouses, $19.8 \%$ daughters, and $7.3 \%$ a child's spouse) ("Summary" 27).

10. For instance, Ojichan no gokurakugokuraku [Grandpa's Paradise, Paradise] (Nishimoto and Hasegawa, 2006) and Obachan ga iruto iinonina [I Wish Grandma Was Here] (Matsuda and Ishikura, 1994) were on the list of books for the SLA's annual, nationwide writing competition. Award-winning Daijobu daijobu [It's Okay, It's Okay] (Ito, 1995) had been reprinted 34 times by 2008 .

11. This is based on content, contextual information such as that available on publishers' websites and the use (or absence) in the books of Chinese characters, the learning of which is integrated into the Courses of Study for primary schools by the Ministry of Education, Culture, Sports, Science and Technology.

12. The English translations of the picturebook titles are used in second and later references.

13. Daisukina obachan [My Dear Grandma] (Hinohara and Okada, 2014) contains a rare example of professional palliative care. The author, who died in 2017 at the age of 105, was a well-known doctor and advocate for endof-life care in Japan. Even here, though, the mother also provides practical care.

14. This moral lesson is also reinforced, throughout the book, by the instructive voice of the third-person narrative: in dialogue, the boy's voice reflects his age and gender, but the third-person narrative evokes a more mature perspective in its use of language. It also uses "desu," a participle that is used to end a sentence in a speech addressed to others.

\section{Works Cited}

\section{Primary Sources}

Asano, Yoko, and Teruo Asano. Ojichan no dobutsuen. Bunka Publishing Bureau, 2002.

Furiya, Kayoko. Chiko-chan no akai chokki. Popular Publishing, 1987.

- Obachan no shima de. Bunken Shuppan, 1995.

Hinohara, Shigeaki, and Chiaki Okada. Daisukina obachan. Asahi Shimbun Publications, 2014.

Imamura, Ashiko, and Nana Furiya. Futari ha dadakko. Doshinsha Publishing, 1995.

Ito, Hiroshi. Daijobu daijobu. Kodansha, 1995.

Kasai, Mari, and Kotaku Yoshinaga. Bachan no onaka. Kyoiku gageki, 2010.

Kimura, Fumiko, and Kahoru Kimura. Hitoride omimai. Kokudosha, 1991.

Koyama, Yoshiko, and Iwao Fukuda. Daisukina obachan. Daughters of St. Paul, 1991.

Matsuda, Motoko, and Fukiko Karino. Obachan ha kaguyahime. Popular Publishing, 2013.

—, and Kinji Ishikura. Obachan ga iruto iinonina. Popular Publishing, 1994. 


\section{Katsura Sako and Sarah Falcus}

Miyakawa, Hiro, and Kinji Ishikura. Yuko to Fumi bachan. Akane Shobo, 1983. Mogami, Ippei, and Mariko Matsunari. Jibun no ki. Iwasaki Shoten, 2009.

Nagano, Hideko. Obachan ga obachan ni nattahi. Doshinsha, 2015.

Nakajima, Kotobuki et al. Obachan to warabeuta. Taihei Shuppansha, 1997.

Nishimoto, Keisuke, and Fukiko Karino. Sayonara, obachan. Koseisha, 2010.

- , and Yoshifumi Hasegawa. Ojichan no gokurakugokuraku. Suzuki Shuppan, 2006.

Nomura, Takayuki. Bachan no engawa. Kodansha, 1983.

- Ojichan no machi. Kodansha, 1989.

Okada, Yutaka, and Yoshitaka Shinohara. Jishinkaminarikaji jichan. Popular Publishing, 1987.

Sueyoshi, Akiko, and Suzuko Makino. Maho ha naishode kakeyone. Hikumano Shuppan, 1984.

Watanabe, Samojiro. Jichan to naishonaisho no yamanobori. Shuzuki Shuppan, 2007.

Watanabe, Shigeo, and Toshio Kajiyama. Yukkurayukkura yotayota. Akane Shobo, 1982.

\section{Secondary Sources}

Aoyama, Tomoko. "The Girl-Grandmother Relation in Japanese Children's Literature." Configurations of Family in Contemporary Japan. Edited by Tomoko Aoyama et al. Routledge, 2014, pp. 49-64.

Aoyama, Tomoko et al. "Introduction." Configurations of Family in Contemporary Japan. Edited by Tomoko Aoyama et al. Routledge, 2014, pp. 1-5.

Arichika, Takashi et al. "Kaigo to watashitachi 2025-nen mondai heno kadai sonzaikan masu 'kaigo Yobo' 'Jiritsu shien'." Asahi Shimbun (Morning issue), 6 Dec. 2020, p. 4.

Bureau of Social Welfare and Public Health, Tokyo Metropolitan Government. "Tokyo to kansatsuimuin de toriatukatta jitaku jukyo de nakunatta tanshin setai no mono no toukei (Reiwa gannen)." Tokyo Metropolitan Government, 2021, www.fukushihoken.metro.tokyo.lg.jp/kansatsu/kodokushitoukei/kodokushitoukei-1.files/31-tokubetuku.pdf.

Coulmas, Florian. Population Decline and Aging in Japan: The Social Consequences. Routledge, 2007.

Danely, Jason. Aging and Loss: Mourning and Maturity in Contemporary Japan. Rutgers UP, 2015.

DB Japan. Tema, janru kara sagasu monogatari ohanashi ehon 1: Kodomono sekai seikatsul kaku no mono fantajil norimono/waraibanashi yumoa. DB Japan, 2011.

Gilligan, Carol. In a Different Voice: Psychological Theory and Women's Development. Harvard UP, 1982.

Gubar, Marah. "Risky Business: Talking about Children in Children's Literature Criticism.” Children's Literature Association Quarterly, vol. 38, no. 4, 2013, pp. 450-7, https://doi.org/10.1353/chq.2013.0048.

Hashimoto, Akiko. The Gift of Generations: Japanese and American Perspectives on Aging and the Social Contract. Cambridge UP, 1996.

Henneberg, Sylvia. "Moms Do Badly, but Grandmas Do Worse: The Nexus of Sexism and Ageism in Children's Classics." Journal of Aging Studies, vol. 24, 2010, pp. 125-34. 
Hisaoka, Miyuki. "Cooperation and Negotiation: Formation of Subjectivity in Japanese and Australian Picture Books." Subjectivity in Asian Children's Literature and Film: Global Theories and Implications. Edited by John Stephens. Routledge, 2012, pp. 59-77.

Honda, Masuko. "Ehon.” Nihon jido bungaku gairon. Edited by Nihon jido bungaku gakkai. Tokyo Shoseki, 1976, pp. 119-27.

—. Kodomo hyakunenno epokku: "Jidono seiki" kara "Kodomonokenrijoyaku” made. Froebel-kan, 2000.

Hirai, Kai et al. "Shingatakorona uirusu kansenka ni kakawaru shakaishinrigakukenkyu (webu chosa) johomatome.” Osaka University, 2021, https://docs.google.com/ document/d/e/2PACX-1vQFIr9pEwwUV7I0FkzUC_c8OpZrqkUPEYytQFeViIV86zgGUnM_wZeIvserq2Aevyw-ajmq3en7duW/pub.

Izuhara, Misa. "Care and Inheritance: Japanese and English Perspectives on the 'Generational Contract.'” Ageing and Society, vol. 22, 2002, pp. 61-77.

Joosen, Vanessa. "Second Childhoods and Intergenerational Dialogues: How Children's Literature Studies and Age Studies Can Supplement Each Other." Children's Literature Association Quarterly, vol. 40, no. 2, 2015, pp. 126-40.

sissippi P, 2018.

Kaneoke, Yoshimasa et al. Tokyo nijusanku ni okeru kodokushi tokei (Heisei 15-19 nen): Setai bunruibetsu ijoshi tokei chosa. Edited by Bureau of Social Welfare and Public Health. Tokyo Metropolitan Government, 2011, www. fukushihoken.metro.tokyo.lg.jp/kansatsu/kodokushitoukei/kodokushitoukei. files/04_dai2syou.pdf.

"Kansensha o semeru watashitachi." Asahi Shimbun (Morning issue), 9 Oct. 2020, p. 13.

Karatani, Kojin. Teihon nibon kindai bungaku no kigen. 1980. Iwanami Shoten, 2008. Translated into English as Origins of Modern Japanese Literature. Duke UP, 2003.

Kasuga, Kisuyo. “'Shinguru ko’ to dokyosuru koreishakazoku no kaigokiki: Kyurai no kazokukan kara dakkyaku o." Homon kaigo to kaigo, vol. 17, no. 2, 2012, pp. 119-23.

Katz, Stephen, and Toni Calasanti. "Critical Perspective on Successful Ageing: Does It 'Appeal More Than It Illuminates'?” The Gerontologist, vol. 55, no. 1, 2015, pp. 26-3.

Kavedžija, Iza. "The Age of Decline? Anxieties about Ageing in Japan.” Ethnos, vol. 81, no. 2, 2016, pp. 214-37.

Kittay, Eva Feder. Love's Labor: Essays on Women, Equality, and Dependency. Routledge, 1999.

- et al. "Dependency, Difference and the Global Ethic of Long-Term Care." The Journal of Political Philosophy, vol. 13, no. 4, 2005, pp. 443-69.

Lamb, Sarah. "Beyond the View of the West: Ageing and Anthropology." Routledge Handbook of Cultural Gerontology. Edited by Julia Twigg and Wendy Martin. Routledge, 2015, pp. 37-44.

Ministry of Heath, Labour and Welfare. “Abridged Life Tables for Japan 2019.” Ministry of Health, Labour and Welfare, 2019, www.mhlw.go.jp/english/database/db-hw/lifetb19/dl/lifetb19-06.pdf.

—. "Reiwa gannen (2019) jinko dosei tokei (kakuteisu) no gaikyo." Ministry of Health, Labour and Welfare, 2019, www.mhlw.go.jp/toukei/saikin/hw/ jinkou/kakutei19/index.html. 


\section{Katsura Sako and Sarab Falcus}

"Summary Report of Comprehensive Survey of Living Conditions 2019." Ministry of Health, Labour and Welfare, 2019, www.mhlw.go.jp/english/data base/db-hss/dl/report_gaikyo_2019.pdf.

Miura, Seiko. "1990 nendai no ehon: Ketsujitsu to hatten to." Torigoe, Hajimete, 2002, pp. 183-202.

Nakagawa, Takeshi, and Yasuyuki Gondo. "Health Care System and Policy Implications for Older Adults in Japan." Healthy Aging in Sociocultural Context. Edited by Andrew E. Scharlach and Kazumi Hoshino. Routledge, 2012, pp. 53-61.

Nikolajeva, Maria. Power, Voice and Subjectivity in Literature for Young Readers. Routledge, 2010.

Noddings, Nel. Caring: A Feminist Approach to Ethics and Moral Education. U of California P, 1984.

Nodelman, Perry. The Hidden Adult: Defining Children's Literature. John Hopkins UP, 2008.

OECD. "Working Better with Age: Japan." 2018, www.oecd-ilibrary.org/ sites/9789264201996-en/index.html?itemId=/content/publication/9789264 201996-en.

Oomachi, Yukina. "Ema obachan ga egaku pojiteibu eijingu - jendaka shita eijingu wo ikiru 'obasan' ko." Ehongaku: Ehon gakkai kenkyu kiyo, vol. 10, 2008, pp. 53-8.

Rudd, David. "Theorising and Theories: The Conditions of Possibility of Children's Literature." International Companion Encyclopedia of Children's Literature. Edited by Peter Hunt. Routledge, 2004, pp. 29-43.

Sasaki, Takayuki. "Healthy Aging and Intergenerational Intervention in Japan." Healthy Aging in Sociocultural Context. Edited by Andrew E. Scharlach and Kazumi Hoshino. Routledge, 2012, pp. 62-71.

School Library Association. Official Website. www.j-sla.or.jp/contest/youngr/

Takahashi, Hisako. "1960 nendai no ehon: Atarashii kodomobunka no kouchikuhe." Torigoe, Hajimete, 2002, pp. 147-64.

Takeda, Kyoko. "A Gender Gap in 'Kodomonotomo'." The Journal of the Center for Educational Research and Practices, vol. 9, 1999, pp. 51-61.

_- "Ehon no nakano kazoku: Gekkan monogatari ehon Kodomonotomo ni mirareru kazokuishiki." Japan Society of Research on Early Childhood Care and Education Convention Proceedings, vol. 54, 2001, pp. 526-7.

Thang, Leng. "Aging and Social Welfare in Japan." Routledge Handbook of Japanese Culture and Society. Edited by Victoria Bestor et al. Routledge, 2011.

Tokoro, Michihiko. "Ageing in Japan: Family Changes and Policy Developments." Ageing in East Asia: Challenges and Policies for the Twenty-First Century. Edited by Tsung-hsi Fu and Rhidian Hughes. Routledge, 2009, pp. 54-71.

Torigoe, Shin. "Sengo jidobungaku no gojunen o gaikansuru: Futatabi meguttekita kikino jidai no nakade." Sengo jido bungaku no 50 nen. Edited by Nihon jido bungakusha kyokai. Bunkei-do, 1996, pp. 8-19.

- editor. Hajimete manabu nibon no ehon shi III - Sengo ehon no ayumi to tenbo. Minerva Shobo, 2002.

Traphagan, John W. "Being a Good Rojin: Senility, Power, and Self-Actualization in Japan." Thinking About Dementia: Culture, Loss, and the Anthropology of Senility. Edited by Annette Leibing and Lawrence Cohen. Rutgers UP, 2006, pp. 269-87. 
Rethinking Autonomy: A Critique of Principlism in Biomedical Ethics. State U of New York P, 2013.

Ueno, Chizuko. Kea no shakai gaku-Tojisha no fukushi shakai he. Ohtabooks, 2011.

_. "Family Strategy on Care: Norms, Preferences, and Resources." Japanese Journal of Family Sociology, vol. 25, no. 1, 2013, pp. 30-42.

White, Merry Isaacs, Perfectly Japanese: Making Families in an Era of Upheaval. U of California P, 2002.

Yamamoto, Kyosuke. "Rising Number of Elderly in Arrears on Nursing Care Insurance." The Asahi Shimbun, 12 Oct. 2020, www.asahi.com/ajw/ articles/13810553. 


\section{Contributors}

Elizabeth Barry is Reader in English at the University of Warwick, UK. She has published widely on modernist literature, medical humanities and age studies, editing special issues of the Journal of Beckett Studies and the Journal of Medical Humanities. She recently edited Literature and Ageing (Boydell), the 2020 volume of the English Association series "Essays and Studies." She has held two UK government grants to investigate literature and medicine and is partner on an age studies project funded by the Norwegian Research Council. Her monograph on Ageing as Embodied Time in Modern Literature and Thought will appear with Bloomsbury in 2023.

Dr Simon Buck is a writer, historian and musician based in Newcastle upon Tyne (UK). His forthcoming monograph with the University of Illinois Press examines the history of old age, ageing and music in the US South. He is also currently working on other projects relating to music, old-age pensions and healthcare spaces in the twentiethcentury United States.

Sally Chivers is Full Professor in the Departments of English and Gender \& Social Justice at Trent University, where she is also a founding Executive Member and Past Director of the Trent Centre for Aging \& Society. Recipient of the Distinguished Research Award, she is the author of From Old Woman to Older Women: Contemporary Culture and Women's Narratives and The Silvering Screen: Old Age and Disability in Cinema and the co-editor of The Problem Body: Projecting Disability on Film and Care Home Stories: Aging, Disability, and Long-Term Residential Care. Her research focuses on the social and cultural politics of disability and ageing, especially in literature and film.

Amir Cohen-Shalev studied at the University of Tel Aviv, The Hebrew University in Jerusalem, and The University of Toronto, where he received a Ph.D. degree in 1985 . He has since taught in The University of Haifa and Tel Aviv University in Israel. Among his publications: 
"Both Worlds at Once" - Art in Old Age (2002), Visions of Aging: Images of the Elderly in Film (2009) and, with Miri Varon, Preying on the Fleeting Abundance: An Anthology of Late-Life Poetry (2017).

MaoHui Deng is Lecturer in Film Studies at the University of Manchester. His research is interested in the ways in which films about dementia and ageing can help further and/or complicate our understanding of time in cinema, gerontology and the wider society. He has published in the journals Asian Cinema and Imagined Theatres, and is currently working on his first monograph (under contract with Edinburgh University Press), provisionally titled Ageing, Dementia and Time in Film: Temporal Performances.

Sarah Falcus is a Reader in Contemporary Literature at the University of Huddersfield. She has research interests in literary and cultural gerontology, science and speculative fiction, and children's literature. She is the co-author, with Katsura Sako, of Contemporary Narratives of Dementia: Ethics, Ageing, Politics (Routledge, 2019). She is the coeditor, with Alison Waller, of a special issue of International Research in Children's Literature (2021) that brings together children's literature studies and ageing studies.

Dr Janet Gibson is the Program Manager, Communication, at UTS College, University of Technology, Sydney. Her book Dementia, Narrative and Performance: Staging Reality, Reimagining Identities was published by Palgrave Macmillan in late 2020. Her most recent article "Talking out, talking back, talking otherwise': Dementia and access in autobiographical performance" was published in Research in Drama Education: The Journal of Applied Theatre and Performance, August 2018. Email: jintyg@iinet.net.au.

Shirley Jordan is Professor of French Studies at Newcastle University. She publishes on twentieth- and twenty-first-century women's writing, visual culture and experimental self-narrative across media. Her most recent work focuses on narratives, visual representations and theories of ageing, ageism and care. She is preparing a guest-edited special issue of French Studies entitled "Ageism, Ageing and Old Age in Contemporary French Culture" and has published on gender and ageing in self-narrative by Annie Ernaux, Jacques Roubaud and Agnès Varda. Her current project analyses the critically neglected portraits and documentary photographs of older people taken by Belgian-born photographer Martine Franck (1938-2012).

Raquel Medina is a visiting research fellow at Aston University. She is the author of Cinematic Representations of Alzheimer's Disease (2018) and Surrealismo en la poesía española de posguerra (1997) and co-editor of Envejecimientos y cines Ibéricos (2021), Sexualidad y escritura 
(2002) and the section "Aging and Audio-Visual Culture" of The Encyclopedia of Gerontology and Population Aging (2020). She has published widely on contemporary Spanish poetry and women writers. Her current research focuses on cultural representations of ageing and dementia. She is the director of the CinemAGEnder network and co-directs with Sarah Falcus the Dementia and Cultural Narrative Network.

Bridie Moore is Senior Lecturer in Drama, Theatre and Performance at the University of Huddersfield. She completed her AHRC-funded Ph.D. at the University of Sheffield in 2018. Her research centres on the performance of age and ageing in contemporary British Theatre. Her Ph.D. included an element of practice-as-research and, to facilitate this, in 2012 she formed Passages Theatre, a group for performers over the age of 50 . They have staged performances that toured locally and nationally. Before her academic career, Bridie was a theatre director and facilitator in mainstream and community theatre. She is currently working on a book for Routledge, provisionally entitled Performing Ageing Femininities.

Katsura Sako is Professor of English at Keio University, Japan. She has research interests in literary and cultural studies of the life course, ageing and gender. She has published in journals such as Contemporary Women's Writing, Feminist Review and Women: A Cultural Review. She is the co-author, with Sarah Falcus, of Contemporary Narratives of Dementia: Ethics, Ageing, Politics (Routledge, 2019). She has held multiple research grants, including "Fund for the Promotion of Joint International Research (Fostering Joint International Research)" from the Japan Society for the Promotion of Science, which funded the conference "Ageing, Illness, Care in Literary and Cultural Narratives" that was held at the University of Huddersfield in 2019 and provided the basis for this volume. 


\section{Index}

Note: Page numbers in italics indicate a figure on the corresponding page. Page numbers followed by " $n$ " indicate a note.

Abbas, Ackbar 116

Abel, Elizabeth 164-5

Abel, Emily K. 164, 166

Accueil et Service (Home Support Services) 21,25

affect $87-8,98,114$

ageism/ageing 1-3; Alzheimerisation of 4; successful ageing 5

Ahmed, Sara 109-10

Ahrne, Marianne 29n12

Almen, Ruth 40

Al-Saji, Alia 106, 107

Alzheimerisation of ageing 4, 129

Alzheimer's Association 124, 138

Alzheimer's disease 4, 5, 39, 41, 42,71

Anderson, Elmer 58-9, 59

Ansello, Edward F. 1

Anthropocene 154

Applewhite, Ashton 137

Arnheim, Rudolf 72

Asano and Asano, Ojichan no dobutsuen (Grandpa's Zoo) 192-3

Atwood, Margaret 144-6, 148, 149, 153-7

Avenzoar, Charles "Yesterday, When I Was Young” 128

Baier, Annette 26

Bakhtin, Mikhail 144, 146

Baldassar, Loretta 32

Balfour, Michael 40, 41

Baraitser, Lisa 26

Barthes, Roland 133

Barth, John 144-5; “Assisted Dying” 157; Development, The 145,
156-9; "Peeping Tom" 144, 145, 149, 156-9

Bartlett, Ruth 65n8

Basting, Anne Davis 111-12; Forget Memory 77; "From Islands to Networks" 39; Penelope Project, The 39

Beauvoir, Simone de: Franck's dialogue with 16-18; La Force des choses 16; La Vieillesse (The Coming of Age) 10, 16, 17, 21, 27, 29n12

Berger, John 11-12

Bergson, Henri 110

Biegeleisen, Sylvain 4; Last Postcard, The 69, 70, 72-81; Twilight of a Life 69, 70, 73, 76-81

Biggs, Simon 148

Black Lives Matter 129

Black, Steven P. 50

Boulogne, Bois de 19

Braedley, Susan 175n3

Brennan, Teresa 87, 88

Breslin, John 86

Brown, Wendy 167, 168

Bruschtein, Natalia 5, 84, 88-92

Bucket List (BL) 47, 49, 51, 57-61

Bucket List, The (Reiner) 55

Burke, Lucy 53

Butchart, Garnet 86

Butler, Judith 27, 88

Butler, Robert 53

Cafe, W.O.W. 32

Caldwell, Jessica 40

Calendar Girls (Cole) 66n13 


\section{Index}

Calendar Projects (CPs) 47, 49, 51, $55,58,60-2,61$

Cameron, Julia Margaret 15, 28n8

Campbell, Glen 5, 124-6; Adiós 129, 133-6, 138; Alive Inside: A Story of Music and Memory 126; "Am I All Alone (Or Is It Only Me)" 133, 136; "Better Place, A" 132, 134, 137; "By the Time I Get to Phoenix" 128, 133; "Country Boy (You've Got Your Feet in L.A.)" 128; "Everybody's Talkin" " 133; fate of 138-40; "Fate of Man" 126, 138; "Funny How Time Slips Away" 134; "Galveston" 133; "Gentle on My Mind" 132-3; Ghost on the Canvas 129-35, 137-9; Glen Campbell Goodtime Hour, The 126; "Glen Campbell Has Alzheimer's Disease" 134, 137; Glen Campbell: I'll Be Me 126, 129, 135-9; "Hey Little One" 133; "I'm Not Gonna Miss You" 135; "It's Your Amazing Grace" 137; "Just Like Always" 133; Meet Glen Campbell 129; "No Trouble" 135; "Rhinestone Cowboy" 128, 133; See You There 129, 132, 134-6; "She Thinks I Still Care" 133; "Thousand Lifetimes, A" 132; "True Grit" 127-9, 133; "Wichita Lineman” 124, 128, 132-4, 137 capacities of incapacity 54 capitalism 110 care: aesthetics of $31,34-7,51$; circuit of 5, 31-44; completion of 52,59 ; crisis of 2 ; definition of 3 , 13; dependency 179; economy 167; elder 70, 180; ethics 38; familial 180-2; feminist ethics of 3; friends 165-7; good 6; kinship-based 5 ; logic of 6 ; partner $65 \mathrm{n} 10$; photography as 11-16; relations 163-75; right to 5 ; in visual field 10-29

"caring about" 3, 6, 13, 98

"caring for" $6,7,39,72,98,181$; concept of 71; female children 183; friend 164; older people 17; person with dementia 69, 84; process of 13 ; spouse/parents 71,181 , 184, 187

Cartesian duality 94
Cartier-Bresson, Henri 11, 15-16

Cash Box (Wilson) 135

Cash, Johnny 129

Chakrabarty, Dipesh 110

Chesney, Kenny "While He Still

Knows Who I Am" 137

Chicks, the, "Silent House" 137

children's picturebooks 177-95

China 14

Chivers, Sally 6, 145, 163

Choy, Howard Y.F. 120n13

Christolhomme, Michel 29n13

chronotope 146

Chungking Express (Wong

Kar-wai) 116

Clarke, Graham 20, 26

Clark, Melissa 145

Clark, Miriam 160

Clock Drawing Test 111, 120n6

Cobussen, Marcel 125

Cohen, Lawrence 108-9

Cohen-Shalev, Amir 4, 69

College Anatomy Theatre 36

Columbus, Christopher 110

Como, Perry 129

Connell, Raewyn 115

corporeality 94

Costello, Elvis 137

Couser, G. Thomas 85, 129

COVID-19 1, 2, 63, 163, 169, 173-4, $177,194 \mathrm{n} 5$

Crystal, Clark 40, 41

curated friendships 6,163

Curtis, Edward Sheriff 15

Dancing with Dementia (SBS) 49, 56-8, 62, 65n5

Danner, Blythe 71

Davis, Oliver 19

Death of Adam (Francesca) 15, 25

decolonisation: of Hong Kong 116-19, 117; worldview 112-15

DeFalco, Amelia 72, 84, 138

Delvaux, Martine 15

dementia 109, 113, 130; and ageing $4,51,55,80,126,129,131-2$; care 4, 5, 40-1, 47, 69, 80, 113; cinema/films about 105-6, 112, 115, 119; Dancing with Dementia $49,56-8,62,65 \mathrm{n} 5$; in familial documentary film 84-101; and fear 108, 159; and medical interventions 111; "Participatory Theatre and 
Dementia" 39; people living with dementia (PLWD) 51, 65n6,65n9; and performance 114; dementia stories 52-3; dementia time 134 dependency: care 179; of grandparents 191-3

Derrida, Jacques 165

Development, The (Barth) 145, 156-9 diagnostic gaze 51, 60, 64

documentary film: dementia in 84-101; ethics of care 85-8; ethics of representation $85-8$

Dodds, Susan 38

Dolan, Josephine 5

Dorow, Sara 32

Dunn, Julie 40, 41

Dussel, Enrique 111, 120n5

duty 183-91

Dyer, Geoff 13

Dylan, Jakob 130

elder care 70, 180

Elliott, Richard 125

Engster, Daniel 37, 38

Erikson, Erik 74

Erni, John Nguyet 120n13

ethics: of care 85-8; of representation $85-8$

Eurocentrism 111

Falconer, Rachel 144, 145

Fan, Victor 116

Filipacchi, Daniel 14

film noir 146, 147

Fineman, Martha 37

Fisher, Berenice 166-7

Fisher, Stuart 114

Fletcher, James R. 111

Fox, Pamela 131

France 28n9

Francesca, Piero della 15, 25

Franck, Martine 4, 10-29; dialogue with Beauvoir 16-18; legacies 27-8; Les petits frères des Pauvres (The Little Brothers of the Poor) 12, 27; Le Temps de vieillir: Journal d'un voyage (The Time to Grow Old: A Travel Diary) 10-16, 18-21, 24, 27, 28n6; photograph in visual gerontology 18-20; photography and contexts of care $20-7,22,23,25$; photography as care 11-16

Frank, Arthur W. 66n11, 125
Freed, Leonard 15

Freeman, Morgan 55

Friedman, Marilyn 165, 167

Friedman, Norman 160-1

friendship 164-5; care 165-7; curated 6, 163

Furiya, Chiko-chan no akai chokki (Chiko-Chan's Red Vest) 187-8, 188

Gardiner, Judith Kegan 164-5

Garner, Helen 6, 163, 164, 170-4

Gerders, Karen 92

Giant, The (Wall) 18-19

Gilleard, Chris 4, 129

Gillespie, Benjamin 39

Gilligan, Carol 11, 85, 164, 179

Gilmour, David 137

Glen Campbell Goodtime Hour, The (TV series) 126, 132

Gnosticism 151, 152

“Golden Girls" (CBC) 167-70, 173, $175 \mathrm{n} 4$

Goldman, Marlene 131, 154

Gorton, Kristyn 87

Grosz, Elizabeth 54

Gullette, Margaret Morganroth 1, 10, $18,19,24,51$

Hals, Frans 15

Harris, Mark Edward 12

Hashimoto, Akiko 179

Hatton, Nicola 39

Herschel, John 15

Higgs, Paul 4, 129

Hisaoka, Miyuki 184

Hockey, Jenny 71

Hodgson, John 39

Hoffman, Philip Seymour 71

Hong Kong 104-20

Hospice d'Ivry 21

Housman, A. E. 152

Hui, Ann 104-6, 108

"Imagine Aging" project 164, 168

Imamura and Furiya, Futari ha dadakko (Two Spoiled Children) 183

improvisation 39-43

India 14

individualism 180

infantilisation 71 


\section{Index}

intergenerational reciprocity 183-91

Izuhara, Misa 180

Jackson, Carl “Arkansas

Farmboy" 134

Japan 1, 14, 177-95

Jennings, Bruce 179

J, Jessie “I Miss Her" 137

Joffe-Walt, Chana 39-40

Johnstone, Keith 39

Jones, Dylan 128

Joosen, Vanessa 178

Kamp, Van de 52

Kasai and Yoshinaga, Bachan no onaka (Grandma's Tummy) 182

Katz, John 85

Katz, Judith 85

Kawafi, Khalil 36

Keating, Norah 167

Kittay, Eva Feder 42, 52, 60, 72, 179

Kodomonotomo 184-5

Koggel, Christine M. 85, 100

Kontos, Alexis P. 113

Kontos, Pia 94, 113

Kowloon Peninsula 105

Koyama and Fukuda, Daisukina obachan (My Dear Grandma) 192, $195 \mathrm{n} 13$

Kriebernegg, Ulla 145, 153

Laslett, Peter 33

Last Postcard, The (Biegeleisen) 69, 70, 77-81

Laugier, Sandra 11, 13, 28

Laws, Glenda 146

Lee, Vivian PY 117-18

Lennon, John "Grow Old with Me" 129

life-giving 76-8

life span ego-development model 74

Lim, Bliss Cua 110

Linney, Laura 71

Magellan, Ferdinand 110

Maison de Nanterre 21

Mandizadza, Shingirai 32

Margolin, Deb 32

Marks, Laura 87

Martin, Wendy 94

Matsuda and Karino, Obachan ha kaguyahime (Grandma is Kaguyahime) 186-7, 192

Matthews, Eric 94

Maunder, Corrine 48, 49, 54
Meagher, Michelle 15

Merla, Laura 32

Merleau-Ponty, Maurice 94

Mignolo, Walter D. 115

Militar, Junta 88

Miller, Karen-Lee 113

Mitchell, David 54

Mitchell, W. J. T. 18

Mittlefehldt, Pamela J. 132

Miyakawa and Ishikura, Yuko to Fumi bachan (Yuko and Grandma Fumi) 184, 185, 192

Mogami and Matsunari, Jibun no ki (One's Tree) 189-91

Mol, Annemarie 6

Moore, Julianne 71

Moyle, Wendy 40, 41

Muvunyi, Antoine 35

Nadar, Félix 15

Nakajima, Takagi and Ikeda, Obachan to warabeuta (Grandma and Nursery Songs) 182, 187

"narra-theatrical" gaze 60

"narra-theatrical" lens 47-68

National Alzheimer's Plan 124

National Alzheimer's Project Act (2011) 124

Negus, Keith 125

Nelson, Margaret K. 164, 166

Nelson, Willie 134

neoliberal economies 2, 51

neo-noir 146

Nichols, Bill 86

Nicks, Stevie 128

Nicolson, Jack 55

Nielsen, Nanette 125

Noddings, Nel 42-3, 59, 85, 86,179

Nomura, Ojichan no machi (Grandpa's Town) 192

Occupy Wall Street 129

O'Connor, Deborah 65n8

Okada and Shinohara, Jishinkaminarikaji jichan (Earthquake, Lightning, Fire, Grandpa) (183, 189

Paris, Grand Palais 15

Pavis, Patrice 49

"Peeping Tom" (Barth) 144, 145, 149, 156-9

performance 48-52; circuits of care in 31-5; consciousness 47, 51, 
57, 60, 62; and dementia 114;

narra-theatrical 61 ; and theatre 43 , $50,51,63,64,64 \mathrm{n} 3$

photography 10-29; as care

11-16; and contexts of care 20-7, $22,23,25$; in visual gerontology 18-20

picturebooks, children's 177-95

Pierre, Tracey La 167

Playful Engagement project 40, 43

pluriverse 115,119

Polan, Dana 147

Pollard, Robert 130

Pratesi, Alessandro 26

Qing Empire 105

racial inequality 3

Rapport de la Commission d'étude des problèmes de la vieillesse (Report of the Commission for Study of the Problems of Old Age, 1962) 17

Raymond, Julian 130-1

reciprocal model of caring 76-8

relational citizenship 113

Relational Clowns 40, 43

Rembrandt, Self-Portrait with Beret 15

Richards, Ernest 39

Ricoeur, Paul 66n11

Robson, Kathryn 27

Rodgers, George Arthur 41

Roseneil, Sasha 6, 166, 167

Rose, Nikolas 111

Rouge (Kwan) 116

Ruff (Shaw) 4, 31-6, 38, 39, 41, $43,44 \mathrm{n} 3$

Savages, The (Jenkins) 71

Schechner, Richard 47-9, 113

Schneider, Stan 124

Schrage-Freuh, Michaela 2

Second Opium War 105

Second World War see World War Two

Señor Liberto y los pequeños placeres, $E l$ (Mr Liberto and the Small Pleasures) (Serret) 5, 84, 85, 88, 93-100, 97, 98

Selberg, Scott 126, 132

Self-Portrait with Beret

(Rembrandt) 15

semiotics 114
Serret, Ana 5, 84, 93, 95, 98

Shaw, Peggy 4, 31-9, 41, 43, $44 n 1,44 n 3$

Sherman, Cindy 19

"silver tsunami" metaphor 52

Snaith, Helen 148

Snyder, Sharon 54

Sobchack, Vivian 146-7, 153

Solga, Kim 34, 35, 37

Song of the Exile (Ann Hui) 116

Sontag, Susan 21, 86-8

space, in older age stories 146-53

Spare Room, The (Garner) 6, 163, 164, 170-3

spectatorship 50-2

Split Britches 31-3, 35-8

Spolin, Viola 39

Starrett Lodge 47, 50, 54-6, 58, 62, 64, 65n 4

Still Alice (Glatzer) 71

Stobbe, Karen 39

Stuart, Amanda 114

"Stuff" (Williams) 147, 149-53, 159

Sueyoshi and Makino, Maho ha naishode kakeyone (Let's Secretly Cast a Spell) 182

Summer Snow (Hui) 5, 104-119

Sundance 2020 festival 71

Takeda, Kyoko 183, 184

Taylor, Janelle S. 108

Temps de vieillir: Journal d'un voyage, Le (The Time to Grow Old:

A Travel Diary) (Franck) 10-16, 18-21, 24, 27, 28n6

Terentowicz-Fotyga, Urzula 145-6

theatrical narrativisation $47,58,62$

Thompson, James 31, 35, 36, 43, $65 \mathrm{n} 7,114$

Thompson, Teddy 130

Tiempo suspendido (Time Suspended) (Bruschtein) 5, 84, 85, 88-93, 90, 91, 99, 100

TimeSlips Method 39

"Torching the Dusties" (Atwood) 144, $145,148,149,153-7$

Tracy, Tony 2

Traphagan, John 180

Tronto, Joan 3, 42, 166-7

Twilight of a Life (Biegeleisen) 69, 70, 73, 76-81

Ueno, Chizuko 177, 179, 180, 182, $194 n 6$

Uniting Care 47, 54, 64n1 


\section{Index}

Vaittinen, Tiina 38

Vanacker, Baastian 86

"Veronica" (Costello) 137

Vespucci, Amerigo 110

Viejas, Las (Goya) 15

visual gerontology $18-20$

vulnerability $37-8$; of grandparents 191-3; improvisation and 31-44

Wall, Jeff 18-19

Walsh, Catherine E. 115

Waring, Gillian 19, 28n11

Wasunna, Angela A. 179

Watanabe, Jichan to naishonaisho no yamanobori (A Secret Secret Mountaineering with Grandpa) 189, 190

Wayne, John 127, 128

Weaver, Lois 31-7, 43
Webb, Jimmy 131

Weiss, Larry 131

Westerberg, Paul 130

What They Had (Chomko) 71

White, Gareth 120n9

White, Merry 180

Williams, Joy 145, 147, 149-53, 159

Wills, Garry 128

Woman Regents (Hals) 15

Woodward, Kathleen 12

World War Two 105, 178, 181

Wrinkles of the City projects (2008-2015) 18

Yen, Anna 40, 41

Young, Malcolm 129

Zecchi, Barbara 96

Zeilig, Hannah 108 